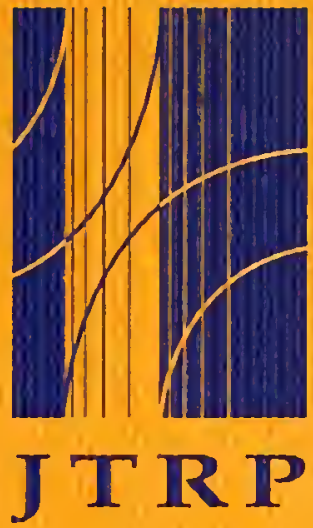

Joint

Transportation

Research

Program

FHWA/IN/JTRP-97/6

Final Report

STUDY OF SIDE DITCH LINERS FOR

HIGHWAY APPLICATIONS - PHASE I

Anthony S. Calderon

Phillippe L. Bourdeau

December 1997

Indiana

Department

of Transportation

Purdue

University 



\section{Final Report \\ FHWA/IN/JTRP-97/6}

STUDY OF SIDE DITCH LINERS FOR HIGHWAY APPLICATIONS - PHASE I

by

Anthony S. Calderon and Philippe L. Bourdeau

Joint Transportation Research Program

Project No: C-36-15M

File No: 6-9-13

Prepared as Part of an Investigation

Conducted by the

Joint Transportation Research Program

Purdue University

In Cooperation with the

Indiana Department of Transportation

and the

U.S. Department of Transportation

Federal Highway Administration

The contents of this report reflect the views of the author who is responsible for the facts and accuracy of the data presented herein. The contents do not necessarily reflect the official views or policies of the Indiana Department of Transportation and Federal Highway Administration. This report does not constitute a standard, specification, or regulation.

Purdue University

West Lafayette, IN 47907

December, 1997 
Digitized by the Internet Archive in 2011 with funding from

LYRASIS members and Sloan Foundation; Indiana Department of Transportation 


\begin{tabular}{|l|l|l|}
\hline 1. Report No. & 2. Government Accession No. & 3. Recipient's Catalog No. \\
\hline $\begin{array}{l}\text { 4. Title and Subtitle } \\
\text { Study of Side Ditch Liners for Highway Applications - Phase 1 }\end{array}$ & 5. Report Date \\
\cline { 2 - 3 } & 6. Performing Organization Code \\
\hline 7. Author(s) & 8. Performing Organization Report No. \\
Anthony S. Calderon and Philippe L. Bourdeau & FHWAMN/JTRP-97/6 \\
\hline $\begin{array}{l}\text { 9. Performing Organization Name and Address } \\
\text { Joint Transportation Research Program } \\
\text { Civil Engineering Building } \\
\text { Purdue University } \\
\text { West Lafayette, Indiana 47907-1284 }\end{array}$ & 10. Work Unit No. \\
\hline $\begin{array}{l}\text { 12. Sponsoring Agency Name and Address } \\
\text { Indiana Department of Transportation } \\
\text { 100 North Senate Avenue } \\
\text { Indianapolis, IN 46204 }\end{array}$ & 11. Contract or Grant No. \\
& SPR-2132 \\
\hline & 13. Type of Report and Period Covered & Final Report \\
\hline 15. Supplementary Notes & & 14. Sponsoring Agency Code \\
\hline
\end{tabular}

15. Supplementary Notes

Prepared in cooperation with the Indiana Department of Transportation and Federal Highway Administration.

\section{Abstract}

Over the past few years, the INDOT new materials department has received numerous erosion control products (mostly geosynthetics) to evaluate as alternatives to riprap and concrete in ditch liners. Potential benefits include lower construction costs and better aesthetics over current products. Unfortunately, no specification, design methodology, or classification system currently exists for these erosion control blankets.

In this project's phase I, existing information and knowledge on erosion control materials used to line highway side drainage ditches were investigated. From the available technical literature (journal and conference publications, other DOTs specifications, manufacturer documentation, independent test laboratory test data), design methodologies, classification system, product approval procedures, and installation methods were reviewed for temporary and permanent geosynthetic erosion control materials. Based on the synthesis of these reviews a design methodology was proposed including design aids (tables, flow charts, and graphs) necessary to perform flexible liner computations. A classification system based on product performance was also proposed. In addition, current design procedures for hard armor materials (fabric formed revetments, concrete block systems, gabions, and riprap) were reviewed. A tentative specification for both flexible and hard armor ditch liners was drafted.

\section{Key Words}

geosynthetic erosion control products, hard armor materials, rirpap, fabric formed revetments, gabions, concrete block systems, straw blankets, excelsior blankets, erosion control and revegetation mats, turf reinforcing mats,

\section{Distribution Statement}

No restrictions. This document is available to the public through the Nalional Technical Information Service, Virginia, 22161
19. Security Classif. (of this report)

Unclassified
20. Security Classif. (of this page)

Unclassified
21. No. of Pages

284 


\section{Acknowledgments}

Support for this project was provided by the Indiana Department of Transportation (INDOT) and the Federal Highway Administration (FHWA). Many thanks go to the Study Advisory Committee for their time, keen insight, and dedication to the erosion control ditch liner study. Special thanks goes to Contech Construction Products, American Excelsior Products, PPS Packaging Products, Synthetic Industries, and North American Green for their phone interviews and company erosion control design software. Moreover this project is indebted to the following companies that provided product information.

\section{Contributing Companies}
Akzo Nobel Geosynthetics
Construction Techniques
Erosion Control Systems
North American Green
Synthetic Industries
Greenfix America
Aqua Shed Manufacturing Corp.
American Excelsior Company
Contech Construction Products
Hydrotex Synthetics
Tenax Corporation
Verdyol Alabama
Nutec Supply

\author{
BonTerra \\ Drainage Products \\ Nicolon Mirafi Group \\ PPS Packaging Company \\ Belton Industries \\ Webtec, Inc. \\ Amoco Fabrics and Fibers \\ Siltco Industries \\ Midwest Construction \\ Presto Products Company \\ EFS, Inc. \\ Eljen Corporation \\ Environmental Protection
}

Thanks also are extended to the Ohio, Illinois, Virginia, Wisconsin, Texas, and Maryland DOTs for their respective erosion control specifications. 


\section{Table of Contents}

Acknowledgments

Page

iii

List of Figures.

viii

List of Tables . xi

Implementation Report xiii

Chapter 1: $\quad$ Literature Review

1.1 Background . . . . . . . . 1

1.2 Temporary Erosion Control Products. . . . 5

1.3 Permanent Erosion Control Products . . . . 6

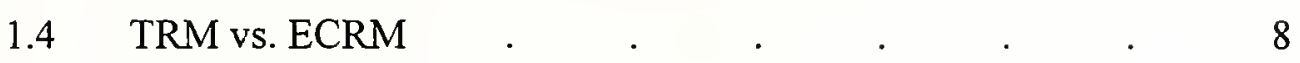

1.5 Available Design Procedures . . . . . 10

1.6 Evaluating Erosion Control Products . . . . . 11

1.7 Government Reports and Case Studies . . . 15

1.8 Other Published Case Studies. . . . . . 24

Chapter 2: Design Methodology for Flexible Channel Liners

2.1 Introduction to Design Procedures . . . . 28

2.2 Permissible Velocity Approach . . . . . 28

2.3 Permissible Shear Approach . . . . . . 32

2.4 Suggested Design Procedure . . . . . . . 36

2.4.1 Note on safety factors . $\quad . \quad$. $\quad . \quad$. 37

2.4.2 Are channel liners necessary?. . . . . $\quad 38$

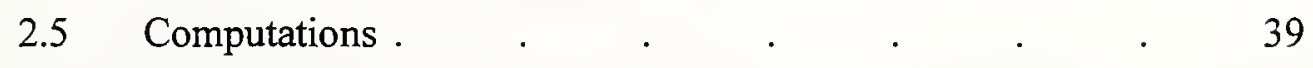

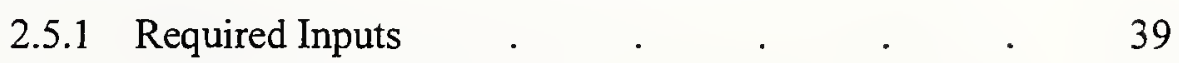

2.5.2 Required Calculations. $\quad$. $\quad$. $\quad . \quad . \quad$. 43

2.6 Design Aids for Computations . . . . . . $\quad$. 48 
Chapter 3: $\quad$ Design Methodology for Hard Armor Channel Lining Systems

3.1 Introduction to Riprap Design ․ . . . . 74

3.2 Descriptions of Riprap Design Procedures . . . 79

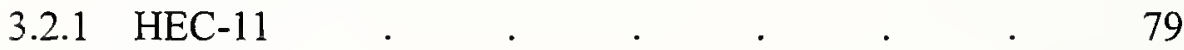

3.2.2 HEC-15 $\quad$. $\quad$. $\quad$. $\quad$. $\quad$. $\quad$. 85

3.2.3 California DOT "Bank \& Shore Protection" Manual . 97

3.2.4 U.S. Army Corps of Engineers . . . . 100

3.2.5 ASCE Sedimentation Manual \#54 . . . . 104

3.2.6 Sediment Transport Technology - Simons \& Senturk 105

3.2.7 U.S. Bureau of Reclamation . . . . . 108

3.2.8 Escarameia and May "Turbulence" Approach . 111

3.2.9 Blodgett Method . . . . . . 112

3.2.10 Probabilistic Method by Froehlich and Benson . 115

3.2.11 Summary of Riprap Design Procedures . . . 121

3.3 Selecting Manning's $\mathrm{n}$ for Riprap $\quad$. $\quad$. $\quad$. $\quad$. 123

3.4 Gradation System for Riprap . . . . . . 127

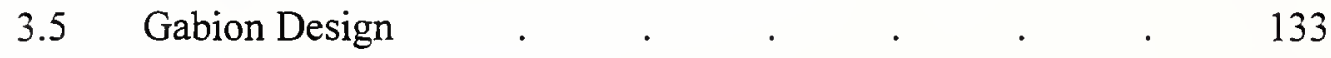

3.5.1 Simons Design Procedure $\quad$. $\quad$. $\quad$. $\quad$. 134

3.5.2 Maynord Design Procedure . . . . . $\quad$. 134

3.5.3 HEC-15 Design Procedure . . . . . 136

3.6 Fabric Formed Revetment Design Procedure. . . 139

3.6.1 Design Principles $\quad . \quad$. $\quad . \quad$. $\quad . \quad 140$

3.6.2 Design Equations $\quad . \quad$. $\quad . \quad$. $\quad . \quad 143$

3.7 Concrete Block System Design $\quad$. $\quad$. $\quad$. 146

3.7.1 Design Principles . . . . . . 147

3.7.2 Design Equations - Simons Approach . . 147

3.7.3 Design Equations - Escarameia and May Approach . 150

3.8 Summary of Hard Armor Design $\quad$. $\quad$. $\quad$. $\quad$. 151

3.9 Design for Composite Channel Linings _ . . 152

Chapter 4: Classification System for Erosion Control Materials

4.1 Why is a Classification System Needed? . . . 156

4.2 Summary of Other DOT Erosion Control Specifications . 158 


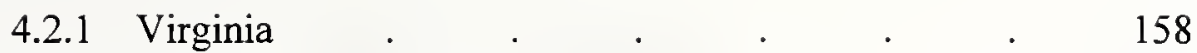

4.2 .2 Illinois. $\quad . \quad$. $\quad . \quad . \quad . \quad . \quad . \quad 158$

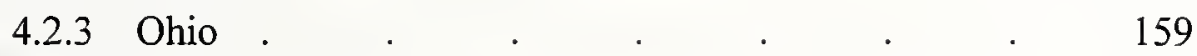

4.2 .4 Texas . $\quad . \quad$. $\quad . \quad$. $\quad . \quad$. 160

4.2.5 Maryland . . . . . . . . . $\quad$. 160

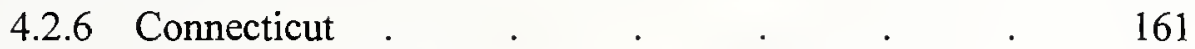

4.2.7 Synthetic Industries . $\quad . \quad$. $\quad$. $\quad$. 161

4.2 .8 FHWA. $\quad . \quad$. $\quad . \quad$. $\quad . \quad$. 161

4.3 Defining a Classification System for Erosion Control Products 163

4.4 Index Properties of Class A products . . . . 171

4.5 Index Properties of Class B products . . . . . 173

4.6 Summary of Erosion Control Product Classification . . 174

Chapter 5: $\quad$ Erosion Control Product Approval Procedure

5.1 Introduction to Approval Procedures . . . . 176

5.2 Texas DOT New Product Approval Procedure . $\quad$. 177

5.3 Virginia DOT New Product Approval Procedure . . 179

5.4 Proposed New Product Approval Procedures. . . 181

5.4.1 Method 1 - Field Testing . . . . . . 181

5.4.2 Method 2 - Guarantee Specification . . . . 183

5.5 Proposed Product Classification . . . . . $\quad 190$

Chapter 6: Installation Procedures

6.1 Introduction to Installation Procedures _ . . . 193

6.2 Installation Procedures for Soft Armor Materials . . 193

6.3 Installation Requirements for Hard Armor Materials. . 199

Chapter 7: $\quad$ Proposed Draft Specification

7.1 Flexible Ditch Lining Specification . . . . 203

7.2 Hard Armor Ditch Lining Specification . . . 210 
Appendix

A Normal Depth Design Equations for Common Channel Geometries

B FHWA Design Procedure for Geotextile Underlays

C List of References

D FHWA Flexible Liner Design Procedure (1995)

E Typical Channel Drawings (courtesy of Synthetic Industries)

F Database of Erosion Control Products

G Summary of Acronyms 


\section{List of Figures}

Figure Title

page

1-1a Elevation \& Plan Views of Test Channels 14

1-1b Elevation \& Plan Views of Test Channels 14

1-2 Cumulative Runoff Volume from Erosion Control Blanket Plots 19

1-3 Cumulative Soil Loss from Mulch Plots 19

1-4 Cumulative Soil Loss from Erosion Control Blanket Plots 20

1-5 Maximum Flow Depth vs Channel Slope Based on Bed Shear Stress 23

2-1 Limiting Velocity Versus Peak Flow 30

2-2 Typical Shear Stress Distribution in a Channel 32

2-3 Plan View Showing High Shear Stress Zones 33

2-4 Worksheet for Steep Channel Design 48

2-5 Flexible Liner Design Flow Chart 49

2-6 Manning's n vs. Relative Roughness for Selected Lining Types 56

2-7a Permissible Shear Stress for Non-cohesive Soils 57

2-7b Permissible Shear Stress for Cohesive Soils 58

2-8 Nomograph for Trapezoidal Design $\quad 59$

2-9 Trapezoidal Design Chart 60

2-10 Geometric Design Chart for Triangular Channels 61

2-11 Geometric Design Chart for Parabolic Channels 62

2-12 Hydraulic Radius Design Chart for Parabolic Channels 63

2-13 Manning's " $n$ " vs Hydraulic Radius for Class A Vegetation 64

2-14 Manning's "n" vs Hydraulic Radius for Class B Vegetation 65

2-15 Manning's "n" vs Hydraulic Radius for Class C Vegetation 66

2-16 Manning's "n" vs Hydraulic Radius for Class D Vegetation 67

2-17 Manning's " $n$ " vs Hydraulic Radius for Class E Vegetation 68

2-18 $\quad \mathrm{K}_{\mathrm{b}}$ Correction Factor for Bend Shear Stress 69 
2-19 Length of Protection, $L_{p}$, Downstream of Channel Bend 70

2-20 Angle of Repose in Terms of $\mathrm{D}_{50}(\mathrm{ft}) \quad 71$

2-21 Channel Side Shear Stress Correction Factor 72

2-22 Tractive Force Ratio as a Function of Angle of Repose and Side Slope 73

3-1 Classification of Principle Types of Failures 76

3-2 Comparison of Procedures for Estimating Stone Size 78

3-3 Flow Chart for Riprap Design Procedure for HEC-11 81

3-4a Design Aids for HEC-11 82

3-4b Flow Chart of HEC-15 Design Procedure 87

3-5 HEC-15 Design Aids for B $<6 \mathrm{ft}$ 90-91

3-6 Shields Diagram of Incipient Motion 94

3-7 Shields Diagram for Large Diameter Riprap 94

3-8 Comparison of $\mathrm{D}_{50}$ Estimates from HEC-15 and Field Data 96

3-9 Flow Chart for Cal-B\&SP Riprap Design Procedure 99

3-10 Design Aids for USACOE Riprap Design Procedure 101

3-11 Location of $\mathrm{V}_{\mathrm{ss}}$ and Definition of "d" 103

3-12 Forces Acting on a Riprap Particle Resting on a Channel 106

3-13 Flow Chart and Equations for Simons \& Senturk Design Procedure 107

3-14a Curve to Determine Stone Size in a Mixture Based on Velocity 109

3-14b Transformed USBR Stone Size Curve 110

3-15 Blodgett's Riprap Design Method 114

3-16a Displaced Ripap as a Function of Dimensionless Shear and Std. Dev 120

3-16b Displaced Riprap as a Function of Dimensionless Shear and Bank Angle 120

3-17 Comparison of Manning's n Based on Theory and Lab Data 125

3-18 Illinois DOT Riprap Gradation Chart 128

3-19a Gabion Mattress Design Aids 137

3-19b Gabion Mattress Design Aids 137

3-20 Permissible Shear Stress vs Rock Fill Diameter for Gabions 138

3-21 Permissible Shear Stress vs Gabion Thickness 138 
3-22 Typical Cylinder Test Results for FFR's 142

3-23 Schematic of Ground Anchors for FFRs 142

3-24 Bend Shear Stress Coefficient 142

3-25 Composite Channel Lining 152

3-26 Composite Channel Lining with Unequal Side Slopes 152

4-1 Limiting Velocity vs. Shear Strengths for Various Hydraulic Radii 165

4-2 Limiting Velocity vs. Shear Strengths (Modified Velocity Ranges) 167

4-3 Modified Shields Diagram 169

5-1 Sample Position Letter on Guarantee Specifications 188 


\section{List of Tables}

Table Title

page

1-1 Temporary Erosion Control Categories 2

1-2a Permanent Erosion Control Categories - Biotechnical Composites 3

1-2b Permanent Erosion Control Categories - Hard Armor Systems 3

1-3 Definitions of TRM \& ECRM Material Properties 9

1-4 Physical Properties of TRMs \& ECRMs 9

1-5 Performance Limits of Several Classes of Erosion Control Products 13

1-6 Summary of 1993 Wisconsin DOT Study on Erosion Control Products 16-17

1-7 Summary of USGS / FHWA Erosion Control Study (1985) 22

2-1 Limiting Shear Stresses for Generic Erosion Control Materials 34

2-2 Suggested H:V ratios for Different Bed Materials 39

2-3 Permissible Shear and Velocity for Current Erosion Control Products 50-51

2-4 Permissible Shear Stress for Generic Lining Materials 52

2-5 Vegetation Classification (A-E) 53

2-6 Manning's Roughness Coefficients by Depth of Flow 54

2-7 Manning's " $n$ " for Current Linings 55

3-1 List of Riprap Design Procedures Detailed in this Report 77

3-2 Values of $A_{3} / A_{2}$ for selected $B$ and $d / B$ Ratios 89

3-3 Bank Angle Correction Factor for USACOE Design 102

3-4 Riprap Example 121

3-5 Comparison of Mannings's n values 126

3-6 California Bank and Shore Protection Manual Gradation Table 128

3-7 Riprap Gradation Limits for a Design $\mathrm{D}_{50}$ from HEC-11 130

3-8 Riprap Gradation Classes Based on HEC-11 130

3-9 USACOE Gradations given as Weights for Percent Finer 131 
3-10 Bank Correction Factor 135

3-11 Typical FFR Thicknesses 145

4-1 Proposed Classification System for Erosion Control Products 163

4-2 Modified Velocity Ranges for Classification System 166

5-1 Texas DOT Approved Products List 178

5-2 Virginia DOT Approved Products List 180

5-3 Method 1 Proposed Approval Procedure 183

5-4 Method 2 Proposed Approval Procedure 185

5-5 Probable Warranty Periods for each Product Class 185

5-6 List of Possible Damage Criteria for Drainage Channels 189

5-7 Classification of Erosion Control Products 191

6-1 Guidelines for Installing Erosion Control Materials 196

6-2 Mix Proportions for FFR Grout 200 


\section{Implementation Report}

Recently, the INDOT new materials department has received numerous erosion control products to evaluate as alternatives to riprap and concrete in ditch liners. Potential benefits include lower construction costs and better aesthetics over current products. Unfortunately, no specification, design methodology, or classification system currently exists for these erosion control blankets. The research proposes to draft a specification implementing erosion control materials as ditch liners.

An extensive literature review of geosynthetic erosion control materials was performed at the request of the Indiana Department of Transportation. These new technologies combine natural vegetation with geosynthetic materials and have emerged as a cost-effective alternative to the traditional materials (riprap and paved side ditch). "Flexible" geosynthetic linings conform to a wide variety of contours, and geometries. Temporary products provide short term erosion protection and degrade to leave the vegetation to resist the hydraulic forces. Similar to temporary products, permanant products protection channels in the short term and accelerate vegetative growth. However, these rugged, UV stabilized erosion control blankets do not degrade. Ultimately, the liner becomes synergistically entangled with living plant tissue to extend the performance limits of natural vegetation.

On the other hand, extremely high flow channels or streambanks require hard armor protection. The solutions for this problem include traditional riprap and gabions (wire enclosed riprap) and more recently, fabric formed revetments and articulating concrete block systems. These products offer the highest level of erosion protection in demanding environments.

Based on this research effort, specific recommendations suggested to INDOT for implementation include:

1. Use a performance based design methodology for flexible ditch liners. The method developed follows the recommendations outlined in the HEC-15 publication by Chen and Cotton, 1988. However, modifications to the procedure have been made that reflect recent research. Such changes include utilizing higher permissible shear stresses 
for the erosion control materials, implementing a design safety factor against shear failure, and designing against velocity failure.

2. Use of the design methodologies present herein for fabric formed revetments (FFRs) and concrete block systems (CBSs). FFRs are designed using a traditional slope stability analysis while CBSs are designed by one of three accepted methods.

3. A performance based erosion control product classification is proposed. Classifications based upon limiting shear stress and velocity were created using current specifications from seven state DOT's.

\begin{tabular}{|c|c|c|}
\hline Classification & $\begin{array}{l}\text { Permissible Velocity } \\
\mathrm{m} / \mathrm{s}(\mathrm{ft} / \mathrm{s})\end{array}$ & $\begin{array}{l}\text { Permissible Shear } \\
\mathrm{Pa}\left(\mathrm{lb} / \mathrm{ft}^{2}\right)\end{array}$ \\
\hline \multicolumn{3}{|c|}{$\begin{array}{c}\text { A (Degradable): Product degrade within } 2 \text { years (e.g. jute mesh, straw or coconut } \\
\text { blanket, excelsior, roving, straw bales, mulches.) }\end{array}$} \\
\hline A-1 & $0.0-1.2(0-4)$ & $0-45 \quad(0-1)$ \\
\hline A-2 & $1.2-2.1 \quad(4-7)$ & $45-96(1-2)$ \\
\hline \multicolumn{3}{|c|}{$\begin{array}{l}\text { B (Non-degradable): Products stabilized with carbon black (e.g nylon mesh, heat } \\
\text { bonded 3-D TRM, synthetic erosion control and revegetation mat }\end{array}$} \\
\hline B-1 & $1.2-2.1(4-7)$ & $45-96(1-2)$ \\
\hline B-2 & $2.1-3.0 \quad(7-10)$ & $96-240(2-5)$ \\
\hline
\end{tabular}

\begin{tabular}{|c|c|}
\hline C (Hard Armor): & $\begin{array}{l}\text { Products made to resist extremely high flowst made of rock, concrete, } \\
\text { and often reinforced with galvanized steel cable } \\
\text { Note: No well-defined upper limit of shear and or velocity in the } \\
\text { literature for classes }(-1-C-4)\end{array}$ \\
\hline C-1 & Riprap \\
\hline $\mathrm{C}-2$ & Gabions \\
\hline C-3 & Fabric Formed Revetments \\
\hline$C-4$ & Articulating Blocks \\
\hline
\end{tabular}


4. This report reviews 10 available riprap design methodologies, Manning's n equations, and standard gradations. Further research is necessary to select an appropriate riprap design methodology for Indiana and test the viability of the standard riprap gradation schemes presented in this report.

5. Use of either an approved list format or a guarantee specification format for erosion control materials. The former puts the classification and field testing burden on INDOT while the latter places the burden on the General or Landscape Contractor. 


\section{Literature Review}

\subsection{Background}

Until recently, erosion of transportation infrastructure through channels such as highway ditches has been controlled using rigid linings made of rocks, concrete, or asphalt liners. Although rigid linings can withstand high discharges, flow velocities and shear stresses, they fail entirely if a portion is damaged. Moreover they are difficult to construct and provide no wildlife habitat.

Recently, new technologies that combine natural vegetation with geosynthetic materials have emerged as a cost-effective alternative to the traditional materials. These flexible linings conform to a wide variety of contours, and geometries. They provide temporary erosion protection and accelerate vegetative growth. Ultimately, the liner becomes synergistically entangled with living plant tissue to extend the performance limits of natural vegetation.

The benefits of using geosynthetics abound. Flexible vegetated linings are easy to install, feature a natural appearance, and provide a better habitat for local floral and fauna. Geosynthetic materials permit infiltration, promote groundwater recharge, and capture sediment. Following an extensive series of rainfall/erosion experiments, Austin (1996) concludes "all products tested reduced sediment loss to below $60 \%$ of the sediment loss from unprotected soil." Unlike rigid linings, flexible liners relieve water pressure. Because of their flexibility, these materials resist differential settlement and frost heave better than the concrete or asphalt lining. Furthermore, in pedestrian areas, geosynthetics are safer; no sharp edges or surfaces to cause injury (Northcutt, 1995).

Most importantly, flexible linings are significantly less expensive than concrete or niprap. Typical estimates are $1 / 3$ to $1 / 2$ the cost of hard armor (riprap and concrete). Heavy duty turf reinforcing mats cost $\$ 8-\$ 13 / \mathrm{m}^{2}$; whereas, concrete and rip rap cost $\$ 25 / \mathrm{m}^{2}$. Revetment systems cost between $\$ 21$ and $\$ 42 / \mathrm{m}^{2}$ depending on the area of the country (Carroll, 1990). Indeed, this economic benefit provides the real impetus for this research. One often cited example is the use of erosion mats in storm water runoff channels at the exclusive Horse Ranch community near Aspen, Colorado. In this case, 
Drexel Barrell installed Turf Reinforcing Mats designed to handle a 100-year storm at approximately $41 \%$ of the cost of conventional rip rap. This resulted in a total saving of over $\$ 250,000$ ! (Theisen, Hageman, \& Austin, 1995).

Erosion control products can be divided into two main categories: TERMs (Temporary Erosion Control Materials) and PERMs (Permanent Erosion Control Materials) (Austin, 1996; Theisen, 1991; Theisen, 1992). TERMs consist of degradable natural or synthetic mats that provide temporary control, and rely on vegetation for longterm resistance to low to medium flow. The blankets prevent erosion during vegetation establishment, then degrade in 1-5 growing seasons.

PERMs on the other hand are permanent erosion control materials designed for medium to high flows. These mats are constructed of UV stabilized materials (i.e. carbon black added to resist photodegradation). They are used on sites where mature vegetation alone could not resist the design flow. These materials are subdivided into biotechnical composites and hard armor systems. Biotechnical composites are non-degradable materials that accelerate vegetative growth and become entangled with the roots. Hard armor systems can resist more extreme conditions - tidal flows, harbors, and commercial riverfront areas in addition to traditional highway ditches. Table 1-1 and 1-2 list the general categories of TERMs and PERMs (Modified from Theisen, 1992).

The following pages provide brief descriptions of each class of products (Lancaster, 1994; Theisen, 1992; Agnew, 1991; Theisen, 1992; Northcutt, 1995; Theisen, 1991; Dikran, 1996). In addition, common applications are noted for each class.

\section{TERM Categories}

1). Hay, straw, and hyromulch

2). Fiber roving systems

3). Erosion control netting \& mesh

4). Erosion control blankets

5). Tackifiers and soil stabilizers

Table 1-1: Temporary erosion control materials 


\section{PERM Categories \\ "Biotechnical Composites"}

1). UV stabilized fiber roving

2). Erosion control revegetation mats

3). Turf Reinforcing mats

4). Vegetated geocelluar containment sys.

5). Vegetated concrete block systems

Table 1-2a: Permanent erosion control materials

\begin{tabular}{l} 
PERM Categories \\
"Hard Armor Systems" \\
\hline 1). Geocellular containment system \\
2). Fabric formed revetment \\
3). Articulating concrete block \\
4). Rip-rap \\
Table 1-2b: Permanent erosion control materials
\end{tabular}


Pictures of Erosion Control Products

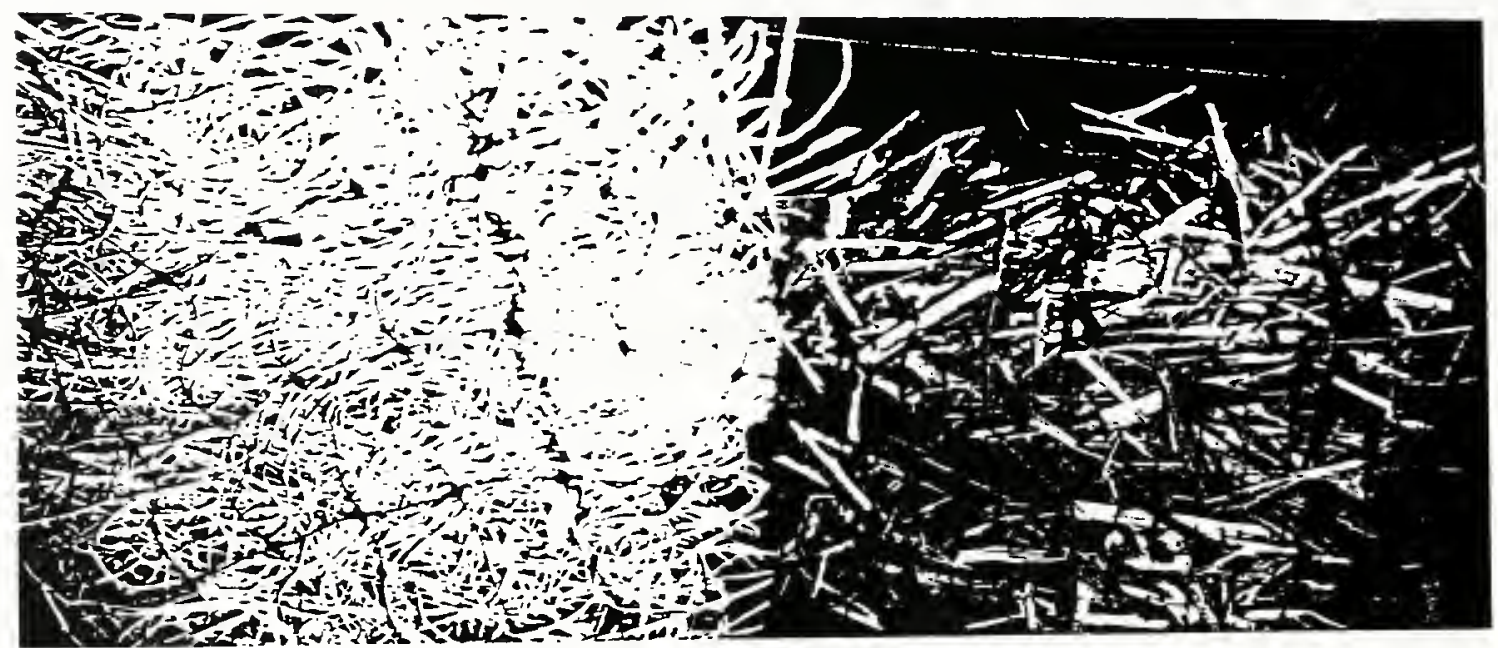

Temporary Erosion Control Products

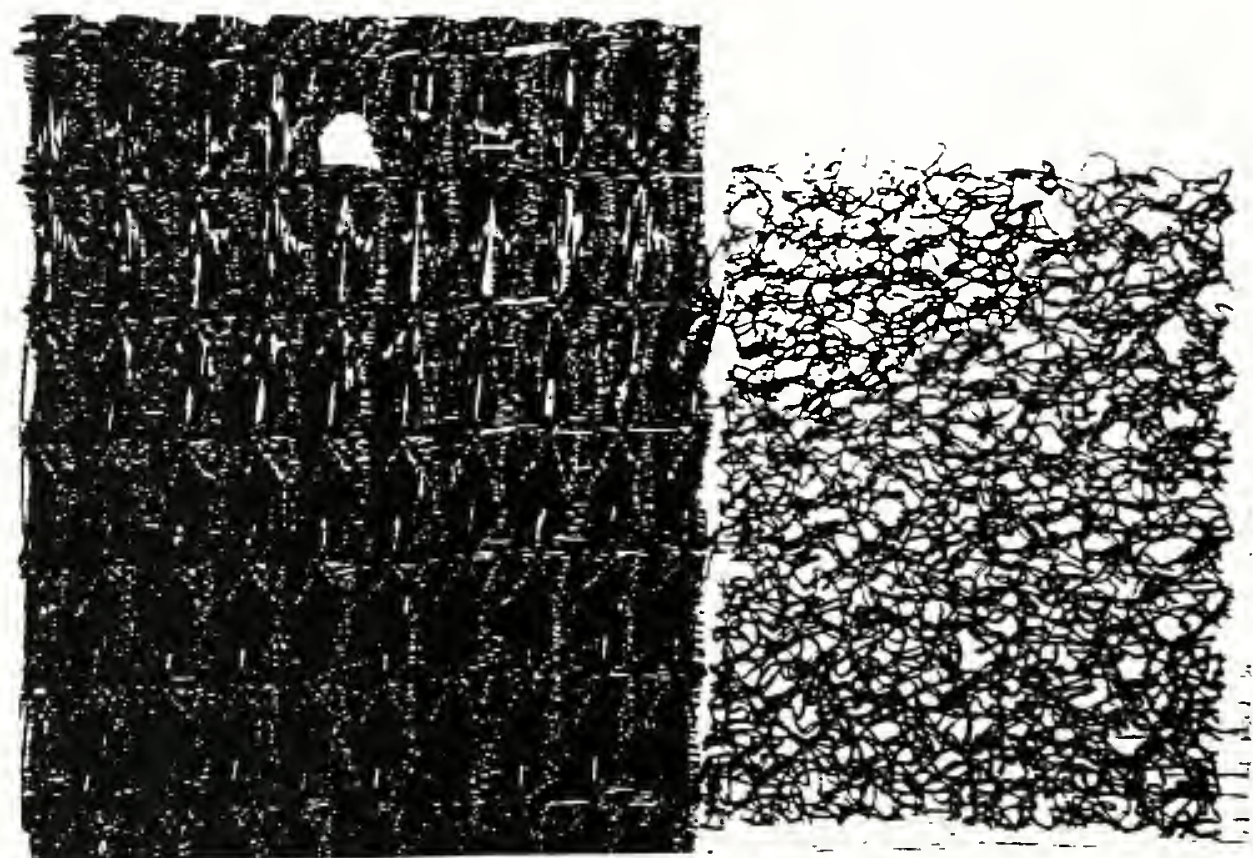

Permanent Erosion Control Products 


\subsection{Temporary Erosion Control Material Characteristics}

Mulches

(a). Assists in soil stabilization; capture sediment and blowing snow

(b). Works by decreasing soil temperature which in tum decreases evaporation and heat stress on plants.

(c). Decomposes into valuable organic matter

(d). Loose : straw / hay 10-20 cm long; $~ 1.5-2.0$ tons/acre

Tackifiers : viscous sprays to anchor mulch fiber; typically nontoxic/degradable asphalt and petroleum are used

Hydraulic : one step application of seed, water, fertilizer, and mulch; fibers only $1 \mathrm{~cm}$ long which degrade quickly

Erosion Control Netting or Biaxially Orientated Process nets (ECN \& BOP, respectively)

(a). 2-D biaxial-orientated process nets from polypropylene or polyethylene resin or woven natural fibers

(b). BOP / ECN's do not show significant shrink/swell behavior (unlike jute)

(c). Suited for moderate conditions

Open Weave Mesh

(a). Woven polyolefin yarns formed into 2-D matrix used with or without mulch layer; mesh has a higher tensile strength than an ECN

(b). Often used as a reinforcing underlay for sod; also used on slopes

Erosion Control Blanket (ECB)

(a). Degradable organic/synthetic fibers woven or glued to nettings or meshes made from straw, wood excelsior, coconut, cotton, polyethylene or polypropylene; A biaxially orientated process net sandwiches the fibers in nearly every case.

(b). Used to retain soil moisture, promote quick seed germination, break up raindrops, and prevent erosion until vegetation becomes established

(c). Applications include low to moderate flow channels (up to $3 \mathrm{~m} / \mathrm{s}$ ) and gradual to steep slopes. 
Fiber Roving Systems (FRS)

(a). Air compressor blown spaghetti-like strands of polypropylene ejected through a nozzle over a slope or channel and anchored with asphalt emulsions;

(b). Material can accommodate any geometry, width, or thickness;

(c). Roving may be a PERM if UV stabilizing chemicals are added

(d). It is very easy to install along highways, surface mines, and landfills

(e). Though non-toxic, black asphalt tackifier may not be environmentally acceptable.

\subsection{Permanent Erosion Control Material Characteristics}

Geocellular Containment System (GCS)

(a). Series of 3-D soil-filled cells up to $20 \mathrm{~cm}$ deep that are interconnected by manufactured joints; the spreadable sheet looks like a large honeycomb stretched across a slope or channel. GCS are made of HDPE 75-100 mils thick.

(b). Wall pattern prevents development of deep plant roots; hence flow velocities cannot exceed $2-3 \mathrm{~m} / \mathrm{s}$ in drainage ditches.

(c). Each cell is hydraulically connected creating a cellular confinement system that is free draining.

Fabric Formed Revetments (FFR)

(a). Double layer of woven geotextile that installed and then filled with pumpable concrete; high strength cables may interconnect the blocks or cells

(b). Used for high discharge / velocity flow or harsh conditions (e.g. coastal zones)

(c). Common fabric types include: filter point, uniform section, and articulating mats.

Concrete Block Systems (CBS)

(a). Prefabricated concrete panels joined by high strength cable

(b). Often allow vegetation to grow through slots in the panel

(c). Used for high flows, canals, riverbanks. 
Turf Reinforcing Mats (TRM)

(a). Stiff, high strength, black, UV stabilized, 3-D polypropylene, polyethylene, or PVC matrix that are installed on graded channel face, seeded and soil filled. Mats are often more than $13 \mathrm{~mm}(0.5$ ") thick and have in excess of $90 \%$ void space

(b). Vulnerable in the short term until vegetation becomes established; however once vegetation mature, mats provide superior shear resistance as roots become entangled with the material.

(c). Used in medium to high flow channels and steep 1:1 slopes.

(d). Mat is resistant to hydrolysis, bio-chemical degradation; It provides permanent erosion control and turf reinforcement.

Erosion Control and Revegetation Mat (ECRM)

(a). Green, dense, 3-D mat of UV stabilized PVC or polypropylene monofilaments that is thinner (lower profile) and weaker than TRMs.

(b). Channel bed is seeded prior to laying down the ECRM. That is, vegetation must grow up through the mat.

(c). Provides superior erosion protection while vegetation gets established. 


\subsection{TRM Vs ECRM}

ECRMs and TRMs have similarities, but also have distinct differences. First the two materials are installed differently. TRMs are first installed, then seeded and soil filled; while, in the case of ECRMs channel bed is seeded before the geosynthetics are rolled out. This means that the roots entangle with the TRM, but not with the ECRM. Thus, the vegetated TRM provides more shear resistance than the ECRM in the long term (Carroll, 1990, 1991, 1992; Theisen, 1992).

TRMs leave bare soil exposed until vegetation is established; whereas, ECRMs provide dense cover during early stages of growth. Therefore, if short term erosion is critical, an ECRM might be preferable. On the other hand, if long term erosion is critical, then a TRM might be the best choice. In the event that both long and short term erosion are critical, a TRM covered with a degradable mat (e.g. straw or excelsior) would be a good solution.

Another difference is that TRMs are much stiffer than ECRMs. The high stretch properties of the ECRM imply that it does not perform as well in the long term (Carroll, 1990). Carroll emphasizes that ECRMs only provide erosion protection for moderate flow channels; they are not designed for turf reinforcement. Hence, while a TRM can provide ECRM benefits, the reverse is not true. In order to grasp the differences between these two products, table 1-3 defines the relevant material properties and table 1-4 provides the corresponding values of each parameter for TRMs and ECRMs. These values are compiled from Carroll (1990) and the FHWA (1992).

A brief example furthers this point. Jason Consultants of Geneva Switzerland published a report comparing various erosion control materials on 2:1 slopes. Materials tested include jute mesh, excelsior, geocells, ECRM, and TRMs. In terms of vegation density and height, the TRM had the best quality of growth. (Theisen, 1990). Similar results were obtained from a 1988 Hartford, Connecticut landfill study. This research is evaluating 20 erosion control products. Soil-filled TRM channel liners showed seed germination within 6 days and had significantly denser vegetation after one month than any of 28 other plots. The TRM also withstood a 5" rain event that devastated other plots. (Theisen, 1990). 
Definitions of TRM and ECRM Material Properties

(Complied from Carroll, 1990 and FHWA, 1992)

\begin{tabular}{|c|c|c|c|}
\hline & $\begin{array}{l}\text { Material } \\
\text { Property }\end{array}$ & $\begin{array}{l}\text { ASTM Test } \\
\text { Number }\end{array}$ & Definition \\
\hline 1). & Thickness & ASTM D-1777 & Minimum thickness of the blanket \\
\hline 2). & Porosity & Calculated & $\begin{array}{l}\text { Ratio of voids to total volume of blanket; based } \\
\text { on weight, thickness, and specific gravity. }\end{array}$ \\
\hline 3). & Ground Cover & Light Projection & Ratio of light passing the specimen to a standard \\
\hline 4). & Resiliency & ASTM D-1777 & $\begin{array}{l}\text { Percent of original thickness retained after } 3 \\
\text { cycles of a } 100 \mathrm{psi}(600 \mathrm{kPa}) \text { load for } 60 \\
\text { seconds followed by } 60 \text { seconds without load. } \\
\text { Thickness measured } 30 \text { minutes after load } \\
\text { removed. }\end{array}$ \\
\hline 5). & $\begin{array}{l}\text { Tensile } \\
\text { Strength }\end{array}$ & ASTM D-4632 & $\begin{array}{l}\text { Strength of both machine and cross direction } \\
\text { using the } 2 \text { " strip method }\end{array}$ \\
\hline 6). & Elongation & ASTM D-1682 & $\begin{array}{l}\text { Elongation of material at failure expressed as a } \\
\text { percent of total length }\end{array}$ \\
\hline 7). & UV Stability & ASTM D-4355 & $\begin{array}{l}\text { Tensile strength retained after } 1000 \text { hours in a } \\
\text { Xenon ARC weatherometer }\end{array}$ \\
\hline
\end{tabular}

Table 1-3: Physical property definitions for TRM and ECRM

Physical Properties of TRMs and ECRMs

(Updated from Carroll, 1990)

\begin{tabular}{ll|ll}
\hline \multicolumn{1}{c|}{ Material Property } & TRM & ECRM \\
\hline 1). Thickness (mm) & $13-18$ & $6-8$ \\
2). Porosity & $>90 \%$ & $>90 \%$ \\
3). Ground Cover & $30-60 \%$ & $50-80 \%$ \\
4). Resiliency & $80 \%$ & $80 \%$ \\
5). Tensile Strength $(\mathrm{kN} / \mathrm{m} ; \mathrm{lb} / \mathrm{ft})$ & $1.9(130)$ & $1.4(95)$ \\
6). Elongation & $40 \%(\max )$. & $70 \%(\max )$. \\
7). UV Stability & $80 \%$ & $80 \%$ \\
\hline
\end{tabular}

Table 1-4: Physical property requirements for TRM and ECRM 


\subsection{Design Procedure}

There are two schools of thought when it comes to designing erosion control systems: performance based and index test based. Current literature supports the former method, while several state DOT's favor the latter. Performance based designs are calculated using Manning's equation or permissible shear stress equation. (Theisen, 1991, 1992; Carroll, 1991; Cotton, 1993, Chen and Cotton, 1988; Theisen et al., 1995; Hewlett et al., 1987; Austin and Theisen, 1994). The flow conditions are a function of channel geometry, design discharge, channel roughness (unique to each lining material), and channel slope. During the mid-1980's, most authors followed a permissible velocity approach (Hewlett, 1987; Virginia DOT Specifications, 1994; Barrett, 1990). Even today, the Federal Highway Administration (FWHA) still endorses this design methodology (Geosynthetic Construction Guidelines, 1995).

Unfortunately, most erosion control materials fail due to shear which is not only a function of flow velocity. Moreover, the erosion control properties of these linings depend on both the resistance imparted to the soil and the boundary shear that results at the soil surface. Erosion occurs beneath the lining when the boundary shear on the soil surface exceeds the threshold for soil particle movement. Furthermore, the velocity criteria is severely limited because velocity is only approximately constant over a narrow range of channel shape and roughness.

These deficiencies in the permissible velocity design method led researchers to develop a permissible shear stress approach (Cotton, 1993; Chen and Cotton, 1988; Austin, 1995; Northcutt, 1995). The tractive force acting on the lining induce a shear stress. This shear stress is related to the flow depth which is easily computed. More importantly, the shear stress virtually independent of channel shape and roughness. The velocity criteria on the other hand is a function of the channel roughness. Note, in this context, channel roughness is essentially Manning's n-value). Since channel roughness (and hence velocity) is a function of vegetation density, flow rate, and slope steepness, the velocity is a very complex design parameter (Hewlett et al., 1987).

On the other hand, shear stress is virtually constant over a channel section. It provides a lining criteria over a wide range of flow rates. This criteria lends itself to the 
development of design safety factors (this idea is further developed in chapters 2 and 3). In addition, the higher stresses developed in channel bends can be quantified by simple shear stress calculations. This provides a higher level of design confidence than otherwise possible (Dodson, 1990). The tractive force approach is used in both the HEC-15 Design Circular (Chen and Cotton, 1988) and Texas DOT specifications (Northcutt, 1996). Dodson (1990) suggests that critical shear stress should be used in tandem with velocity calculations for erosion control lining designs. Hence, a combination of the permissible velocity and shear design methodologies are reviewed in this report.

The other design methodology utilizes index properties of the material. For a given site, one needs to determine the required tensile strength, elongation, UV stability, Mullen burst strength (ASTM D-3786), and ground cover factor (see Table 1-4 for all ASTM test references). Based on these results, one selects erosion control products that meet or exceed these requirements. Illinois, Ohio, and the FWHA currently use index property designs (ILDOT, ODOT, 1994; FWHA, 1992). One problem with using such a system is that the majority of manufactures do not provide index test data for their products. The reason for the lack of index data is that there no consensus on how to perform erosion material index tests. According to the Erosion Control Technology Council, a committee is currently attempting to standardize these index tests. Moreover, ASTM has recently started a subcommittee (D-18.25) to investigate standard designs, classifications, and testing procedures for erosion control products.

\subsection{Evaluation of Geosynthetic Erosion Control Materials}

In order to adopt a performance based specification, one needs to know how much shear or velocity a given product can withstand. Several authors conducted flume tests over the past decade to establish permissible velocity and more recently permissible shear values for erosion control products. In 1987, the Construction Industry Research and Information Association (CIRCA) from the United Kingdom published a report on field testing of various erosion control products (Hewlett et al., 1987). Nine reinforced grassed channels were constructed on the upstream face of a $10 \mathrm{~m}$ high abandoned earth dam. Materials tested included cellular concrete blocks, TRMs, roving, 2-D meshes, and woven 
geotextile fabric. The CIRIA engineers established guidelines for the design of grassed channels. Their velocity recommendations are noted below.

\begin{tabular}{lcll} 
Erosion Control Measure & Max. Velocity & & Duration of Flow \\
\cline { 2 - 3 } Mature unreinforced grass & $4.5 \mathrm{~m} / \mathrm{s}$ & Short event $(0.5 \mathrm{hrs})$ \\
& $2.0 \mathrm{~m} / \mathrm{s}$ & Long event $(50 \mathrm{hrs})$ \\
Long Term Vegetated ECMs ${ }^{1}$ & $6.0 \mathrm{~m} / \mathrm{s}$ & Short event $(0.5 \mathrm{hrs})$ \\
& $4.4 \mathrm{~m} / \mathrm{s}$ & Long event $(50 \mathrm{hrs})$ \\
Concrete blocks & $6.1 \mathrm{~m} / \mathrm{s}$ & Long event $(50 \mathrm{hrs})$ \\
${ }^{1} E C M s=$ Erosion Control Materials & &
\end{tabular}

Notice that the allowable design flow velocities decrease with extended flow duration. Increasing the duration of flow decreases the resistance of the material. The CIRIA group chose a 2-day design duration because this period is longer than most high velocity events. After two days, grass should recover and the subsoil should drain (Theisen, 1990).

This initial work spurned numerous studies by universities (Colorado State and Utah State) and private companies (Synthetic Industries and North American Green). Vegetated and non-vegetated materials were installed in flumes $0.6-1.2 \mathrm{~m}(2-4 \mathrm{ft})$ wide and $15.2 \mathrm{~m}(50 \mathrm{ft})$ long. Flows of $0.57,0.91,1.3,1.7$, and $2.1 \mathrm{~m}^{3} / \mathrm{s}(20,32,45,60$, and $\left.75 \mathrm{ft}^{3} / \mathrm{s}\right)$ gave rise to velocities of $0.91,2.4,3.4,4.6$, and $6.1 \mathrm{~m} / \mathrm{s}(3,8,11,15$, and $20 \mathrm{ft} / \mathrm{s})$ (Schematic of channel in figure 1-1). Flow depth measurements were taken throughout the channel to calculate maximum shear stress. Table 1-5 provides performance limits for several classes of erosion control materials. Note that the information is combined from several sources (Northcutt, 1995; Carroll, 1990, 1991; Theisen, 1991, 1992; Austin, 1995; Cotton, 1993). Some researchers determined permissible velocity, while others determined maximum shear. Consequently, there are several categories of incomplete information. 
Performance Limits of Several Classes of Erosion Control Products

\begin{tabular}{|c|c|c|c|c|}
\hline Product Class & $\begin{array}{l}\text { Short Term } \\
\text { Velocity } \\
\mathrm{m} / \mathrm{s} \text { (ft/s) }\end{array}$ & $\begin{array}{l}\text { Long Term } \\
\text { Velocity } \\
\mathrm{m} / \mathrm{s}(\mathrm{ft} / \mathrm{s})\end{array}$ & $\begin{array}{l}\text { Short Term } \\
\text { Shear } \\
N / m^{2}\left(b / f t^{2}\right)\end{array}$ & $\begin{array}{l}\text { Long Term } \\
\text { Shear } \\
N / m^{2}\left(b / f^{2}\right)\end{array}$ \\
\hline Bare Soil & & & $5.4(0.11)$ & \\
\hline Grass - good cover & $3.0(9.8)$ & $1.5(4.9)$ & & \\
\hline Grass - poor cover & $2.0(6.6)$ & $1.0(3.0)$ & & \\
\hline Fiber Roving & $1.8(6.0)$ & $1.2(4.0)$ & $\begin{array}{l}29-68(0.61- \\
1.4)\end{array}$ & \\
\hline ECN - degradable & & & $9(0.2)$ & \\
\hline ECM - degradable & & & $140(3.0)$ & \\
\hline ECB - single net & & & $95(2.0)$ & \\
\hline ECB - double net & & & $140(3.0)$ & \\
\hline ECB - excelsior & & & $74(1.6)$ & \\
\hline ECB - straw w/ net & & & $67(1.4)$ & \\
\hline Jute mesh & & & $25(0.53)$ & \\
\hline Hydromulch & $0.76(2.5)$ & & & \\
\hline ECRM - bare soil & $4.0(13)$ & $2.7(9.0)$ & & \\
\hline ECRM - vegetated & $5.8(19)$ & $4.6(15)$ & & \\
\hline TRM - no soil & $5.8(19)$ & $4.3(14)$ & & \\
\hline TRM - bare soil & $4.0(13)$ & $2.4(8.0)$ & & $280(5.8)$ \\
\hline TRM - vegetated & $6.0(20)$ & $4.6(15)$ & & $380(7.9)$ \\
\hline Concrete & $8.0+(26+)$ & $6.0+(20+)$ & & \\
\hline
\end{tabular}

Note: Short Term $\Rightarrow 30-60$ minutes; Long Term $\Rightarrow 24$ or 50 hours

Table 1-5: Allowable shear and velocity for several classes of erosion control products 


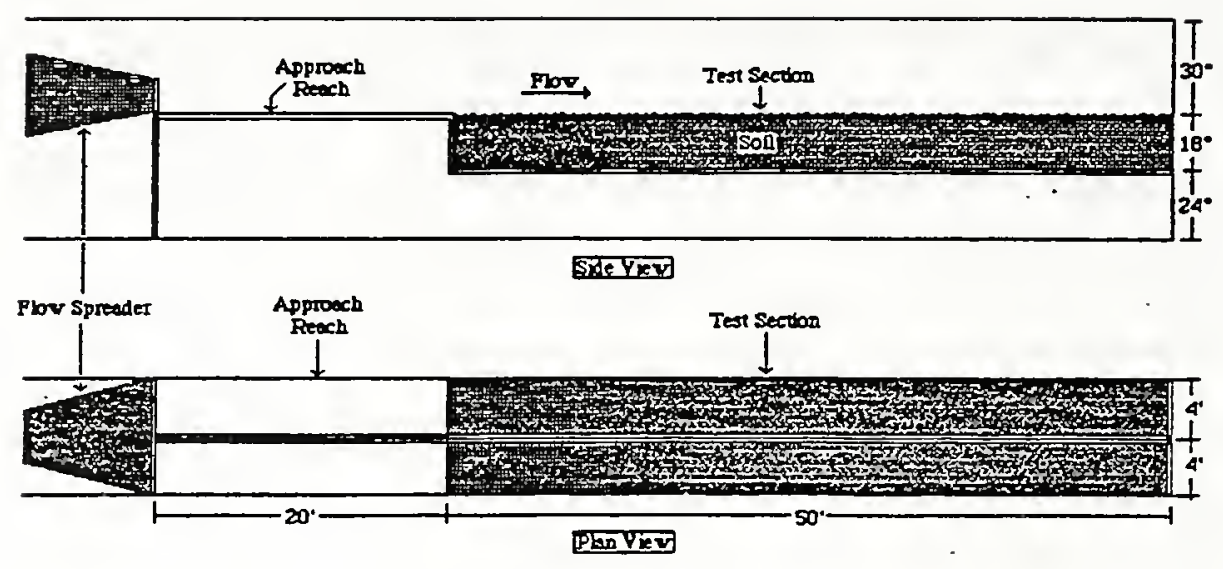

Figure 1-1a: Elevation and plan views of the test channels (Reprinted from Theisen, 1992)

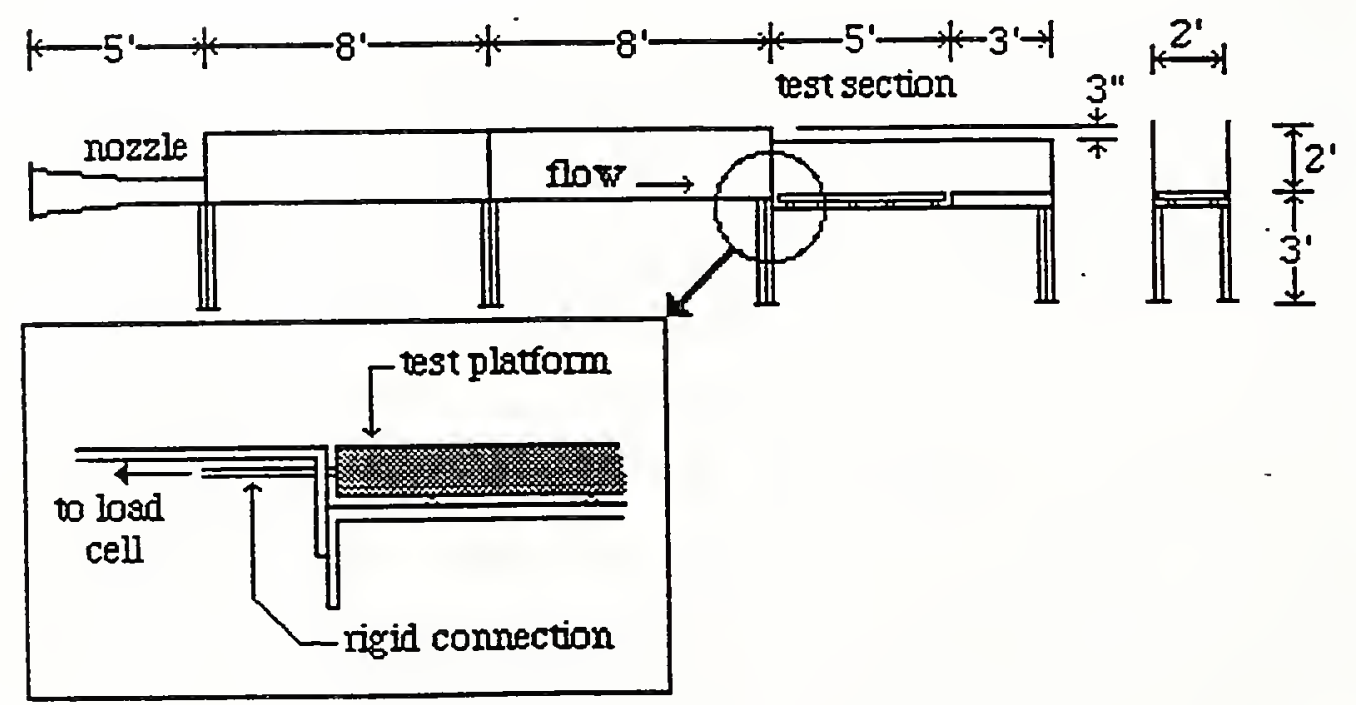

Figure 1-1b: Elevation and plan views of the test channels (Reprinted from Theisen, 1992) 


\subsection{Government Reports \& Case Studies on Erosion Control Materials}

This section presents several case studies found in the literature. The first four are summaries of government field study reports. Missouri DOT, Wisconsin DOT, the Ontario Ministry of Transportation and the FHWA installed and evaluated several erosion control products. The next four are summaries of specific applications found in the literature. For references, see Appendix C.

\section{Missouri DOT - Investigation of Erosion Control Materials for Ditches, 1983}

Summary: This field study compares a TRM (Enkamat), mulch blanket (Hold Gro), Excelsior (Curlex), mulch blanket (Roll Lite) to traditional sod, rip rap, and concrete. The Enkamat worked well at half the cost. The other materials worked, but did not significantly improve shear resistance or offer any savings over straw, sod, or netting.

$\begin{array}{lll}\text { Results } & \text { Product } & \text { Permissible Velocity } \\ \text { Enkamat } & \mathrm{V}<3.4 \mathrm{~m} / \mathrm{s}(11 \mathrm{ft} / \mathrm{s}) \\ \text { Mulch Blanket } & \mathrm{V}<1.8 \mathrm{~m} / \mathrm{s}(6 \mathrm{ft} / \mathrm{s}) \\ \text { Curlex } & \mathrm{V}<1.8 \mathrm{~m} / \mathrm{s}(6 \mathrm{ft} / \mathrm{s}) \\ \text { Roll Lite } & \mathrm{V}<1.8 \mathrm{~m} / \mathrm{s}(6 \mathrm{ft} / \mathrm{s})\end{array}$

Conclusions

1). Enkamat is easy to place, promotes faster seed germination than other products

2). Mulch blanket ravels when subject to heavy flows and water undercut the blanket

3). Curlex was successful, but blanket did have undercutting problems

4). Maintaining good contact between the ground and blanket was difficult

5). Two failures occurred after a 3.1" storm 2 weeks after installation. It was considered a rare event and not indicative of the products performance. 


\section{Wisconsin DOT - A Statewide Erosion Control Study - Evaluation Report, 1993}

Thirty blankets, tackifiers, and mulches were installed at 10 sites throughout Wisconsin. Twenty two of the thirty erosion blankets tested effectively controlled erosion, and encouraged seed germination. Four of the eight failures were attributed to improper installation. The other four failing blankets were installed on sites exceeding product limitations. All of the products tested then appeared to play a beneficial role in highway construction. In addition, the report cautions users to be aware of product limitations and strictly adhere to the manufacturers installation guidelines. Table 1-6 lists each product tested, its composition, and the field performance.

\begin{tabular}{|l|l|l|}
\hline $\begin{array}{l}\text { Manufacturer / } \\
\text { Product }\end{array}$ & Composition & Field Performance \\
\hline BonTerra S1 & $\begin{array}{l}100 \% \text { straw w/ top } \\
\text { net }\end{array}$ & $\begin{array}{l}\text { Installed on backslope; held up well } \\
\text { and prevented erosion }\end{array}$ \\
\hline BonTerra S2 & $\begin{array}{l}100 \% \text { straw w/ top \& } \\
\text { bottom net }\end{array}$ & $\begin{array}{l}\text { Resisted 3" rain 2 weeks after installed; } \\
\text { good plant growth }\end{array}$ \\
\hline BonTerra CS2 & $\begin{array}{l}70 \% \text { straw; 30\% } \\
\text { coconut w/ netting }\end{array}$ & $\begin{array}{l}\text { Resisted 3" rain 2 weeks after } \\
\text { installation; good plant growth }\end{array}$ \\
\hline BonTerra C2 & $\begin{array}{l}100 \% \text { coconut fiber } \\
\text { w/ top \& bottom net }\end{array}$ & $\begin{array}{l}\text { Resisted 1.5" rain first night after } \\
\text { installation; good plant growth }\end{array}$ \\
\hline BonTerra SFB & $\begin{array}{l}100 \% \text { PP staple fiber } \\
\text { w/ top \& bottom net }\end{array}$ & $\begin{array}{l}\text { Resisted 1.5" rain first night after } \\
\text { installation; good plant growth }\end{array}$ \\
\hline $\begin{array}{l}\text { North American. } \\
\text { Green - SC150 }\end{array}$ & $\begin{array}{l}70 \% \text { straw; 30\% } \\
\text { coconut w/ netting }\end{array}$ & $\begin{array}{l}\text { Performed well; no erosion; good seed } \\
\text { germination }\end{array}$ \\
\hline $\begin{array}{l}\text { Synthetic Industries - } \\
\text { Polyjute 407 GT }\end{array}$ & Degradable PP fibers & $\begin{array}{l}\text { Performed well despite late fall } \\
\text { installation }\end{array}$ \\
\hline $\begin{array}{l}\text { Synthetic Industries - } \\
\text { Landlok TRM 1060 }\end{array}$ & $\begin{array}{l}\text { Black polyolefin } \\
\text { fibers w/ netting }\end{array}$ & $\begin{array}{l}\text { Severe erosion during heavy rain; } \\
\text { improper installation - no check slots }\end{array}$ \\
\hline $\begin{array}{l}\text { Synthetic Industries - } \\
\text { Landlok ECRM 450 }\end{array}$ & $\begin{array}{l}\text { Green polyolefin } \\
\text { fibers w/ netting }\end{array}$ & $\begin{array}{l}\text { Severe erosion during heavy rain; } \\
\text { improper installation - no check slots }\end{array}$ \\
\hline $\begin{array}{l}\text { Phillips Fibers Corp. } \\
\text { SuperGro }\end{array}$ & $\begin{array}{l}\text { Nonwoven PP fiber } \\
\text { blanket w/ netting }\end{array}$ & Performed well; no erosion \\
\hline $\begin{array}{l}\text { ProSeed (USA) Inc. - } \\
\text { PS100 }\end{array}$ & $\begin{array}{l}79 \% \text { hay, 21\% } \\
\text { polymer; no netting }\end{array}$ & $\begin{array}{l}\text { Washed away on ditch bottom; } \\
\text { product should only be used on slopes }\end{array}$ \\
\hline $\begin{array}{l}\text { ProSeed (USA) Inc - } \\
\text { PS200 }\end{array}$ & $\begin{array}{l}\text { same as PS100; seed } \\
\text { implanted in material }\end{array}$ & $\begin{array}{l}\text { Washed away on ditch bottom; } \\
\text { product should only be used on slopes }\end{array}$ \\
\hline $\begin{array}{l}\text { Nicolon Mirafi - } \\
\text { Miramat 1000 }\end{array}$ & $\begin{array}{l}\text { Permanent mat of } \\
\text { PVC monofilaments }\end{array}$ & $\begin{array}{l}\text { Performed well, but vegetation pushed } \\
\text { up mat in some places }\end{array}$ \\
\hline
\end{tabular}




\begin{tabular}{|c|c|c|}
\hline $\begin{array}{l}\text { Manufacturer/ } \\
\text { Product }\end{array}$ & Composition & Field Performance \\
\hline $\begin{array}{l}\text { Akzo Industrial Sys. - } \\
\text { Enkamat } 7020\end{array}$ & $\begin{array}{l}\text { Permanent nylon } \\
\text { monofilaments }\end{array}$ & $\begin{array}{l}\text { Resisted spring } 1993 \text { mudslide; } \\
\text { excellent erosion control }\end{array}$ \\
\hline $\begin{array}{l}\text { Belton Industries - } \\
\text { Dekowe } 700\end{array}$ & $100 \%$ coconut fiber & $\begin{array}{l}\text { Performed well; encouraged seed } \\
\text { germination and resisted erosion }\end{array}$ \\
\hline $\begin{array}{l}\text { Belton Industries - } \\
\text { Dekowe } 900\end{array}$ & $100 \%$ coconut fiber & $\begin{array}{l}\text { Performed well; encouraged seed } \\
\text { germination and resisted erosion }\end{array}$ \\
\hline $\begin{array}{l}\text { Verdyol - } \\
\text { High Velocity Ero-mat }\end{array}$ & $\begin{array}{l}\text { Wheat fiber w/ top \& } \\
\text { bottom netting }\end{array}$ & $\begin{array}{l}\text { Resisted } 1.5 \text { " rain first night after } \\
\text { installation; good plant growth }\end{array}$ \\
\hline $\begin{array}{l}\text { Verdyol - } \\
\text { Std Velocity Ero-mat }\end{array}$ & $\begin{array}{l}\text { Wheat fiber w/ top } \\
\text { net only }\end{array}$ & $\begin{array}{l}\text { Resisted initial erosion; Spring } 1993 \\
\text { mudslide tore \& washed away blanket }\end{array}$ \\
\hline $\begin{array}{l}\text { Verdyol - } \\
\text { High Velocity Excels. }\end{array}$ & $\begin{array}{l}\text { Wood excelsior fiber } \\
\text { w/ top \& bottom net }\end{array}$ & $\begin{array}{l}\text { Resisted } 1.5 \text { " rain first night after } \\
\text { installation; good plant growth }\end{array}$ \\
\hline $\begin{array}{l}\text { Verdyol - } \\
\text { Std Velocity Excelsior }\end{array}$ & $\begin{array}{l}\text { Wood excelsior fiber } \\
\text { w/ top net only }\end{array}$ & $\begin{array}{l}\text { Resisted initial erosion; Spring } 1993 \\
\text { mudslide tore \& washed away blanket }\end{array}$ \\
\hline $\begin{array}{l}\text { Erosion Control Sys. - } \\
\text { High Velocity Straw }\end{array}$ & $\begin{array}{l}\text { Straw w/ top \& } \\
\text { bottom netting }\end{array}$ & $\begin{array}{l}\text { Moderate erosion after } 3 \text { " storm } 2 \\
\text { weeks after installation }\end{array}$ \\
\hline $\begin{array}{l}\text { Erosion Control Sys. - } \\
\text { Std. Velocity Straw }\end{array}$ & Straw w/ top netting & $\begin{array}{l}\text { Performed well; Survived a 3" storm } 2 \\
\text { weeks after installation }\end{array}$ \\
\hline $\begin{array}{l}\text { Erosion Control Sys. - } \\
\text { High Impact Excelsior }\end{array}$ & $\begin{array}{l}\text { Wood excelsior fiber } \\
\text { w/ top \& bottom net }\end{array}$ & $\begin{array}{l}\text { Moderate erosion after } 3 \text { " storm } 2 \\
\text { weeks after installation }\end{array}$ \\
\hline $\begin{array}{l}\text { Erosion Control Sys. - } \\
\text { Std. Excelsior }\end{array}$ & $\begin{array}{l}\text { Wood excelsior fiber } \\
\text { w/ top net }\end{array}$ & $\begin{array}{l}\text { Moderate erosion after } 3 \text { " storm } 2 \\
\text { weeks after installation }\end{array}$ \\
\hline $\begin{array}{l}\text { Contech Constr. Prod.- } \\
\text { TRM C-60 }\end{array}$ & $\begin{array}{l}\text { Web of polyolefin } \\
\text { fibers w/ netting }\end{array}$ & No erosion; Performed well \\
\hline $\begin{array}{l}\text { Contech Constr. Prod.- } \\
\text { ECRM C-45 }\end{array}$ & $\begin{array}{l}\text { Green polyolefin } \\
\text { fibers w/ netting }\end{array}$ & Performed well \\
\hline $\begin{array}{l}\text { Conwed Fibers } \\
\text { Futtera Mat }\end{array}$ & $\begin{array}{l}\text { Recycled waste wood } \\
\text { fibers w/ netting }\end{array}$ & $\begin{array}{l}\text { Resisted initial erosion; Spring } 1993 \\
\text { mudslide tore \& washed away blanket }\end{array}$ \\
\hline $\begin{array}{l}\text { Conwed Fibers } \\
\text { Conwed } 2000 \\
\end{array}$ & $\begin{array}{l}\text { Reclaimed waste } \\
\text { wood fiber }\end{array}$ & Performed well \\
\hline $\begin{array}{l}\text { Research Products - } \\
\text { Earth Gard }\end{array}$ & Recycled paper & $\begin{array}{l}\text { Severe erosion after } 3 \text { " storm; blanket } \\
\text { rolled over and balled up with flow }\end{array}$ \\
\hline
\end{tabular}

Table 1-6: Summary of 1993 Wisconsin DOT erosion control study 


\section{Ontario Ministry of Transportation -}

\section{Effectiveness of Surficial Erosion Control Products, 1991}

Summary: This study uses simulated rainfall to evaluate the effectiveness of 7 erosion control products on highway construction sites. Three blankets (Curlex, Ero-mat, and S75) and four mulches (Conwed, Ecofibre, Albion Hills hydromulch, and Verdyol) were installed on 2:1 slopes. Simulated rainfall was applied to each plot for 30 minutes. Runoff volumes were recorded and $100 \mathrm{ml}$ samples were taken to determine the sediment content.

Conclusions:

1). All of the products reduced runoff volumes relative to bare control plots. Curlex and Conwed products were most effective, while Ero-mat and the hydromulch were least effective (see Figure 1-2).

2). All products reduced sediment loss relative to the bare soil control plots. Here, Ero-mat and the hydromulch were most effective, while the Ecofibre, Fibramulch, and Verdyol products were least effective (see Figure 1-3 and 1-4).

3). Analysis of the data indicated that all products remained stable throughout the simulated rainfall events (abrupt changes in sediment concentration with time would indicate a failure). 


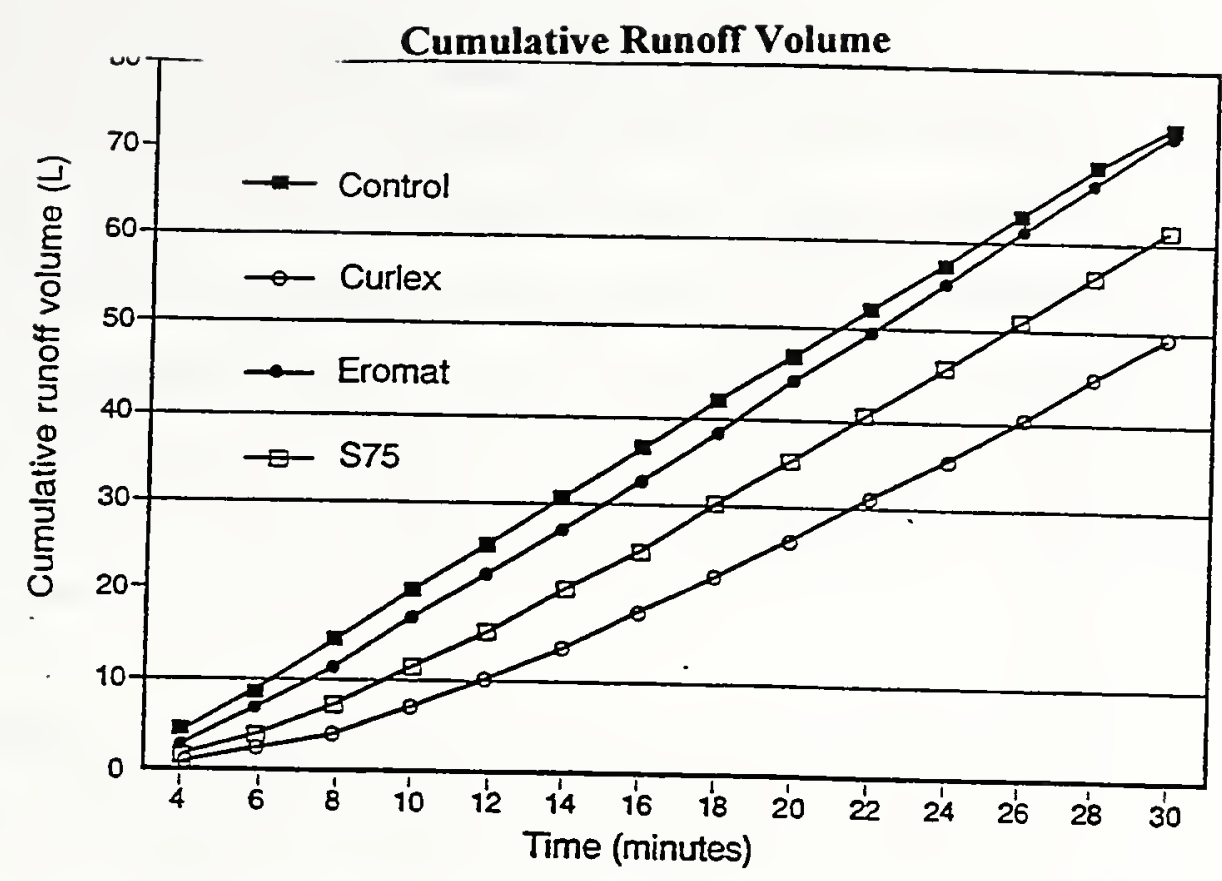

Figure 1-2: Cumulative runoff volume from erosion control blanket plots

$$
\text { Cumulative Soil Loss - Mulches }
$$

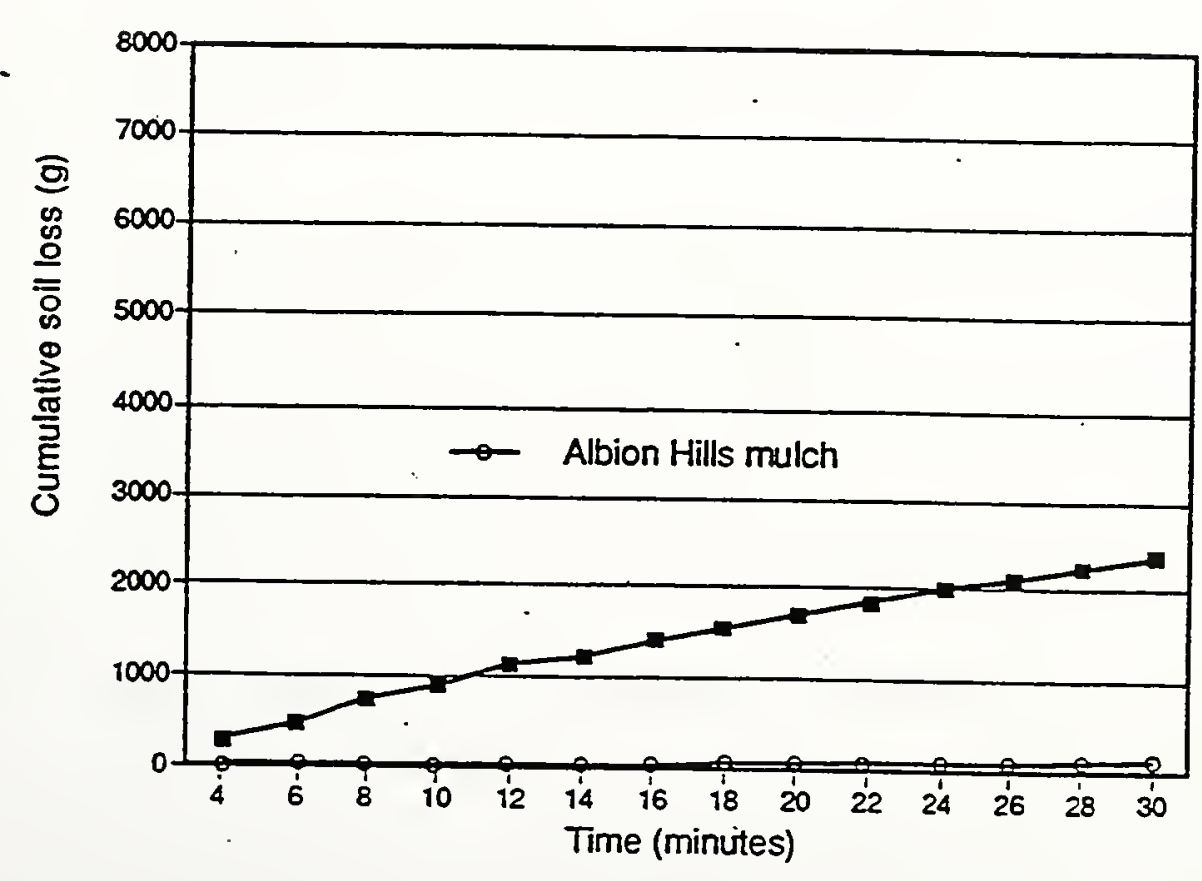

Figure 1-3: Cumulative soil loss from mulch plots 
Cumulative Soil Loss - Blankets

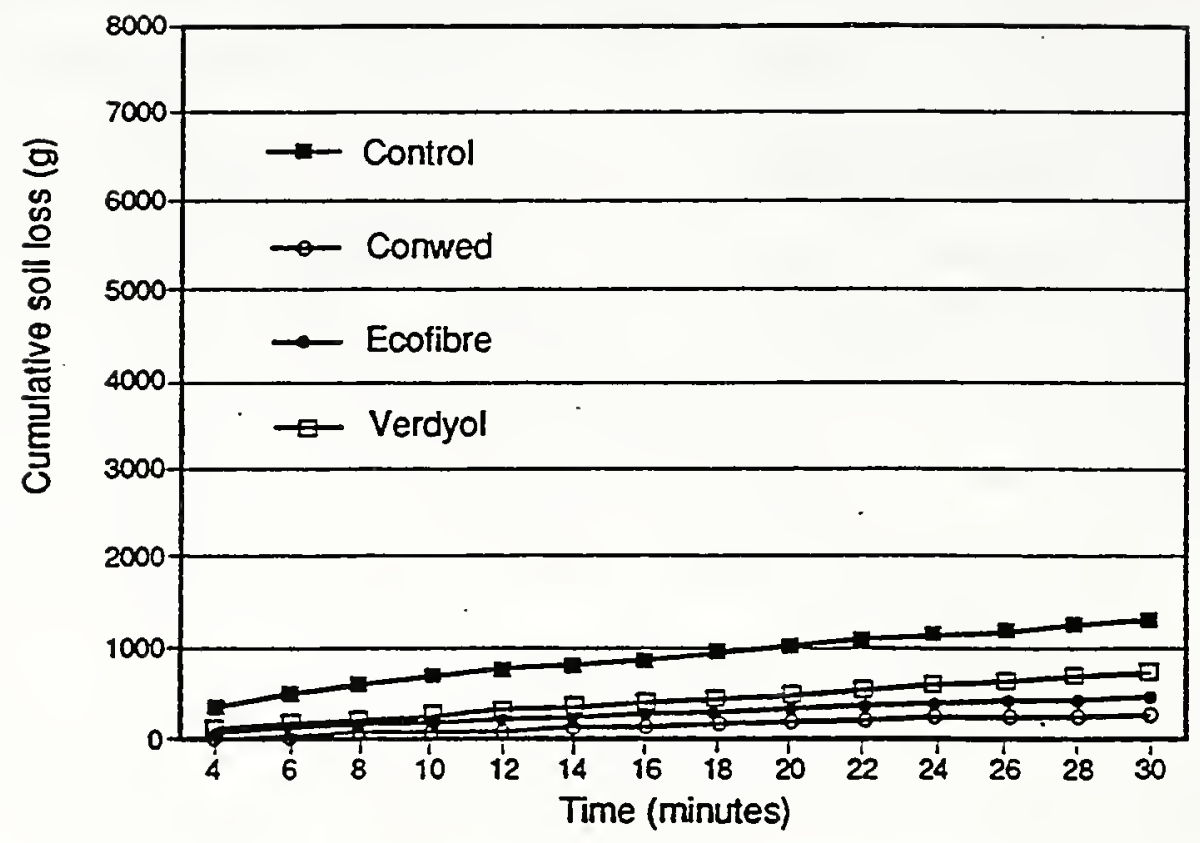

Figure 1-4: Cumulative soil loss from erosion control blanket plots 
Performance of Flexible Ditch Linings, U.S. Geological Survey / FHWA, Sept. 1985.

A series of tests to determine the performance of 10 flexible ditch liners were conducted at the USGS Gulf Coast Hydroscience Center Hydraulic Laboratory. Each liner was tested to failure in a $70 \mathrm{ft}$ long trapezoidal channel. Data collected included flow rate and normal depth at failure, channel elevation and slope, cross sectional area of flow, and percentage grass cover. These values were reduced to channel velocity, induced shear stress, and the Manning's roughness coefficient for the material. Table 1-7 and Figure 5 provide good summaries of the data.

\section{Conclusion / Comments on Each Product}

Hold Gro
1). Paper came loose from liner even at low flow velocities
2). Water flowed under liner at all discharge rates
3). The liner tends to move in the direction of flow

\section{Enkamat}

1). Erosion damage was minimal in all tests; only erosion around wood stakes

2). Liner stretched at high slopes and high water flows

\section{Excelsior Mat}

1). Wood fiber always moved down the ditch under the plastic net; it piled in front of the staples creating small check dams

2). A large portion of the liner damage occurred along the side slope of the ditch, especially as flow depth increased

3). If the liner is secured tighter to the ditch surface, less wood fiber migrates Gravel

1). Gravel moves down the ditch throughout the entire test

2). Erosion damage was minimal in all tests

\section{Rolled Gravel}

1). Gravel moves down the ditch throughout the entire test

2). After failure, only gravel embedded deep in the soil remained. 
Jute Netting

1). Netting unraveled at high water flows between the staples

2). Longitudinal jute strands offer adequate protection in unraveled areas Jute w/ Asphalt

1). Liner had tendency to float

2). Most erosion damage occurred at the overlap of the jute netting

3). Straw moves down ditch during the test

Fiberglass Roving

1). Little or no erosion damage throughout the entire test

2). Failures occurred if liner bunched, allowing water to flow under it

3). Asphalt washed away in early tests

Summary of Flow Parameters from Erosion Control Experiments

\begin{tabular}{|lllll}
\hline Material & Manning's & $\begin{array}{l}\text { Velocity @ Failure } \\
(\mathbf{f t} / \mathbf{s})\end{array}$ & $\begin{array}{l}\text { Shear @ Failure } \\
\left(\mathbf{1 b} / \mathbf{f t}^{2}\right)\end{array}$ & $\begin{array}{l}\text { \% Cover @ } \\
\text { 6 wks / 6 mo. }\end{array}$ \\
Bare Soil & 0.015 & 2.60 & 0.10 & $*$ \\
Hold Gro & 0.023 & 3.93 & 0.71 & $50 / 70$ \\
Excelsior Mat & 0.079 & 1.95 & 0.70 & $80 / 80$ \\
Enkamat & 0.034 & $*$ & $2.34^{*}$ & $50 / 60$ \\
Gravel & 0.021 & 3.77 & 0.27 & $80 / 80$ \\
Gravel-Rolled & 0.020 & 4.30 & 0.29 & $70 / 80$ \\
Jute Mesh & 0.026 & $*$ & $2.24^{*}$ & $*$ \\
Jute/Straw/Asphalt & 0.079 & 4.66 & 2.18 & $60 / 80$ \\
Straw/Asphalt & 0.056 & 2.90 & 0.88 & $50 / 50$ \\
Fiberglass Roving & 0.024 & 2.79 & 0.18 & $80 / 100$ \\
\hline
\end{tabular}

Table 1-7: Summary of USGS / FHWA erosion control material flow parameters (Note: “*” $\Rightarrow$ liner did not fail or data was not collected during testing.) 
Maximum Flow Depth Based on Bed Shear Stress

(Reprinted from Thibodeaux, 1985)

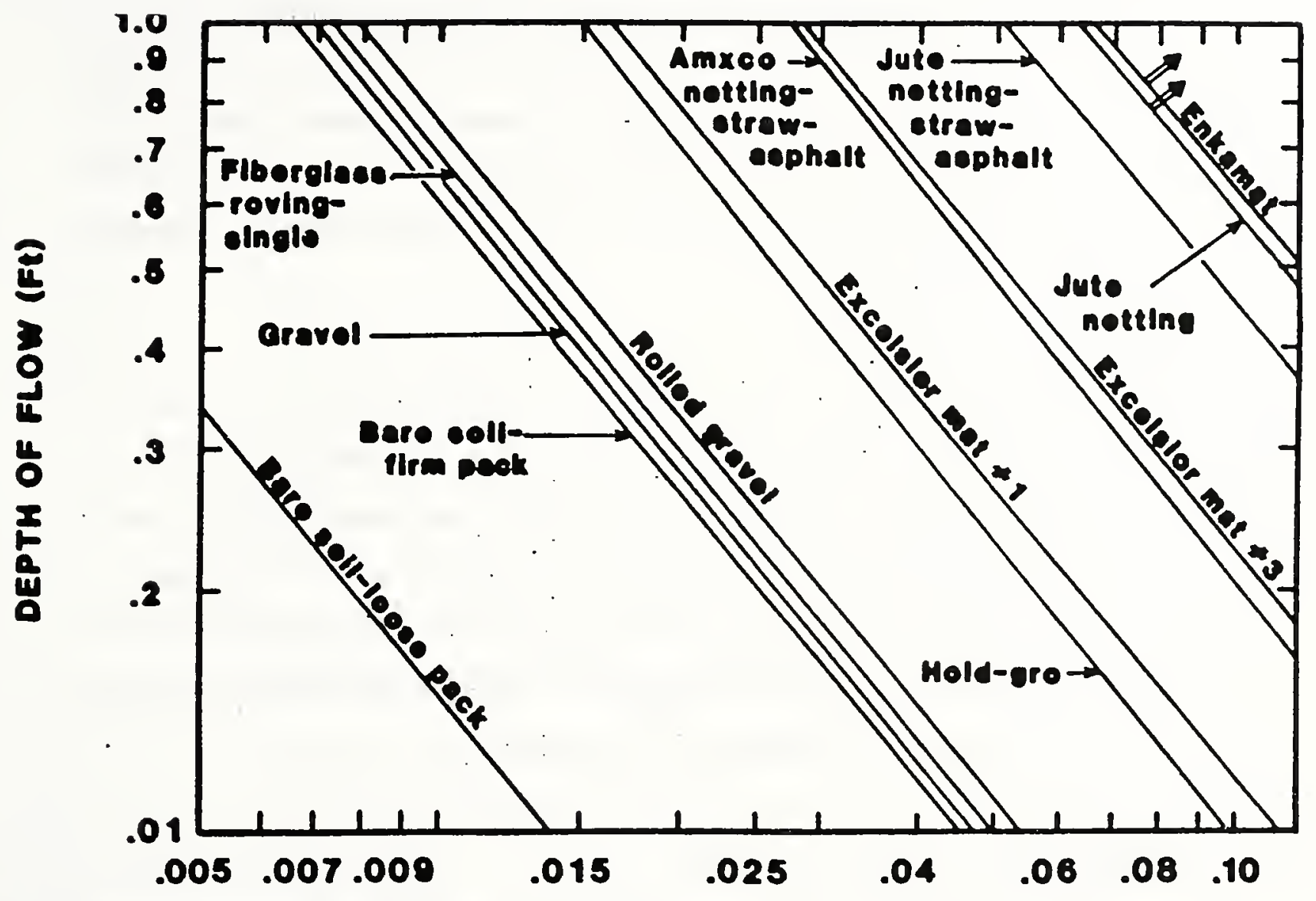

Channel slope (Ft/Ft)

Figure 1-5: Flow depth versus channel slope for all liners tested in USGS / FHWA study, 1985 


\subsection{Published Case Studies}

\section{"Fabric Controls Roadside Erosion"}

Location: Rte 23 in Wise County \& Rte 220 bypass, Maritinsville, Virginia

Application: $2: 1 \& 1.5: 1$ roadside slopes

Product: Armater by Akzo Industrial

A 3-D, semi-rigid, honeycomb mat (Geocellular Containment System)

Problem: Previously, VDOT crews tried dumping dirt on the area and hydroseeding but the slope always eroded out. The alternatives included filling the area to decrease the grade or installing gabions or retaining walls. All of these options were too costly. Instead, the DOT installed an Armater over the $700 \mathrm{ft}$ long slope.

Solution: After applying 2 tons/acre of lime on the existing shale/gravel slope, the 4" deep honeycomb fabric was stretched across the slope. The cells were filled using dump trucks and a grade-all. The Armater acted like a heavy blanket and held the soil on the slope. Within 10 days, rye and fescue sprouted on the slope. The same material was also successfully used on I81 north of Roanoke. Plants grew in the separate pockets and prevent the soil from being eroded out when it rains.

\section{"Geomatrix Aids Soil Erosion Problem,"}

Location: Highway 14, Wyoming (Road leads to Devil's Tower national monument in the northeast corner of Wyoming)

Application: 4:1 to 1:1 slopes along 6.5 mile section of Highway 14

Product: $\quad$ Enkamat by BASF (TRM)

Problem: Heavy rains and the lack of vegetation threatened to wash out a large portion of the 1.2 million cu. yds of excavation. The option of using concrete or rip rap was dismissed as being too costly. The 3-D resilient, 
black, nylon matting was selected because it is not subject to biological degradation and resists chemical attack.

Solution: Topsoil was first loosened in erosion prone areas. Next the area was seeded, fertilized, and straw was spread. The Enkamat was then staked on top of this layer. Despite immediate rainfall, the seed germinated in 7 days. Even after several heavy rains, the matting stayed firmly in place.

\section{"BMW Extends Vegetation Performance Limits"}

Location: Greenville-Spartanburg International Airport, Greer, SC.

Application: Diversion channel for two streams around construction of BMW plant Product: $\quad$ ECRM

Problem: The South Carolina Land Resources Conservation Commission required the channel to resist a 10 -year event. Lockewood Greene initially considered several rigid materials (rip rap and concrete), but design calculations using Manning's equation indicated a rigid lining was not necessary. Unfortunately, unreinforced natural vegetation could not accommodate the $1.8 \mathrm{~m} / \mathrm{s}(6 \mathrm{ft} / \mathrm{s})$ design velocity. Even though straw, coconut, and excelsior blanket manufacturers quoted values that exceeded the required velocity, these products ultimately degrade. Hence, a permanent, non-degradable, geosynthetic erosion-control mat seemed to be the best solution.

Design: The design entailed calculating the $10 \& 100$-year storm runoff velocities by Manning's equation. These results were compared to the maximum permissible design velocity of the ECRM to establish a factor of safety. Next, the hydraulic tractive force induced by the flowing water was calculated. It cannot exceed the permissible shear stress of the lining material. Using the Tractive Force Equation, the average shear stress in the cross section was determined and again a safety factor against shear 
failure was calculated. Since all safety factors were at least 1.3 , the ECRM was deemed appropriate for the channel.

Solution: Once the channel was graded, anchor slots were constructed. The bed was next seeded and fertilized before securing the ECRM. Despite continuous low flow conditions and persistent rain, the ECRM filled with sediment. The vegetation quickly covered the mat with a dense stand. Even though ECRMs are not intended for use in continuous flow channels, the material performed excellently at this site.

\section{"Geosynthetic Erosion Mats for the Horse Ranch - A Case History"}

Location: Horse Ranch housing community near Aspen, $\mathrm{CO}$.

Application: Storm water runoff channels on steep slopes in a harsh climate

Product: $\quad$ Landlok 1060 by Synthetic Industries - TRM

Problem: Reducing runoff velocities and controlling sedimentation spurned Drexell Barrell Engineers to consider both rigid and flexible lining materials to line the channels. Water quality, freeze-thaw, aesthetic, and cost concerns quickly ruled out concrete lined channels. Rip rap was overkill, but unreinforced vegetation could not handle the predicted long term velocities of $1.7-3.3 \mathrm{~m} / \mathrm{s}(5.6-10.8 \mathrm{ft} / \mathrm{s})$. Thus, TRMs were chosen for the channels.

Design: The engineers designed a series of grass-lined, TRM-reinforced channels designed to handle a 100-year storm. A $1.6 \mathrm{~km}$ main channel with 11 smaller laterals made up the system. The initial cross section was chosen based upon a permissible velocity approach. Using Manning's Equation, normal depth and channel velocity were calculated. The maximum velocity was determined at several different points along the channel route. From these values, the highest expected velocity was compared to the permissible velocity of the TRM and a safety factor was calculated. This 
procedure was repeated until the safety factor was greater than 1.2.

Similarly, the tractive force was calculated at several locations along the channel. Again, a safety factor was computed. If the factor of safety was less than 1.2, the channel geometry was altered and the tractive force recomputed.

Construction: During excavation of the main channel, natural springs from a perched water table halted construction. Subsurface nonwoven geotextile-wrapped trench drains were placed along the centerline of the channel to accommodate this constant flow of water. The drains lowered the water table $1.3 \mathrm{~m}$ ( $4.2 \mathrm{ft})$, enough to allow construction to continue 30 days later. The TRM was installed, hydraulically seeded, fertilized and irrigated.

Solution: More than $19,228 \mathrm{~m}^{2}\left(23,000 \mathrm{yd}^{2}\right)$ of TRMs were installed at a cost of $\$ 9.90 / \mathrm{m}^{2}$. This cost was less than half the cost of rip rap $\left(\$ 24 / \mathrm{m}^{2}\right)$. The owner saved approximately $\$ 270,000$ by using the TRM. The site has since survived two snowy winters, one wet summer, and one dry summer with no perceptible erosion. The channel is well vegetated and blends naturally into the surrounding terrain. 


\section{Design Methodology for Flexible Channel Liners}

\subsection{Introduction}

This chapter presents a synthesis of current design methodologies found in the literature. Two schools of thought were identified in the literature: 1). permissible velocity and 2). permissible shear stress. The first generation of design methods focused only on the permissible velocity because insufficient data existed for a permissible shear stress approach. Recent flume tests on a wide range of erosion control products have made the shear stress design method more practicable. Most of these tests were conducted at Colorado State University and Utah State University Water Research Laboratory. The erosion control industry has begun to favor this latter design technique because it seems technically more relevant and it is easily incorporated into computer software (North American Green 1995, Synthetic Industries 1996). Both methodologies are described below.

\subsection{Permissible Velocity Approach}

The permissible velocity approach (as its name implies) calculates the velocity from Manning's equation (equation 2.1) and compares it to the maximum velocity of the erosion control material. A channel (or drainage ditch) is considered stable if the mean velocity is less than the maximum permissible velocity (Chen and Cotton, 1988). These maximum velocities are found in manufacturer product documentation. A list of the permissible velocities for several products are found in Table 2-3.

$$
\mathrm{V}=\frac{1}{\mathrm{n}} \mathrm{R}^{2 / 3} \mathrm{~S}^{1 / 2}
$$

Permissible velocity procedures were first developed around the 1920's and use continues today. The design is very empirical in nature. It uses a "roughness coefficient" and channel geometry to determine the velocity and/or discharge. Typical limiting values for erosion resistance are found in figure 2-1. Included are limiting velocities of plain and reinforced grass using a variety of erosion control materials. 
As illustrated in figure 2-1, increasing duration of flow reduces the erosion resistance of a grassed surface. Notice that permissible velocities decrease as the duration of flow increases. Fibers loosen from their stitching, netting stretches, and the entire blanket tends to slide downstream. The erosion resistance is significantly reduced under extended flow durations.

Manufacturers of organic, natural, and synthetic erosion control products often use maximum allowable velocity or shear stress to express the erosion resistance of these materials. Manufacturer's information may be misleading when they quote maximum velocities. These flow limits are typically for very short durations - usually a half hour flume test for temporary erosion control materials. Such tests do not reflect the potential for severe erosion damage that results from moderate to severe flow events during a period of several hours. Because many storms are in excess of a half hour, a short term stable lining may fail under extended flow conditions.

Hewlett and Boorman (1982) propose a 2 day flow duration to account for long, erosive storms. Although no data are supplied, it is thought that two days is sufficient time for storm waters to subside and for partially submerged vegetation to recover. In light of the fact that erosion control blankets weaken as flow duration increases, 50 hour ( $\sim 2$ day) flume tests produce the best design velocities for erosion control materials.

Maximum permissible velocities for several erosion control techniques are shown in figure 2-1. It is a compilation of various researchers data, and it attempts to categorize erosion control materials into their cost-effective ranges. The graph shows permissible velocities of vegetated and unvegetated linings. This provides a designer with performance guidelines from the time a material is installed until it becomes fully vegetated (Thesien, 1992). Early stages of growth may be designed with only a 1-2 year storm for unvegated conditions. At full vegetative maturity, the designer can determine the erosion resistance for a 5-10 year storm using the same product. In the first case, the material may only withstand a $2 \mathrm{~m} / \mathrm{s}$ flow, but in the second case, the strength of the vegetation enables the channel to withstand a $4 \mathrm{~m} / \mathrm{s}$ flow without significant damage. 


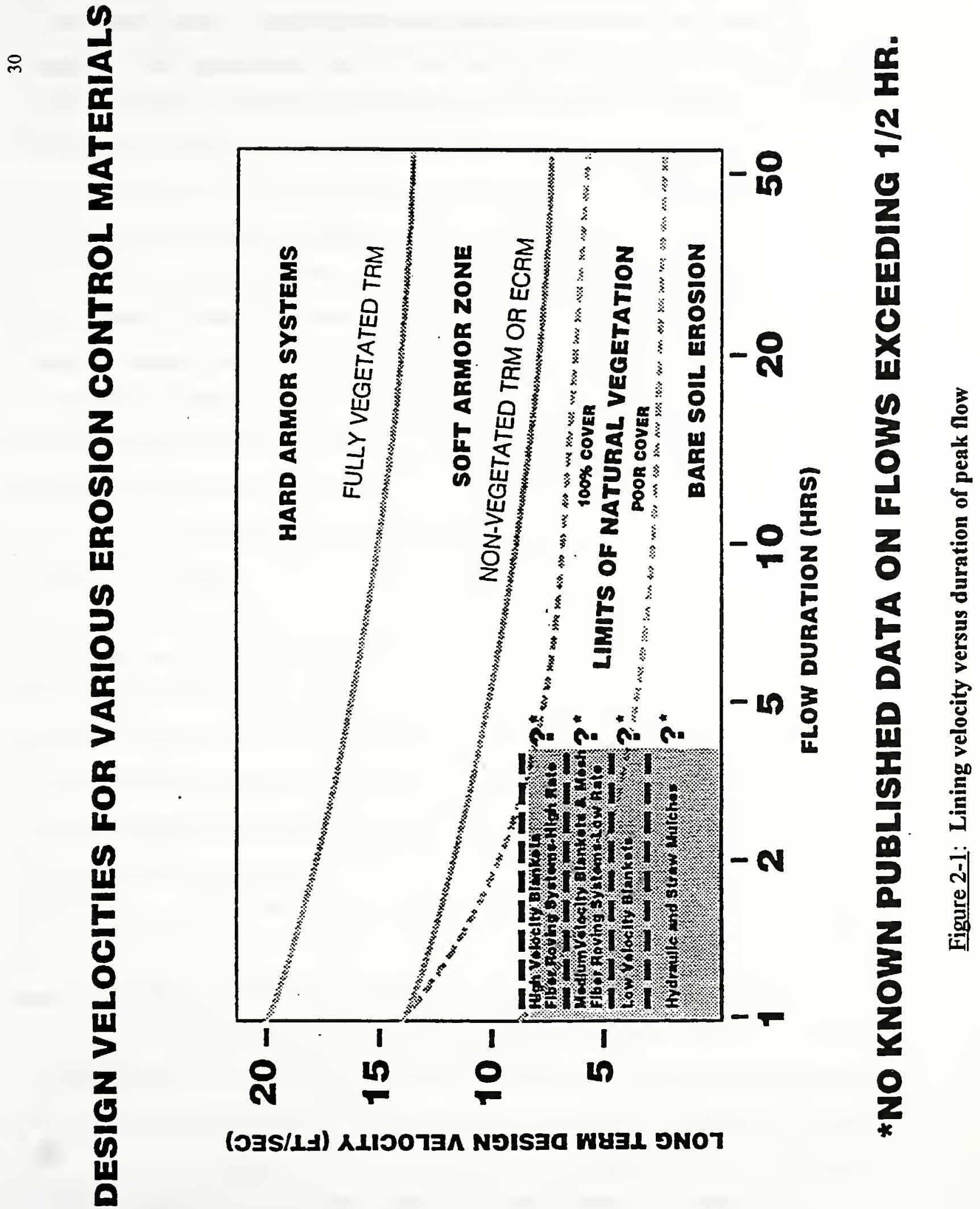


The long term performance guidelines show the limits of various temporary and permanent erosion control products. Flow values for the blankets, mulches, meshes, and rovings have question marks assigned to them because extended flow trials have not been reported. However, since these products are only meant to survive until vegetation becomes established, long term performance is not as important. It is the vegetation rather than the reinforcement that provides the erosion resistance in the long term. Hence, when a project calls for temporary erosion control, preliminary designs should use the "Limit of Natural Vegetation" for a conservative estimate of the permissible velocity (Thesien, 1992).

As an example, notice that the short term performance of well-vegetated channel is rather high $-4 \mathrm{~m} / \mathrm{s}(13.1 \mathrm{ft} / \mathrm{s}$ ) (refer to figure 2-1). However, at flows longer than 1.5 hours, the allowable velocity drops to $2 \mathrm{~m} / \mathrm{s}(6.1 \mathrm{ft} / \mathrm{s})$ for good stands of vegetation and 1 $\mathrm{m} / \mathrm{s}(3 \mathrm{ft} / \mathrm{s})$ for poor vegetative cover. Using a non-vegetated TRM or ECRM rather than a temporary erosion control product increases the long term velocity to $2.4 \mathrm{~m} / \mathrm{s}(8 \mathrm{ft} / \mathrm{s})$. Using fully vegetated "Soft Armor" (TRM or ECRM) further increases the long term permissible velocity to $4 \mathrm{~m} / \mathrm{s}(13.1 \mathrm{ft} / \mathrm{s}$ ) (Thesien, 1992).

The upper end of the graph shows the performance of hard armor materials (fabric formed mats, articulating concrete blocks, concrete mattresses). This graph is not intended to establish the upper boundary of these materials; rather, it defines the upper boundary of soft armor materials (reinforced vegetation) (Caroll et al, 1990; Caroll et al, 1991; Northcutt, 1995; Thesien, 1995; Thesien, 1992;). Such hard armor materials are necessary for tidal zones, coastal areas, harbors, or streambanks. However, these materials are overkill for drainage ditches. Costs for fabric form erosion control materials are comparable to concrete ditches.

The permissible velocity design methodology is detailed in IFAI (1995). Known parameters include the design storm and peak discharge, channel shape, width, maximum depth, slope, and location of any bends. The methodology iterates on the normal depth to determine the channel velocity. The computed velocity is then compared to the allowable velocity of the specific channel liner. It is presented in detail in Appendix D.

Unfortunately, this design method ignores the actual soil erosion processes occurring in open channel flow. Soil erosion is actually a function of the force required to 
move a soil particle. It is the shear force rather than the velocity of flow that most often causes erosion. A permissible velocity design approach does not address this point. On the other hand, the permissible shear force method takes account of the soil erosion process (i.e. includes the hydraulic force causing erosion).

\subsection{Permissible Shear Stress}

A more realistic model of soil detachment is based on the permissible tractive force. The hydrodynamic force of water flowing in a channel is known as the tractive force. Such design methodologies are based on the concept that flow-induced tractive force should not exceed the permissible or critical shear stress of the lining materials. The shear force is equal to the component of the gravitational force acting on the body of water, parallel to the channel bottom.

It is important to realize that shear is not uniformly distributed along the wetted perimeter. Maximum shear occurs on the centerline of the channel bed and it gradually decreases toward zero at the corners of the bed. Sideslope's peak shear occurs about onethird of the way up the sides. Flow around bends also imposes higher currents near the inside and outside of the bend. This stress increase in the bend increases as the ratio of the radius of the curve to the channel width decreases. The point is that shear stress is not a constant throughout the entire cross section. Moreover, as will be pointed out later, shear is directly proportional to channel depth. Hence, the shear varies both normal and parallel to the flow (see figure 2-2).

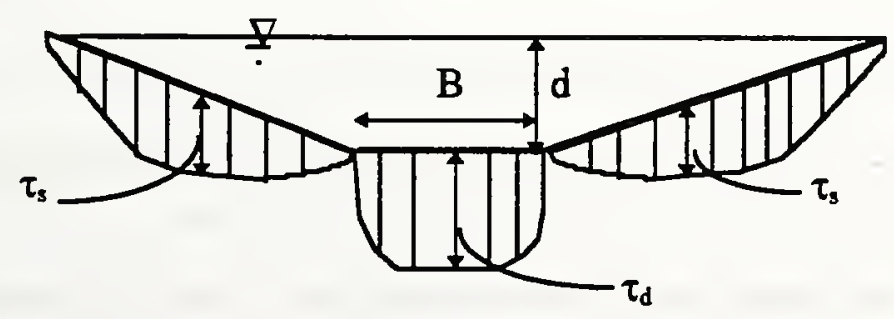

Figure 2-2: Typical Distribution of Shear Stress in a Channel (Modified from Chen and Cotton, 1988) 
Despite the obvious non-homogeneity of the problem, the tractive force method has several advantages. First, it is a more compact approach than the permissible velocity method. Stability is represented by a single shear stress value which is applicable to a wide range of channel geometries (i.e. permissible shear stresses are not a function of lining roughness and channel shape) (Chen and Cotton, 1988). Permissible velocities on the other hand are a function of a highly variable roughness coefficient.

Moreover, the higher stresses developed in channel bends or other changes in stream channel geometry can be quantified by simplified shear stress calculations (see figure 2-3). This allows better designs than would normally be possible for the permissible velocity design method. In addition, designs using permissible velocity require complex nomographs or a series of long hand calculations. On the other hand, the permissible shear approach is easier to perform by hand and it is readily programmable.

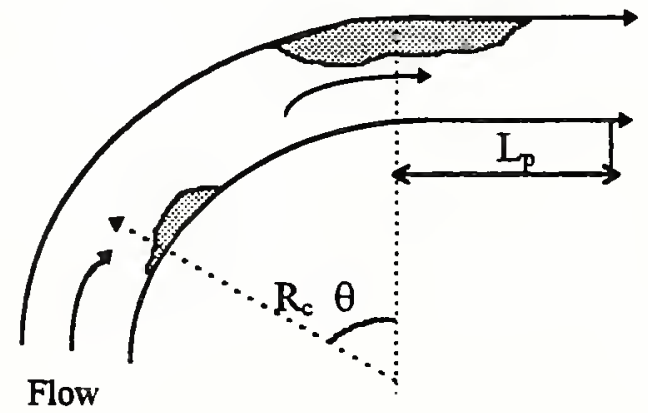

High Shear Stress Zone

\section{Figure 2-3: Plan View of Plan Showing High Shear Stress Zones (Modified from Chen and Cotton, 1988)}

The approach requires that maximum shear strength of the erosion control material is known. To this end, several western universities have conducted numerous independent

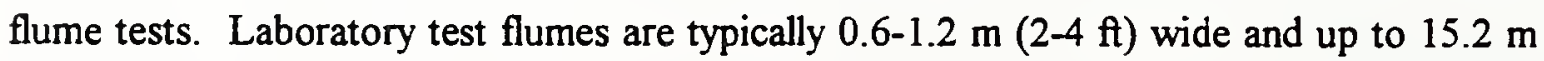
$(50 \mathrm{ft})$ long. They either have rectangular or trapezoidal shapes. Products are tested at various flow velocities typically up to 50 hours ( $\sim 2$ days) or until material failure.

HEC-15 published by the FHWA in 1988 endorses the shear stress design methodology. The document proposes permissible shear stress values for bare soil, riprap, 
vegetation, fiber roving, meshes, blankets, and both permanent synthetic erosion control revegetation mats (ECRMs) as well as turf reinforcement mats (TRMs).

However, many of the above mentioned tests have indicated significantly higher shear stress values. A comparison of HEC-15 shear stress guidelines and the results of the university tests are shown in Table 2-1. Notice that for the more persistent materials, HEC15 guidelines are extremely conservative.

The discrepancy is understandable; many advances in erosion control technology in the past seven years have improved the performance of these materials. Since these results are very well documented, the design methodology presented herein uses the industry shear stress data (Carroll et al., 1991; Dodson, 1990; Hewlett et al., 1987; Lancaster and Austin, 1994; Theisen, 1991, 1992).

In the permissible shear stress method, flow duration also becomes an issue. Shear resistance of the erosion control material decreases as flow duration increases. Again, a two day design period is preferred. In fact, Table 2-1 gives permissible shear stresses for a two day flow duration.

Comparison Permissible Shear Stress Values: HEC-15 vs. University Flume Tests (Adapted from Austin and Ward, 1996)

\begin{tabular}{llll}
\hline $\begin{array}{l}\text { Erosion Control } \\
\text { Material }\end{array}$ & Product Type & $\begin{array}{l}\text { University Tests } \\
\text { Permissible Shear } \\
\left(\mathbf{l b} / \mathbf{f t}^{2}\right)\end{array}$ & $\begin{array}{l}\text { HEC-15 } \\
\text { Permissible Shear } \\
\left(\mathbf{l b} / \mathbf{f t}^{2}\right)\end{array}$ \\
\hline $\begin{array}{l}\text { Low velocity } \\
\text { degradable }\end{array}$ & $\begin{array}{l}\text { Net } \\
\text { Mat }\end{array}$ & $\begin{array}{l}0.1-0.2 \\
1.4-0\end{array}$ & 0.15 \\
& Blanket - single net & $1.4-2.0$ & $1.45-1.45$ \\
$\begin{array}{l}\text { High velocity } \\
\text { degradable }\end{array}$ & Blanket - two nets & $2.0-3.0$ & 1.55 \\
$\begin{array}{l}\text { Long term } \\
\text { nondegradable }\end{array}$ & TRM- unvegetated & $3.0-6.0$ & 2.00 \\
\hline & TRM- vegetated & $5.0-8.0$ & 3.70 \\
\hline
\end{tabular}

Table 2-1: Limiting shear stresses for generic erosion control materials 
One additional problem with the permissible shear approach is that the equation for maximum shear depends only on depth of flow (equation 2.2). It is conceivable to have shallow, turbulent flow. This situation also produces significant erosion, but it would not be taken into consideration using a shear stress approach. Hence, it seems that the best overall approach is to combine the two methods. Critical shear stress calculations are meant to be used in conjunction with Manning's equation.

$$
\begin{aligned}
\tau=\gamma_{w} \mathrm{DS} & \\
\tau & =\text { hydraulic shear stress } \\
\gamma & =\text { unit weight of water } \\
\mathrm{D} & =\text { depth of flow } \\
\mathrm{S} & =\text { channel slope }
\end{aligned}
$$




\subsection{Design Procedure}

This section outlines a possible design procedure based on the synthesis of existing flexible channel lining information. Channels with steep gradients (slopes greater than $10 \%$ ) or very deep channels usually produce tractive forces in excess of the permissible shear stress for most linings. For such steep channels, refer to chapter 3 - Hard Armor Design. In addition, it is possible to design the channel using composite materials (e.g. use riprap in the center of the channel and a TRM along the side slopes). This may be done for economy or aesthetic reasons. Such designs are also detailed in chapter 3 under Designing Composite Flexible Liners.

The basic design procedure requires first calculating the maximum flow depth (normal depth) in the channel. Next, maximum shear stress is calculated at that depth. This value is compared to the permissible shear stress and a factor of safety is computed. Typical factors of safety against shear failure are 1.2-1.4. Using this shear stress, a maximum velocity is calculated using a modified form of Manning's equation. This velocity is also compared to the permissible velocity and a factor of safety against "velocity failure" is computed. Here again, a typical factor of safety range is 1.2-1.4 (Austin and Thesien, 1994; Austin and Ward; 1996; North American Green, 1995; Synthetic Industries, 1995; Thesien et al, 1995;). Worksheets, similar to those provided in HEC-15, are included at the end of this section to aid calculations (figure 2-4).

Designers familiar with methods for determining normal depth may use any convenient method and the Manning's roughness coefficients provided herein. Helpful equations for selected channel geometries are provided in appendix A to ease calculations. Nomographs are also provided to determine normal depth in trapezoidal channels. This calculation often requires a few iterations. Typically one iterates until the estimate and the calculated depth differ by no more than $0.03 \mathrm{~m}(0.1 \mathrm{ft}$ or 1.2 ").

Once the normal depth is acceptable, the shear stress is easily computed using the shear equation. The calculated shear stress is compared to the permissible shear stress for that lining. Tables of permissible shear from HEC-15 are provided for generic classes of materials. In addition, a list of current erosion control products (manufacturer and product name) shear stresses are appended at the end of the chapter (tables 2-3 \& 2-4). 
If the permissible shear stress is greater than the computed shear (and the safety factor is greater than 1.2-1.4), then the lining is adequate. If a lining is inadequate, a lining with a higher permissible shear stress may be selected from the tables. Since the roughness coefficient of the new material is in general not equal to that of the initial lining, a new normal depth needs to be calculated. If the new, stronger lining still fails to meet the safety factor criteria, then the channel geometry may be changed (say, decreasing the side slopes or increasing bottom width). Typically, there is a least cost alternative that could conceivably include both geometry and product changes. Note, if the channel geometry changes (slope, bottom width, $\mathrm{H}: \mathrm{V}$ ratio of side slopes, etc...), then a new normal depth must again be computed.

Once the shear stress requirement is satisfied, one enters the maximum shear into the modified Manning's equation. Again, if the computed velocity exceeds the permissible velocity, a new lining must be selected. All calculations must be redone and shear strength must be checked again.

\subsubsection{Note on Safety Factors}

It is worth noting here that computing safety factors against shear and "velocity" failure is not mentioned in the HEC-15 publication. The suggested safety factors of 1.2-1.4 for shear stress and velocity, respectively, come from current practice. HEC-15 does not include such factors of safety because the permissible shear stresses already are very conservative (i.e. the permissible shear stress include significant factors of safety). Merely, satisfying the requirement that the actual shear be less than the permissible is sufficient. In other words, HEC-15 considers a safety factor of 1.0 as satisfactory.

However, the design methodology presented in this report uses higher permissible shear stresses from independent testing labs. Conservative designs should include a minimum safety factor. Such a procedure is recommended despite the fact that most manufacturers already include a safety factor in the permissible shear stress of their product.

Unfortunately, each manufacturer uses different safety factors or this information is not provided. Therefore it is difficult to quantify the conservatism included in 
manufacturers' reported permissible shear stresses. The best approach is to require a minimum factor of safety, $\mathrm{FS}_{\mathrm{r}}$, for all designs.

According to current industry practice, this required safety factor would likely be in the range of 1.2-1.5. Throughout the remainder of this report, the notation $\mathrm{FS}_{\mathrm{r}}$ is used as the required safety factor for the design.

\subsubsection{Is a flexible lining even needed for this design?}

Before beginning lengthy design calculations for a particular project, it is prudent to ask oneself, "are erosion control products needed?" To help answer this question, allowable shear stress charts for bare non-cohesive and cohesive soil are included at the end of this section. Figure 2-7a plots permissible shear stress versus particle diameter for noncohesive materials. Figure $2-7 \mathrm{~b}$ similarly plots permissible shear stress versus plasticity index. Unless the grains of a non-cohesive material are very large $(>10 \mathrm{~mm})$, the bare soil can only withstand a maximum of $0.1 \mathrm{lb} / \mathrm{ft}^{2}$ of shear. Even compact, highly plastic (high cohesion) soils can only withstand a maximum $0.5 \mathrm{lb} / \mathrm{ft}^{2}$ of shear. Consequently, in almost every case, erosion control will be needed. 


\subsection{Computations}

\subsubsection{Required Input Data}

(a). Channel Geometry

(i). Slope (S) - It is usually the slope of the road. The slope is used in Manning's equation to the depth of flow.

(ii). Channel Shape - trapezoidal is most common; triangular, and parabolic are also possible.

(iii). Top width (T) / Bottom width (B) - Typical trapezoidal bottom widths are 1-4 $\mathrm{m}$ (3-12.2 ft). Note that a bottom width of zero gives a triangular cross section. Top widths are used in parabolic designs.

(iv). Horizontal to Vertical Ratio ( $Z$ ) for slide slopes - Typical values of $Z$ are 3 or 4. Slopes 2:1 and steeper are not recommended for loose sands or normally consolidated clay because the soil becomes unstable. See table 2-2 for a list of appropriate $Z$ values for several soil types (Adapted from Chow, 1959). (Note: See appendix A for typical cross sections)

\section{Suitable Side Slopes for Channels as a Function of Bed Material}

(From Chow, 1959)

\begin{tabular}{lc}
\hline Material & Side Slope Ratio (Z) \\
\hline Rock & Nearly Vertical \\
Muck and Peat & $1 / 4: 1$ \\
Stiff clay with concrete lining & $1 / 2: 1$ to $1: 1$ \\
Earth with stone lining & $1: 1$ \\
Firm clay or earth for small ditches & $1 / 2: 1$ \\
Loose sandy earth & $2: 1$ \\
Sandy loam or normally consolidated clay & $3: 1$ \\
\hline
\end{tabular}

Table 2-2: Suggested H:V ratios for different bed materials 
(v). Channel Bends - If the channel has a bend such that the radius divided by the bottom width is in less than 10 (i.e. $R_{d} / B<10$ ), the elevated shear must be considered. As the ratio decreases, the severity of the curve increases (i.e. elevated shear inside and outside of the bend. To account for a channel bend, obtain a factor $\mathrm{K}_{b}$ off of Figure 2-18 and multiply it by the straight channel shear stress. Note that the shear stress corrections for bends are not applicable to triangular channels.

(v). Note also that the shear is elevated for a significant distance downstream of the bend. To account for the elevated shear downstream of the bend, enter figure 2-19 with the roughness coefficient and read off $L_{p} / R_{c}$ and calculate $\mathrm{L}_{\mathbf{p}}$.

Also, flow around a bend in an open channel induces centrifugal forces because of the change in direction. This results in a superelevation of the water surface at the outside of the bend. Channels with bends must include superelevation freeboard (Chen and Cotton, 1988). More detail on calculating shear stresses in bends is discussed in the next section.

If the channel changes significantly in slope, shape (bottom / top width / side slopes) or roughness, the channel should be discretized into representative reaches and the calculations performed for each reach.

\section{(b). Design Storm}

(i). 1-2 year peak discharge for temporary blankets or for the early growth stages of permanent reinforcing mats (TRMs and ECRMs)

(ii). 5-10 year peak discharge for long term, fully vegetated applications

(iii). 25-100 year peak discharge for critical applications or as specified by local / regional regulating entity (State DOT, County, EPA, etc...) 
(c). Duration

(i). Laboratory results have shown that the permissible shear and velocity decrease over time. The ultimate value of permissible shear and velocity is reached after approximately 50 hours of peak discharge. Local data may indicate a longer or shorter duration depending on prevailing climatic conditions.

(ii). If a local hydrograph of the peak flow is available, the duration is the time between $90 \%$ of peak on rising limb and $90 \%$ of peak on falling limb. However, in most cases, such information is not readily available. Hence, the 50 hour duration would be the best estimate in most situations.

Note that duration does not enter into the hydraulic equations because steady state flow is assumed. It does however effect the magnitude of the permissible shear stress and/or velocity control materials over time.

(iii). Determine how long you expect the geosynthetic to be functional. If nonreinforced vegetation adequately supplies erosion resistance, then use a temporary netting or blanket made of straw, excelsior, or coir. If permanent reinforcement is needed, use a nondegradable TRM or ECRM. See Table 2-4 for a list of the generic erosion control products and Table 2-3 for a list of current products and their classification.

Note here again that the project life does not affect the hydraulic equations; rather it determines which products are acceptable for a specific site. Ultimately, geosynthetic life governs the cost of the erosion control program (i.e. longer geosynthetic life implies a more expensive product). 
(d). Manning's Roughness Coefficient, " $\mathrm{n}$ "

(i). Values for Manning's " $n$ " can be broken into 2 categories: 1).

Vegetated and 2). Unvegetated.

(ii). Vegetated - Calculating " $\mathrm{n}$ " is an iterative process based on Manning's equation

(iii). Unvegetated - Read off " $n$ " from table 2-4 or 2-5. These values are compiled from manufacturer data and Chen and Cotton, 1988. Figure 2-6 also gives Manning's " $n$ " as a function of Relative Roughness (modified from HEC-15, 1988) 


\subsubsection{Required Calculations}

A flow chart of the required steps in the design process is shown in figure 2-5. Details of the steps are shown below. A computation sheet (adapted from Chen and Cotton, 1988) is shown in figure 2-4.

1). First determine the required inputs outlined previously in section 2.1 .

Discharge, channel slope, horizontal to vertical ratio, bottom width, and top width are among the required inputs.

2). Select a flexible lining and determine the permissible shear stress $\left(\tau_{\mathrm{p}}\right)$ either from table 2-3 or $2-4$.

3). Estimate the flow depth range for vegetative or non-vegetative linings. This brackets the roughness coefficients. Select one depth as an initial estimate. If no information is available, a good first guess is $0.30 \mathrm{~m}(\sim 1 \mathrm{ft})$.

4). Determine Manning's " $n$ " for this estimated depth

(a). For non-vegetative linings, use Table 2-6 or 2-7. If the table does not have a particular erosion control product, an " $n$ " of 0.02 is considered fairly conservative (roughness coefficient for bare, soil filled liner)

(Synthetic Industries, 1995).

(b). For vegetative linings, use the following procedure:

(i). Calculate the hydraulic radius, $R$ (Use figures 2-9 through 2-12 or equations in Appendix A)

(ii). Determine vegetation class (Table 2-5)

(iii). Read off " $n$ " from vegetation class figures (figures 2-13 through 2-17). 
(c). If the bottom or sides of the channel have different " $n$ " values, a composite value is determined for use in the Manning's equation. The equation is presented by Chow, 1959 .

$$
n_{c}=\frac{\left(P_{1} n_{1}^{3 / 2}+P_{b} n_{b}^{3 / 2}+P_{r} n_{r}^{3 / 2}\right)^{2 / 3}}{P_{t}^{2 / 3}}
$$

$\mathrm{n}_{\mathrm{c}}, \mathrm{n}_{\mathrm{l}},=$ Manning's " $\mathrm{n}$ " of the composite, left side slope, right

$\mathrm{n}_{\mathrm{r}}, \mathrm{n}_{\mathrm{b}} \quad$ side slope, and bottom, respectively

$P_{1}, P_{r}=$ Wetted perimeter of left side slope, right side slope,

$\mathbf{P}_{b}, P_{t} \quad$ bottom, and entire channel, respectively, in meters (feet)

5). Calculate flow depth (d) using above " $n$ " and Manning's equation. Equations for finding normal depth are in Appendix A. A nomograph for trapezoidal channels is included to ease calculations (figure 2-8).

6). Compare computed depth to estimate. If the two values differ by more than $0.03 \mathrm{~m}(0.1 \mathrm{ft})$, then redo steps 3-6.

7). Calculate shear stress using equation 2.4 , $\tau_{d}$. If $\tau_{d}>\tau_{p}$, the lining is not adequate. Either change the channel geometry or select a stronger lining; repeat steps 1-6.

$$
\tau=\gamma_{w} \mathrm{DS}
$$

8). For Channel Bends:

(a). Determine the factor for maximum shear stress on channel bends $\left(\mathrm{K}_{\mathrm{b}}\right)$ from figure 2-18. $\mathrm{K}_{\mathrm{b}}$ is a function of the ratio of channel curvature to bottom width, $R_{d} / B$. Recall that a bend is considered significant if $R_{d} / B<10$.

(b). Using $\mathrm{K}_{\mathrm{b}}$, calculate the shear stress in the bend from equation 2.5. If 
$\tau_{b}>\tau_{p}$, the lining is not acceptable. Either change the channel geometry or select a stronger lining; repeat steps 1-7.

$$
\begin{aligned}
\tau_{b}=K_{b} \tau_{d}= & K_{b} \gamma_{w} D S \\
\tau_{b} & =\text { shear stress in bend } \\
\tau_{d} & =\text { maximum shear in straight channel } \\
K_{b} & =\text { bend shear stress coefficient }
\end{aligned}
$$

(c). Calculate the length of protection $\left(L_{\mathrm{p}}\right)$ required downstream of a bend to protect against the elevated shear. Enter figure 2-19 with Manning's " $n$ " and read off $L_{p} / R_{c}$ for the given radius, $R_{c}$ and calculate $L_{p}$.

(d). Calculate the shear stress on the side slope if the material on the side slopes is different than the material on the bottom of the channel (typically it would be a weaker material).

Enter figure 2-21 with $\mathrm{Z}$ and $\mathrm{B} / \mathrm{d}$ (bottom width to normal flow depth ratio), and determine $K_{1}$. If $\tau_{s}>\tau_{p}$, redo steps (1-8). The side slope stress is:

$$
\begin{aligned}
\tau_{\mathrm{s}}=\mathrm{K}_{1} \tau_{\mathrm{d}} & \\
\tau_{\mathrm{s}} & =\text { shear stress on side slope } \\
\tau_{\mathrm{d}} & =\text { shear stress on bottom of channel } \\
\mathrm{K}_{1} & =\text { correction factor for side slope shear }
\end{aligned}
$$

(e). Calculate the superelevation of the water surface on the outside of the bend. This is the amount of freeboard to accommodate the superelevation of the water surface.

$$
\begin{aligned}
\Delta d=\frac{v^{2} T}{g R_{c}} & \\
v & =\text { mean velocity = Discharge/Area }(Q / A) \\
T & =\text { surface width of the channel } \\
g & =\text { gravitational acceleration } \\
R_{c} & =\text { mean radius of the bend }
\end{aligned}
$$


9). Calculate the average velocity by substituting the shear stress into the a modified form of Manning's equation. If $V_{\text {ave }}>V_{\text {allow, }}$, redo steps 1-9.

For velocity on the channel bottom (accounting for any bends)

$$
\begin{aligned}
& V_{\text {ave }}=\frac{K_{s}}{n} R^{1 / 6}\left(K_{b} \tau_{d}\right)^{1 / 2} \\
& \mathrm{~V}_{\mathrm{ave}} \quad=\text { velocity on the channel bottom } \\
& \mathbf{R} \quad=\text { hydraulic radius } \\
& \mathrm{n} \quad=\text { Manning's " } \mathrm{n} \text { " (composite " } \mathrm{n} \text { " if required) } \\
& \mathrm{K}_{\mathrm{s}} \quad=\text { conversion factor that takes account of the unit weight of } \\
& \text { water; } 0.189 \text { for English units, } 0.0316 \text { for Metric units. } \\
& \tau_{\mathrm{d}}=\text { shear stress at maximum depth }\left(\mathrm{lb} / \mathrm{ft}^{2}\right) \\
& \text { Note: unit weight of water }=62.4 \mathrm{lb} / \mathrm{ft}^{3} \text { or } 9.81 \mathrm{kN} / \mathrm{m}^{3} \text {. }
\end{aligned}
$$

Similarly, for velocity on the side slopes:

$$
\begin{aligned}
& V_{\text {ave }}= \frac{K_{s}}{n} R^{1 / 6}\left(K_{b} K_{1} \tau_{d}\right)^{1 / 2} \\
& K_{1} \quad=\text { correction factor for side slope shear }
\end{aligned}
$$

Velocity can also be calculated using the original form of Manning's equation

$$
\mathrm{V}_{\mathrm{ave}}=\frac{\theta}{\mathrm{n}} \mathrm{R}^{2 / 3} \mathrm{~S}_{\mathrm{i}}^{1 / 2}
$$

$\mathrm{V}_{\mathrm{ave}}=$ average velocity in the cross section

$\theta=$ unit conversion; 1.49 for English units, 1.0 for Metric units

$\mathrm{n} \quad=$ Manning's roughness coefficient (composite " $\mathrm{n}$ " if required)

$\mathbf{R}=$ hydraulic radius; equal to the cross-sectional area, $\mathrm{A}$, divided by the wetted perimeter, $P$

$\mathrm{S}_{\mathrm{f}} \quad=$ friction slope of the channel approximated by the average bed slope (uniform flow conditions) 
10).

Calculated Safety Factors

(a). Safety factor against shear failure must be greater than $\mathrm{FS}_{\mathrm{r}}$

(the required Safety Factor):

$S F_{\tau}=\frac{\tau_{p}}{\tau_{d}}>F S$

Note: One can calculate SF's against shear failure on side slopes and in bends by substituting $\tau_{s}$ and $\tau_{b}$ for $\tau_{d}$, respectively.

(b). Safety factor against velocity failure must be greater than FS:

$$
\mathrm{SF}_{\mathrm{v}}=\frac{\mathrm{V}_{\text {ulow }}}{\mathrm{V}_{\text {sve }}}>\mathrm{FS}_{\mathrm{r}}
$$

Note: One can calculate SF's against velocity failure on side slopes and in bends by substituting $V_{\text {sideslope }}$ and $V_{\text {bend }}$ for $V_{\text {ave }}$ respectively.

As usual, one would like to be conservative in design calculations (i.e. design for the worst case scenario). For stable channel slopes, this means designing for long-term, unvegetated conditions. The reasons for long duration designs have already been noted. It is readily apparent that a vegetated channel can resist erosion better than an unvegetated channel. Denser vegetation implies a denser root mass which in turn holds the soil tighter. In the event of drought or severe flooding, the vegetation may die. Hence, it is most conservative to design the channel as if the vegetation is not there.

It is advised to perform the calculation twice - once for the early stages of growth (bare soil, 1-2 year storm) and once for long term, fully vegetated conditions (5-10 $0^{+}$year storm). One should keep in mind that long term shear resistance for temporary products is controlled by the strength of the vegetation. Based on recommendations from the SAC, the design flow chart (figure 2-5) has been modified to design for both long term and short term shear resistance. The long term case will have an increased design shear as compared to the short term case (i.e. vegetation and root structure increases the permissible shear stress of the channel). Provided the erosion control material is installed appropriately, the long term permissible shear should also increase. For more conservative designs (especially in continuous flow channels where TRMs or ECRMs are required), it is advisable to design for an unvegetated condition. That is, you ignore increase in permissible shear afforded by the vegetation and design only on the permissible shear of the geosynthetic. 
2.7 Design Charts \& Tables for Flexible Liner Design

Figure 2-4: Worksheet for Steep Channel Design

Designer:

Project:

Station

Drainage Area:

Design Storm (yrs):

Design Flow $-\mathrm{m}^{3} / \mathrm{s}\left(\mathrm{ft}^{3} / \mathrm{s}\right)$ :

Temporary Design Flow

Channel Description

Slope

Shape

Triangular

Trapezoidal

Parabolic

Other

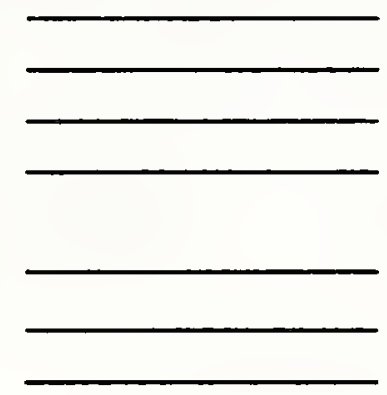

Bends

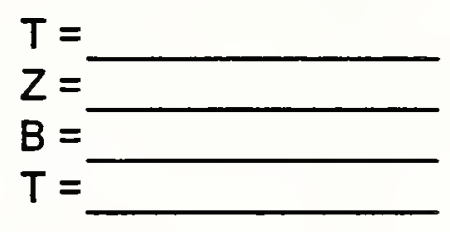

Calculations

\begin{tabular}{|c|c|c|c|c|c|c|c|c|}
\hline Lining & $\mathbf{Q}$ & $\mathrm{S}$ & $\mathrm{d}_{\mathrm{i}}$ & $\mathrm{d}_{50 \mathrm{i}}$ & $\mathbf{z}$ & $\mathrm{A}_{3} / \mathrm{A}_{\mathbf{z}}$ & $\mathrm{d}$ & $\mathrm{d}_{50}$ \\
\hline & & & & & & & & \\
\hline & & & & & & & & \\
\hline & & & & & & & & \\
\hline & & & & & & & & \\
\hline & & & & & & & & \\
\hline & & & & & & & & \\
\hline & & & & & & & & \\
\hline
\end{tabular}

Safety Factors

Shear FS

Velocity

FS

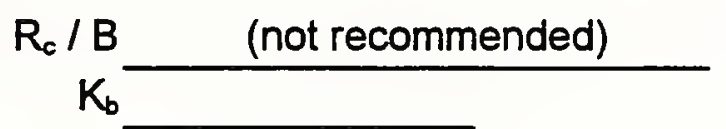




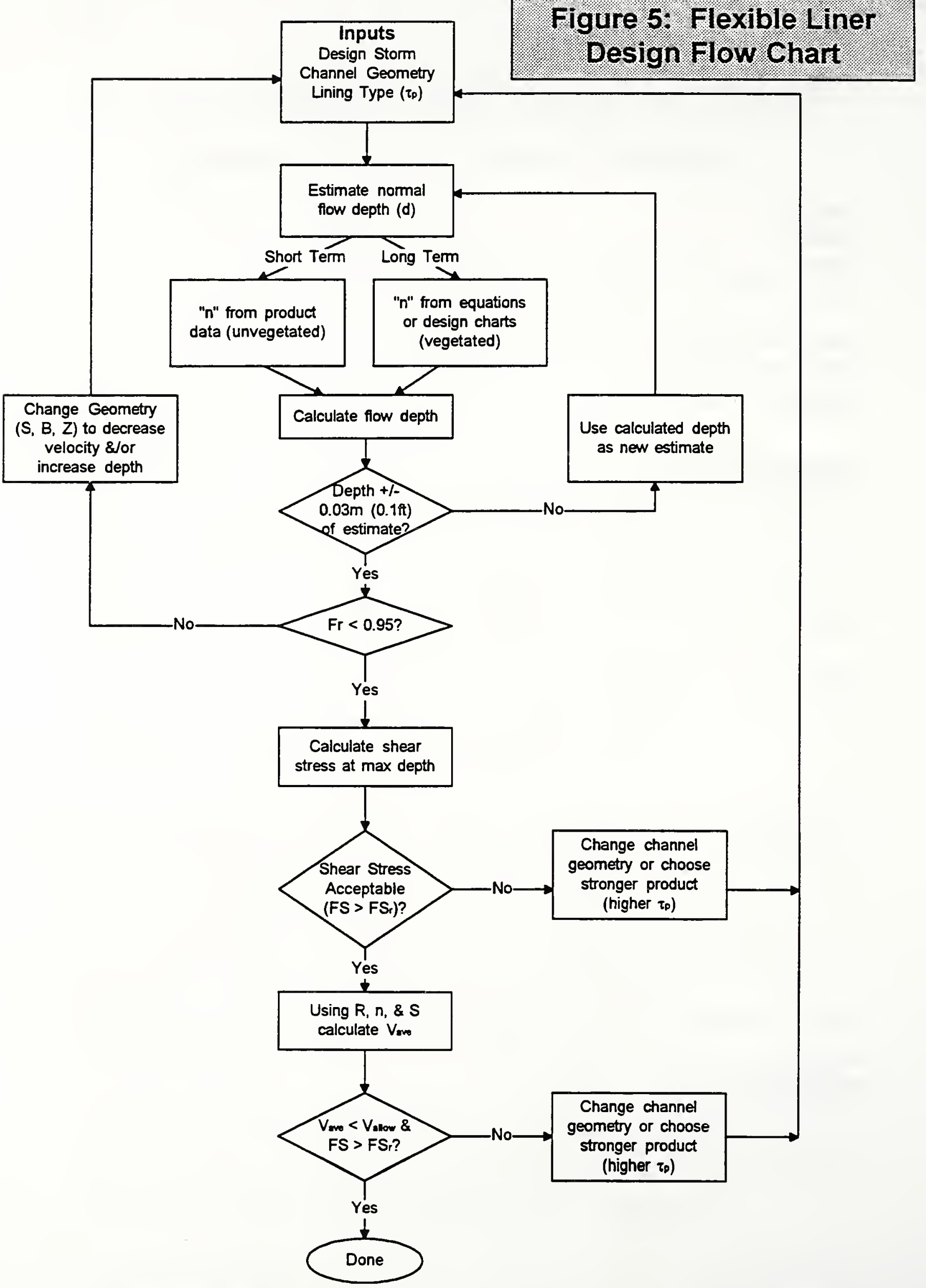




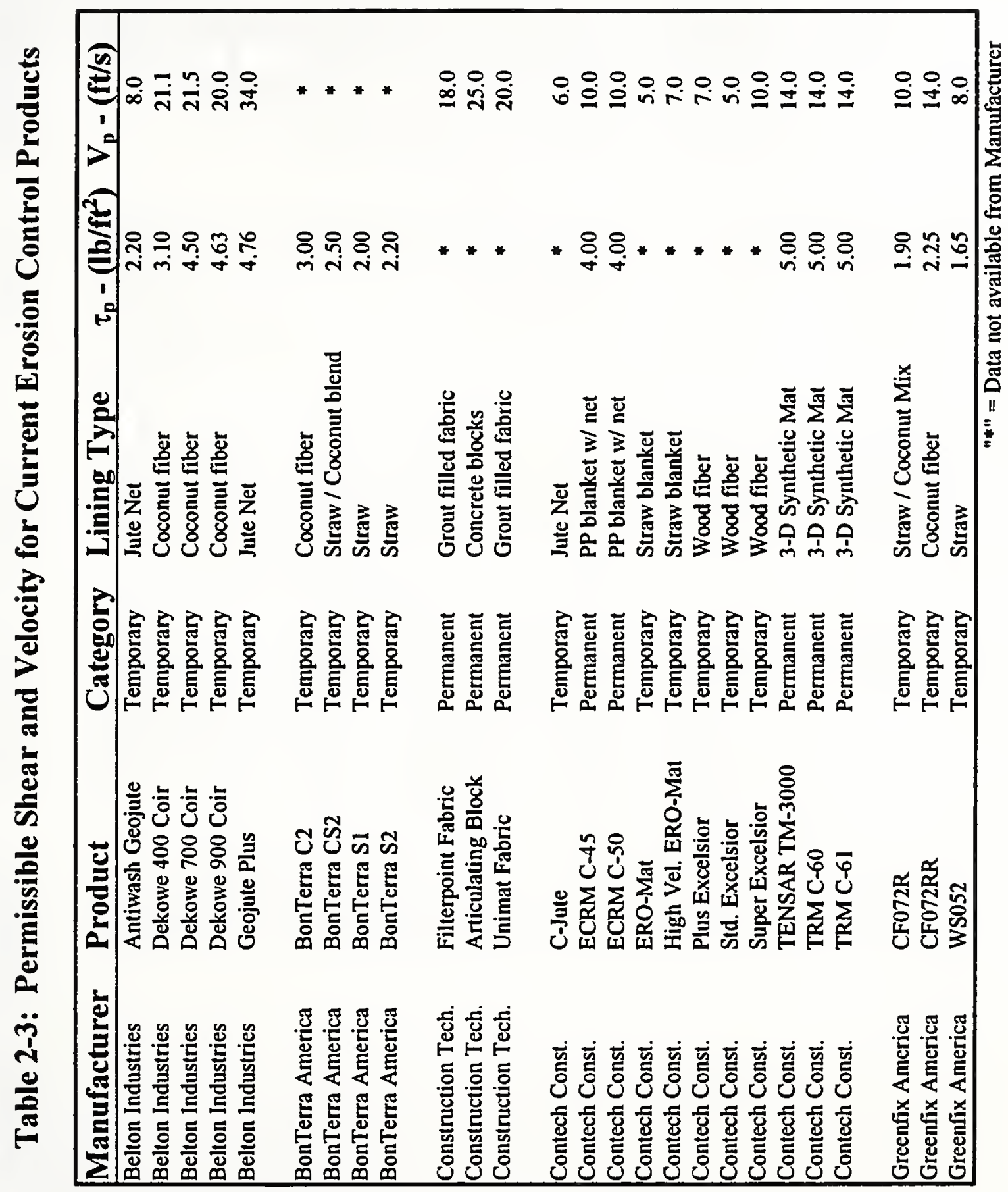


Table 2-4: Permissible Shear Stress for Generic Lining Materials (Modified from Chen and Cotton, 1988)

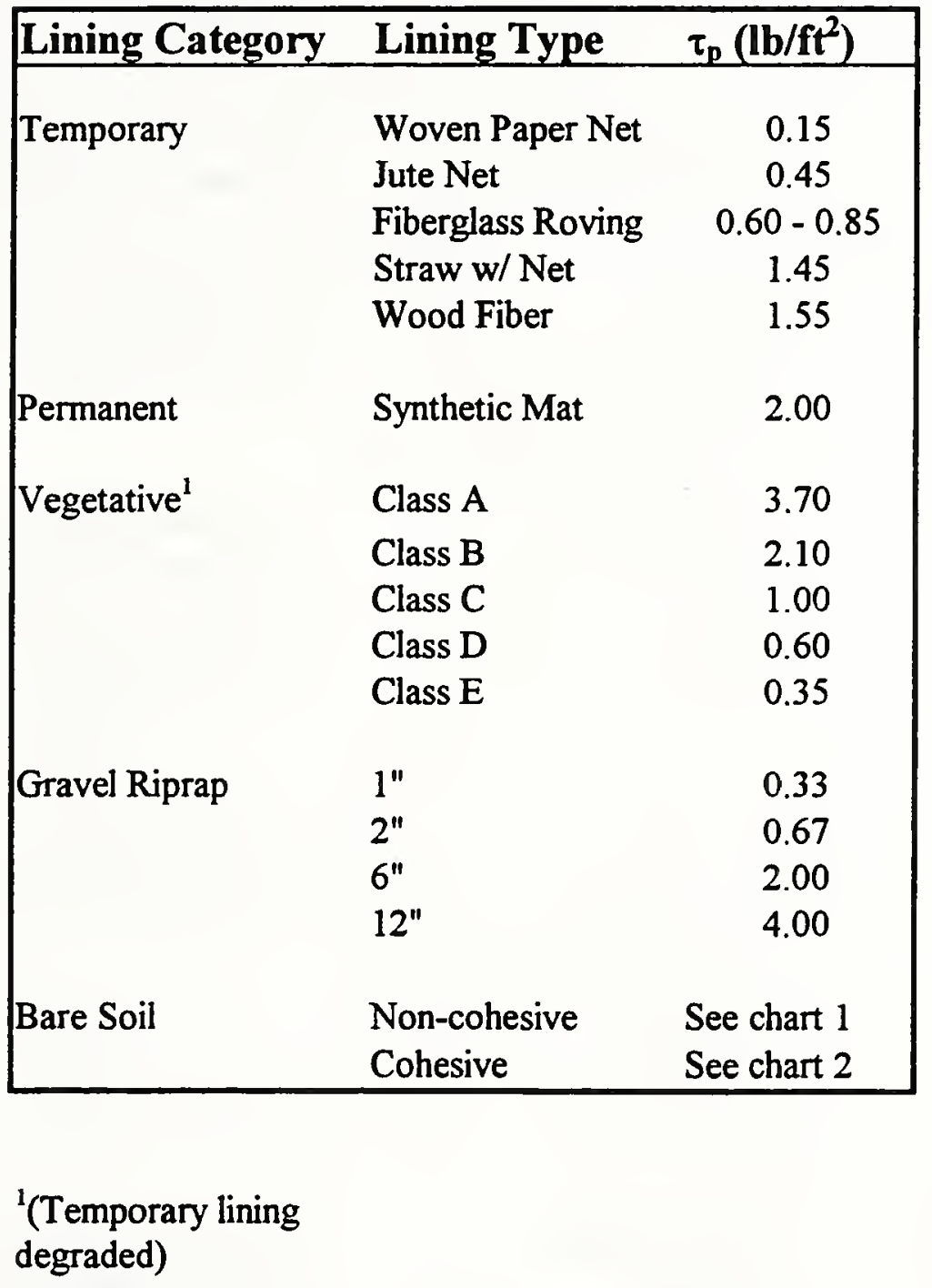




\section{Vegetation Classification - Retardance Classes}

(Modified from the Handbook of Channel Design for Soil and water Conservation, 1954)

\begin{tabular}{|c|c|c|}
\hline Retardance Class & Cover Vegetation & Condition \\
\hline $\mathbf{A}$ & $\begin{array}{l}\text { Weeping lovegrass } \\
\text { Yellow bluestem Ischaemum }\end{array}$ & $\begin{array}{l}\text { Excellent stand, tall (average } 30^{\prime \prime}(76 \mathrm{~cm}) \\
\left.\text { Excellent stand, tall (average } 36^{\prime \prime}\right)(91 \mathrm{~cm})\end{array}$ \\
\hline $\mathbf{B}$ & $\begin{array}{l}\text { Kudzu } \\
\text { Bermuda grass } \\
\text { Native grass mixture } \\
\text { (little bluestem, bluestem, } \\
\text { bluegamma, and other long and } \\
\text { short midwest grasses) } \\
\text { Weeping lovegrass } \\
\text { Lespedeza sericea } \\
\text { Alfalfa } \\
\text { Weeping lovegrass } \\
\text { Kuszu } \\
\text { Blue gamma }\end{array}$ & $\begin{array}{l}\text { Very dense growth, uncut } \\
\left.\text { Good stand, tall (average } 12^{\prime \prime}\right)(30 \mathrm{~cm}) \\
\text { Good stand, unmowed } \\
\left.\text { Good stand, tall (average } 24^{\prime \prime}\right)(61 \mathrm{~cm}) \\
\text { Good stand, not woody, tall (average 19") } \\
\text { Good stand, uncut (average 11") }(28 \mathrm{~cm}) \\
\left.\text { Good stand, uncut (average } 13^{\prime \prime}\right)(33 \mathrm{~cm}) \\
\text { Dense growth, uncut } \\
\left.\text { Good stand, uncut (average } 13^{\prime \prime}\right)(28 \mathrm{~cm})\end{array}$ \\
\hline $\mathbf{C}$ & $\begin{array}{l}\text { Crabgrass } \\
\text { Bermuda Grass } \\
\text { Common lespedeza } \\
\text { Grass-legume mixture - summer } \\
\text { (orchard grass, redtop, Italian } \\
\text { ryegrass, and common } \\
\text { lespedeza) } \\
\text { Centipedegrass } \\
\text { Kentucky bluegrass }\end{array}$ & $\begin{array}{l}\text { Fair stand, uncut (10-48" average) } \\
\text { Good stand, mowed (average 6") }(15 \mathrm{~cm}) \\
\left.\text { Good stand, uncut (average } 11^{\prime \prime}\right)(28 \mathrm{~cm}) \\
\text { Good stand, uncut }\left(6-8^{\prime \prime}\right)(15-20 \mathrm{~cm}) \\
\text { Very dense cover (average 6") }(15 \mathrm{~cm}) \\
\text { Good stand, headed }\left(6-12^{\prime \prime}\right)(15-20 \mathrm{~cm})\end{array}$ \\
\hline $\mathbf{D}$ & $\begin{array}{l}\text { Bermuda grass } \\
\text { Common lespedeza } \\
\text { buffalo grass } \\
\text { Grass-legume mixture - fall / } \\
\text { spring } \\
\text { (orchard grass, redtop, Italian } \\
\text { ryegrass, and common } \\
\text { lespedeza) } \\
\text { Lespedeza sericea }\end{array}$ & $\begin{array}{l}\text { Good stand, cut to } 2.5^{\prime \prime}(6 \mathrm{~cm}) \\
\left.\text { Excellent stand, uncut (ave. } 4.5^{\prime \prime}\right)(11 \mathrm{~cm}) \\
\text { Good stand, uncut }(3-6 ")(8-15 \mathrm{~cm}) \\
\text { Good stand, uncut }\left(4-5^{\prime \prime}\right)(10 \text { to } 13 \mathrm{~cm})\end{array}$ \\
\hline $\mathbf{E}$ & $\begin{array}{l}\text { Bermuda grass } \\
\text { Bermuda grass }\end{array}$ & $\begin{array}{l}\text { Good stand, cut to } 1.5^{\prime \prime}(4 \mathrm{~cm}) \\
\text { Burned stubble }\end{array}$ \\
\hline
\end{tabular}


Table 2-6: Manning's Roughness Coefficients by Depth of Flow

(Reprinted from Chen and Cotton, 1988)

Lining Category Type $\quad$ n $(0-0.5 f t) \quad \mathbf{n}(0.5-2.0 f t) \quad \mathbf{n}\left(2.0^{+} f t\right)$

\begin{tabular}{|c|c|c|c|c|}
\hline \multirow{5}{*}{ Rigid } & Concrete & 0.015 & 0.013 & 0.013 \\
\hline & Grouted riprap & 0.040 & 0.030 & 0.028 \\
\hline & Stone Masonry & 0.042 & 0.032 & 0.030 \\
\hline & Soil Cement & 0.025 & 0.022 & 0.020 \\
\hline & Asphalt & 0.018 & 0.016 & 0.016 \\
\hline \multirow[t]{2}{*}{ Unlined } & Bare soil & 0.023 & 0.020 & 0.020 \\
\hline & Rock cut & 0.045 & 0.035 & 0.025 \\
\hline \multirow[t]{6}{*}{ Temporary } & Paper net & 0.016 & 0.015 & 0.015 \\
\hline & Jute net & 0.028 & 0.022 & 0.019 \\
\hline & PP roving & 0.028 & 0.021 & 0.019 \\
\hline & Straw w/ net & 0.065 & 0.033 & 0.025 \\
\hline & Wood fiber & 0.066 & 0.035 & 0.028 \\
\hline & Synthetic mat & 0.036 & 0.025 & 0.021 \\
\hline \multirow[t]{2}{*}{ Gravel Riprap } & $1 " D_{s 0}$ & 0.044 & 0.033 & 0.030 \\
\hline & 2" $D_{50}$ & 0.066 & 0.041 & 0.034 \\
\hline \multirow[t]{2}{*}{ Rock Riprap } & $6 " \mathrm{D}_{50}$ & 0.104 & 0.039 & 0.035 \\
\hline & $12 ” D_{50}$ & - & 0.078 & 0.040 \\
\hline
\end{tabular}




\section{Table 2-7: Manning's “n” for Current Linings}

(Compiled from manufacturer data)

Lining Type

Manufacturer
Product
Manning's "n"

(0.5-2.0 ft Flow)

Straw w/ Net

Greenfix America

Greenfix America

Greenfix America

North American Green

North American Green

Jute

Coconut fiber $w /$ Net

Belton Industries

Belton Industries

Belton Industries

Greenfix America

North American Green

\section{Belton Industries \\ Belton Industries}

Contech

Synthetic Industries
WS052

WS072

WS072B

S150

S75

Anitwash Geojute

Geojute Plus

C-Jute

Polyjute

0.025

0.025

0.025

0.021

0.021

0.019

0.019

0.028

0.028
Dekowe 400 Coir

0.025

Dekowe 700 Coir

0.029

Dekowe 900 Coir

0.033

CF072RR

0.014

C125

0.014

Straw / Coconut Mix

Greenfix America

North American Green

CF072R

0.018

$\mathrm{SC} 150$

0.025

Construction Techniques

Unimat

0.025

Hydrotex

Hydrotex

Uniform Section - 3"

0.018

Uniform Section - 4"

0.018

Hydrotex

Filter Point - 5"

0.027

Hydrotex

Filter Point - 8"

0.027

TM8

0.029

Nicolon Mirafi

C350

0.025

North American Green

C300

0.024

Synthetic Industries

Synthetic Industries

Synthetic Industries

Landlok ECRM 450

0.025

Landlok ECRM 1060

0.028

Pryamat 


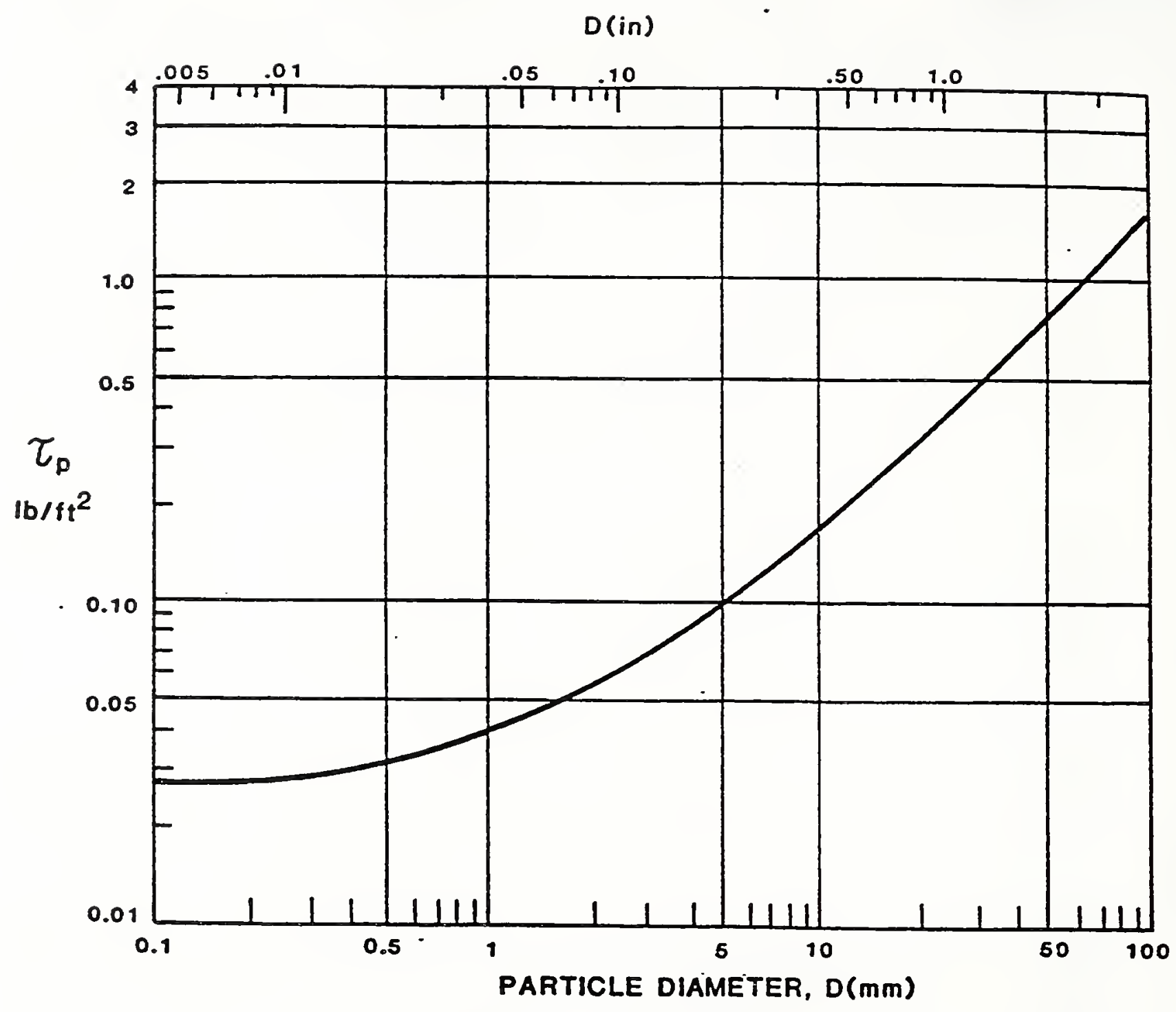

Figure 2-7a: Permissible shear stress for non-cohesive soils (Thibodeaux, 1985) 


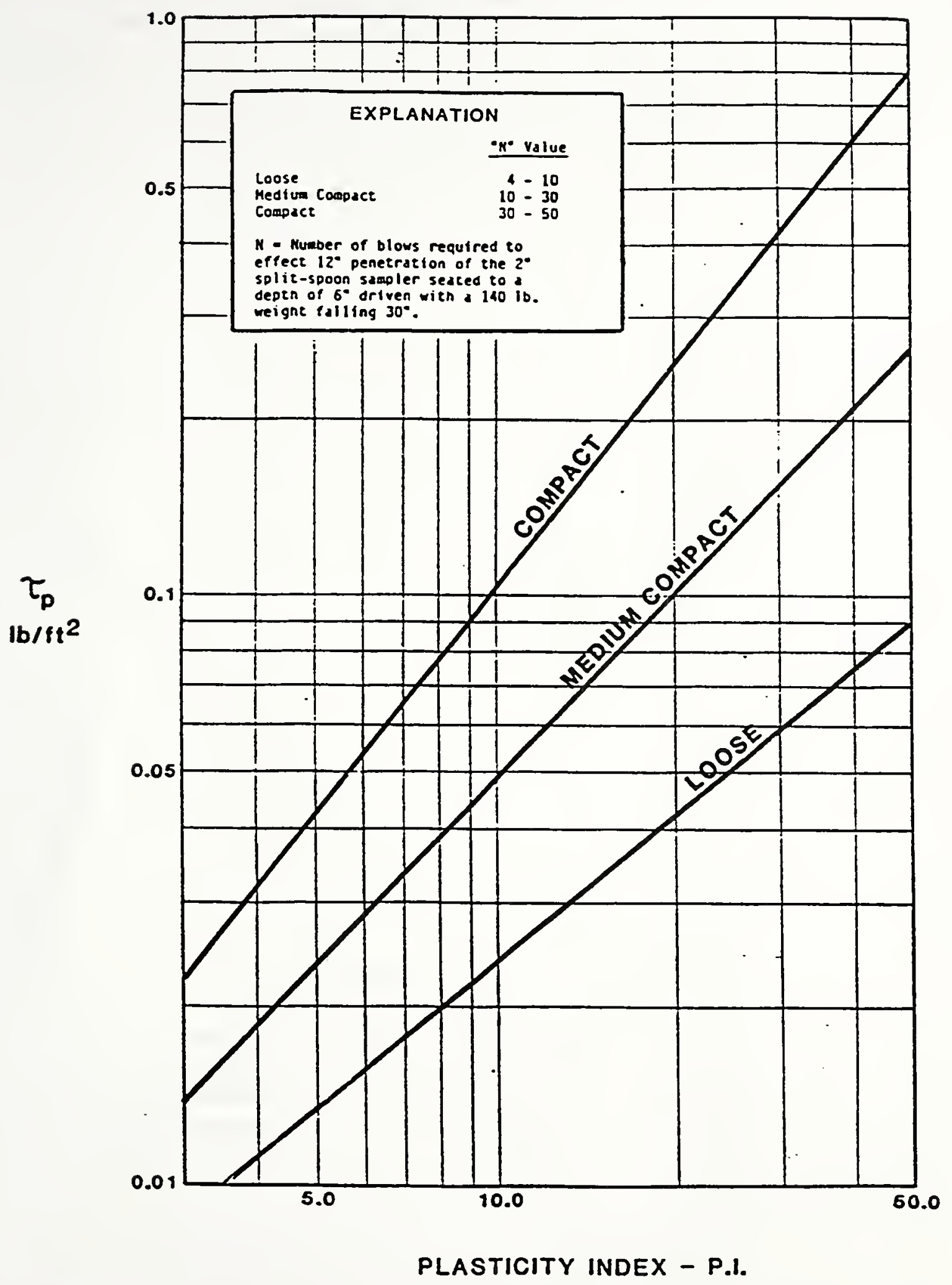

Figure 2-7b: Permissible shear stress for cohesive soils (Smerdon and Beaseley, 1959) 


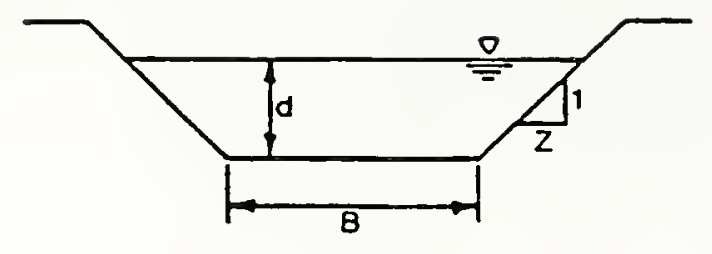

to obtaln votues for $Z=1$ to 6

S

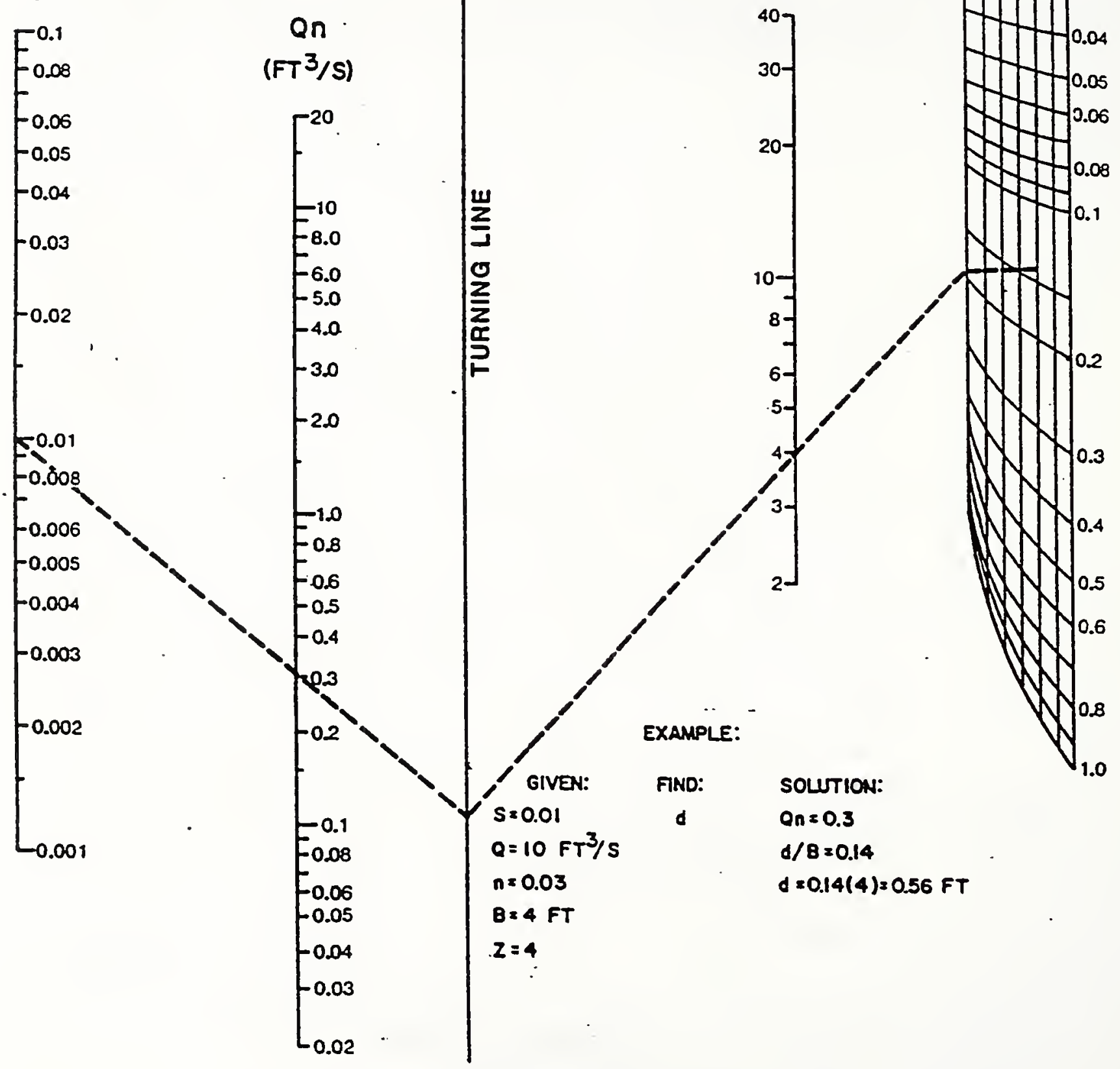

Figure 2-8: Nomograph for Trapezoidal Design - Finding Normal Depth (Chen and Cotton, 1988) 


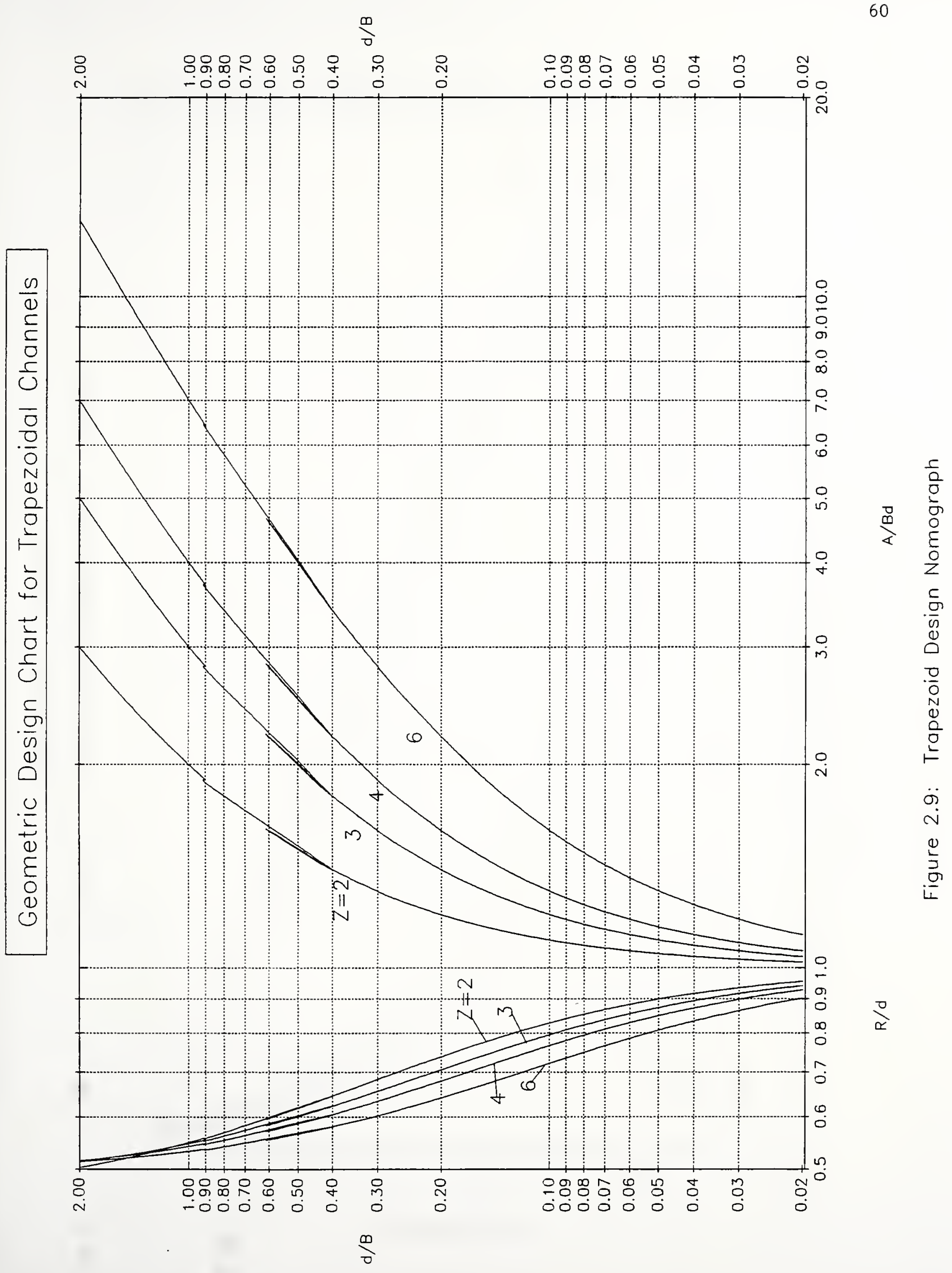




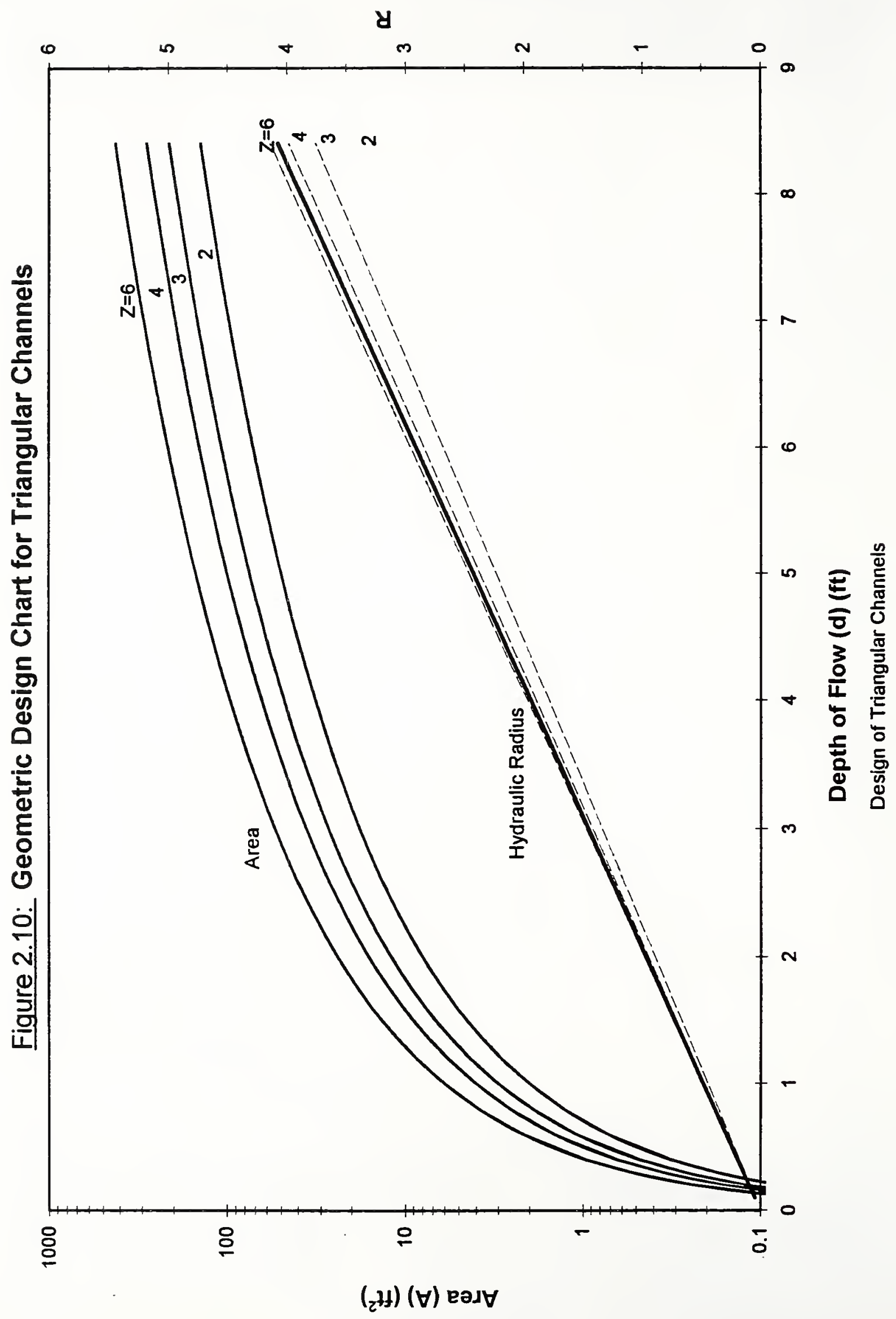




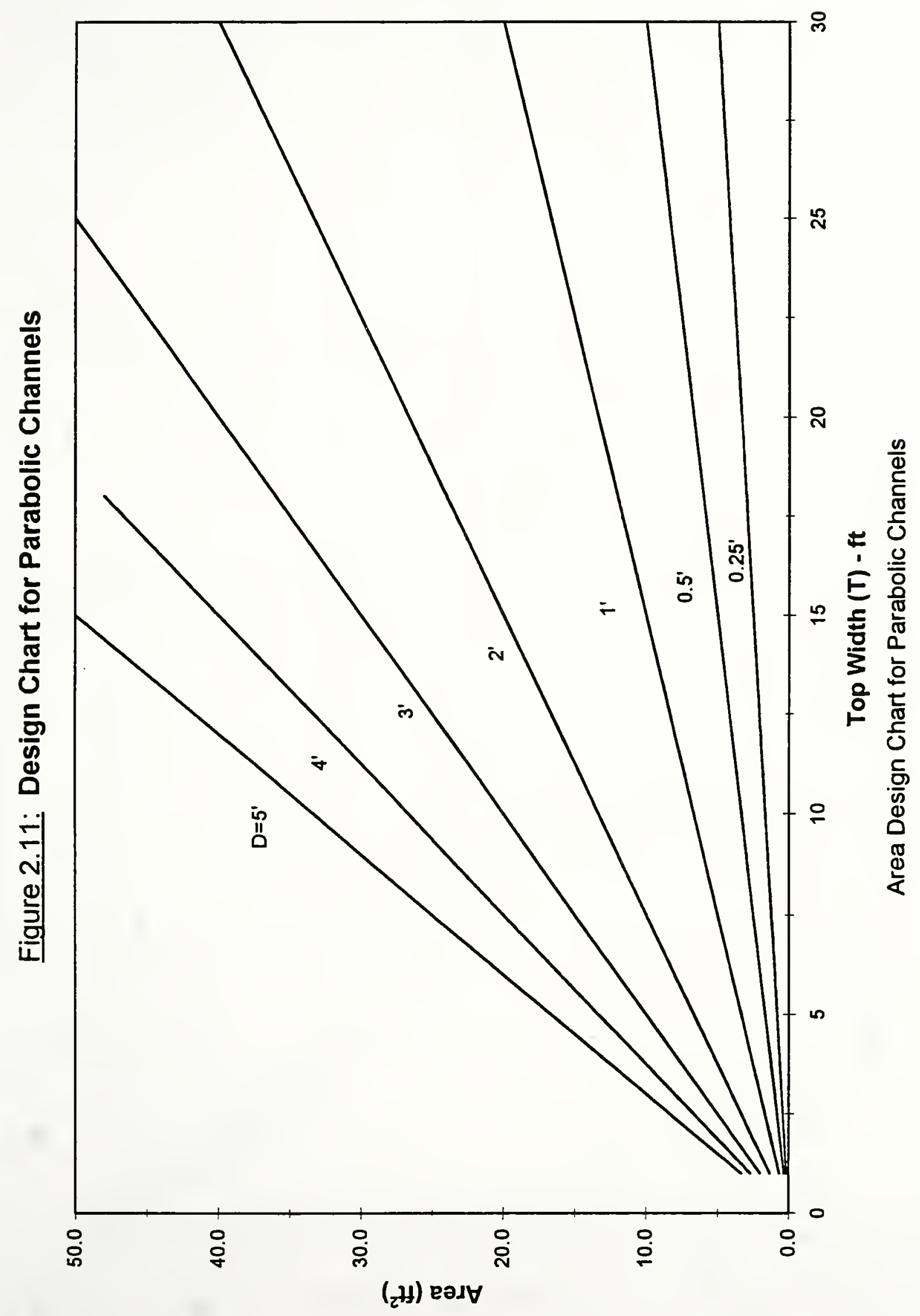




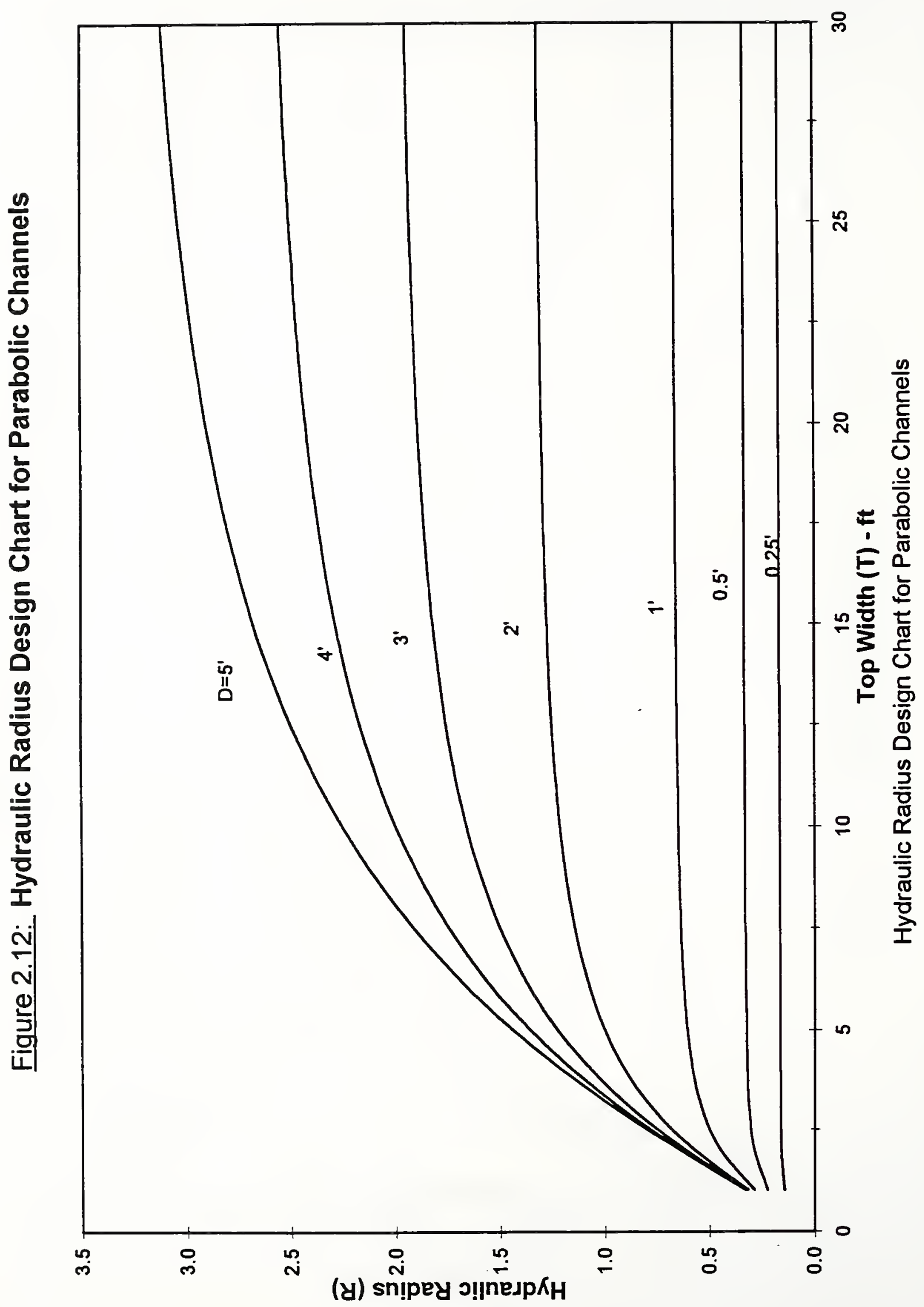




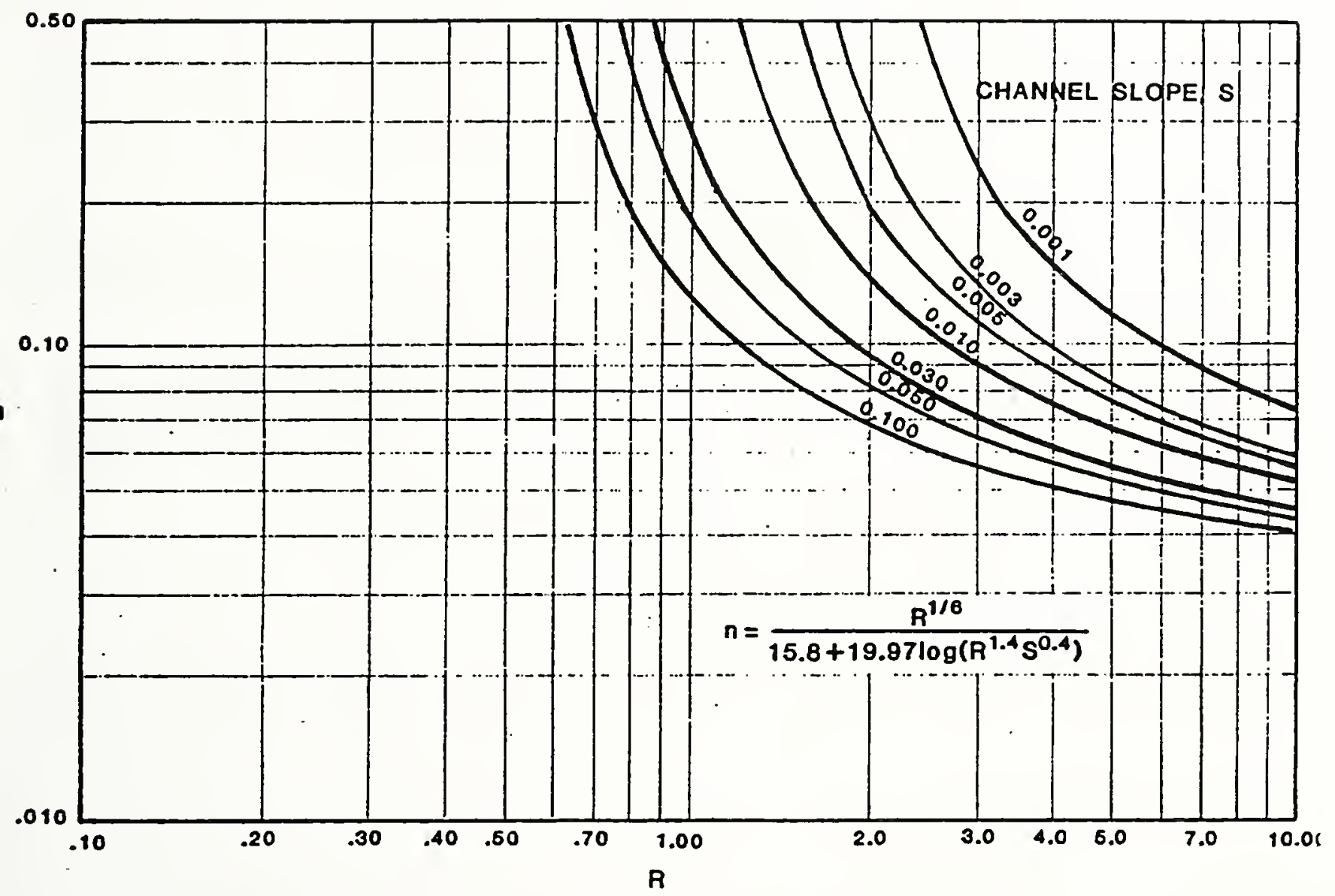

Figure 2-13: Manning's "n" vs. hydraulic radius for class A Vegetation 


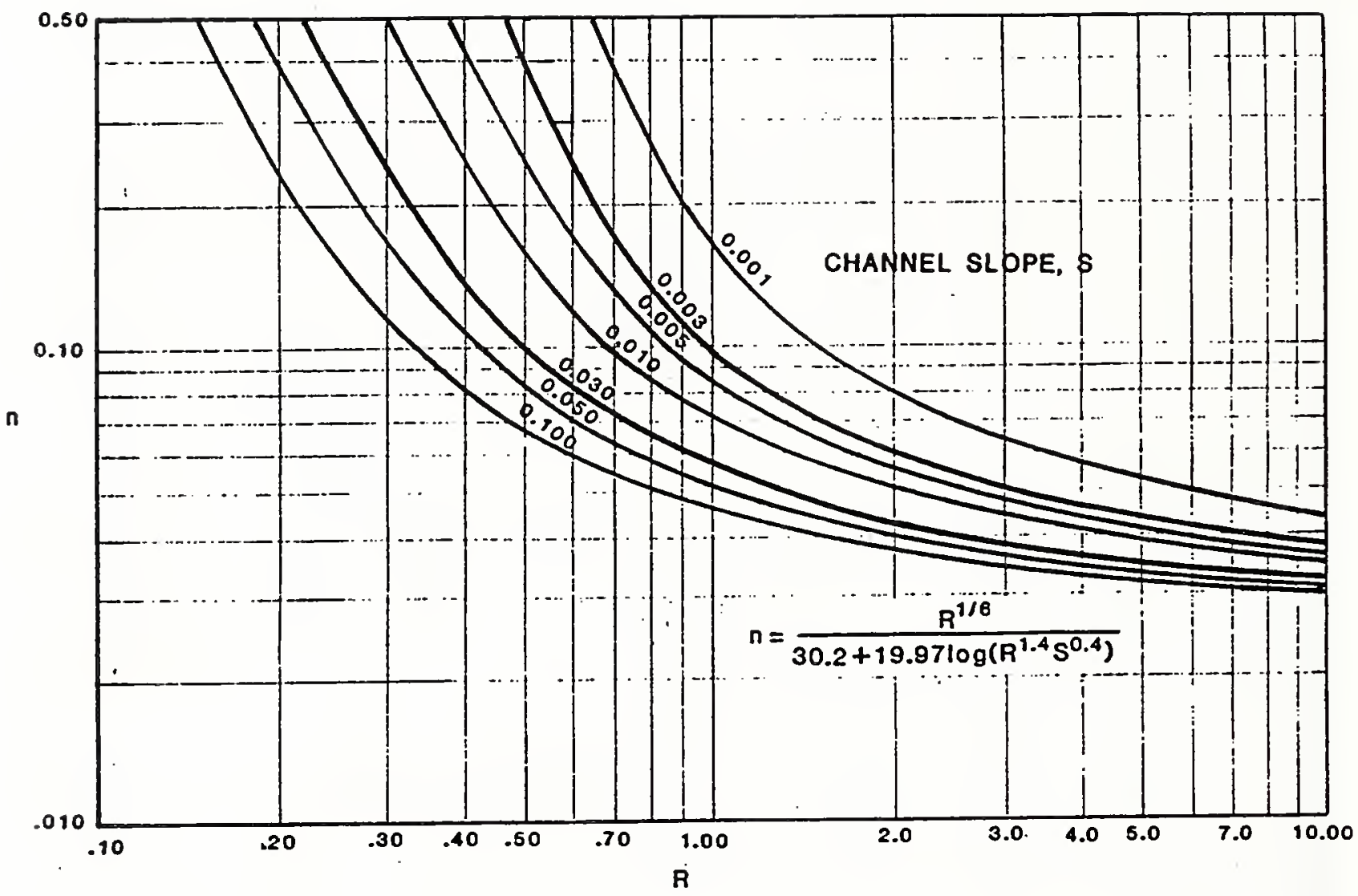

Figure 2-14: Manning's " $n$ " vs. hydraulic radius for class B Vegetation 


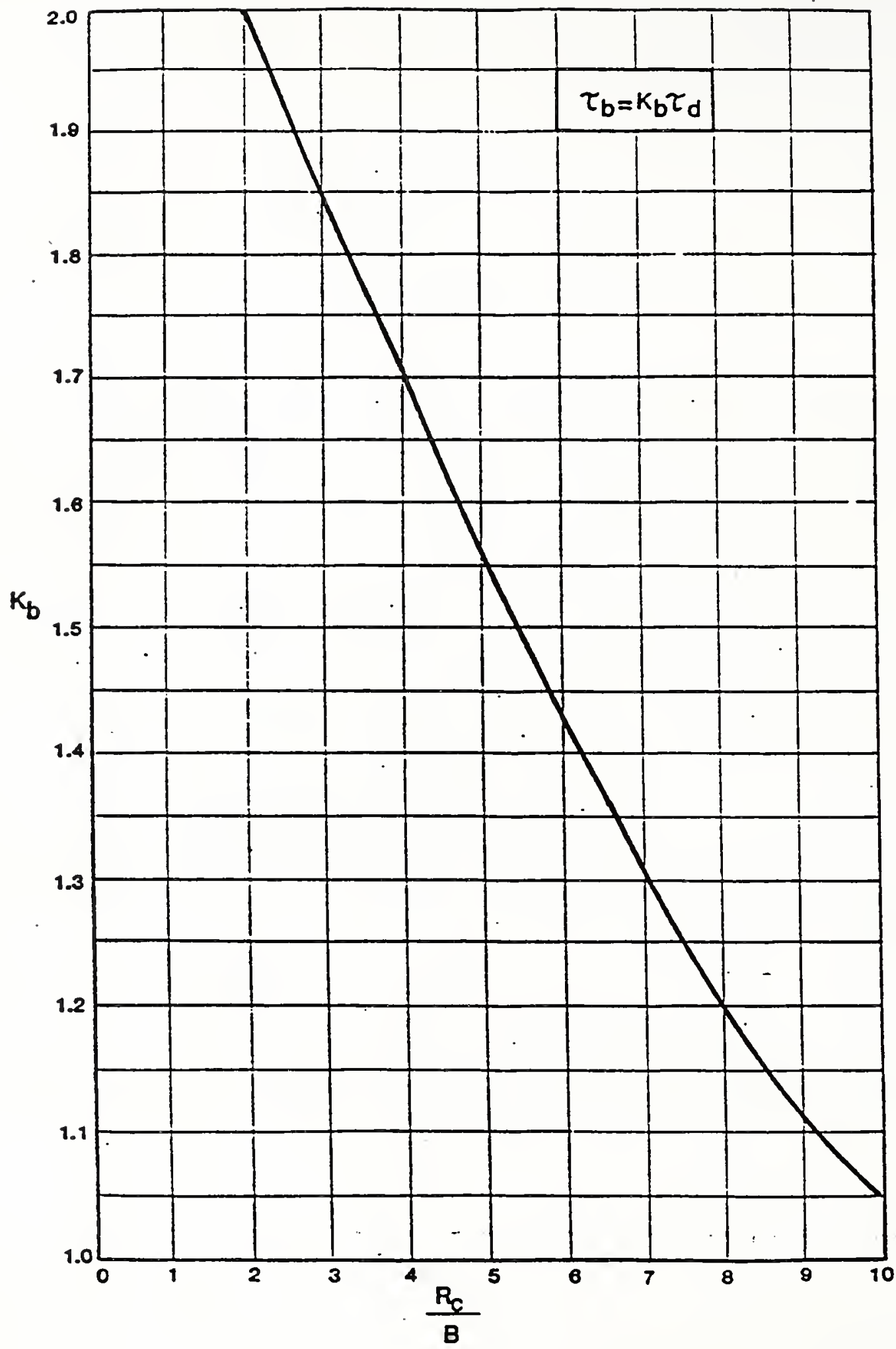

Figure 2-18: $\mathbf{K}_{b}$ correction factor for bend shear stress 


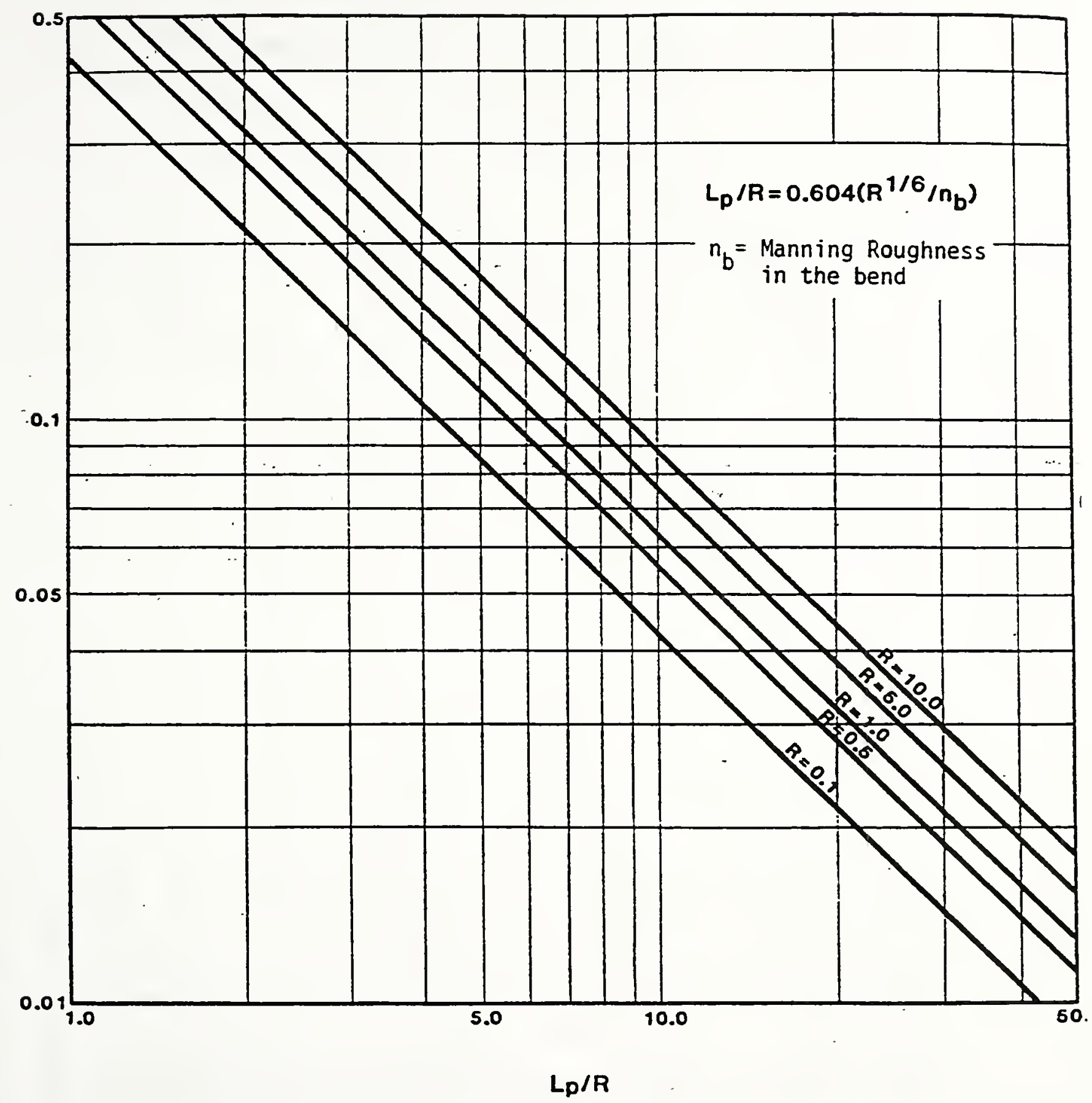

Figure 2-19: Length of protection, $L_{p}$, downstream of channel bend 
MEAN STONE SIZE, $D_{50}, F T$.

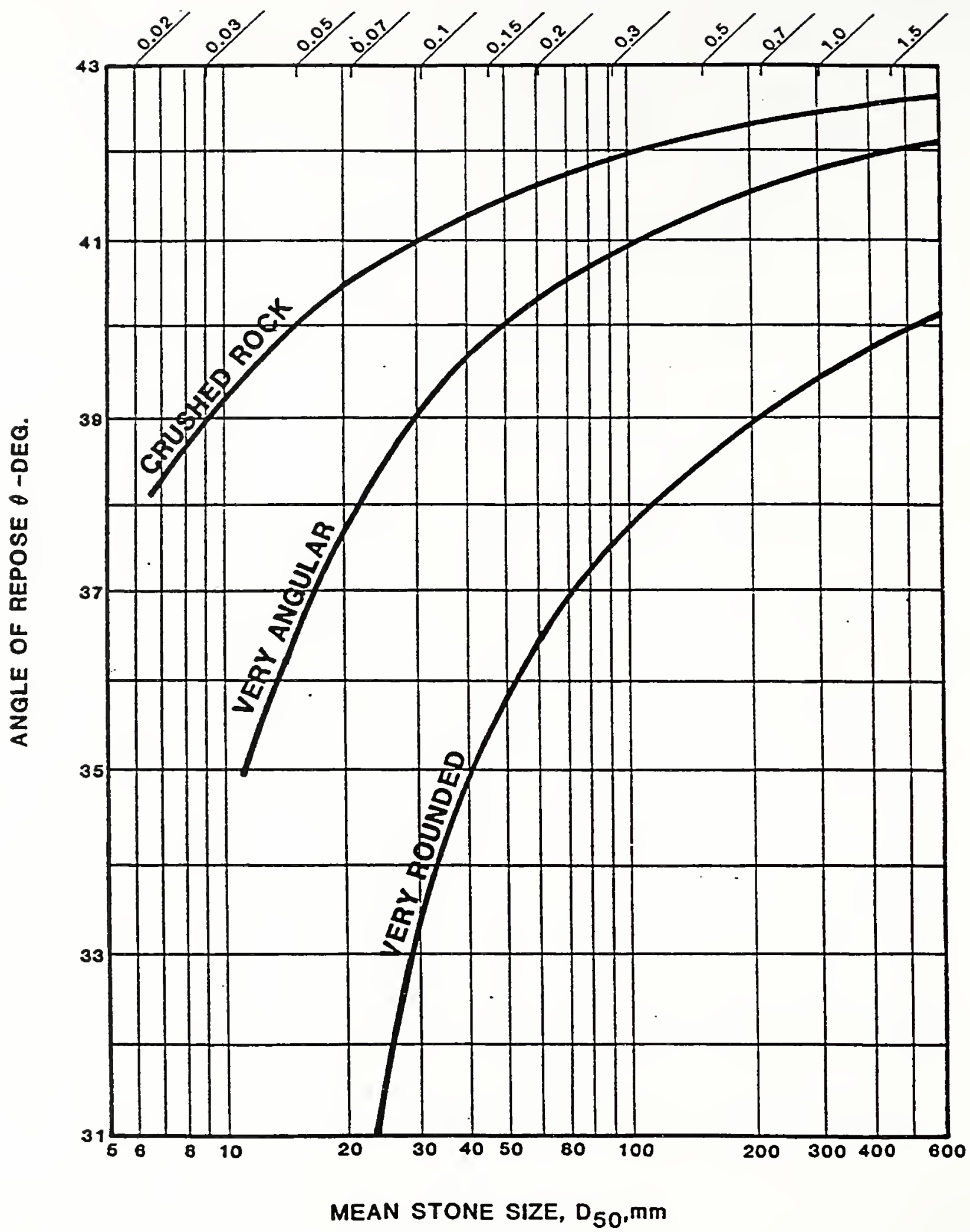

Figure 2-20: Angle of Repose in Terms of $D_{50}-\mathbf{f t}(\mathbf{m m})$ Reprinted from Chen \& Cotton, 1988) 


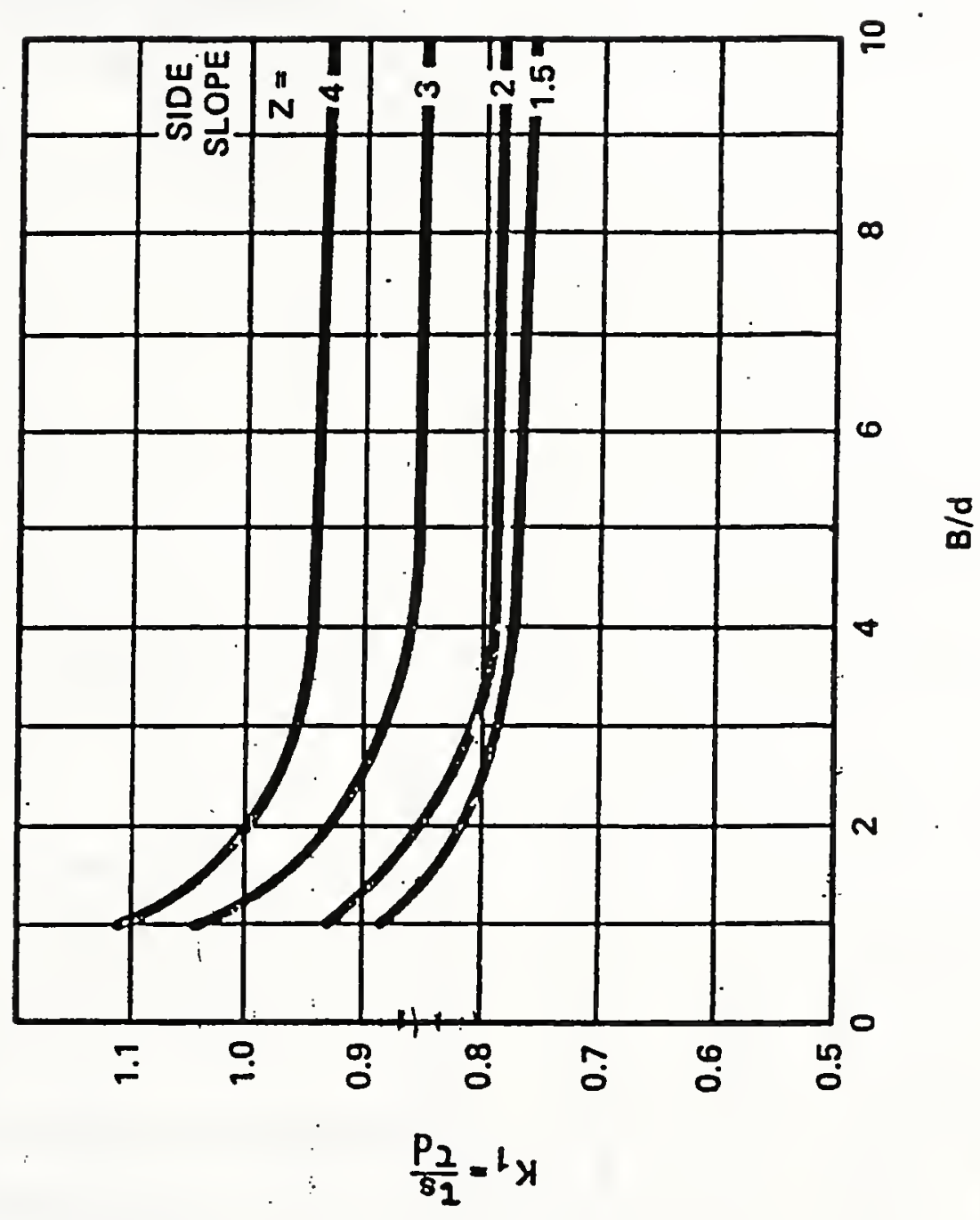

농

곰 


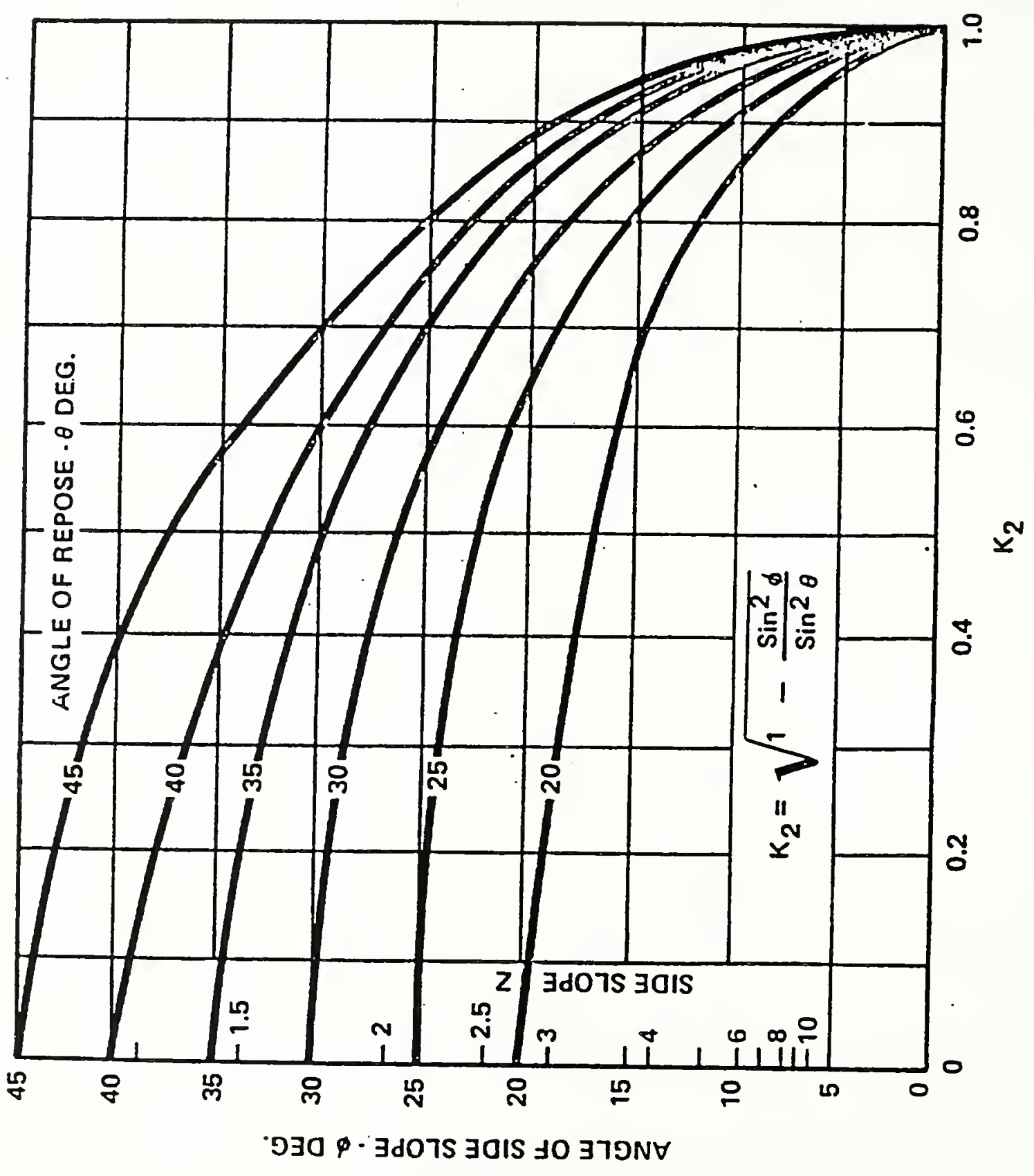

을 


\section{Hard Armor Design - Riprap, Gabion, FFR, ABS Design}

The synthesis of design procedures presented in the previous sections is supplemented in the present section for steep side slope channels, high velocity drainage ditches (typically in excess of $10 \mathrm{ft} / \mathrm{s}$ ), and continuous, turbulent flows. Erosion control products used in this category include riprap, concrete blocks, gabions, articulating block systems, and fabric formed revetments. Each class of products has its own characteristics and thus no one design methodology is appropriate for all types. All classes will be addressed individually in this chapter.

Chen and Cotton (1988) recommend using a steep channel design procedure for side slopes greater than 3:1. Recent research has targeted these "hard armor" materials for 2-2.5:1 side slopes (Escarameia et al, 1995; Maynord, 1991). Such designs are restricted to cohesive soils because these soils have a large angle of repose. Non-cohesive soils on the other hand are unstable at side slope ratios smaller than 3:1 because these soils have smaller angles of repose. In other words, as the angle of the side slope approaches the angle of repose, the channel becomes less stable (Chen and Cotton, 1988). Side slope stability must be checked for steep channels. This computation is found in many geotechnical texts and will not be repeated here (Das, 1990; Lambe and Whiteman, 1969).

\subsection{Introduction to Riprap Design}

Riprap is one of the most widely used forms of channel protection. For a given project, the required mean riprap size increases rapidly as the slope and discharge increase. Riprap gradation should follow a smooth size distribution curve. Ideally, small stones will fill the gaps left by larger rocks. Such interlocking prevents open pockets which are very susceptible to erosion. Moreover, rough, angular riprap are preferred to smooth, flat riprap. The latter types are easily moved by high flows.

Nearly every state department of transportation has specifications for riprap. For example, Illinois and Ohio utilize a class system for riprap. Moreover, each DOT has hydraulic design guidelines for riprap. For example, Indiana DOT uses HEC-11 or HEC-15 methodologies for all riprap designs. 
Despite all of the specifications and design methodologies, failures still frequently occur. Indiana DOT has problems with riprap "blowouts" downstream of drainage pipes and other highway culverts. Figure 3-1 sketches three principal types of failures: transitional slide, modified slump, and deep seated slump. Often the reasons for riprap failure are difficult to quantify. It could be design flaws, installation problems, or simply poor stone from the quarry. For the present discussion, we will limit ourselves to design flaws. Blodgett (1986) gives several reasons for these failures:

$-\quad$ Particle size is too small
$-\quad$ Riprap material had improper gradation
$-\quad$ Side slopes too steep
$-\quad$ No filter blanket installed or filter blanket improperly installed
$-\quad$ Differential settlement following excessive precipitation
$-\quad$ No account made for impinging flow, toe scour, hydrostatic pressure

There are several other considerations that need to be addressed in steep slope design. First, transition regions between steep and shallow slopes need riprap protection. Hydraulic jumps often form in these areas and can lead to excessive erosion. Hence, it is good practice to protect the channel in these turbulent regions. A good rule of thumb is to use riprap a distance equal to five "normal" depths upstream of the transition from steep to mild slopes (Blodgett, 1986). Second, bends should be avoided because the superelevation on the outside of the bend often exceeds the available freeboard (note: superelevation is often estimated as two times the normal depth).

There is need for design methodologies that address all of the above failure modes. Many different riprap designs procedures have been proposed. As one might expect, each methodology provides a different "answer" to the riprap problem. Figure 3-2 plots median stone size against average velocity for several design procedures (Blodgett, 1986; HEC-11, 1989). Note the wide range of $D_{s 0}$ 's for a given velocity. For an average velocity of $15 \mathrm{ft} / \mathrm{s}$, median stone sizes range from $0.75-3.5 \mathrm{ft}$ ! Such a range is undoubtedly going to influence the performance of the channel. 
Lower part of riprap separates from upper part, and moves downslope as homogeneous body. The toe may not show a buige If channel bed is scoured. Translational slide usually occurs If side slope is too steep or toe of riprap Is undermined.

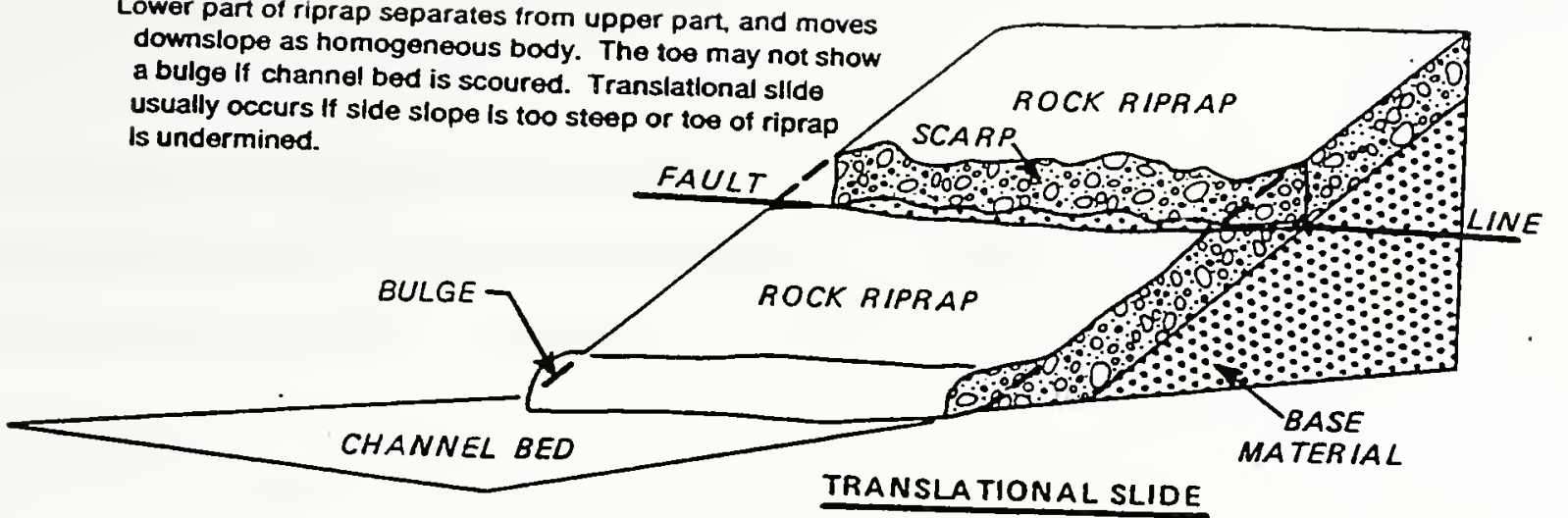

Riprap moves downslope along a fallure plane that lies at or above base material. Fallure plane is at a flatter slope than original riprap layer. This type of failure is usually caused by excess hydrostatic pressure in riprap layer or shear along filter blanket.

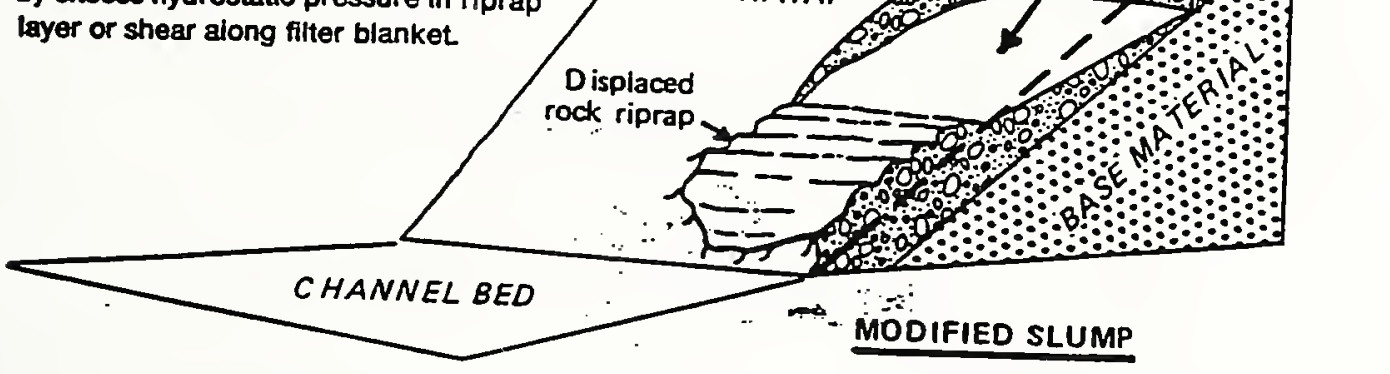

Filter blanket at surface of base material (not shown)

Riprap moves downslope along a failure plane that lies in base material. Fallure zone is dish-shaped. This type of fallure is usually caused by excess hydrostatic pressure in base material.

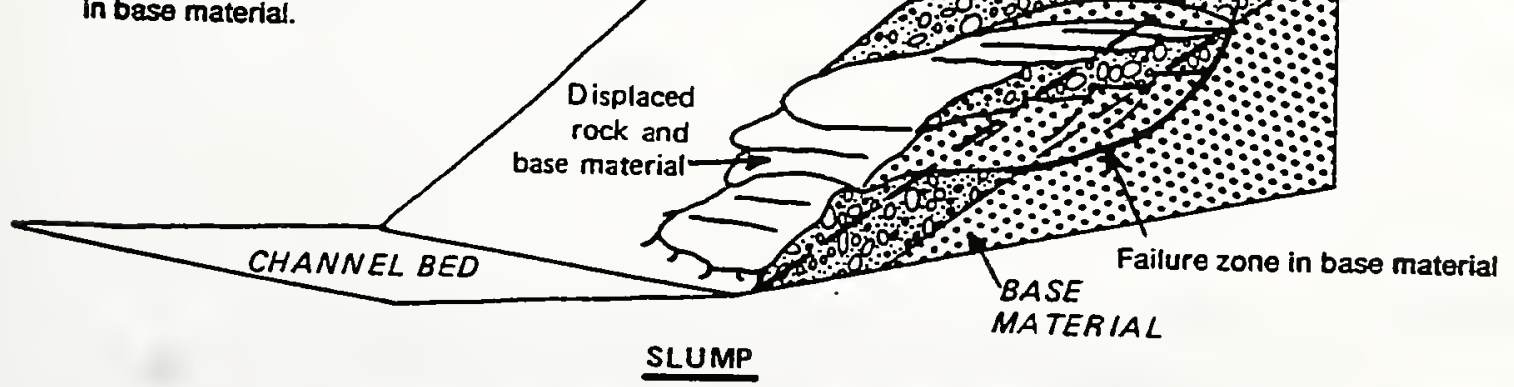

Figure 3-1: Classification of principle types of failures (from Blodgett, 1986) 
This section provides an overview of 10 different design methodologies. This description is followed by a few notes regarding the selection and/or calculation of an appropriate value for Manning's coefficient, $\boldsymbol{n}$. Finally, with regard to establishing a "class" system for riprap, three different methods are given that create a gradation from $\mathrm{D}_{50}$ 's.

Table 3-1 lists the agencies and/or authors of the 10 different design methodologies that will be detailed. A review of each methodology follows the table.

\section{Sources of Design Procedures \\ (Updated from Blodgett, 1986)}

\begin{tabular}{|c|c|c|}
\hline Agency / Author & Title/ Author / Date of Publication & Abbreviation \\
\hline $\begin{array}{l}\text { Federal Highway } \\
\text { Administration }\end{array}$ & $\begin{array}{l}\text { Hydraulic Engineering Circulars for bank } \\
\text { Protection (Searcy, 1967) }\end{array}$ & HEC-11 \\
\hline $\begin{array}{l}\text { Federal Highway } \\
\text { Administration }\end{array}$ & $\begin{array}{l}\text { Hydraulic Engineering Circulars - design of } \\
\text { stable channels for flexible linings } \\
\text { (Chen \& Cotton, 1988) }\end{array}$ & HEC-15 \\
\hline California DOT & $\begin{array}{l}\text { Bank and shore protection in California } \\
\text { highway practice (1970) }\end{array}$ & Cal-B\&SP \\
\hline $\begin{array}{l}\text { U.S. Army Corps of } \\
\text { Engineers }\end{array}$ & $\begin{array}{l}\text { Hydraulic design of flood control channels } \\
\text { (Maynord, 1970, 1991) }\end{array}$ & EM-1601 \\
\hline $\begin{array}{l}\text { American Society of } \\
\text { Civil Engineers }\end{array}$ & $\begin{array}{l}\text { Sedimentation Engineering, Manual No. } 54 \\
\text { (Vanoni, 1975) }\end{array}$ & Man-54 \\
\hline Blodgett & $\begin{array}{l}\text { Riprap design protection of stream channels } \\
\text { near highway structures (1986) }\end{array}$ & Blodgett \\
\hline Escarameia \& May & $\begin{array}{l}\text { Stability of riprap in highly turbulent flows } \\
\text { (1995) }\end{array}$ & $E \& M$ \\
\hline Froehlich \& Benson & Sizing dumped rock riprap (1996) & $F \& B$ \\
\hline Simons \& Senturk & Sediment transport technology (1977) & Simons \\
\hline $\begin{array}{l}\text { U.S. Bureau } \\
\text { Reclamation }\end{array}$ & $\begin{array}{l}\text { Hydraulic design of stilling basins and energy } \\
\text { dissipaters (Peterka, 1958) }\end{array}$ & USBR \\
\hline
\end{tabular}

Table 3-1: List of riprap design procedures described in this report 


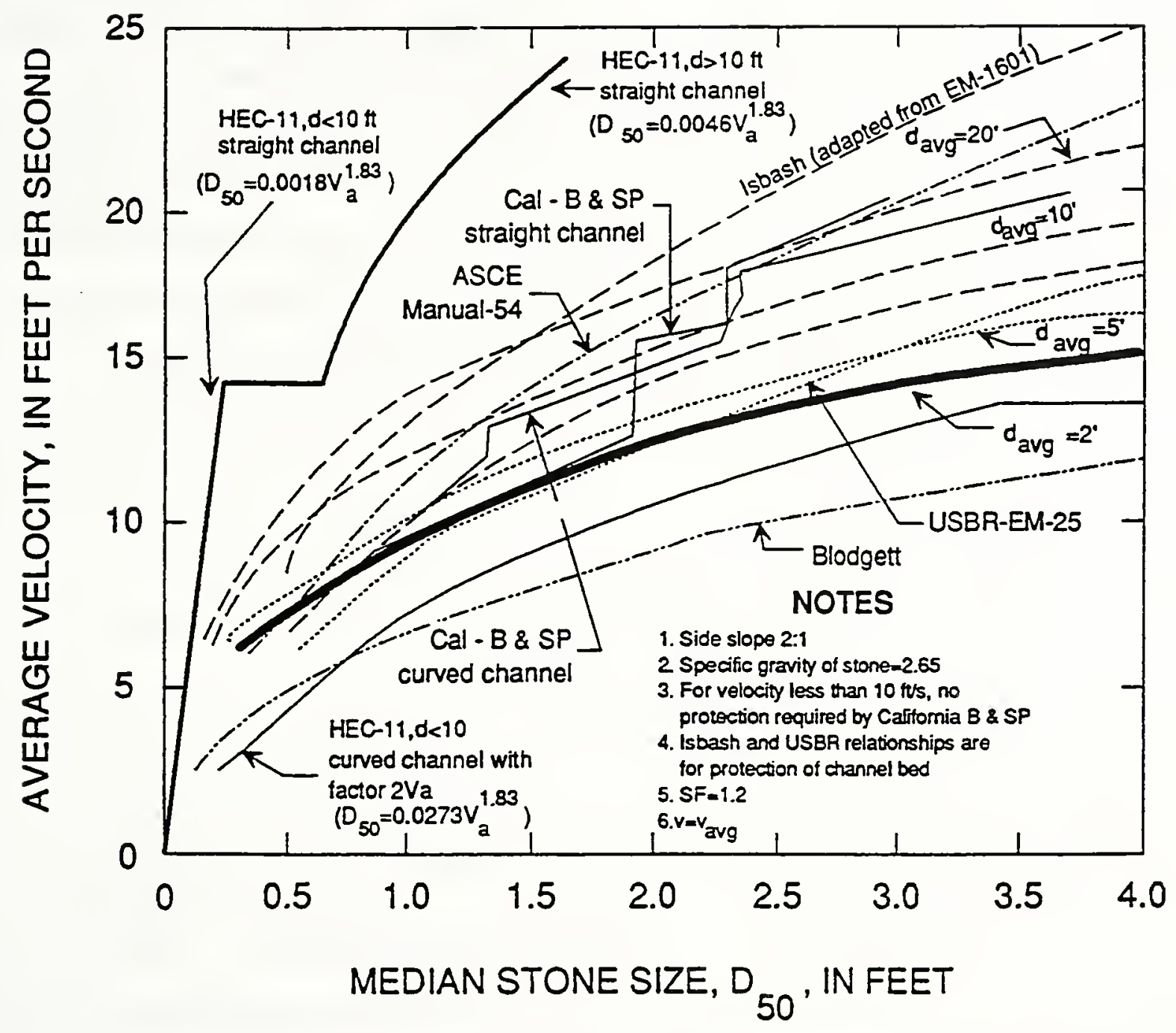

Figure 3-2: Comparison of procedures for estimating stone size based on permissible velocities (from Appendix $A$ of $H E C-11$ ) 


\subsection{Riprap Design Procedures}

\subsubsection{HEC-11}

The size of riprap needed to protect the streambank is determined on a trial and error basis using estimated stone size, design velocity, and depth. A flow chart illustrating the HEC-11 procedure and relevant graphs are shown in figure 3-3 and 3-4. Depths exceeding $10 \mathrm{ft}$ are multiplied by 0.4 . Velocity is multiplied by a factor of 1 to 2 for impinging flow.

Blodgett (1986) developed regression equations for each graph to simplify the computations. These equations are developed with an assumed side slope of $2 \mathrm{H}: 1 \mathrm{~V}(\mathrm{Z}=2)$ (most designs require side slopes of $1.5-3: 1$ ). Note that the symbol $Z$ is used interchangeably with the $\mathrm{H}: \mathrm{V}$ ratio in this report. Since $\mathrm{D}_{s 0}$ is the unknown variable, the regression equations are combined to included mean velocity and maximum depth. The equations are listed below:

(a). Relationship of $\mathrm{D}_{50}$ stone size on channel bottom to velocity against stone

$$
\begin{array}{ll}
\mathrm{D}_{50}=1.15 \mathrm{~d}_{\mathrm{m}}\left(\frac{\mathrm{V}_{\mathrm{s}}}{\mathrm{V}_{\mathrm{a}}}\right)^{3.72} \\
\mathrm{D}_{50}= & \text { Median stone size }(\mathrm{ft}) \\
\mathrm{d}_{\mathrm{m}}= & \text { Total depth }(\mathrm{ft}) \sim 1.5 \mathrm{~d}_{\text {mean }} \\
\mathrm{V}_{\mathrm{s}}= & \text { Velocity against stone }(\mathrm{ft} / \mathrm{s}) \\
\mathrm{V}_{\mathrm{a}}= & \text { Average Velocity }(\mathrm{ft} / \mathrm{s})
\end{array}
$$

(b). Velocity against stone

$$
\begin{array}{ll}
V_{s}=10.63\left(D_{50}\right)^{0.522} & \text { (straight channels) } \\
V_{s}=5.32\left(D_{50}\right)^{0.522} & \text { (curves - includes factor of 2.0) }
\end{array}
$$

(c). Overall regression equation

$$
\begin{aligned}
& \mathrm{D}_{50}=\frac{\mathrm{CV}_{\mathrm{a}}^{3.95}}{\mathrm{~d}_{\mathrm{m}}^{1.06}} \\
& \mathrm{C}=0.000076 \text { for } \mathrm{Z}=2: 1, \mathrm{~d}_{\mathrm{m}}<10 \mathrm{ft} \text {, and straight channel; }(Z=H: V) \\
& \mathrm{C}=0.000202 \text { for } Z=2: 1, \mathrm{~d}_{\mathrm{m}}>10 \mathrm{ft} \text {, and straight channel } \\
& \mathrm{C}=0.00117 \text { for } \mathrm{Z}=2: 1, \mathrm{~d}_{\mathrm{m}}<10 \mathrm{ft} \text {, and curved channel } \\
& \mathrm{C}=0.00310 \text { for } \mathrm{Z}=2: 1, \mathrm{~d}_{\mathrm{m}}<10 \mathrm{ft} \text {, and curved channel }
\end{aligned}
$$


(d). Rewrite (3.3a) to include effect of the Froude Number, $\mathrm{F}_{\mathrm{r}}=0.95$ (borderline subcritical flow \& limit of applicability of Manning's equation). Note that total depth $\left(d_{m}\right)$ is approximately 1.5 times average depth $\left(d_{2}\right)$

$$
\begin{aligned}
& F_{R}=0.95=\frac{V_{.}}{\sqrt{g d_{a}}} \Rightarrow d_{m}=1.5 d_{a}=0.0516\left(V_{.}\right)^{2} \\
& D_{50}=C\left(V_{a}\right)^{1.83} \\
& C \quad=0.0018 \text { for } Z=2, d m<10^{\prime}, F_{r} \sim 0.95, \text { straight channel } \\
& C \quad=0.0046 \text { for } Z=2, d m>10^{\prime}, F_{r} \sim 0.95, \text { straight channel } \\
& C \quad=0.0273 \text { for } Z=2, d m<10^{\prime}, F_{r} \sim 0.95, \text { curved channel } \\
& C \quad=0.0718 \text { for } Z=2, d m>10^{\prime}, F_{r} \sim 0.95 \text {, curved channel }
\end{aligned}
$$

Problems with HEC-11 (from Blodgett, 1986)

1). The graphs require an estimate of velocity against stone, yet no data are given in HEC11 to estimate it. Further, HEC-11 only shows $V_{8} / V_{2}<1$, yet it is conceivable in highly turbulent flow to have near bed velocities in excess of the average velocity.

2). The resulting value of $D_{s 0}$ is too small for straight reaches and too large for curved channels. This conclusion was reached after comparing HEC-11 predicted $\mathrm{D}_{50}$ to actual failed riprap lined creeks (i.e. HEC-11 $D_{s 0}$ was the same size or less than the $D_{s 0}$ of the failed riprap revetment).

3). An adjustment for specific gravity is unwarranted if it is $2.65 \pm 10 \%$. Errors in the ability to asses hydraulic and frictional forces are of the same magnitude. Hence, the specific gravity adjustment provides little, if any improvement in the design.

4). No guidelines for using the adjustment factor of 2 for curved channels. Moreover a range of 1 to 2 for this adjustment factor is given with no justification. 
Select trial $D_{50}$. Determine $d, V_{a}$,

$\mathrm{D}_{50} / \mathrm{d}$ for design conditions.

Depth of flow $>10$ feet, substitute

$0.4 d$ for $d$ in ratio $D_{50} / d$.

Impinging flow, apply factor

of 1 to 2 times $V_{s}$.

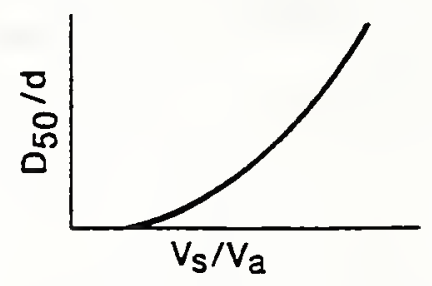

Fig. 1 - Velocity of stone on channel bottom.

Determine $V_{S}, V_{S}=\left(V a, D_{50} / d\right)$

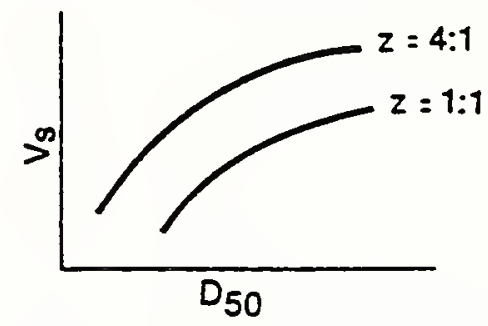

Fig. 2 - Size of stone that will resist displacement for various velocities and side slopes.

Determine $D_{50}, D_{50}=\left(V_{5}, z\right)$.

Continue until $D_{50}$ selected in step 1 is in reasonable agreement with size from Fig. 2 in step 3.

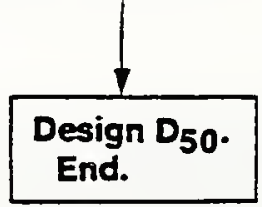

Figure 3-3: Flow chart of riprap design procedure for HEC-11 

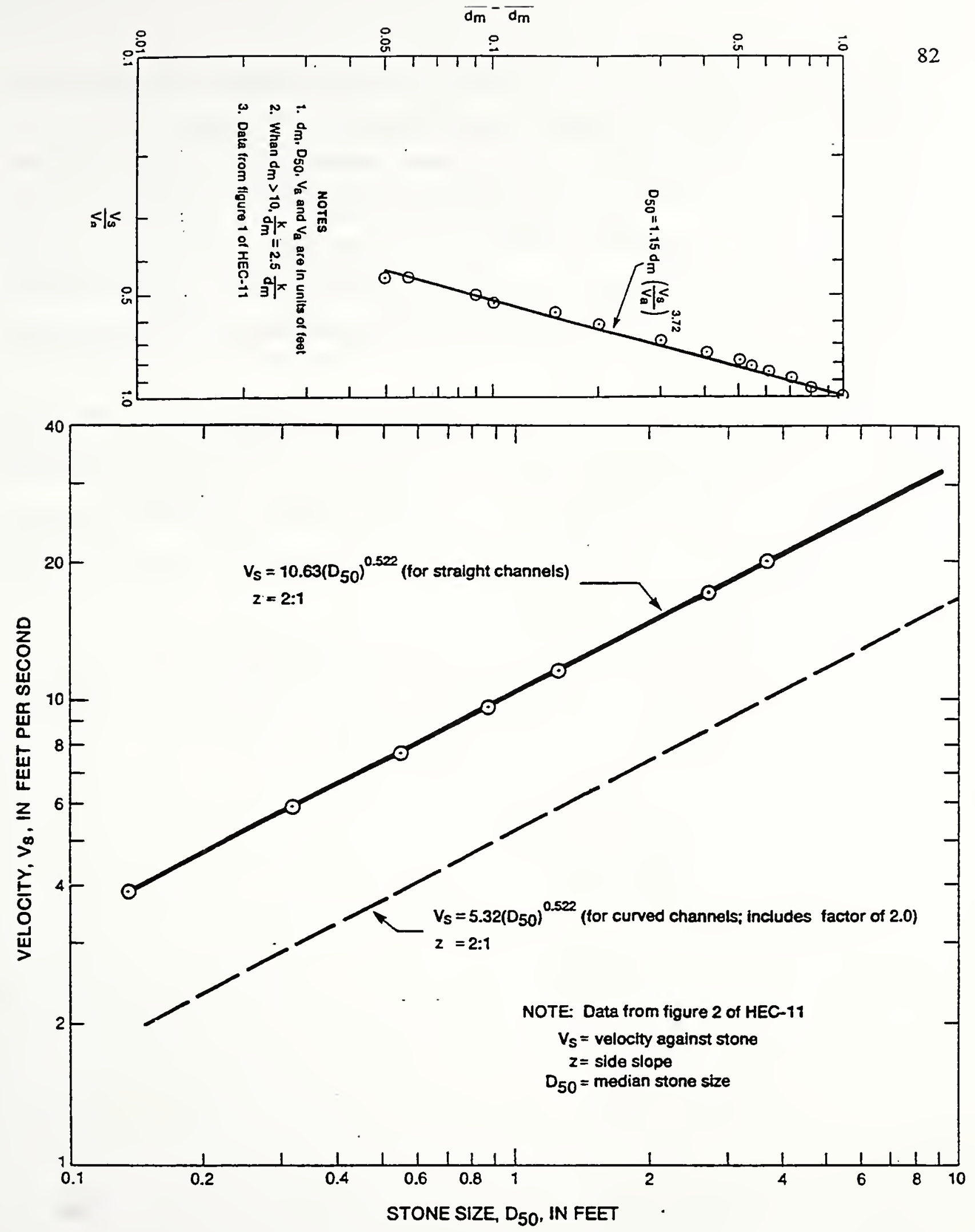

Figure 3-4: Design aids for HEC-11 (1970 version) 
Recently (1989), HEC-11 has been updated. It incorporates new research results with the suggestions recommended by Blodgett. The revised design procedure applies only to those open channels with discharges in excess of 50 cubic feet per second (cfs). Design for most highway channels now comes under HEC-15 (i.e. discharges less than $50 \mathrm{cfs}$ ). In addition to design procedures, HEC-11 recommends gradations for the riprap based on $\mathrm{D}_{50}$. This new design procedure uses the critical velocity rather than the critical shear approach. Even though tractive force methods are better models, permissible velocity approaches are more accepted by the engineering community (HEC-11, 1989).

The required equations for this revised version of HEC-11 are shown below. Note that a trial and error process is still required to find the normal depth, $d$. Once this depth is known, the velocity is computed by Manning's equation and the equations below are used directly.

Equations for Revised HEC-11 Procedure

(a). Compute Manning's n

$$
\begin{aligned}
& n=0.093 d^{0.167} \quad \text { for } 1.5<d / D 50<185 ; S<0.002 \\
& n=0.019 d^{0.167} \quad \text { for } 185<d / D 50<30,000 ; S<0.002 \\
& n=039 S_{f}^{0.038} R^{-0.16} \text { (If information is available) } \\
& d \quad=\text { Mean flow depth } \\
& D_{50} \quad=\text { Median riprap size } \\
& S_{f} \quad=\text { friction slope } \\
& R \quad=\text { hydraulic radius }
\end{aligned}
$$

(b). Compute $\mathrm{D}_{\text {so }}$

$$
\begin{aligned}
& \mathrm{D}_{\mathrm{s} 0}=\mathrm{c}_{\mathrm{sg}} \mathrm{c}_{\mathrm{SF}} \frac{0.001 \mathrm{~V}_{\mathrm{a}}^{3}}{\mathrm{~d}^{0.5} \mathrm{~K}_{1}{ }^{1.5}} \\
& \mathrm{~K}_{1}=\sqrt{1-\frac{\sin ^{2} \theta}{\sin ^{2} \phi}} \\
& \mathrm{c}_{\mathrm{sg}}=\frac{2.12}{\left(\mathrm{G}_{\mathrm{s}}-1\right)^{1.5}} \\
& \mathrm{c}_{\mathrm{SF}}=\left(\frac{\mathrm{SF}}{12}\right)^{1.5}
\end{aligned}
$$




$$
\mathrm{T}=2 \mathrm{D}_{50}
$$

$\mathrm{V}_{\mathrm{s}} \quad$ = average velocity computed from Manning's equation

$\mathrm{K}_{1} \quad=$ bank angle correction

$\phi \quad=$ riprap angle of repose $\left(\sim 36-42^{\circ}\right)$

$\theta \quad=$ bank angle with the horizontal (degrees)

$\mathrm{c}_{\mathrm{gg}}=$ specific gravity correction factor if $\mathrm{Gs} \neq 2.65$

$\mathrm{G}_{\mathbf{s}} \quad$ = specific gravity of riprap

$\mathrm{c}_{\mathrm{SF}} \quad=$ stability correction factor

$\mathrm{SF} \quad=$ safety factor applied (see table below)

$\mathrm{T}=$ thickness of riprap layer

\section{Guidelines for Selection of the Stability Factors}

Uniform flow; straight or mild curves $(\mathrm{R} / \mathrm{W}>30)$; Little uncertainty in parameters $1.0-1.2$ Gradually varying flow; Moderate bends $(\mathrm{R} / \mathrm{W}<30)$; Moderate wave impact $1.3-1.6$ Rapidly varying flow; Sharp bends $(\mathrm{R} / \mathrm{W}<10)$; Large wave impact $1.6-2.0$

As with all riprap designs, a filter layer must be placed underneath the riprap. See Appendix B for the most recent FHWA geosynthetic filter layer design procedure. 


\subsubsection{HEC-15}

Note: This review is based on the 1988 version of HEC-15 by Chen and Cotton and not the 1975 version by Normann.

This design procedure is based on the concept of maximum permissible flow and hydraulic resistance of the lining material. As with HEC-11, the size of riprap is determined from a trial and error procedure. Two separate design procedures are used - one for slopes 3:1 and flatter and one for 3:1 and steeper. A flow chart for each procedure follows on the next pages. Relevant graphs for determining the angle of repose, $K_{1}$ (ratio of side to bottom shear), and $K_{2}$ (tractive force ratio) follow the flow charts.

For steep channel design, HEC-15 provides simple charts and tables (also reproduced) to facilitate the design. The first flow chart uses these graphs. Unfortunately, the charts are limited to bottom widths of $6 \mathrm{ft}$. A rigorous design solution for the case of $\mathrm{B}>6 \mathrm{ft}$ is presented in the second steep channel flow chart.

The design is based on the Bathurst resistance equation to predict hydraulic conditions and the Simons and Senturk factor of safety equation to assess riprap stability. Bathurst (1981) found that the flow resistance significantly decreased as the Reynolds number increased and as relative submergence increased. He also showed that form drag of the roughness elements and the relative roughness area had to be included in the resistance equation. The above elements are combined into a power law. The general resistance equation is very complex due to the complexity of the processes it attempts to describe. Moreover, the equation is empirical. Thus, its validity is limited to the ranges of data on which it is based. These limitations are listed in the original paper. Readers interested in a more complete description of the resistance equation are referred to the Bathurst (1981) paper.

The HEC-15 procedure next requires calculation of the Simons and Senturk (1977) factor of safety equation to assess riprap stability. This equation analyzes the forces acting on an individual particle and calculates a factor of safety against it movements. These forces include the weight of the particle, drag in the direction of flow, and lift. Since the element tends to roll rather 
than slide, its stability is calculated by taking moments about the contact point. A full explanation of the Simons equation is given later in this chapter.

Listed below are the relevant equations for the HEC-15 riprap design procedure. For convenience, the equations are grouped in order of there use for a particular method. Three main methods are presented: Flat slope $(Z \leq 3)$, Steep Slope $(b \leq 6)$, and Steep Slope $(b>6)$.

\section{Flat slope (Z $\leq 3)$ Design Equations}

(a). Manning's $n$

$$
\mathrm{n}=0.0395\left(\mathrm{D}_{50}\right)^{1 / 6}
$$

(b). Equation to find depth of flow (see Appendix A for more detail)

(trapezoidal channels with side slope ratio $Z$ and base width $b$ )

$$
\mathrm{AR}^{2 / 3}=\frac{\left(\mathrm{b}+\mathrm{Zd}^{2}\right)^{5 / 3}}{\left(\mathrm{~b}+2 \mathrm{~d} \sqrt{\mathrm{Z}^{2}+1}\right)^{2 / 3}}=\frac{\mathrm{Qn}}{1.486 \mathrm{~S}^{1 / 2}}
$$

(c). Calculate design shear

$$
\tau=\gamma \mathrm{d} S
$$

(d). Calculate permissible shear

$$
\tau_{\mathrm{p}}=4.0 \mathrm{D}_{\mathrm{s0}}
$$

(e). Calculate velocity

$$
\mathrm{V}=\frac{1.486}{\mathrm{n}} \mathrm{R}^{2 / 3} \mathrm{~S}^{1 / 2}
$$

(f). Froude Number

$$
\mathrm{Fr}=\frac{\mathrm{V}}{\sqrt{\mathrm{gd}}}<0.95
$$

(g). Determine $\mathrm{D}_{50 \text { side }}$ (median stone size on the side slopes)

$$
\mathrm{D}_{50 \_ \text {ide }}=\frac{\mathrm{K}_{1}}{\mathrm{~K}_{2}} \mathrm{D}_{\mathrm{s0}}
$$


$\mathrm{B} \leq 6 \mathrm{ft}$
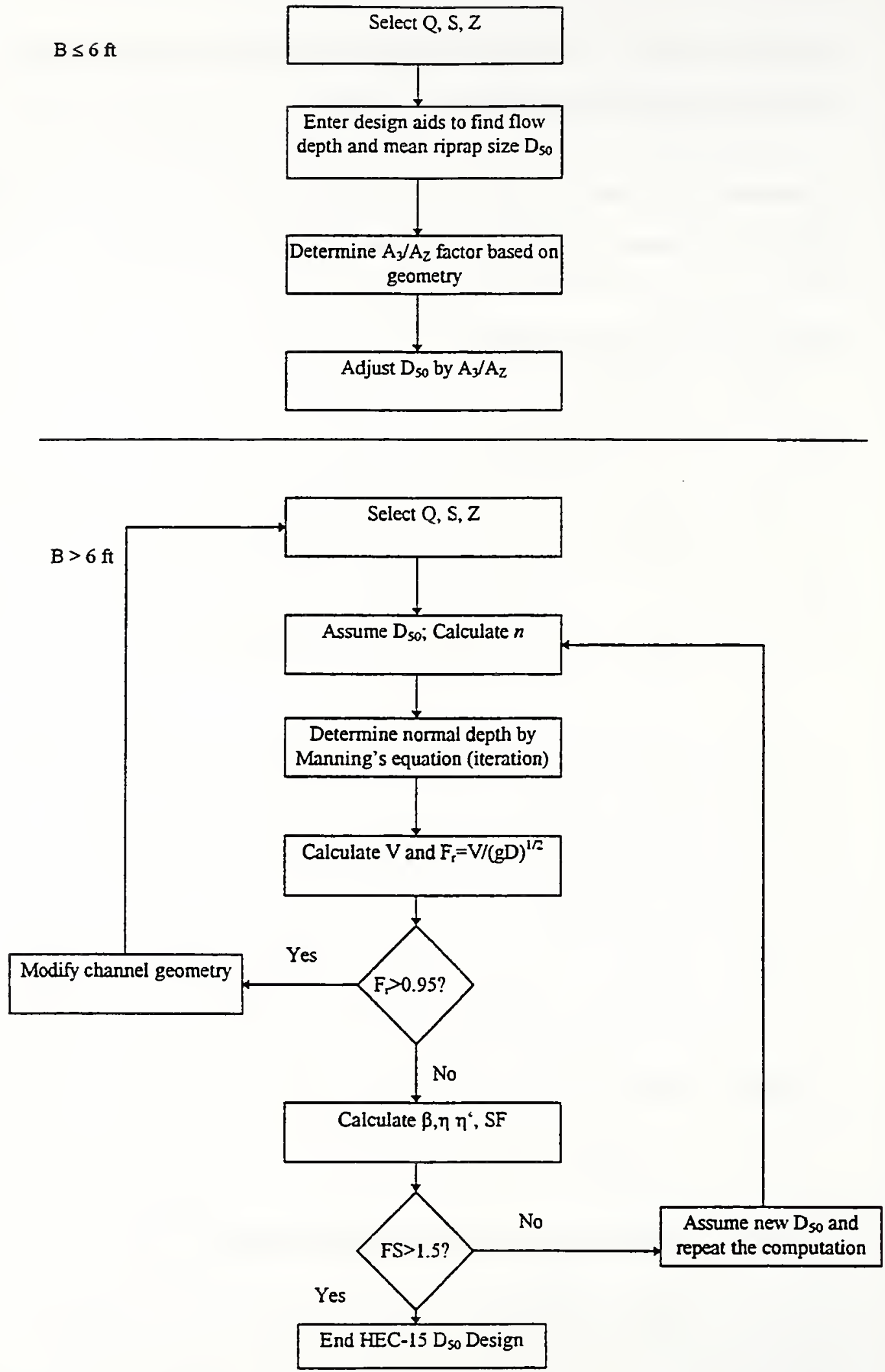

Figure 3-4: Flow chart of riprap design procedure for HEC-15 
Steep slope equations $(Z>3)$ for graph design of riprap channels $(b \leq 6 \mathrm{ft})$

(a). Find the flow depth using the following equation (values of $A_{3} / A_{z}$ are found on table 7):

$\mathrm{d}=\frac{\mathrm{A}_{3}}{\mathrm{~A}_{\mathrm{z}}} \mathrm{d}_{\mathrm{i}}$

$\mathrm{d}=$ depth of flow in channel with side slope ratio $Z_{1}$

$d_{i} \quad=$ depth of flow from design charts (3:1 side slopes)

$A_{3} / A_{Z}=$ conversion factor from $Z=3$ to $Z=Z_{1}$ side slopes

(b). Find the riprap size using the equation

$\mathrm{D}_{50}=\frac{\mathrm{d}}{\mathrm{d}_{\mathrm{i}}} \mathrm{D}_{50_{\mathrm{i}}}$

$\mathrm{D}_{50 \mathrm{i}} \quad=$ mean riprap size from design charts

$\mathrm{D}_{s 0} \quad=$ mean riprap size in channel

Steep channel design $(b>6)$

(a). Bathurst Resistance Equation

$$
\begin{array}{lll}
\frac{\mathrm{U}}{\mathrm{U} .}=\frac{1.49}{\sqrt{\mathrm{g}}} \frac{\left(\mathrm{d}^{1 / 6}\right)}{\mathrm{n}}=\mathrm{f}(\mathrm{Fr}) \times \mathrm{f}(\mathrm{REG}) \times \mathrm{f}(\mathrm{CG}) \\
\mathrm{U} / \mathrm{U}^{*}= & \text { mean velocity divided by shear velocity } \\
\mathrm{d}= & \text { mean flow depth } \\
\mathrm{U}^{*}= & (\mathrm{gdS})^{1 / 2} \\
\mathrm{~F}_{\mathrm{r}}= & \text { Froude number } \\
\mathrm{REG}= & \text { Roughness Element Geometry } \\
\mathrm{CG}= & \text { Channel Geometry }
\end{array}
$$

$$
\begin{aligned}
& f(F r)=\left(\frac{0.28}{b} F r\right)^{\log \frac{0.755}{b}} \\
& f(R E G)=13.434\left(\frac{T}{D_{50}}\right)^{0.492} b^{1.025\left(\frac{T}{D_{50}}\right)^{0.118}} \\
& f(C G)=\left(\frac{T}{d}\right)^{-b}
\end{aligned}
$$




\section{$A_{3} / A_{z}$ for selected d/B Ratios}

\begin{tabular}{|c|c|c|c|c|c|}
\hline $\mathrm{d} / \mathbf{B}$ & $\mathrm{Z}=2$ & $Z=3$ & $Z=4$ & $\mathrm{Z}=5$ & $Z=6$ \\
\hline 0.1 & 1.083 & 1.900 & 0.928 & 0.866 & 0.812 \\
\hline 0.2 & 0.142 & & 0.888 & 0.800 & 0.727 \\
\hline 0.3 & 1.187 & & 0.853 & 0.760 & 0.678 \\
\hline 0.4 & 1.222 & & 0.846 & 0.733 & 0.647 \\
\hline 0.5 & 1.250 & & 0.833 & 0.714 & 0.625 \\
\hline 0.6 & 1.272 & & 0.823 & 0.700 & 0.608 \\
\hline 0.7 & 1.291 & & 0.815 & 0.688 & 0.596 \\
\hline 0.8 & 1.307 & & 0.809 & 0.680 & 0.586 \\
\hline 0.9 & 1.321 & & 0.804 & 0.672 & 0.587 \\
\hline 1.0 & 1.333 & & 0.800 & 0.666 & 0.571 \\
\hline 1.1 & 1.343 & & 0.796 & 0.661 & 0.565 \\
\hline 1.2 & 1.352 & & 0.793 & 0.657 & 0.561 \\
\hline 1.3 & 1.361 & & 0.790 & 0.653 & 0.556 \\
\hline 1.4 & 1.368 & & 0.787 & 0.650 & 0.553 \\
\hline 1.5 & 1.378 & & 0.785 & 0.647 & 0.550 \\
\hline 1.6 & 1.381 & & 0.783 & 0.644 & 0.547 \\
\hline 1.7 & 1.386 & & 0.782 & 0.642 & 0.544 \\
\hline 1.8 & 1.391 & & 0.780 & 0.640 & 0.542 \\
\hline 1.9 & 1.395 & $\downarrow$ & 0.779 & 0.638 & 0.540 \\
\hline 2.0 & 1.400 & 1.000 & 0.777 & 0.636 & 0.538 \\
\hline
\end{tabular}

Table 3-2: $\quad$ Values of $A_{3} / A_{Z}$ for selected $Z$ and $d / B$ ratios ${ }^{1}$

(Reprinted from Chen and Cotton, 1988)

${ }^{1}$ Based on the equation:

$$
\frac{A_{3}}{A_{2}}=\frac{1+3(d / B)}{1+Z(d / B)}
$$


RIPRAP MEAN DIAMETER. (tt)

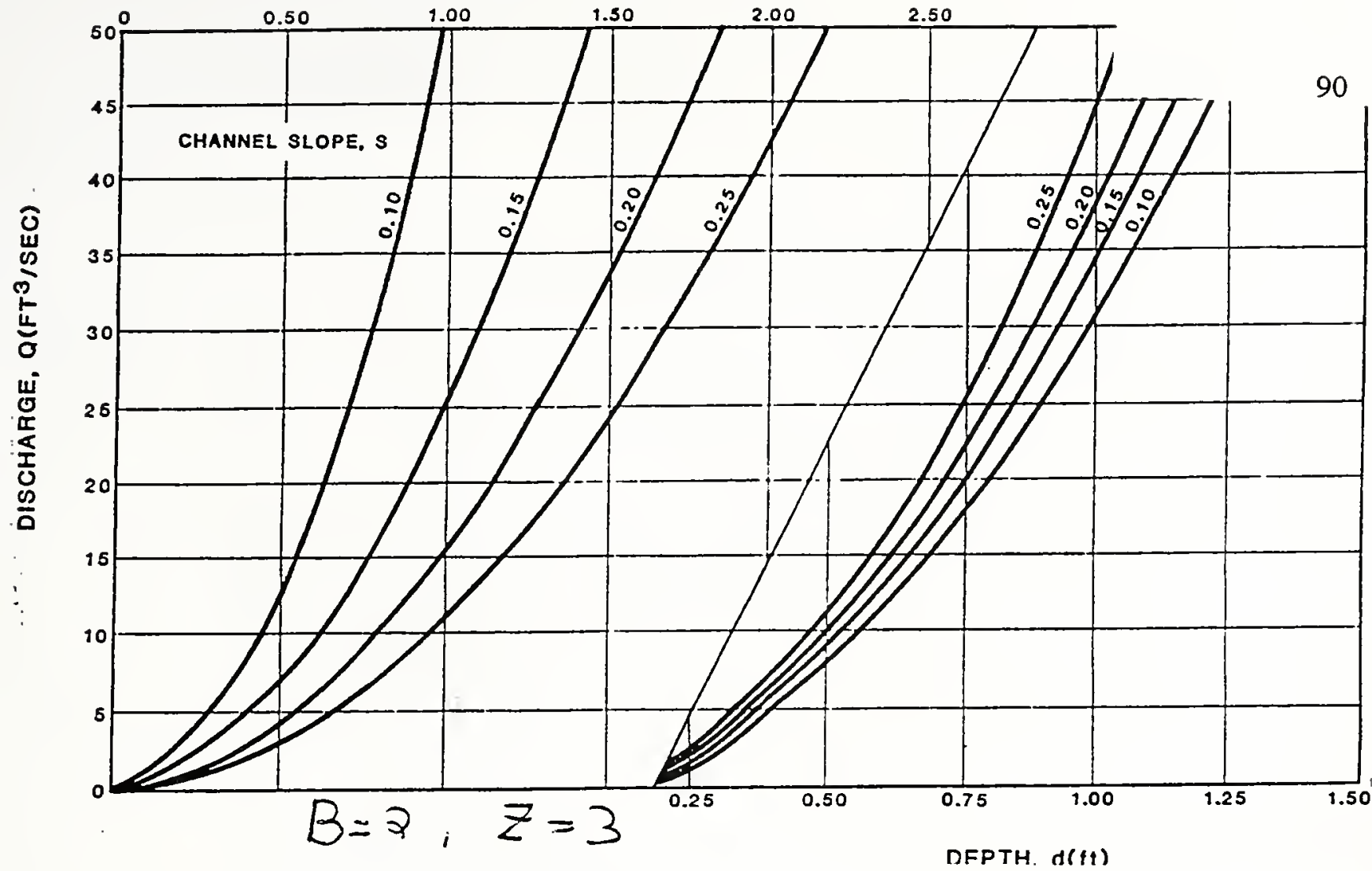

RIPRAP MEAN DIAMETER, $(t)$

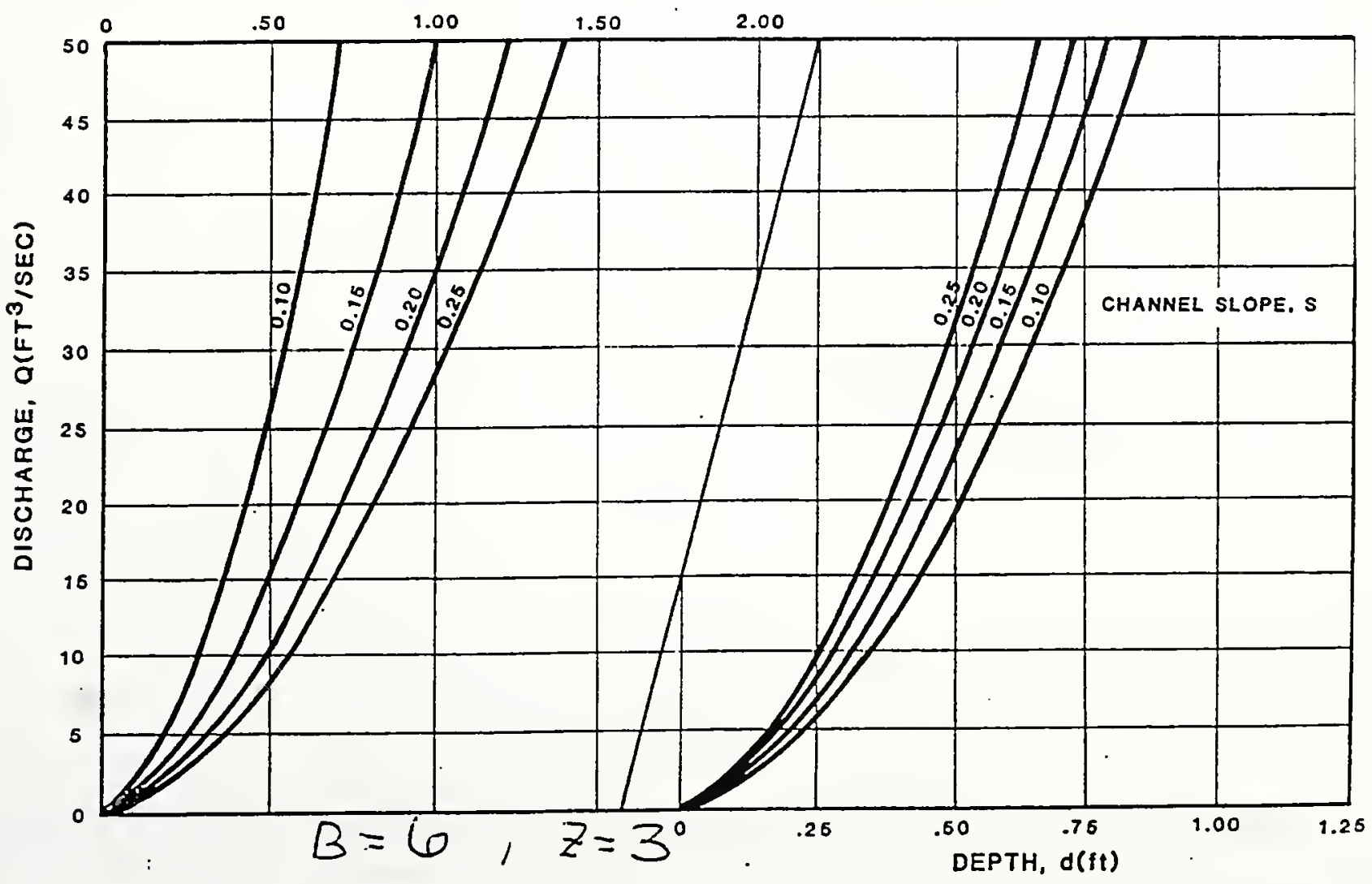

Figure 3-5: $\quad$ HEC-15 Design Aids for $\mathbf{b} \leq \mathbf{6}^{\text {' }}$ (Reprinted from HEC-15, 1988) 


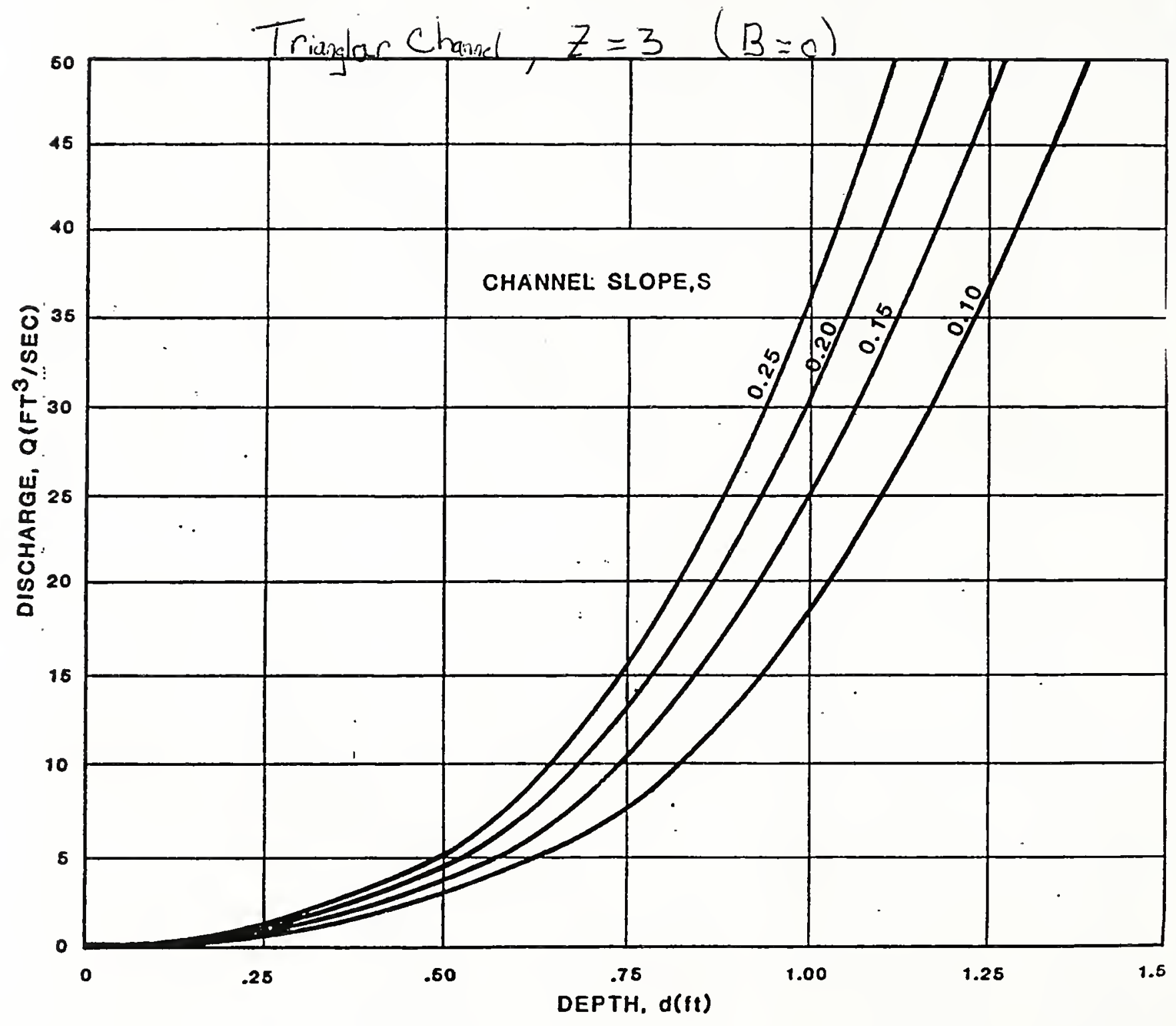

Figure 3-5 (cont'd): HEC-15 Design Aids for $\mathbf{b} \leq 6$ ' (Reprinted from HEC-15, 1988) 
$\mathrm{b}=\left[1.175\left(\frac{\mathrm{D}_{50}}{\mathrm{~T}}\right)^{0.557}\left(\frac{\mathrm{d}}{\mathrm{D}_{50}}\right)\right]^{0.648 \sigma^{-0.114}}$

$\sigma-0.182$ (for most standard riprap gradations)

$\mathrm{T}=$ channel top width

$\mathrm{D}_{\text {so }}=$ mean diameter of the stone

b $=$ parameter describing roughness concentration

(b). Simons \& Senturk Safety Factor equation

$$
\begin{aligned}
& \mathrm{SF}=\frac{\cos \theta \tan \phi}{\eta^{\prime} \tan \phi+\sin \theta \cos \beta} \\
& b=\tan ^{-1}\left[\frac{\cos \alpha}{\left(\frac{2 \sin \theta}{\eta \tan \phi}\right)+\sin \alpha}\right] \\
& \eta=\frac{\tau_{s}}{F^{*}\left(\gamma_{s} \gamma\right) D_{50}} \\
& \eta^{\prime}=\eta \frac{1+\sin (\alpha+\beta)}{2} \\
& \tau_{\mathrm{s}}=\mathrm{K}_{1} \tau_{0}=\mathrm{K}_{1} \gamma \mathrm{dS} \\
& \alpha \quad=\text { angle of the channel bed slope } \\
& \beta \quad=\text { angles between the vectors weight and drag } \\
& \phi \quad=\text { angle of the channel side slope } \\
& \theta \quad=\text { angle of repose for the riprap } \\
& \tau_{s} \quad=\text { side slope shear stress } \\
& \tau_{0}=\text { shear stress at channel bottom } \\
& \gamma \quad=\text { specific weight of water }
\end{aligned}
$$




$$
\begin{array}{ll}
\gamma^{*} & =\text { specific weight of rock } \\
\eta & =\text { stability number } \\
\eta^{\prime} & =\text { side slope stability number } \\
\mathrm{K}_{1} & =\text { ratio of side to bottom shear stress } \\
\mathbf{F}^{*} & =0.15=\text { dimensionless critical shear stress (see note below) }
\end{array}
$$

\section{Note on $F^{*}$}

In the derivation given by Simons and Senturk, $\mathrm{F}^{*}$ was 0.047 (this value comes straight from the Shields diagram (see figure 3-6). The equation for $\mathrm{F}^{*}$ is:

$$
\begin{aligned}
& \mathrm{F}^{*}=\frac{\tau_{c}}{\left(\gamma_{\mathrm{s}}-\gamma_{\mathrm{f}}\right) \mathrm{d}} \\
& \gamma_{\mathrm{s}} \quad=\text { specific weight of the stone } \\
& \gamma_{\mathrm{f}} \quad=\text { specific weight of the fluid (water) }
\end{aligned}
$$

However, recent studies have shown $\mathrm{F}^{*}$ to take on much larger values for large diameter riprap (Wang and Shen, 1983). For large particles, the drag coefficient drops abruptly for a Reynolds number between $10^{4}$ and $10^{5}$. Consequently, resistance to flow (the denominator of equation 3.30) decreases and $\mathrm{F}^{*}$ increases for Reynolds numbers between $10^{4}-10^{5}$. This is shown in the figure below (note that $\mathrm{K}^{*}$ on the vertical axis is the same as $\mathrm{F}^{*}$ ).

Note that before and after this transition phase, $\mathrm{F}^{*}$ is nearly constant. This result is similar to the constant $\mathrm{F}^{*}$ in the high Reynolds number region on the Shields diagram above. Wang and Shen conclude for large diameter riprap that (figure 3-7):

For $100<\mathrm{Re}<10^{5}, \mathrm{~F}^{*}=0.0625$

$$
\text { For } \operatorname{Re} \geq 10^{6}, \quad F^{*}=0.25
$$

Based on this work and the Reynolds numbers generally encountered in practice, HEC-15 sets $\mathrm{F}^{*}$ arbitrarily at 0.15 . It should be noted that no explanation is given for selecting an intermediate $\mathrm{F}^{*}$ value. 


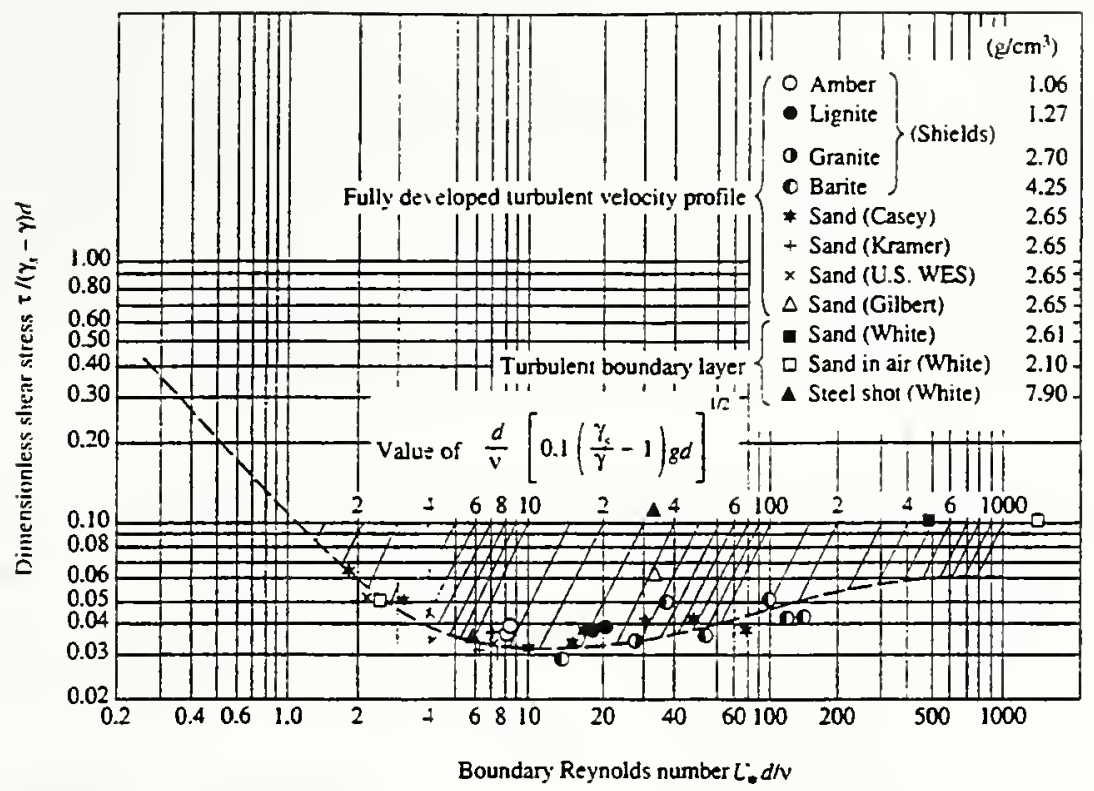

Figure 3-6: Shields Diagram of Incipient Motion (Reprinted from Shen, 1996)

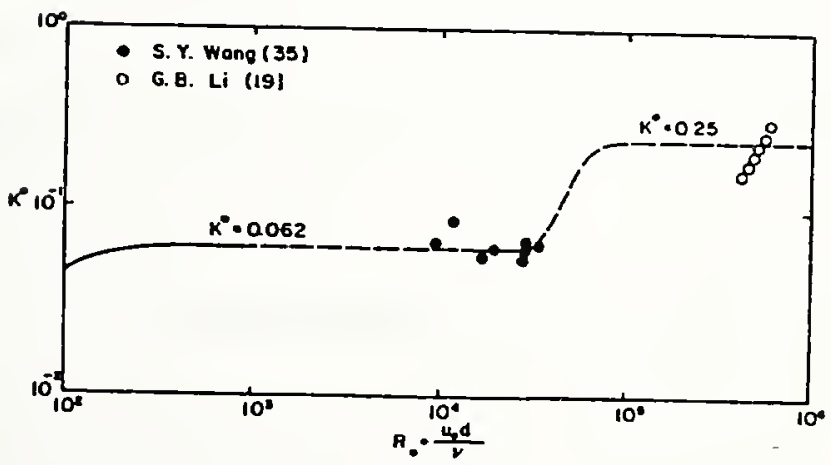

Figure 3-7: Shields Diagram for Large Diameter Riprap - Note $F^{*}=K^{*}$ in this plot (Reprinted from Wang \& Shen, 1983) 
1). The equation for Manning's $n$ gives low estimates of channel roughness. For a given discharge and slope, lower roughness coefficients give smaller flow depths which in turn indicate a $\mathrm{D}_{s 0}$ that is smaller than needed for erosion protection. Other methods for selecting a Manning's $n$ are discussed later in this chapter.

2). Flat and steep channels both require a time consuming trial and error process to find normal depth. Moreover, for steep channel design with $b>6$, the resistance and factor of safety equations are exceedingly complex. Although the equations account for many processes involved with riprap failure, many assumptions are required to calculate the median stone size (for example, assuming an $F^{*}$ ). Hence, the benefits of such an inclusive approach are severely lessened. A simpler approach may produce results that are just as acceptable.

3). There is some evidence that the permissible shear stress equation $\left(\tau_{\mathrm{p}}=4 \mathrm{D}_{50}\right)$ overestimates the allowable riprap shear stress. Blodgett (1986) superimposes this equation on a performance data from 39 field sites. 12 of the 31 sites on or below the line $\tau_{p}=4 D_{s 0}$ sustained some particle erosion (i.e. $39 \%$ of the investigated sites failed to some degree - figure 3-8). The data is limited to $D_{s 0}$ up to 24 " so a general conclusion can't be made; however, there is some question as to the validity of the HEC-15 equation. 


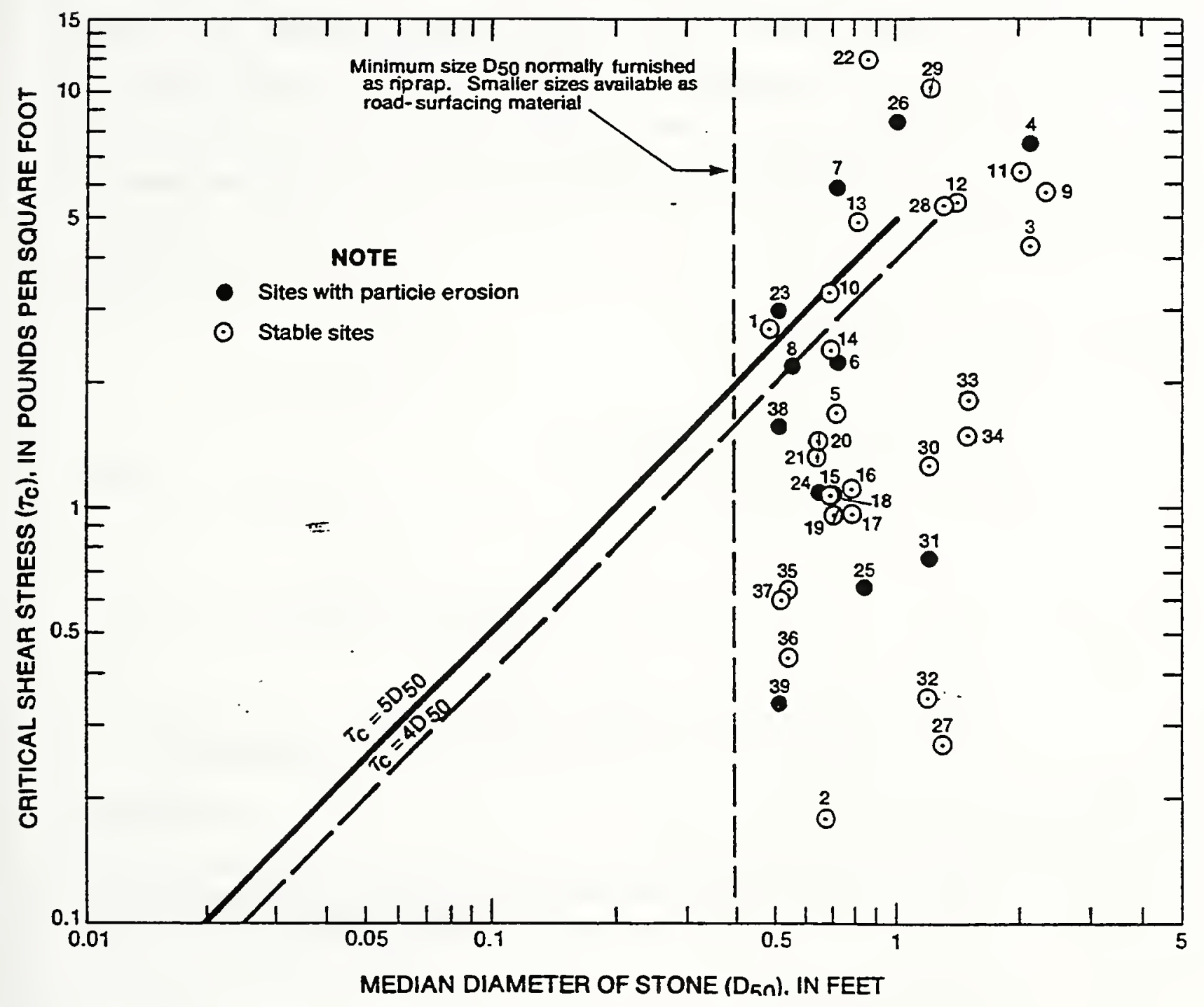

Figure 3-8: Comparison of $\mathbf{D}_{\text {so }}$ estimates based on shear stress from HEC-15 and field data (Reprinted from Blodgett, 1986) 


\subsubsection{California DOT "Bank and Shore Protection" Manual}

The California Department of Transportation (Cal-B\&SP, 1970) approach to riprap design is based on the analysis of wave action by wind or vessels. California DOT analyzed wave-theory and force-energy relationships necessary to dislodge a particle. The result was an equation relating velocity, specific gravity, and the angle of the side slopes to a minimum weight of the rock. Based on this weight, riprap layer characteristics are then specified (gradation and riprap layer thickness). A flow chart for this "Cal-B\&SP" procedure is given in figure 3-9. Terms in the equation are defined below.

Cal-B\&SP Equations for Riprap Design

(a). Minimum weight of stone

$$
W_{33}=\frac{0.00002 V^{6} G_{s} \csc ^{3}(\rho-\psi)}{\left(G_{s}-1\right)^{3}}
$$

$\mathrm{W}_{33}=$ Minimum weight of stone (lbs), $2 / 3$ of stone must be heavier

$\mathrm{V}=$ Stream velocity to which bank exposed $(\mathrm{ft} / \mathrm{s})$

Flow near bank in tangential reaches (straight channel): $\quad V=2 / 3 V_{\text {mean }}$

Flow impinging on the bank (curved channels)

$V=4 / 3 v_{\text {mean }}$

$\mathrm{G}_{\mathbf{s}} \quad=$ specific gravity of the stones

$\rho \quad=70^{\circ}$ for randomly placed rubble (maximum angle of slope before stone is dislodged from the channel bed - determined from experiments)

$\psi \quad=$ side slope (degrees)

Note: The velocity here is not the mean stream velocity. Cal-B\&SP requires an adjustment to reflect the actual velocity acting on the riprap. An assumption is made that velocity of flow near the bank is $2 / 3$ of the mean velocity for straight channels and $4 / 3$ of the mean velocity for bends in the channel. No details are given to support the use of these adjustment factors. 
(b). Thickness of the riprap layer

$$
\begin{array}{ll}
\mathrm{t}=1.5 \mathrm{~K} \sin \psi \sqrt[3]{\mathrm{W}_{\mathrm{c}}} \\
\mathrm{t} \quad=\text { thickness of riprap layer } \\
\mathrm{K} \quad=\text { shape factor of stone }=0.4 \text { (upper limit based on experiments) } \\
\psi \quad=\text { angle of side slope } \\
\mathrm{W}_{\mathrm{c}} \quad=\text { class weight of the stone determined from class/gradation table }
\end{array}
$$

Once the $W_{33}$ is calculated, the gradation is determined from a table (see section 3.4). It is very difficult to interpolate the size class for which $67 \%$ are larger from this table. Hence, it is often easier to convert the $W_{33}$ to $D_{33}$. Assuming an equivalent a spherical diameter, $D_{33}$ is:

$$
D_{33}=\left(\frac{6 W_{33}}{\pi \gamma_{s}}\right)^{1 / 3}
$$

(c). Combined equation (3.31 \& 3.33) for finding $\mathrm{D}_{33}$ based on $\mathrm{Cal}-\mathrm{B} \& \mathrm{SP}$

$$
D_{33}=\left[\frac{0.00012 V^{6} G_{s} \csc ^{3}(\rho-\varphi)}{\pi \gamma_{s}\left(G_{s}-1\right)^{3}}\right]^{1 / 3}
$$

Equation (3.34) is similar to the equation (3.5) of the HEC-11 procedure in that it relates stone size directly to velocity. If one considers $\gamma_{s}, \mathrm{G}_{\mathrm{s}}$, and $\psi$ constant (See Lambe and Whiteman, 1969), then we can rewrite equation (3.34). Assuming $G_{s}=2.65, \gamma_{s}=165 \mathrm{lb} / \mathrm{ft}^{3}, \psi=26.6^{\circ}(2: 1)$, $\mathrm{V}=2 / 3 \mathrm{~V}_{\mathrm{a}}$ (straight channel), we have:

$$
\mathrm{D}_{33}=0.0016 \mathrm{~V}^{2}
$$

Compare this equation to the HEC-11 equation with $\mathrm{F}_{\mathrm{r}}=0.95$ for the same conditions:

$$
\mathrm{D}_{50}=0.0018 \mathrm{~V}^{1.83}
$$

Notice that for a given average stream velocity, the Cal-B\&SP predicts larger stone sizes (i.e. the power to which $V_{2}$ is raised is larger for the Cal-B\&SP model). In other words, for the same velocity of flow, the Cal-B\&SP is more conservative than HEC-11.

This conclusion has been verified by Weng and Shen (1983) and Blodgett (1986). 
For impinging velocity use $4 / 3 V_{a}$; tangent velocity use $2 / 3 \mathrm{~V}_{\mathrm{a}}$.

Assume/determine mean channel velocity, side slope, and specific gravity of rock for design condition.

$$
w=\frac{0.00002 V^{6} G_{S} \csc ^{3}(\rho-\psi)}{\left(G_{s}-1\right)^{3}}
$$

(Minimum rock size equals $W_{33}$ of size distribution.)

or use nomograph.

Figure 3-9: $\quad$ Flow Chart for CAL-B\&SP Design Procedure 


\subsubsection{Army Corps of Engineers - EM-1601 (Maynord, 1992)}

This method utilizes a trial and error approach based on the Chezy equation. Once the depth of flow, velocity, and hydraulic radius are determined, one can either follow a permissible shear or permissible velocity solution. For simplicity, this section only deals with the permissible shear solution. Recently, USCOE has revised their design equations and these are presented here.

The design procedure requires an estimate of the proposed channel roughness (called $\mathrm{k}$ in the literature). This roughness is a measure of the linear dimension of the roughness factor, but is not necessarily equal to $D_{50}$. While EM-1601 states that designs are relatively insensitive to $k$, Blodgett shows that there is a strong dependence on $\mathrm{k}$ (Blodgett, 1986). However, in absence of other information, it is often assumed that $k \sim D_{s 0}$.

Using this estimate of the roughness, one calculates the velocity and hydraulic radius Next one calculates the tractive force for a straight reach and compares it to the permissible shear stress for the selected $D_{s 0}$. For unspecified reasons, irregularly shaped channels include a safety factor of 1.5 to account for flow turbulence, pressure variations, water surges. One iterates on median riprap size until the design shear is less than the permissible shear. Notice that changing $D_{50}$ changes the roughness, $k$. Hence, the entire process must be repeated with the new $D_{50}$.

Since this design method is quite complex, the Corps of Engineers has issued an updated design methodology (Maynord, 1988, 1991, 1992). This procedure no longer requires a trial and error process to determine median riprap size. Instead, an equation is derived from the above mentioned shear equations. The method relates the depth-averaged velocity plus a variety of correction factors directly to $D_{30}$. This design process is "limited to low turbulent flow" situations (all situation except those downstream of hydraulic structures - weir, damns) as well as depth to stone size ratios $\left(d / D_{50}\right)$ less than 50.

The equations and relevant constants for determining $D_{30}$ and $D_{50}$ are shown next. Notice that the velocity used in this procedure is the depth averaged velocity. EM-1601 uses a depthaveraged velocity at a point $20 \%$ upslope from the toe for riprap design. The equations for selecting a depth averaged velocity are include below as are the original design charts (figure 310) from Maynord's paper. 


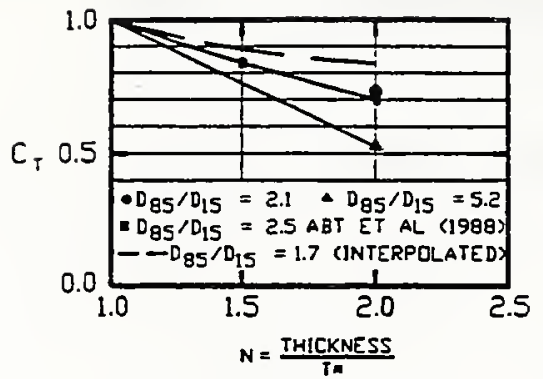

VHERE $C_{\mathrm{T}}=$ CORRECTION FOR THICKNESS

$$
\begin{aligned}
= & \frac{D_{30} \text { FER THICKNESS OF } N T=}{D_{30} \text { FOR THICKNESS OF TM }} \\
T \approx & =I_{10 D} \text { GR } 1.5 D_{50} \text {. WHICHEVER IS GREATER }
\end{aligned}
$$

FIGURE 1 Correction for riprap blanket thickness.
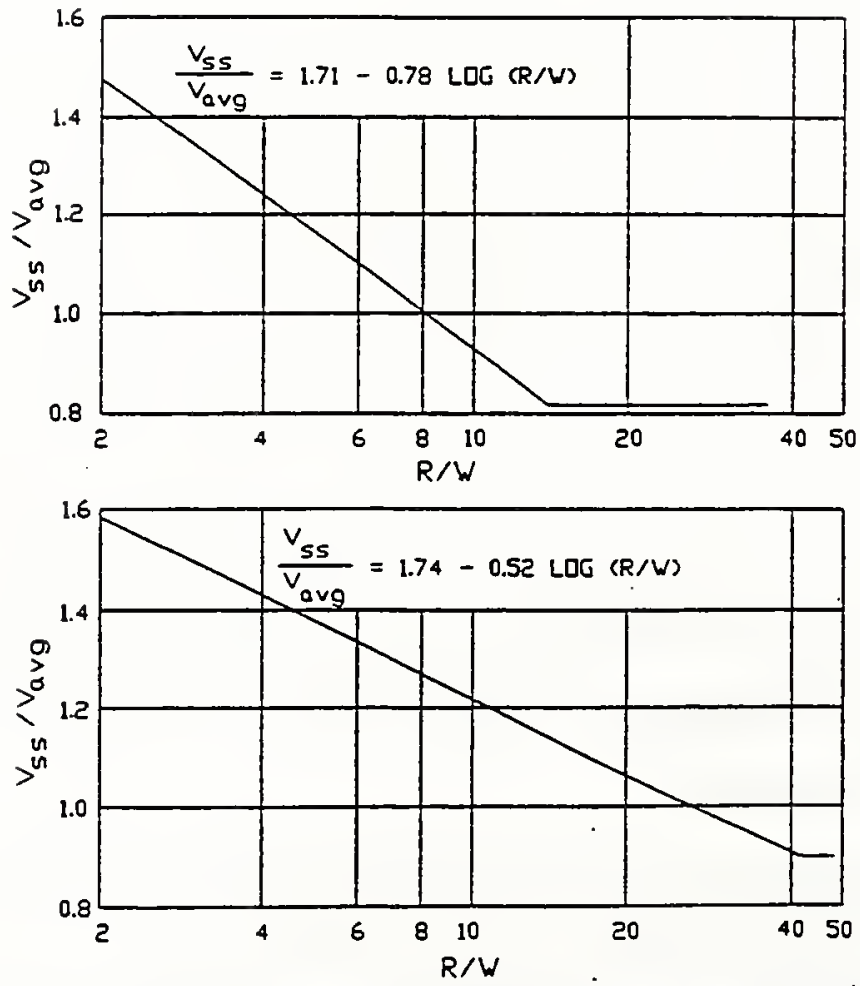

Figure 3-10: Design aids for USCOE riprap design procedures 
U.S. Army Corps of Engineers Riprap Design Equations

(a). $\mathrm{D}_{50}, \mathrm{D}_{30}, \mathrm{~V}$

$$
\begin{aligned}
& D_{50}=D_{30}\left(D_{85} / D_{15}\right)^{0.32} \\
& D_{30}=S_{f} C_{.} C_{V} C_{T} d\left[\left(\frac{\gamma_{w}}{\gamma_{S}-\gamma_{w}}\right)^{0.5} \frac{V}{\sqrt{K_{1} g d}}\right]^{2.5}
\end{aligned}
$$

$$
\frac{V_{\infty}}{V_{.}}=1.71-0.78 \log (R / W) \quad \text { (Trapezoidal channel) }
$$

$\frac{\mathrm{V}_{\mathrm{sg}}}{\mathrm{V}_{\mathrm{g}}}=1.74-0.52 \log (\mathrm{R} / \mathrm{W}) \quad$ (Natural channels)

$\mathrm{D}_{30} \quad=$ riprap size of which $30 \%$ finer by weight

$\mathrm{S}_{\mathrm{f}} \quad=$ safety factor (minimum 1.1)

$\mathrm{D}_{85} / \mathrm{D}_{15}=$ gradation uniformity coefficient

$\mathrm{R} \quad=$ radius of curvature of bend

$\mathrm{W}=$ water surface width immediately upstream of bend

$\mathrm{d} \quad=$ local depth of flow $=0.8 \mathrm{~d}_{\text {ave }}$

$\gamma_{w} \quad=$ unit weight of water

$\gamma_{s} \quad=$ unit weight of stone

$\mathrm{V} \quad=$ local depth averaged velocity

$\mathrm{K}_{1} \quad=$ side slope correction factor (defined in table below) coefficients are adjusted from equation defined in HEC-11 to be more conservative

Bank Angle Correction Factor - Modified from HEC-11 Criteria

\begin{tabular}{cc}
\hline Side Slope $(H: V)$ Ratio & $K_{1}$ \\
\hline $1: 1$ & 0.46 \\
$1.5: 1$ & 0.7 .1 \\
$2: 1$ & 0.88 \\
$3: 1$ & 0.98 \\
$4: 1$ or flatter & 1.00 \\
\hline
\end{tabular}

Table 3-3: Bank angle correction factor 


$$
\begin{aligned}
\mathrm{C}_{\mathrm{s}} & =\text { stability coefficient for incipient failure } \\
& =0.30 \text { for angular rock } \\
& =0.375 \text { for rounded rock } \\
\mathrm{C}_{\mathrm{v}} \quad & =\text { vertical velocity coefficient } \\
& =1.0 \text { for straight channels \& inside of bends } \\
& =1.283-0.2 \log (\mathrm{R} / \mathrm{W}) \\
& =1.25 \text { downstream of concrete channels or end of dikes } \\
\mathrm{C}_{\mathrm{T}} & =\text { blanket thickness factor } \\
& =1.0 \text { for thickness }=\mathrm{DD}_{100}
\end{aligned}
$$

Notes:

1). Since the velocity is often estimated conservatively and since one usually needs to select a gradation larger than computed $D_{30}$ (due to availability considerations), $S_{\mathrm{f}}$ is often set low. Larger safety factors are used if there are significant consequences of failure.

2). Slopes steeper than 1.5:1 are not recommended for riprap design

3). Figure 3-11 below sketches the point for local depth of flow

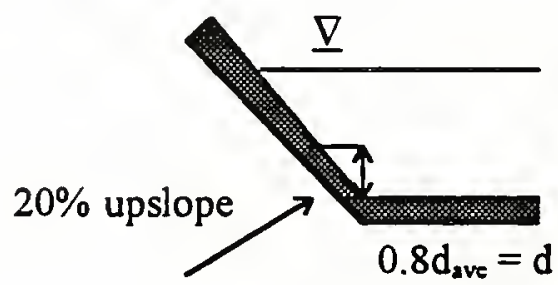

Figure 3-11: Location of $V_{s s}$ and definition of " $d$ " 


\subsubsection{Sedimentation Engineering, ASCE Manual \#54 (Man-54)}

This riprap design is based on studies of the Missouri River. The median rock size is based on flow velocity and the gradation is such that $D_{100}=1.5 D_{50}$. Although Man-54 gives the required stone as a function of $W_{50}$, it is converted to $D_{50}$ assuming spherical diameter riprap as was done with Cal-B\&SP. No flow chart is given because the design is straightforward. The relevant equations are presented below.

Design Equations for Man-54

(a). $\mathrm{W}_{50} \& \mathrm{D}_{50}$

$$
\begin{aligned}
& W_{s 0}=\frac{0.000041 G_{s} V^{6}}{\left(G_{s}-1\right)^{3} \cos ^{3} \theta} \\
& D_{s 0}=\left(\frac{6 W_{50}}{\pi \gamma_{s}}\right)^{1 / 3}=\left(\frac{0.000246 G_{s} V^{6}}{\pi \gamma_{s}\left(G_{s}-1\right)^{3} \cos ^{3} \theta}\right)^{1 / 3}
\end{aligned}
$$

For 2:1 side slopes $\left(\theta=26.6^{\circ}\right) \& G_{s}=2.65$ :

$$
\begin{array}{ll}
\mathrm{D}_{s 0}= & 0.00732 \mathrm{~V}^{2} \\
\mathrm{~W}_{s 0} & =\text { Median weight of the stone (lbs) } \\
\mathrm{V} & =\text { mean velocity in the channel } \\
\mathrm{G}_{s} & =\text { specific gravity } \\
\mathrm{D}_{s 0} & =\text { median spherical stone size } \\
\theta & =\text { angle of the side slope }
\end{array}
$$

(b). Thickness of the riprap layer

$$
\mathrm{T}=1.5 \mathrm{D}_{s_{0}}
$$

Problems with Man-54 Riprap Design Procedure

1). The flow velocity actually is the velocity $10 \mathrm{ft}$ from the bank. No information is provided to determine the velocity at this distance. Hence mean velocity is used.

2). The simplified equation for $D_{s 0}$ above gives stone sizes that are 3.5 times larger than similar riprap equations (i.e. HEC-11 and Cal-B\&SP).

3). No equations to account for the effects of channel curvature, highly turbulent flow, or side slope variations in velocity. 


\subsubsection{Sediment Transport Technology (Simons and Senturk, 1977)}

The procedure involves a set of 4 equations that describe the stability of riprap particle for a given set of hydraulic conditions. Equations describe the passive forces affecting particle stability and active fluid forces tending to rotate the particle out of position. Recall that these equations were also used in the HEC-15 procedure. A full explanation of all terms for the Simons-Senturk factor of safety equation are found under the HEC-15 design section. A flow chart illustrating the design procedure is given in figure 3-13. Applicable equations are shown for each of 4 different design situations:

- Bed protection for a horizontal channel

- Bed protection for a sloping channel

- Side slope protection for horizontal side slopes

- Side slope protection for non-horizontal side slopes

\section{Problems with Simons \& Senturk Riprap Design Procedure}

1). The development stems from a rigorous analysis of the forces acting on one particle (see figure 3-12). Several assumptions made in the analysis have been questioned. For example, the drag force is assumed to be twice the lift force on a particle; however, no basis is given for this assumption. Blodgett explores these shortcomings.

2). No corrections are given for curves, bends, or impinging flows.

3). Safety factor equations are presented in a confusing fashion. Moreover, no range of suitable safety factors are given in the model's development. Hence, an engineer does not know what safety factor would lead to an adequate $\mathrm{D}_{50}$ for the given situation. 


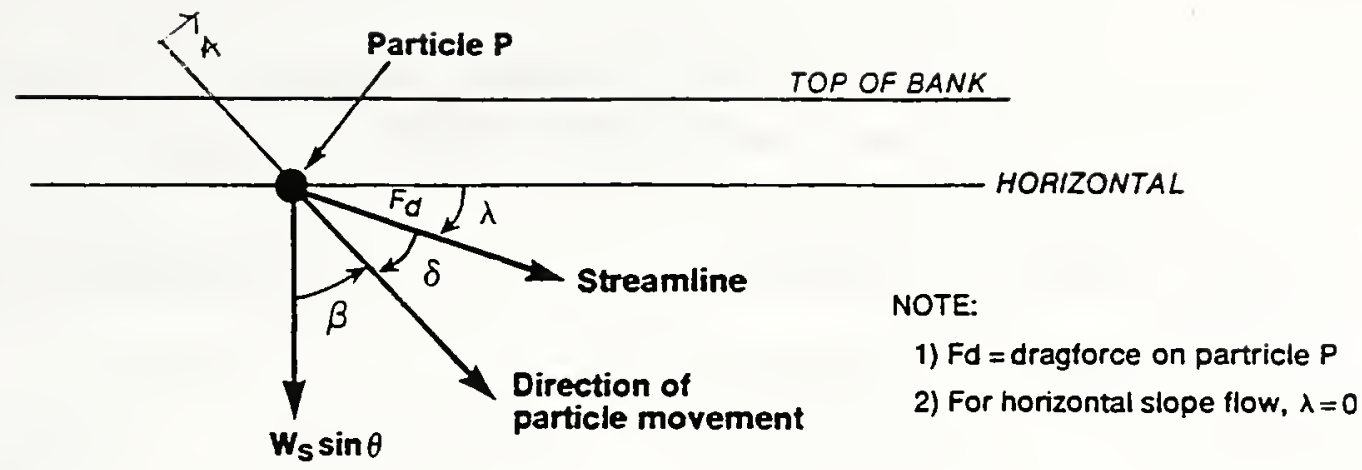

VIEW NORMAL TO SIDE SLOPE (FOR NONHORIZONTAL FLOW)

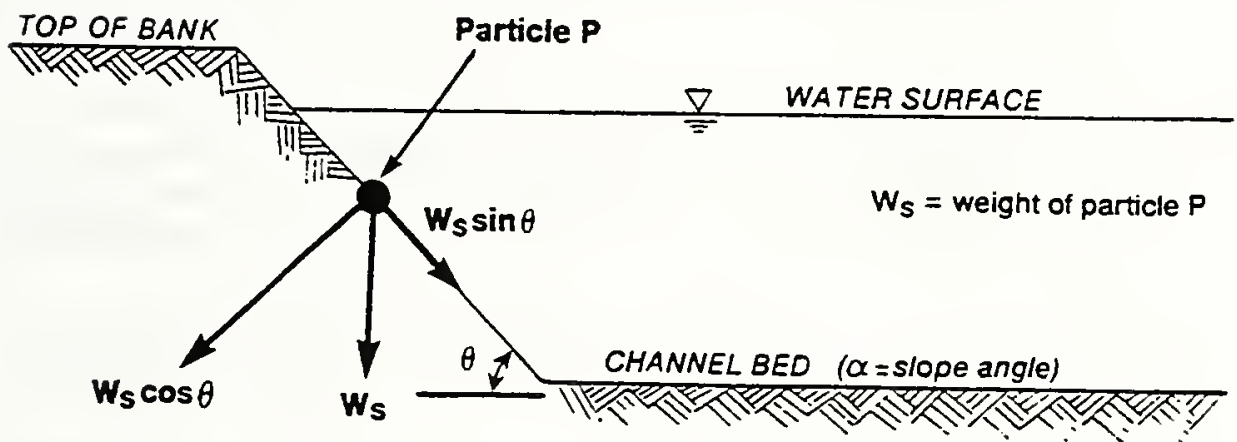

CHANNEL CROSS-SECTION

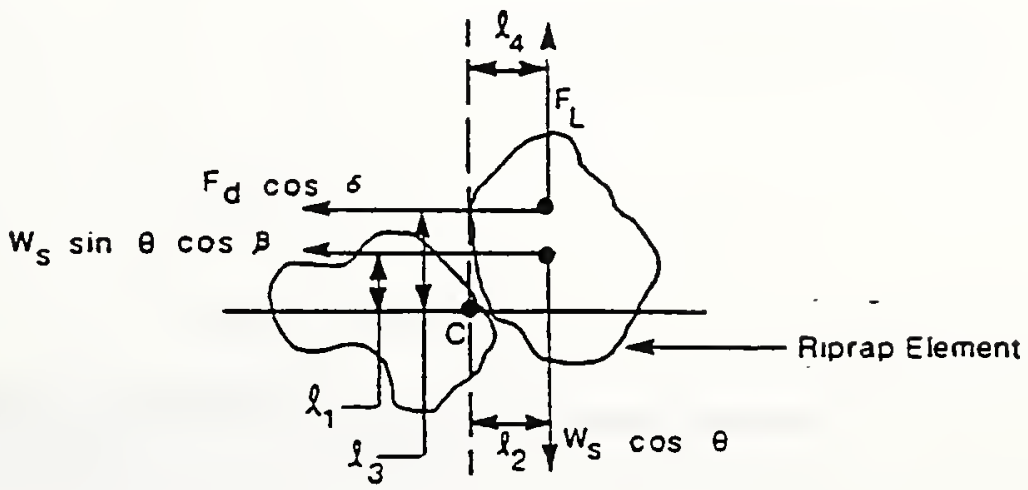

SECTION A-A

Figure 3-12: Forces acting on a riprap particle resting on the slide slope of a channel 


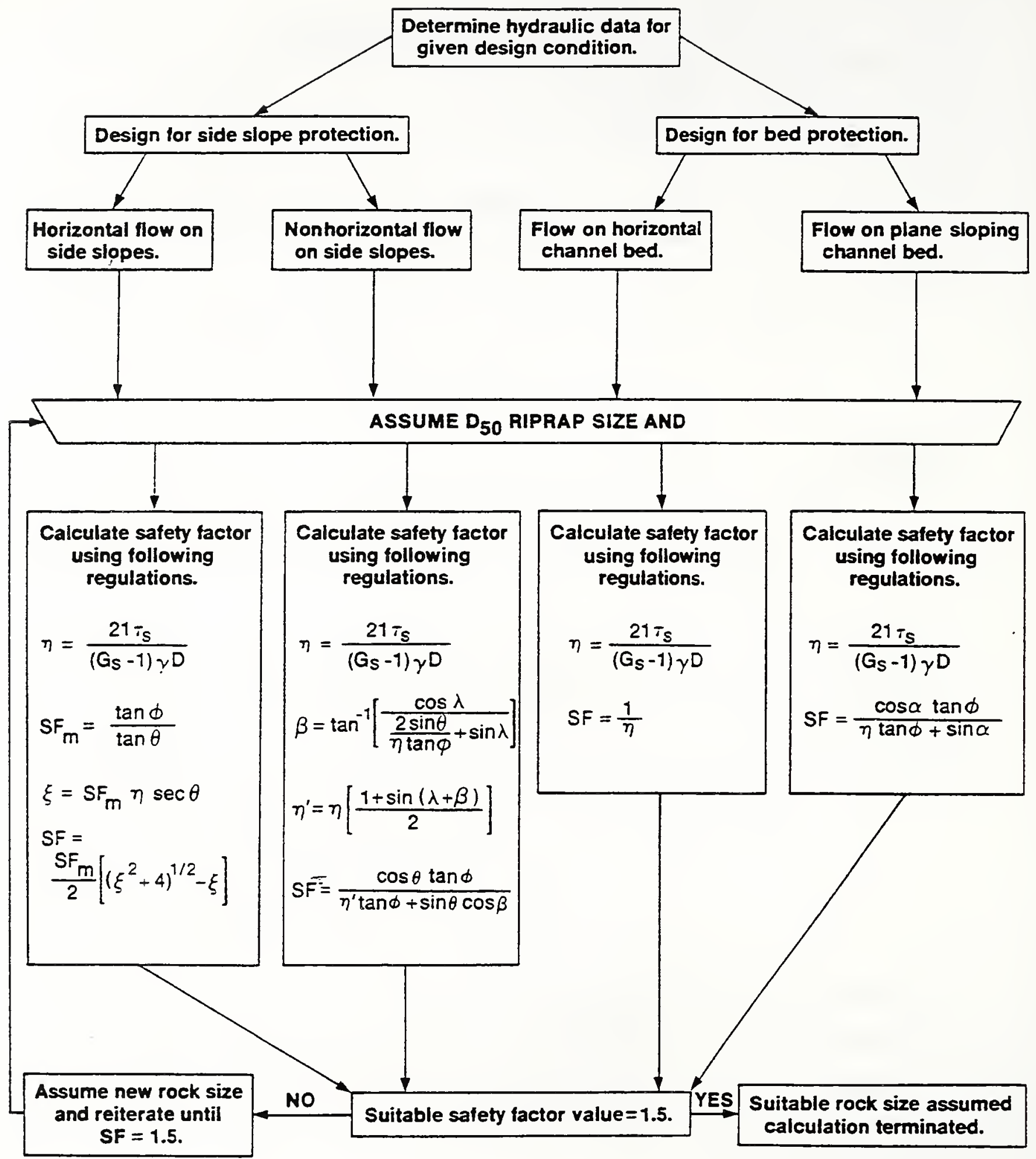

Figure 3-13: Flow chart and design equations for Simons \& Senturk protection procedure 


\subsubsection{U.S. Bureau of Reclamation Riprap Design Procedure (USBR, 1958)}

This design procedure uses published flume test data to develop a curve between stone size and bottom velocity. Initially, the curve was developed to determine the maximum stone size downstream of a stilling basin (Simons et al, 1977; Blodgett, 1986). From their tests, the USBR concluded that a well-graded riprap layer with $40 \%$ stone smaller than the required size was the most stable configuration.

The results are shown in figure 3-14a. These data points were taken downstream of an end sill where the flow is highly turbulent. Since the erosive potential of this flow is considered greater than that normally encountered in drainage channels, this data should be a good indication of the stone size required to resist erosion in highway ditches (Blodgett, 1986). Notice that stone size here is $D_{40}$ and not $D_{50}$. Given the bottom velocity (assumed here to be the mean velocity), one merely enters figure 3-14a and reads off the corresponding $D_{40}$.

In order to convert the curve to other methods presented in this section, Blodgett applies a logarithmic transformation to the data. Then, this equation is adjusted to $D_{50}$ according to the HEC-11 gradations. The resulting graph is shown as figure $3-14 \mathrm{~b}$ and the associated equations are reprinted for clarity as well.

\section{Equations for USBR Riprap Design Procedure}

(a). Logarithmic transformation of the data

$$
\mathrm{D}_{40}=0.0105 \mathrm{~V}^{2.06}
$$

(b). Adjusting the gradation to $\mathrm{D}_{50}$

$$
\begin{aligned}
& \mathrm{D}_{50}=1.16 \mathrm{D}_{40}=0.0122 \mathrm{~V}_{\mathrm{a}}^{2.06} \\
& \mathrm{D}_{50}=\text { median stone size } \\
& \mathrm{V}_{2} \quad=\text { average velocity in the channel }
\end{aligned}
$$

\section{Problems with the USBR Riprap Design Procedure}

1). No method is given for finding Manning's n, normal depth (d), or velocity (V).

It is assumed that normal is computed from a trial and error process. Methods of determining Manning's $\mathrm{n}$ will be discussed subsequently.

2). No adjustment for impinging flow or bends. 


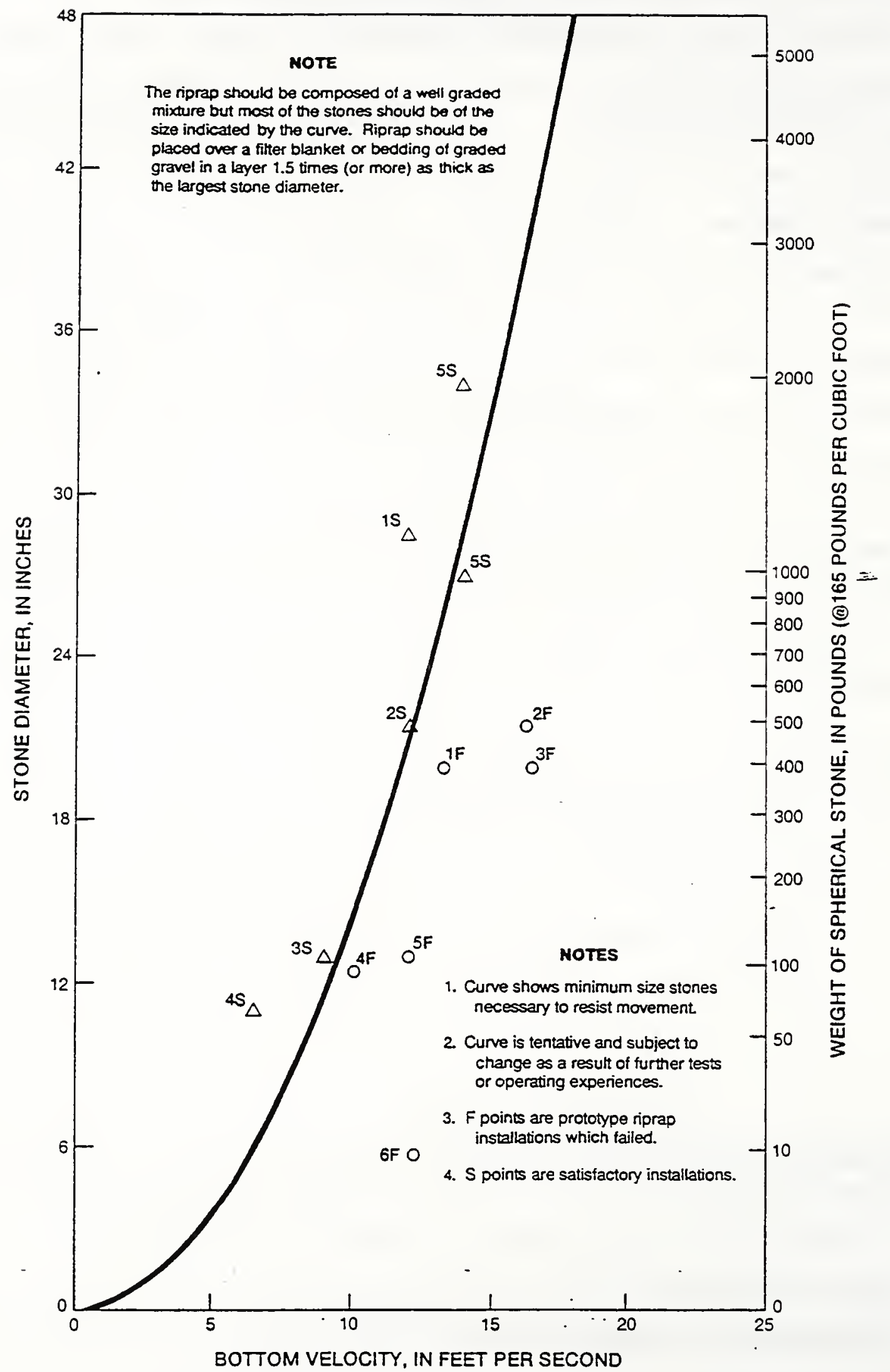




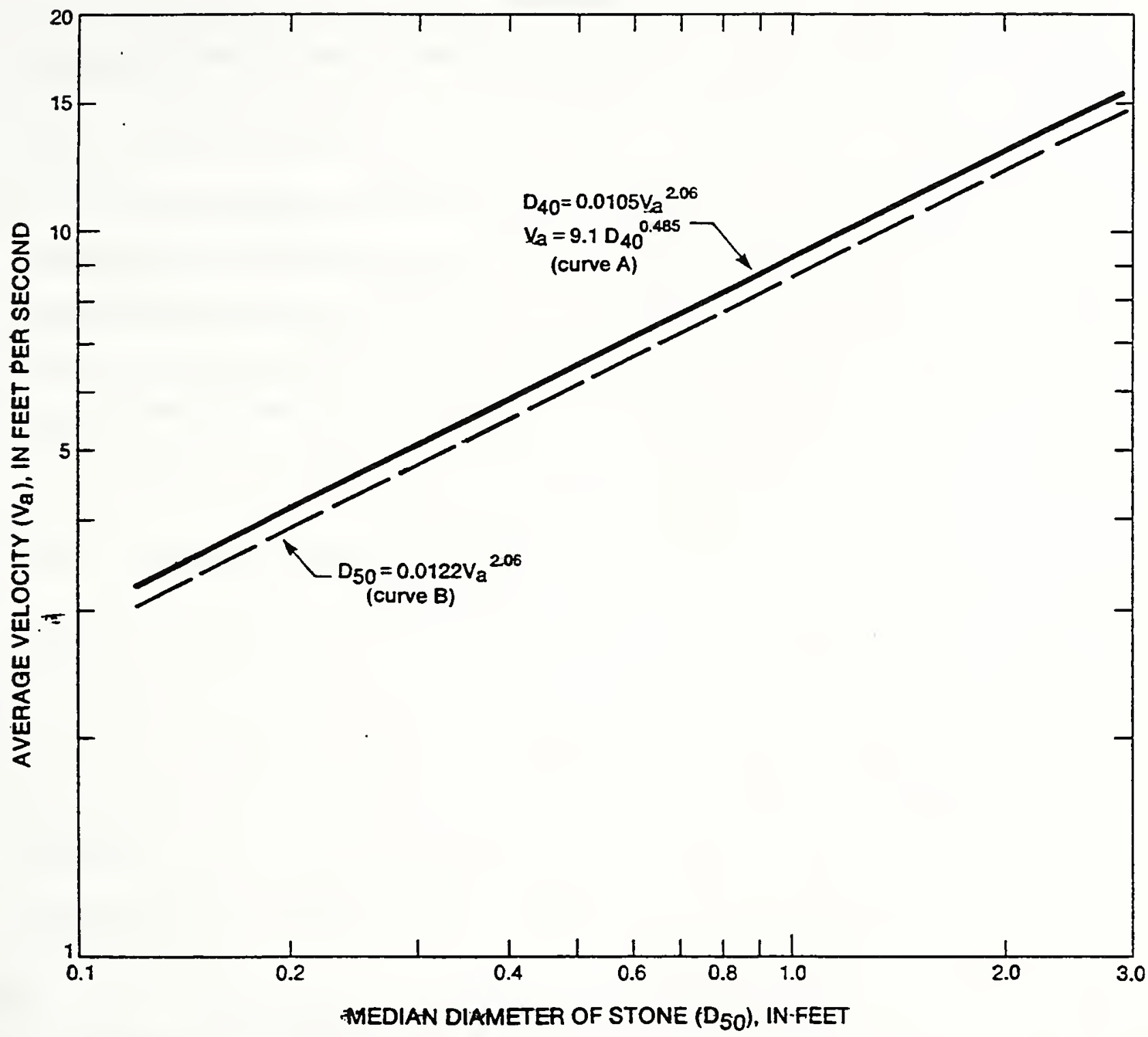

Figure 3-14b: Transformed USBR stone size curve $\left(\mathbf{D}_{50}\right)$ - Reprinted from Blodgett 


\subsubsection{Escarameia \& May Riprap Design Procedure (E\&M, 1995)}

Although existing riprap design methods often incorporate velocity and/or shear strength into their governing equations, these methods do not consider the effect of turbulence directly. These researchers state that turbulence ultimately causes failure of riprap. In their opinion, stones are subject to random fluctuations in lift and drag forces.

Following an experimental study on small diameter riprap, Escarameia and May propose an equation relating velocity to mean riprap diameter under high turbulence conditions. The equation is based on an estimate of bottom velocity from Rouse's formula (shown below) (1988). Hence, a trial and error process is required to size the riprap (note that the computing the mean velocity itself was an iterative process). A turbulence coefficient, $\mathrm{C}$, determines the level of the velocity fluctuations. The design procedure is basically a plug-and-chug process using the equations below; hence, no design flow chart is given.

Equations for Escarameia \& May Riprap Design Procedure

(a). Median stone size, velocity, turbulence coefficient $\&$ intensity equations

$$
\begin{aligned}
& D_{s 0}=C \frac{V_{b}^{2}}{2 g\left(G_{s}-1\right)} \\
& C=0.36 \quad T_{i} \leq 0.10 \\
& C=12.3 T_{i}-0.20 \quad 0.10 \leq T i \leq 0.30 \\
& T_{i}=V_{r m o s} / V_{b} \\
& V / V_{b}=0.68 \log \left(d / D_{s 0}\right)+0.71 \\
& D_{s 0} \quad=\text { median stone size } \\
& C \quad=\text { turbulence coefficient } \\
& V_{b} \quad=\text { near-bed velocity (point is above bottom at a height of } 10 \% \text { depth) } \\
& V_{\mathrm{rms}} \quad=\text { root mean square of velocity fluctuation about } V_{b} \\
& V \quad=\text { mean flow velocity } \\
& G_{s} \quad=\text { specific gravity of the riprap } \\
& T_{i} \quad=\text { turbulence intensity } \\
& d \quad=\text { depth of flow }
\end{aligned}
$$

Problems with the Escarameia and May Procedure

1). Need estimate of $V_{b}$ (function of $D_{50}$ ). This requires a lengthy iterative analysis.

2). No consideration of bends or impinging flow 


\subsubsection{Blodgett Riprap Design Procedure (Blodgett, 1986)}

Using riprap field data from 26 sites throughout Washington, Oregon, California, Nevada, and Arizona, Blodgett plotted median diameter against average channel velocity. Based upon the relative positions of the sites that worked and failed, a tentative regression relationship was fit to the data. The equation designs against particle erosion (see figure 3-15). The equation fit to the data is given below.

The main advantage of the Blodgett method is its simplicity. There are no charts to enter, safety factors to calculate, or difficult procedures to follow. Moreover, the relationship applies for all channels, curved or straight, with side slopes 1.5:1 or less. Median stone size is a function of $\mathrm{V}^{2.44}$ which is considerably larger than other relationships. Hence, the Blodgett method appears to be more conservative than Cal-B\&SP, Man-54, and HEC-11. The main disadvantage to this method is that extensive verification has not been done. Blodgett himself concedes this point; however, it does not detract from the potential his method has to become an accepted design procedure.

Notice that Blodgett based his design on velocity rather than shear. This is no accident. First, the energy slope $\left(S_{f}\right)$ must be well defined or else the shear stress equation ( $\tau=\gamma \mathrm{d} S$ ) may be greatly in error. Second, it is easier to estimate the design velocity rather than shear from a site survey or an analysis of hydraulic data (i.e. channel geometry and discharge). Lastly, a velocity approach is more intuitive for the designer. That is, most engineers have a better appreciation of permissible velocities than permissible shear strengths (Blodgett, 1986).

\section{Blodgett Equation for Riprap Design}

(a). $\mathrm{D}_{50}$

$$
\mathrm{D}_{s 0}=0.01 \mathrm{~V}^{2.44}
$$

$\mathrm{V}=$ mean velocity in the channel $-\mathrm{ft} / \mathrm{s}$ (from a trial and error solution to Manning's equation)

$\mathrm{D}_{s 0} \quad=$ mean riprap size $(\mathrm{ft})$ 
Problems with Blodgett Design Procedure

1). Limited data to support the equation. Only 39 sites went into developing the equation. Further verification is still required before the method is widely accepted.

2). No procedure is given for finding mean velocity. It is assumed that a trial and error process based on an estimate of $D_{50}$ is required to compute normal depth and velocity.

3). The method may be an oversimplification of a very complex process. There is no dependence on flow depth, specific gravity, side slope angle, and turbulence. Further, no mention of safety factor adjustments is made for severe flow situations.

4). No gradation guidelines or revetment thickness information is provided. It is assumed that the revetment must be equal to $2 \mathrm{D}_{50}$. 


\subsubsection{Probabilistic Approach to Riprap Design (Froehlich \& Benson, 1996)}

All of the previous riprap design procedures are based on the idea of a single critical velocity and/or shear stress. However, lift and drag fluctuations (noted by Escaramia and May) inevitably cause small degree of damage to a revetment after construction. Often such damage is acceptable and expected. Thus, these researchers believe that an allowable degree of damage provides a subjective criteria to size riprap revetments. The researchers quantify the damage from the probability distribution of loose particle critical shear stress.

The cumulative Weibull distribution estimates the fraction of particles of mean diameter, $D$, that are displaced by a given dimensionless shear stress, $\tau_{2 / c}$. This shear stress is itself a function of a scale parameter $(\eta)$, a shape parameter $(\beta)$, and the percentage of allowable displaced particles ( $\xi \%)$. In other words, $\tau_{2 / c}$ is a function of the cumulative number of particle displacements.

The design procedure is fairly complex and requires some detailed description (see steps listed below). To begin, one must have an estimate of the mean channel velocity from either a site investigation or a Manning's equation analysis. Note that a Manning's analysis is an iterative procedure requiring an estimate of the channel roughness (i.e. a $D_{50}$ must be assumed in most cases to enter a roughness equation). Using this mean velocity, the depth-averaged velocity $\left(V_{s}\right)$ is computed. Here, $V_{8}$ is defined using the Army Corps of Engineers criteria - the velocity corresponding to a depth $20 \%$ up the bank from the toe of the slope (i.e. $0.8 \mathrm{~d}_{\text {ave }}$ ). This velocity is then used to calculate the shear stress $\left(\tau_{s}\right)$ on the slope using the Manning-Strickler equation. Once $\tau_{s}$ is calculated, the method includes the following steps:

\section{Steps in the Froehlich and Benson Riprap Design Procedure}

1). Divide the mixture into at least 10 size classes. Each class ( $i$ ) must contain an equal percentage of riprap by weight. The size classes are characterized by a diameter $D_{i}$.

2). Calculate $\phi_{i s 0}, \eta, \beta$, and $K_{1}$ using the equations below

3). Calculate $\tau_{s} / K_{1}=\tau$ and dimensionless shear $\tau_{* c}$

4). Calculate $F\left(\tau_{*}\right)$ using the cumulative Weibull distribution - i.e. the fraction of particles displaced within each class of diameter $D_{i}$. Note, the author assumes that 
lower boundary of the shear stress $\left(\tau_{*_{\mathrm{cl}}}\right)$ is zero. Obviously, below this boundary, no displacement occurs.

5). Calculate $\Sigma F\left(\tau_{\bullet_{c}}\right)$; multiply this sum by the constant fraction of riprap in each size class. The result is the total fraction of dumped riprap particles by weight that is displaced with shear $\tau_{\mathrm{s}}$. If the predicted degree of damage is greater than allowable, then redo the entire procedure with a larger $\mathrm{D}_{50}$. If the predicted degree of damage is much less than allowable, then redo the entire procedure with a smaller $D_{50}$.

Equations for the Froehlich and Benson Riprap Design Procedure

(a). Calculate depth-averaged velocity, $\mathrm{V}_{\mathrm{s}}$

$$
\mathrm{V}_{\mathrm{s}}=\mathrm{V}\left[1.74-0.52 \log \left(\frac{\mathrm{R}_{\mathrm{b}}}{\mathrm{W}}\right)\right]
$$

$\mathrm{V}_{\mathrm{s}}=$ depth averaged velocity at $20 \%$ up from toe of the slope $(\mathrm{m} / \mathrm{s})$

$\mathbf{R}_{\mathrm{b}} \quad=$ channel bend radius ( $\mathrm{m}$ )

$\mathrm{W} \quad=$ water surface width $(\mathrm{m})$

(b). Calculate shear stress on side slope

$$
\tau_{\mathrm{s}}=\frac{\gamma}{\mathrm{k}_{\mathrm{a}}{ }^{2}}\left(\frac{\mathrm{D}_{\mathrm{s}}}{0.8 \mathrm{~d}}\right)^{1 / 3} \mathrm{~V}_{\mathrm{s}}{ }^{2}
$$

$\tau_{\mathrm{s}} \quad=$ side slope shear stress $(\mathrm{Pa})$

$\gamma \quad=$ unit weight of water

$\mathrm{D}_{s 0} \quad=$ assumed median stone size (m)

$\mathrm{k}_{\mathrm{n}} \quad=21.1$ for metric units

(c). Equations of $\phi_{i s 0}, \eta, \beta$, and $\mathrm{K}_{1}$

$$
\begin{aligned}
& \phi_{i 50}=35.0+46.5\left(\frac{D_{50}}{D_{i}}\right) \sigma_{8}^{-0.63} \\
& \eta=0.0561+\exp \left(1.73-2.68 \frac{D_{i}}{D_{50}}-0.177 \sigma_{g}\right) \\
& \beta=1.59+0.161 \frac{D_{i}}{D_{50}}-0.208 \sigma_{g}
\end{aligned}
$$


$K_{1}(i)=\sqrt{1-\frac{\sin ^{2} \theta}{\sin ^{2} \phi_{i s 0}}}$

$\phi_{i s 0}=$ median angle of initial yield (basically, the angle of repose)

$\sigma_{\mathrm{g}} \quad=$ geometric standard deviation of the riprap sizes

$=1.5$ for most well graded riprap mixtures (from Blodgett, 1986)

$\sim\left(D_{85} / D_{15}\right)^{1 / 2}$ for most gradations

$\mathrm{D}_{i} \quad=$ median diameter for class size $i$

$\mathrm{D}_{50} \quad=$ median riprap diameter for entire mixture

$\eta \quad=$ scale parameter related to particle size

$\beta \quad=$ shape parameter related to particle size

$\mathrm{K}_{1}(i)=$ correction factor for channel side slopes for class $i$

$\theta \quad=$ angle of side slopes

(d). Dimensionless shear, $\tau_{\circ}$

$$
\begin{aligned}
& \tau_{* c}(i)=\frac{\tau_{i}}{\left(G_{a}-1\right) \gamma D_{i}} \\
& \tau_{i}=\tau_{\mathrm{g}} / K_{1}(I)
\end{aligned}
$$

(e). Calculate $\mathrm{F}\left(\tau_{*_{c}}\right)$, fraction of particles within each size class $i$ that move

$$
F\left(\tau_{* c}\right)=1-\exp \left[-\left(\frac{\tau_{*_{c}}}{\eta}\right)^{\beta}\right]
$$

$\mathrm{F}\left(\tau_{*}\right)=$ fraction of particles displaced in each size class $i$

$\tau_{* c}=$ dimensionless shear acting on each class size $i$

(f). Sum of all $F\left(\tau_{*_{c}}\right)$ and total percent of displaced riprap

$$
\%_{\text {_displaced }}=\mathrm{p} \sum_{\mathbf{i}} \mathrm{F}\left(\tau_{*_{c}}\right)
$$

$\mathrm{p} \quad=$ fraction of mixture in each class size

note: if the predicted "\%_displaced" is larger than allowed, then increase

$D_{50}$ and repeat the entire process 
Selecting the an allowable "damage" level

The allowable degree of damage is based upon the consequences of failure for a given project. Four classes of damage are defined that correspond reasonably well to the observations of Blodgett (1986). The percentage displacement associated with each damage class is as follows:

$\begin{array}{lll}- & \text { Insignificant damage } & \leq 1 \% \\ \text { - } & \text { Minor damage } & 1-3 \% \\ \text { - } & \text { Moderate damage } & 3-7 \% \\ & \text { Severe damage } & >7 \%\end{array}$

According to the authors, damage becomes noticeable when more than $3 \%$ of the particles are displaced. These observations lead to the following design criteria for revetments:

- $\quad$ if minor damage is allowed, design the revetment for $2 \%$ displacement

- if only insignificant damage is allowed, design the revetment for $1 \%$ displacement

In order to facilitate design, the authors present two dimensionless shear versus percentage displaced riprap graphs. These are shown on the following page. Figures 3-16 a \& $b$ help refine the answer before finishing the iteration. For minor damage and typical $\sigma_{g}, \tau_{*}$ ranges from 0.014 to 0.028 . Hence, if calculated $\tau_{* c}$ is larger than 0.028 , one can terminate the iteration and revise $D_{s 0}$ without further calculation (i.e. increase $D_{s 0}$ to make $\tau_{*_{c}}$ less than 0.028 ). Figure $3-16 \mathrm{~b}$ works in similar fashion using the bank angle, $\theta$.

\section{Problems with Froehlich and Benson Approach}

1). There is some discrepancy between the predicted damage and the observed damage using the Blodgett data. For example, only 6 of the 18 sites where minor damage was predicted sustained any noticeable damage. This is not a deficiency in the method; rather, it shows that for low damage areas, this approach tends to be conservative.

2). The method requires defining 10 or more class sizes. However, no method is given for selecting these class sizes. 
3). No mention is made of how to determine the mean flow velocity in the channel. A trial and error approach using Manning's equation is assumed. Moreover, no method is given for determining Manning's $\boldsymbol{n}$.

4). The method is quite time consuming. A computer program may be necessary. Moreover, a designer must be knowledgeable in basic probability in order to understand the computation method. 


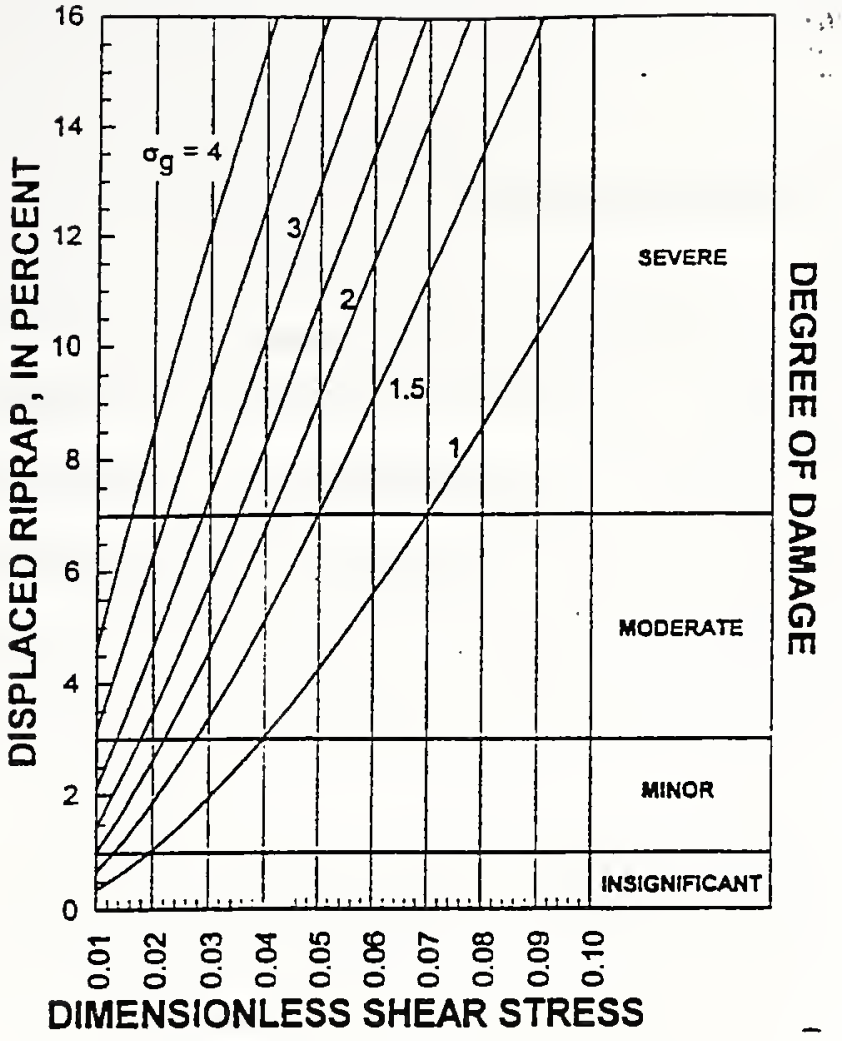

Figure 3-16a: Displaced riprap as a function of median dimensionless shear stress and $\sigma$

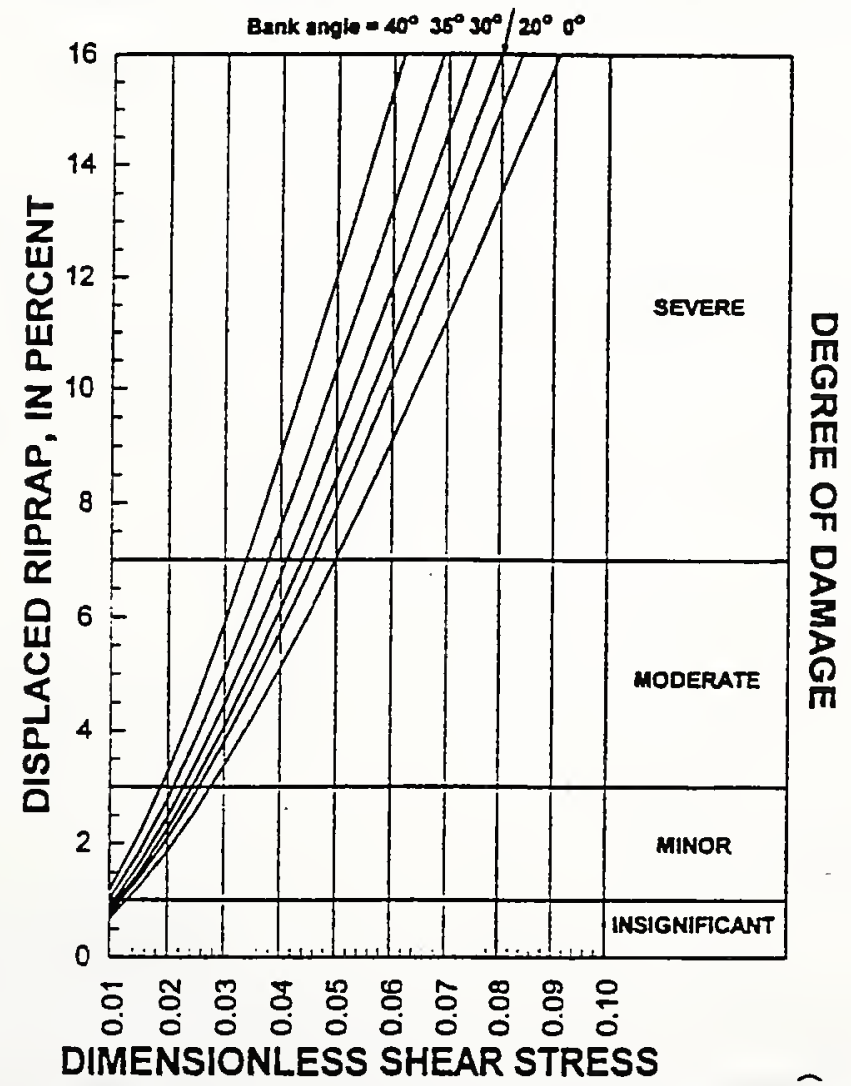

Figure 3-16b: Displaced riprap as a function of median dimensionless shear stress and bank slope angle $(\sigma=1.5)$ 


\subsubsection{Summary of Riprap Design Procedures}

In order to get a feel for the range of $D_{50}$ 's predicted by the various methods, a hypothetical example is given. For simplicity, only straight channel flow is considered with average flow velocities of $5,10,15 \mathrm{ft} / \mathrm{s}$, respectively. Other reasonable assumptions made include: $\mathrm{G}_{\mathrm{s}}=2.65, \gamma_{\mathrm{s}}=165 \mathrm{lb} / \mathrm{ft}^{3}, 2 \mathrm{H}: 1 \mathrm{~V}$ side slopes, fully turbulent flow, $\mathrm{n}=0.040, \mathrm{~d}=3 \mathrm{ft}$. Table 3-4 below gives the equation, $D_{50}$, and relevant comments for each procedure based on these assumptions. Note: no results are reported for those methods that are not based on velocity.

\section{Riprap $\mathbf{D}_{\mathbf{5 0}}$ Design Equations and Results}

\begin{tabular}{|c|c|c|c|c|c|}
\hline \multirow[t]{2}{*}{ Agency / Author } & \multirow[t]{2}{*}{ Equation for $D_{50}$} & \multicolumn{3}{|c|}{$D_{\mathbf{s 0}}(f t) ; V=(f t / s)$} & \multirow[t]{2}{*}{ Comments } \\
\hline & & 5 & 10 & 15 & \\
\hline HEC-11 & $D_{s 0}=0.0018 V^{1.83}$ & $<.1$ & 0.1 & 0.25 & \\
\hline HEC-15 & $\mathrm{D}_{50}=1.24 \mathrm{D}_{50 \mathrm{i}}$ & & & & $\mathrm{A}_{3} / \mathrm{A}_{2}=1.24$ \\
\hline California DOT & $\mathrm{D}_{50}=0.0021 \mathrm{~V}^{2}$ & $<.1$ & 0.2 & 0.47 & $\begin{array}{l}\mathrm{D}_{50}=1.32 \mathrm{D}_{33} \text { (using HEC- } \\
11 \text { gradation info) }\end{array}$ \\
\hline $\begin{array}{l}\text { U.S. Army Corps of } \\
\text { Engineers }\end{array}$ & $D_{s 0}=0.0035 V^{2.5}$ & 0.20 & 1.1 & 3.05 & $\begin{array}{l}\mathrm{D}_{50}=1.30 \mathrm{D}_{30}, \quad \mathrm{~K}_{1}=0.717 \\
\mathrm{C}_{\mathrm{l}}=1, \\
\mathrm{~S}_{\mathrm{f}}=1.1, \mathrm{C}_{\mathrm{V}}=1, \mathrm{C}_{\mathrm{B}}=0.3\end{array}$ \\
\hline $\begin{array}{l}\text { American Society of } \\
\text { Civil Engineers }\end{array}$ & $\mathrm{D}_{s 0}=0.0073 \mathrm{~V}^{2}$ & 0.20 & 0.73 & 1.64 & \\
\hline Blodgett & $D_{50}=0.010 V^{244}$ & $<.51$ & 2.8 & 7.41 & \\
\hline Escarameia \& May & $D_{s 0}=0.0041 \mathrm{~V}^{2}$ & 0.1 & 0.41 & 0.92 & $\mathrm{~V}_{\mathrm{b}}=1.1 \mathrm{~V} ; \mathrm{d} / \mathrm{D}_{50} \sim 3-6$ \\
\hline Froehlich \& Benson & $\begin{array}{l}D_{s 0} \text { can't be given } \\
\text { as } \Im\left(V^{n}\right)\end{array}$ & & & & \\
\hline Simons \& Senturk & $D_{50}=0.20 \tau_{s} / \eta$ & 0.6 & & & $\begin{array}{l}\tau_{3}=1.9 \mathrm{psf} ; \eta \sim 0.65 \\
R \sim d=3 \mathrm{ft}\end{array}$ \\
\hline $\begin{array}{l}\text { U.S. Bureau of } \\
\text { Reclamation }\end{array}$ & $D_{50}=0.0122 V^{2.06}$ & 0.34 & 1.40 & 3.23 & \\
\hline
\end{tabular}


It is obvious that there is wide range of resulting $D_{50}$ 's for this simple example. The USBR and USCOE methods seem to produce the most conservative results.

Some methods are relatively simple (Blodgett, Escarameia and May, Cal-B\&SP), while others are quite rigorous (Simons / Senturk, and Froehlich / Benson). The latter design procedures require hydraulic factors that are difficult to estimate. (depth-averaged or near-bed velocity, velocity $10 \mathrm{ft}$ from the bank, impinging vs. straight flow, determining safety factors, etc...). Given the limited data these values are derived from, further adjustments for bends, specific gravity, side slope angle, and turbulence may be unwarranted. In this light, a simple approach seems more appropriate.

The most appropriate design method will depend on the availability of hydrologic data and the experience of the engineer. Blodgett (1986) covers this subject in further detail. 


\subsection{Selecting Manning's $n$}

Nearly all of the previous designs requires an estimate of channel roughness. Often, $D_{50}$ is used to calculate Manning's $n$ (HEC-11, Cal-B\&SP, HEC-15, USBR, etc..). Unfortunately, most procedures do not provide an equation for Manning's $n$. The following paragraphs provide some insight in selecting an appropriate Manning's $\boldsymbol{n}$.

One of the most common equations for determining Manning's $n$ was proposed by Strickler and modified by Anderson (1970).

$$
\mathrm{n}=0.0395\left(\mathrm{D}_{50}\right)^{1 / 6}
$$

This equation is used in HEC-11, HEC-15, and the U.S. Corps of Engineers' design procedures. Another common method of finding Manning's $n$ is given by Limerinos (1970). It is based on a study of 11 sites on California streams. The equation relates a relative roughness $\left(n / R^{1 / 6}\right)$ to the relative particle size and hydraulic radius of a channel:

$$
\begin{array}{ll}
\frac{\mathrm{n}}{\mathrm{R}^{1 / 6}}= & \frac{0.0926}{\mathrm{a}+\mathrm{b} \log (\mathrm{R} / \mathrm{D})} \\
\mathrm{R} & =\text { hydraulic radius } \\
\mathrm{D} & =\text { selected percentile size of riprap } \\
\mathrm{a}, \mathrm{b} & =\text { constants dependent on percentile of riprap size }
\end{array}
$$

This equation can be rearranged assuming $R \sim d_{a}$ (depth of flow) to give:

$$
\mathrm{n}=\frac{0.0926 \mathrm{~d}_{\mathrm{a}}^{0.167}}{0.35+2.0 \log \left(\mathrm{d}_{\mathrm{a}} / \mathrm{D}_{50}\right)}
$$

Blodgett provides a similar equation from a regression analysis on 142 Manning's $n$ measurements. In this equation, the constants ( $\mathrm{a} \& \mathrm{~b}$ ) change slightly.

$$
\mathrm{n}=\frac{0.0926 \mathrm{~d}_{\mathrm{a}}^{0.167}}{0.79+1.85 \log \left(\mathrm{d}_{\mathrm{s}} / \mathrm{D}_{50}\right)} \quad 1.5<\mathrm{d}_{\mathrm{z}} / \mathrm{D}_{50}<185
$$


It is common practice to define a roughness factor $\left(\mathrm{ng}^{1 / 2} / \mathrm{d}_{3}{ }^{1 / 6}\right)$ to compare various Manning's $n$ equations. Blodgett presents such a graph (figure 3-17). For typical side ditch channels, the range of interest is $1<\mathrm{d} / \mathrm{D}_{50}<200$ (i.e. the left side of the graph). On this graph, the equation above is curve C. Notice that the suggested Manning's $n$ equation for HEC-15 falls below curve C. This implies that the HEC-15 equation tends to underestimate $n$. This in turn gives flow depths less than actually occurs. 
In some cases, a conservative estimate of Manning's $n$ is required. Based on the data shown in figure 3-17, Blodgett develops an enveloping curve for the worst case scenarios (low depth / high velocity flow). This is given as curve $A$. The equation of this curve is:

$$
\mathrm{n}=\frac{0.211 \mathrm{D}_{50}^{0.5}}{\mathrm{~d}_{\mathrm{a}}^{0.333}} \quad 1.5<\mathrm{d}_{2} / \mathrm{D}_{50}<35
$$

The graph gives other equations in terms of the roughness factor $\left(\mathrm{ng}^{1 / 2} / \mathrm{d}^{1 / 6}\right)$. In general, those curves are only applicable to sand beds and hence do not have application to riprap design.

Jarrett (1984) presents still another approach to finding Manning's $n$. His equation relates roughness to the hydraulic radius and the friction slope. It is valid for $D_{50}$ larger than $0.2 \mathrm{ft}$ and is only recommended for $\mathrm{d}_{\mathbf{2}} / \mathrm{D}_{50}<35$.

$$
\begin{aligned}
& \mathrm{n}=0.395 \mathrm{~S}_{\mathrm{f}}^{0.38} \mathrm{R}^{-0.16} \sim 0.395 \mathrm{~S}_{\mathrm{w}}^{0.38} \mathrm{~d}_{\mathrm{a}}^{-0.16} \mathrm{~d}_{\mathrm{a}} / \mathrm{D}_{50}<35 \\
& \mathrm{~S}_{\mathrm{f}} \quad=\text { friction slope } \\
& \mathrm{S}_{\mathrm{w}} \quad=\text { water-surface slope }
\end{aligned}
$$

\begin{tabular}{|c|c|c|c|c|c|c|}
\hline Channel & $\begin{array}{l}D_{50} \\
\text { (ft) }\end{array}$ & $\begin{array}{c}\text { HEC-15 } \\
\text { Eqn. 3-61 } \\
\end{array}$ & $\begin{array}{c}\text { Limerinos } \\
\text { Egn. 3-63 }\end{array}$ & $\begin{array}{c}\text { Blodgett } \\
\text { Eqn. 3-64 }\end{array}$ & $\begin{array}{l}\text { Envelope } \\
\text { Egn 3-65 }\end{array}$ & $\begin{array}{c}\text { Jarret } \\
\text { Egn. 3-66 }\end{array}$ \\
\hline 1 & 0.5 & 0.035 & 0.067 & 0.043 & 0.118 & 0.053 \\
\hline 2 & 1.5 & 0.042 & 0.165 & 0.097 & 0.205 & 0.053 \\
\hline
\end{tabular}

As an example of the range produced by the various equations, consider two riprapped channels each with a slope of 0.007 and depth of $2 \mathrm{ft}$. $D_{50}$ is equal to 0.5 and $1.5 \mathrm{ft}$ for channel 1 and 2 respectively. The table below was produced from the previous equations.

Table 3-5: Comparison of Manning's $\boldsymbol{n}$ based on various researchers equations

From the above example, it is apparent that the HEC-11 / HEC-15 method for finding Manning's $n$ consistently gives lower roughness coefficients than the others. On the other hand, notice that the enveloping equation gives significantly higher $n$ values. The method for selecting Manning's $\boldsymbol{n}$ will undoubtedly be left up to the designer. However, a reasonable approach to selecting a Manning's $n$ would be to average the $n$ values from 2 of the above methods. Remember, the $d_{a} / D_{50}$ is assumed in the previous equations. This necessitates an iterative procedure until the assumed and calculated $d_{2} / D_{s 0}$ agree with each other. 


\subsection{Class System for Riprap Gradation}

There has been interest expressed in a class system for riprap. The desire for a class system for riprap stems from requests from local quarries.

For example, consider a hypothetical project along highway I-65. A one mile section of channel of relatively flat terrain may require a $D_{50}$ of $7.5^{\prime \prime}$, a second mile requires $D_{50}$ of $9.5^{\prime \prime}$, and a third requires a $D_{50}$ of $11 "$. A completely different project calls for $D_{50}$ 's of 6,8 , and 12". Rather than crush separate batches for each different project, the quarries desire a standard gradation system. The 6", 7.5", and 8" riprap could hypothetically fall under gradation Class I, while the 9.5", 11", and 12" may fall under gradation Class II. Such standardization would allow quarries to stockpile only those gradations rather than attempt to meet the design $D_{50}$ for every DOT project. Illinois DOT currently uses such a system. The basic definition for riprap is as follows:

"Riprap shall be stone quarried form undisturbed, consolidated deposits of rock reasonably free of shale...seams, lamination, cracks, or other structural defects. Field stone or boulders are not acceptable (sic)."

From this definition, seven separate gradations constitute the riprap classification system. Each gradation is defined in terms of percent finer that the given sieve size. A maximum of $5 \%$ by weight of the riprap may be oversized. Moreover, each oversized piece shall not be more than $1.2 \mathrm{D}_{100}$. The gradations are reprinted on the next page for reference (figure 3-18). In addition, each gradation is given a separate quality-designation - A, B, or C. These categories are defined as follows:

Quality Level

A

B

\section{Definition}

Stone shall not exceed $15 \%$ sodium sulfate soundness loss. Elongated pieces shall not exceed $10 \%$ by weight. Specific gravity be at least 2.45

Stone shall not exceed $25 \%$ sodium sulfate soundness loss. Elongated pieces shall not exceed $10 \%$ by weight.

Stone only conforms to above definition and gradation requirements 
The goal then is to establish a gradation system for riprap similar to that of Illinois. To accomplish this task, a major hurdle must be overcome. The $\mathrm{D}_{50}$ calculated from any of the previous design methods must be converted into a gradation. This gradation must be compared to standard gradations to determine the proper class.

Of the available methods, only the probabilistic approach of Froehlich and Benson provides a gradation as a result. Unfortunately, the gradation is given in terms of equal weight for each class rather than a percent finer as is normally used. No method is given in the Froehlich and Benson paper for making this conversion.

All of the remaining methods give $\mathrm{D}_{50}$. Only three of these methods provide any insight into selecting a gradation from this $\mathrm{D}_{50}$. Recall that Cal-B\&SP method computes the minimum stone weight $\left(\mathrm{W}_{33}\right)$ (i.e. $67 \%$ of the stone must be larger). The California $\mathrm{B} \& S P$ procedure gives a gradation table based on weight class (See table 3-6). One picks the class at which $67 \%$ of the stone in the gradation is larger than the computed value $\left(\mathrm{W}_{33}\right)$. The process is not straight forward. It depends on placement method - dumped (B) vs. not dumped (A). Moreover, the required gradation is based upon one number $\left(\mathrm{W}_{33}\right)$ rather than a range of riprap weights. Finally, no mention is made on how the gradations were delineated (although some type of channel testing is assumed).

HEC-11 provides a somewhat easier approach to selecting a channel gradation. This procedure gives conversions to diameters other than $D_{s 0}$ which helps to construct the required gradation (see table 3-7). HEC-11 goes further to provide the AASHTO gradations based on diameter, weight, and percent finer. HEC-11 gives the following table that defines the various gradations. This gradation must in turn be superimposed on a graph of the standard gradations (given in table 3-8) in order to select the gradation for the revetment.

Note that the following tables all assume that the specific gravity is 2.65 . Unless the specific gravity differs by more than 0.2 from this value, no corrections are recommended (i.e. so many other assumptions go into calculating $\mathrm{D}_{50}$ that it does not make sense to correct for specific gravity). Also, the standard gradation table comes directly from the AASHTO handbook. 
Stone Size (ft)

Stone Weight (lb)

Percent Finer Gradation

$\begin{array}{ccc}1.5 \mathrm{D}_{50} \text { to } 1.7 \mathrm{D}_{50} & 3.0 \mathrm{~W}_{50} \text { to } 5.0 \mathrm{~W}_{50} & 100 \\ 1.2 \mathrm{D}_{50} \text { to } 1.4 \mathrm{D}_{s 0} & 2.0 \mathrm{~W}_{50} \text { to } 2.75 \mathrm{~W}_{50} & 85 \\ 1.0 \mathrm{D}_{50} \text { to } 1.15 \mathrm{D}_{50} & 1.0 \mathrm{~W}_{50} \text { to } 1.5 \mathrm{~W}_{50} & 50 \\ 0.4 \mathrm{D}_{50} \text { to } 0.6 \mathrm{D}_{50} & 0.1 \mathrm{~W}_{50} \text { to } 0.2 \mathrm{~W}_{50} & 15\end{array}$

Table 3-7: $\quad$ Rock riprap gradation limits for a design $\mathrm{D}_{50}$ from HEC-11

\begin{tabular}{lccc}
\hline Riprap Class & Rock Size (ft) & Rock Size (lb) & Percent Finer \\
\hline Facing & 1.30 & 200 & 100 \\
& 0.95 & 75 & 50 \\
Light & 0.40 & 5 & 10 \\
& 1.80 & 500 & 100 \\
& 1.30 & 200 & 50 \\
$1 / 4$ ton & 0.40 & 5 & 10 \\
& 2.25 & 1000 & 100 \\
& 1.80 & 500 & 50 \\
$1 / 2$ ton & 0.95 & 75 & 10 \\
& 2.85 & 2000 & 100 \\
& 2.25 & 1000 & 50 \\
1 ton & 1.80 & 500 & 5 \\
& 3.60 & 4000 & 100 \\
& 2.85 & 2000 & 50 \\
2 & 2.25 & 1000 & 5 \\
& 4.50 & 8000 & 100 \\
& 3.60 & 4000 & 50 \\
& 2.85 & 2000 & 5 \\
\hline
\end{tabular}

Table 3-8: $\quad$ Riprap gradation classes based on HEC-11 (Modified from HEC-11)

The U.S. Corps of Engineers provide another "standard" gradation scheme. The gradations are given in terms of $D_{100}, D_{30}$, and $D_{90}$. For each size, USCOE provides maximum and minimum percent finer by weight by weight. The method is even easier than the HEC-11 gradation procedure. One simply enters with $\mathrm{D}_{100}$ or $\mathrm{D}_{30}$ and reads the corresponding gradation directly off of the table. Rather than interpolate in-between any two $D_{30}$ 's, merely select the next largest size. The gradations are reprinted here from ETL 110-2-120 (Table 3-9). 


\begin{tabular}{cccrrrrrr}
\hline & & \multicolumn{8}{c}{ Limits of Stone Weight by Percent Finer } \\
$\mathbf{D}_{\mathbf{1 0 0}}$ (ft) & $\mathbf{D}_{\mathbf{9 0}}(\mathbf{f t})$ & $\mathbf{D}_{\mathbf{3 0}}(\mathbf{f t})$ & \multicolumn{1}{c}{ Max } & \multicolumn{1}{c}{ Min } & Max & \multicolumn{1}{c}{ Min } & Max & \multicolumn{1}{c}{ Min } \\
\hline 1.00 & 0.70 & 0.48 & 86 & 35 & 26 & 17 & 13 & 5 \\
1.33 & 0.88 & 0.61 & 169 & 67 & 50 & 34 & 25 & 11 \\
1.50 & 1.06 & 0.73 & 292 & 117 & 86 & 58 & 43 & 18 \\
1.66 & 1.23 & 0.85 & 463 & 185 & 137 & 993 & 69 & 29 \\
2.00 & 1.40 & 0.97 & 691 & 276 & 205 & 138 & 102 & 43 \\
2.33 & 1.59 & 1.10 & 984 & 394 & 292 & 197 & 146 & 62 \\
2.50 & 1.77 & 1.22 & 1350 & 540 & 400 & 270 & 200 & 84 \\
2.66 & 1.96 & 1.34 & 1797 & 719 & 532 & 359 & 266 & 112 \\
3.00 & 2.11 & 1.46 & 2331 & 933 & 691 & 467 & 346 & 146 \\
3.50 & 2.47 & 1.70 & 3704 & 1482 & 1098 & 741 & 549 & 232 \\
4.00 & 2.82 & 1.95 & 5529 & 2122 & 1638 & 1106 & 819 & 346 \\
4.50 & 3.17 & 2.19 & 7873 & 3149 & 2335 & 1575 & 1168 & 492 \\
\hline
\end{tabular}

Table 3-9: $\quad$ USCOE gradations given as weights for a percentage lighter (ETL-1 10-2-120)

The next question to ask is how comparable are the results of the three methods. For simplicity, assume that the computed $D_{50}$ is $0.5 \mathrm{ft}$. The required gradations predicted by each method is shown below.

Example using the Cal-B\&SP, HEC-11, and USCOE gradation procedures Cal-B\&SP:

$\mathrm{D}_{33}=\mathrm{D}_{50} / 1.32=0.38$

$\mathrm{W}_{33}=4.70 \mathrm{lb}$ (assuming spherical particles)

$\mathrm{W}_{100}=14.2 \mathrm{lb}$

$\Rightarrow \# 3$ backing is required (25-75\% larger than $\left.5 \mathrm{lbs} ; \mathrm{W}_{100} \sim 25 \mathrm{lbs}\right)$

HEC-11:

$$
\begin{aligned}
& \mathrm{D}_{100}=0.5 * 1.6=0.8 \mathrm{ft} \quad \mathrm{W}_{100}=44.2 \mathrm{lb} \quad \text { (Assuming spherical } \\
& \mathrm{D}_{85}=0.5 * 1.3=0.65 \mathrm{ft} \quad \mathrm{W}_{85}=23.7 \mathrm{lb} \quad \text { particles) } \\
& \mathrm{D}_{50}=0.5 \mathrm{ft} \quad \mathrm{W}_{30}=10.8 \mathrm{lb} \\
& \mathrm{D}_{15}=0.5 * 0.5=0.25 \mathrm{ft} \quad \mathrm{W}_{15}=1.4 \mathrm{lb} \\
& \Rightarrow \text { Facing required }\left(\mathrm{W}_{100}<200, \mathrm{~W}_{50}<75\right) \\
& \text { Note: This gradation category is too big for this design }
\end{aligned}
$$




\section{$\underline{\text { USCOE }}$}

$$
\begin{aligned}
& \mathrm{D}_{30}=\mathrm{D}_{50} / 1.3=0.5 / 1.3=0.39 \\
& \mathrm{~W}_{100}: \quad 35-86 \mathrm{lb} \\
& \mathrm{W}_{50}: \quad 17-26 \mathrm{lb} \\
& \mathrm{W}_{15}: \quad 5-13 \mathrm{lb}
\end{aligned}
$$

Notice that the calculated $\mathrm{W}_{\mathrm{n}}$ 's (" $\mathrm{n}$ " is a percent lighter) from HEC-11 agree well with those from both the USCOE and Cal-B\&SP tables. However, the minimum gradation (facing) for HEC-11 is much larger than that required by USCOE for this design. Without testing, there is no way of knowing which method is more appropriate. That is, for the range of drainage ditch designs, the HEC-11 method may be overly conservative for it does not provide sufficient design gradations for small $D_{50}$. On the other hand, it is possible that the USCOE gradations are much too small for the required flow. For this case, since the Cal-B\&SP and USCOE methods produce similar results, it is suggested that the HEC-11 gradation is too large.

Unlike with geosynthetics, there is not agreement amongst the various methods to classify gradations. Although well detailed, the Illinois DOT method does not convert from $D_{s 0}$ to one of the seven gradations. The Cal-B\&SP, HEC-11, and USCOE all provide gradation information as function of $\mathrm{D}_{50}$ or $\mathrm{W}_{33}$. The latter two methods are easy to use, but provide different results at for small diameter riprap.

Although not recorded here, the same analysis was repeated for $D_{50}$ of $2.5 \mathrm{ft}$ with satisfactory results (all three methods give similar gradations). However, in drainage ditch design, most projects will only require $D_{50}$ of about $1 \mathrm{ft}$. In this range, there appears to be some discrepancy between the various methods. Hence, there is no way to devise a suitable gradation classification system without further research. 


\section{Other Hard Armor Systems}

In addition to riprap, several other hard armor techniques are available to line channels. These include gabions, concrete blocks (including articulating blocks), and fabric formed revetments (grout filled mats). Each technology has distinct advantages over traditional riprap. These advantages as well as design procedures for each class of materials are explored in the next several sections.

\subsection{Gabions - Description and Design Principles}

Increasingly, many riprap designs are being replaced by gabions (wire-enclosed riprap). These structures are more rigid than dumped riprap. Rather than individual particle displacement, gabions tend to deform as a unit. Since each unit weighs many times that of the largest riprap particles, the entire gabion system is altogether more stable than the riprap system. Gabions also provide a uniform channel appearance; an important consideration in aesthetically-sensitive areas. This uniform appearance is more than just an aesthetic benefit; rather, the uniformity allows gabions to be easily described by a single stability coefficient or equation. In design terms, uniformity implies similarity of shape, roughness, unit weight, and attachment to other units (Maynord, 1995).

A few schools of thought regarding the design of gabions are found in the literature. The first (and most common) method of design utilizes Simons (1984) procedure. This method is based on velocity only and ignores flow depth. The procedure also assumes that stability increases as gabion thickness increases for the same median riprap.

HEC-15 presents a shear stress approach to gabion design. Although the method is not well detailed, it seems to be based on the Simons and Senturk riprap design procedure. Similar to HEC-15 riprap design, gabion designs for base widths less than $6 \mathrm{ft}$ only require entering the design charts to determine a $D_{s 0}$, correct for the side slope ratio, reading off permissible shear for the $D_{s 0}$ and gabion thickness, and finally comparing the permissible shear to the maximum shear acting on the channel $\left(\tau_{d}=\gamma d S\right)$. For base widths in excess of $6 \mathrm{ft}$, the complex Simons and Senturk safety factor approach is required (detailed in the previous riprap section). 
The third approach is based on the USCOE riprap design procedure. It uses a depthaveraged velocity and channel depth to calculate the average diameter riprap in the mattress. This allows variation of gabion-mattress size with cross-section shape and channel alignment. Stability in this latter approach is based on the gabion's median rock size instead of the thickness of the gabion (i.e. the previous approach assumes one rock size is applicable to a wide range of gabion thicknesses). By designing against rock movement within the mattress, rock deformation does not occur. If such movement went unchecked, the resulting change in surficial roughness and flow patterns may cause the gabion to fail (Maynord, 1995).

\subsubsection{Equations for the Simons (1984) Approach to Gabion Design}

(a). Calculate the median mattress stone size $\mathrm{Dm}$

$$
\mathrm{D}_{\mathrm{m}}=0.1 \mathrm{~d}\left[\left(\frac{\gamma_{\mathrm{w}}}{\gamma_{\mathrm{s}}-\gamma_{\mathrm{w}}}\right)^{0.5}\left(\frac{\mathrm{V}}{\sqrt{\mathrm{gd}}}\right)\right]^{2.5}
$$

$\mathrm{D}_{\mathrm{m}} \quad=$ Median mattress stone size

d $\quad=$ depth of flow

$\gamma_{w} \quad=$ specific weight of water

$\gamma_{\mathrm{s}} \quad=$ specific weight of stone

$\mathrm{V}=$ mean velocity in the channel

Note: This procedure is iterative. One must assume a $D_{m}$ to calculate the flow depth (d) from a Manning's analysis. This in turn is used to calculate $D_{m}$. The assumed and computed $D_{m}$ are compared and the process is repeated until good agreement is achieved. Also, no minimum gabion thickness is given for this method. This equation was derived from 4 data points, yet it seems to be the most widely accepted design procedure used today.

\subsubsection{Equation for the Maynord Design Method}

(a). Equation for $D_{m}$

$$
D_{m}=S_{f} C_{s} C_{v} d\left[\left(\frac{\gamma_{w}}{\gamma_{s}-\gamma_{w}}\right)^{0.5}\left(\frac{V_{s s}}{\sqrt{K_{1} g d}}\right)\right]^{2.5}
$$

$\mathbf{S}_{\mathbf{f}} \quad=$ Safety factor for gabion design

$$
\geq 1.1
$$


$\mathrm{C}_{3} \quad=$ Stability coefficient of rock in the gabion

$=0.1$ (from data of several researchers)

$\mathrm{C}_{v} \quad=$ Velocity distribution coefficient

$=1.0 \quad$ Straight channels \& R/W $>25$

$=1.283-0.3 \log (\mathrm{R} / \mathrm{W}) \quad \mathrm{R} / \mathrm{W} \leq 25$

$\mathbf{R} \quad=$ centerline bend radius

$\mathrm{W}=$ water surface width

$\mathrm{K}_{1} \quad=$ side slope correction factor which is function of side slope ratio correction factor is adjusted from HEC-11/ HEC-15 equation to be more conservative

Modified Bank Correction Factor $\left(K_{1}\right)$ from HEC-11

\begin{tabular}{cc}
\hline Side Slope $(H: V)$ Ratio & $K_{1}$ \\
\hline $1: 1$ & 0.46 \\
$1.5: 1$ & 0.71 \\
$2: 1$ & 0.88 \\
$3: 1$ & 0.98 \\
$4: 1$ or flatter & 1.00 \\
\hline
\end{tabular}

Table 3-10: Bank correction factor (from HEC-11)

$\mathrm{V}_{\mathrm{ss}}=$ Depth-averaged velocity at point $20 \%$ up from toe of bank

$\mathrm{V}_{\mathrm{ss}} / \mathrm{V}_{\mathrm{a}}=1.74-0.52 \log (\mathrm{R} / \mathrm{W}) \quad \mathrm{V}_{\mathrm{ss}} / \mathrm{V}_{\mathrm{a}} \geq 1.0$

$\mathrm{V}_{\mathrm{a}} \quad=$ average velocity in channel

(b). Thickness of Gabion

$$
\mathrm{T}=2 \mathrm{D}_{\mathrm{m}}
$$

$\mathrm{T}=$ thickness of the gabion 


\subsubsection{HEC-15 Equations and Design Charts $(B \leq 6 \mathrm{ft})$}

(a). For a given discharge and channel slope, enter figure 3-19a-b for correct shape and determine flow depth. For channels where $H: V \neq 3: 1$, use the interpolation chart (given in the riprap design section); compute design flow depth.

$$
\mathrm{d}=\frac{\mathrm{A}_{3}}{\mathrm{~A}_{\mathrm{z}}} \mathrm{d}_{\mathrm{i}}
$$

$$
\begin{aligned}
& A_{3} / A_{z}=\text { Interpolation factor from table 3-2 } \\
& d \quad=\text { Flow depth for side slope where } H: V \neq 3: 1
\end{aligned}
$$

(b). Calculate design shear stress

$$
\tau_{\mathrm{d}}=\gamma \mathrm{d} S
$$

(c). Select $D_{s_{0}}$ and gabion thickness. Read off permissible shear strength for each from figure 3-20 \& 3-21 respectively. The larger of the two values is the permissible shear stress. Modify the selection so that $\tau_{d}<\tau_{p}$. 


\subsection{Fabric Formed Revetments - Description}

Fabric formed revetments (FFR's) consist of two synthetic fabric plies linked to form a series of small cells. This "formwork" is filled with highly impermeable, high strength concrete. Some FFR's are further reinforced with cables to form articulating mats. The intent of FFR is to combine the durability of conventional rigid linings (such as cast-in-place concrete, asphaltic concrete, grouted riprap, and soil cement) with more flexible and/or water-permeable protective rock systems (such as riprap and gabions) (Sprague et al, 1992).

The question arises of how FFR's differ from the paved side ditch already used in Indiana. Conventional rigid linings are expensive and tend to progressively fail when a portion of the lining is damaged. Slight cracks easily erode into spalls which in turn breaks up the concrete into large sections. Structural damage to the lining develops as a result of poor subgrade conditions, hydrostatic uplift pressure, swelling soils, embankment slumping, or frost heave (Sprague et al, 1992). Repair of such damage is often time consuming and expensive. FFR's limit these problems through the use of articulating mats, pressure relief points, and a UV resistant fabric envelope around the concrete. Moreover, FFR offer significantly increased strength over conventional paved side ditch (see discussion below).

FFR's also have several advantages over conventional riprap and gabion solutions. In some areas, riprap is quite expensive because it is not readily available. Well-graded mixtures often contain a select percentage of stones that cannot resist the flow and are consequently eroded. Loss of these small stones can lead to progressive liner failure. Gabions require a laborintensive installation procedure and hence may extend the construction schedule. In high sediment channels, abrasive forces may weaken the gabion wire basket and ultimately cause the basket to collapse.

The technology has its roots in the 1960's when Dutch engineer H.F. Hillen joined two layers of nylon fabric together and filling it with fine fluid aggregate (Lamberton, 1989). Since this crude experiment, three main types of FFR's have emerged: articulating block, uniform section, and filter point fabrics.

The articulating block styles provides the flexibility necessary in most erosion control applications. This fabric is produced by weaving two layers of fabric along regularly spaced grid lines. These points serve as hinges between adjacent concrete blocks. Block thickness range 
from 4-8". Cables are threaded through these hinge points after the concrete hardens in order to interconnect the blocks. The connecting cables and fabric maintain the relative block positions as the entire structure settles (Sprague et al, 1992). Types of reinforcement include galvanized steel cable, synthetic rope, or polyester revetment cable.

Uniform section styles are produced by using equal length cords between the fabric layers. The tie cords are located at 3-6" intervals. The integrity of these cords is crucial to the performance of these products. These mats are nearly impermeable and most often used in channel lining work where low coefficient of friction is required (Lamberton, 1989; Monnet, 1990). Typical thicknesses are 3-8" with 4 " being the most common fabric used.

Filter point fabric provides a permeable, highly flexible mat of non-uniform cross section. These mats look like concrete "pillows" (Monnet, 1990). The points not only serve to join the two layers of fabric, but they also provide relief for hydrostatic uplift from upward water pressure. Groundwater is allowed to pass through the "points," but soil is retained on the fabric (hence, the name filter-point). The layers of fabric are woven on $5^{\prime \prime}, 8$ ", or $10^{\prime \prime}$ centers with thicknesses varying from 3-6" (Lamberton, 1989).

Concrete is pumped through hoses into slits in the fabric. Because of the restricted flow space, the coarsest aggregate can only be concrete sand. Mixes often have a high percentage of cement content because of the lack of large aggregate (water/cement ratio of 0.65-0.75). Typical concrete breaking strength is $2000-3000$ psi in 28 days for conventional forms. If the mix is placed in fabric forms ("concrete socks"), strength increases an average of 75\% (see figure 3-22). This implies that FFR's offer more durability than the concrete lined side ditch. For more detail, consult Lamberton (1989); he gives a complete review of concrete mixes and fabric properties.

\subsubsection{Design Principles of FFR Systems}

The design of FFR systems is similar to that proposed for soft armor geosynthetic erosion control systems. Given the hydraulic characteristics of the channel, one sets up Manning's equation and iterates to find the flow depth $(y)$. Once the normal depth is determined, the hydraulic radius is back calculated and the design shear stress (driving force) is computed ( $\tau=\mathrm{R} \gamma \mathrm{S}$ ). The resisting shear stress comes from the friction between the mat / geotextile system and the subgrade. The friction angle in this analysis is the least of the mat/soil, mat/geotextile or 
soil/geotextile interface. A safety factor is computed from the resisting and driving stresses and the thickness is readily calculated.

Modifications to this procedure are required for waves, curved sections, and anchors. In curved sections, the tractive force is increased by a factor $\mathrm{K}_{b}$; hence the driving force becomes $\tau=\mathrm{K}_{b} \mathrm{R} \gamma \mathrm{S}$. For sites subject to wave attack, the thickness of the mat (uniform section or filter point) must be adjusted. This adjustment depends on the bank angle, wave height, and a nondimensional mat coefficient.

In most cases, anchors are used to further secure the FFR to the bank. To account for this increased stability, a static analysis is carried out for the FFR system. Here, the necessary force provided by the anchors is the difference between the required submerged weight and the submerged weight of the mat itself. By resolving this force into components along and parallel to the slope, respectively, the length and distance between anchors is calculated. Figure 3-23 sketches the anchor/bolt system for a FFR. 


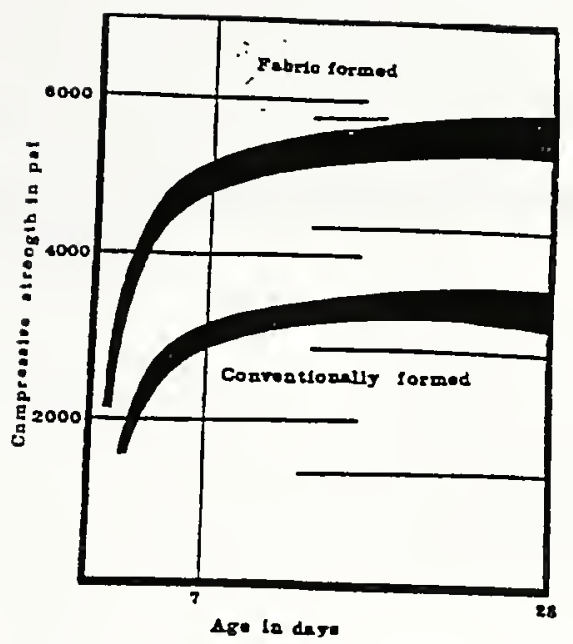

Figure 3-22: Typical cylinder test results for FFR's (Reprinted from Lamberton, 1989)

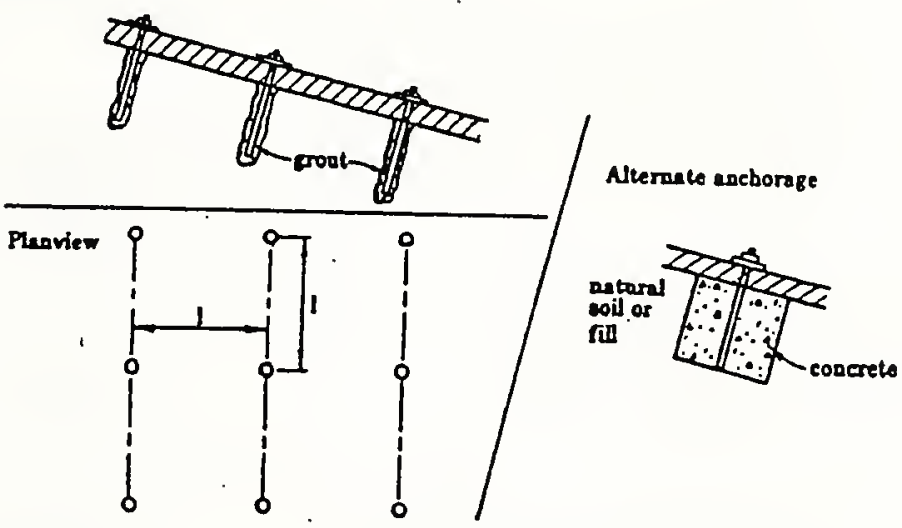

Figure 3-23: Schematic of ground anchor system for FFRs (Reprinted from Sprague, 1992)

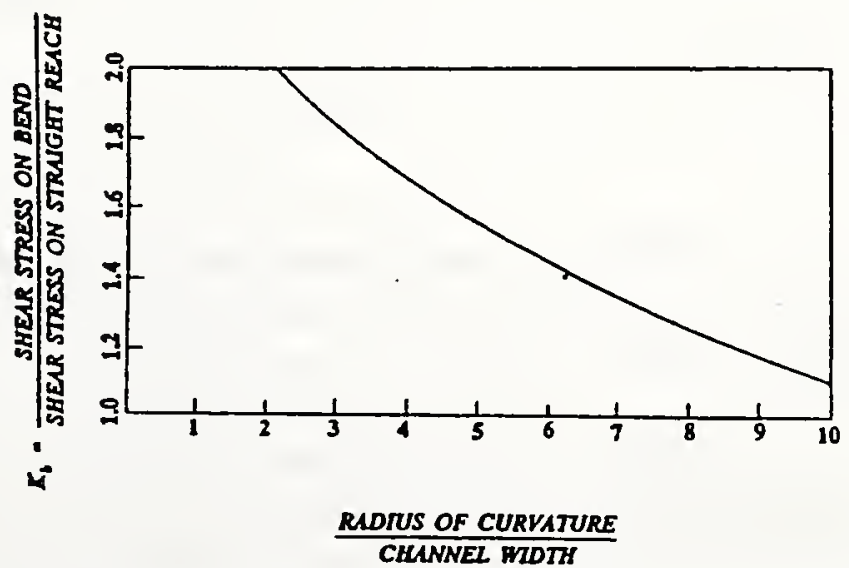

Figure 3-24: Bend shear stress coefficient (Reprinted from Sprague, 1992) 


\subsubsection{Equations for FFR Design Method}

(a). Determine depth and velocity of flow (iterate to find normal depth)

$$
\mathrm{Q}=\frac{1.0}{\mathrm{n}} \mathrm{AR}^{2 / 3} \mathrm{~S}^{1 / 2}
$$

$$
\begin{array}{ll}
\mathbf{n} & =\text { roughness coefficient } \\
\mathbf{Q} & =\text { discharge }\left(\mathrm{m}^{3} / \mathrm{s}\right) \\
\mathbf{A} & =\text { cross sectional area }\left(\mathrm{m}^{2}\right) \\
\mathbf{R} & =\text { hydraulic radius } \\
\mathbf{S} & =\text { bottom slope }
\end{array}
$$

(b). Determine tractive shear stress

$$
\tau=\gamma \mathrm{RSK}_{\mathrm{b}}
$$

$$
\begin{array}{ll}
\tau & =\text { tractive shear stress }(\mathrm{kPa}) \\
\gamma & =\text { unit weight of water }\left(\mathrm{kN} / \mathrm{m}^{3}\right) \\
\mathrm{R} & =\text { hydraulic radius } \\
\mathrm{K}_{\mathrm{b}} & =\text { bend shear stress coefficient (see figure 3-24 below) }
\end{array}
$$

(c). Determine resisting shear stress

$$
\mathrm{M}=\frac{\left(\gamma_{c}-\gamma_{w}\right)(\tan \delta-S) t}{\sqrt{1+S^{2}}}
$$

$\mathrm{M} \quad=$ resisting shear stress $(\mathrm{kPa})$

$\gamma_{c} \quad=$ unit weight of concrete $\left(\mathrm{kN} / \mathrm{m}^{3}\right)$

$\delta \quad=$ minimum friction angle within the system

$\mathrm{S} \quad=$ slope

$\mathrm{t}=$ thickness of the mat (given by manufacturer; typically $5,8,10$ ")

(d). Calculate the Safety Factor

$\mathrm{FS}=\frac{\mathrm{M}}{\mathrm{T}} \geq 1.5$

Note: if $\mathrm{FS}<1.5$, a thickness that would provide an adequate $\mathrm{FS}$ is given by:

$$
\mathrm{t}=\frac{100(\mathrm{FS}) \mathrm{T}}{\mathrm{M}}
$$

$\mathrm{t}=$ thickness $(\mathrm{cm})$

FS = given by above equation 
(e). For waves, the thickness is given by:

$$
\begin{aligned}
& \mathrm{t}=\frac{8.328 \mathrm{C}_{w} \mathrm{H}}{\left(\mathrm{G}_{s}-1\right) \sqrt[3]{\cot \theta}} \\
& \begin{array}{ll}
\mathrm{t} & =\text { thickness }(\mathrm{cm}) \\
\mathrm{C}_{\mathrm{w}} & =\text { mat coefficient } \\
& =1.3 \text { for short term Uniform Section or Filter Point } \\
& =3.7 \text { for long term Uniform Section or Filter Point } \\
& =2.0 \text { for Articulating Block Mat } \\
\mathrm{H} & =\text { design wave height (m) } \\
\mathrm{G}_{\mathrm{s}} & =\text { specific gravity } \\
\theta & =\text { bank angle to be protected }
\end{array}
\end{aligned}
$$

(f). Added stability for using anchors

$$
\begin{aligned}
& \mathrm{F}=\mathrm{W}^{\prime}-\mathrm{W}_{\mathrm{m}} \\
& F_{p}=F \sin \theta ; F_{n}=\cos \theta \\
& F_{p}=A_{s} \phi \frac{f_{s}}{s^{2}} \\
& F_{n}=P_{s} \frac{f_{a}}{F_{s}} \frac{d}{s^{2}} \\
& \mathrm{~W}^{\prime} \quad=\text { required weight per unit area }(\mathrm{kPa}) \\
& \mathrm{W}_{\mathrm{m}}{ }^{\prime}=\text { weight provided by mat itself }(\mathrm{kPa}) \\
& \mathrm{F} \quad=\text { anchoring force }(\mathrm{kPa}) \\
& \mathrm{F}_{\mathrm{n}} \quad=\text { normal component of the anchor force }(\mathrm{kPa}) \\
& F_{p}=\text { parallel component of the anchor force }(\mathrm{kPa}) \\
& \theta \quad=\text { bank angle } \\
& \mathrm{A}_{8} \quad=\text { area of anchor bolt used } \\
& \phi \quad=0.85 \text {; reduction factor for shear } \\
& \mathrm{f}_{3} \quad=13.78 \mathrm{kN} / \mathrm{cm}^{2} \text {; allowable shear stress for steel } \\
& \mathrm{s} \quad=\text { distance between anchors in a square grid }(\mathrm{m}) \\
& \mathrm{P}_{\mathrm{s}} \quad=\text { perimeter of the anchor }(\mathrm{m}) \\
& \mathrm{f}_{\mathrm{a}} \quad=\text { adhesion between the steel/soil }(\mathrm{kPa}) \\
& F_{8} \quad=1.5 \text {; factor of safety } \\
& \mathrm{d}_{\mathrm{a}} \quad=\text { necessary length of anchors }(\mathrm{m})
\end{aligned}
$$


Typical Thicknesses of FFR

\begin{tabular}{lcc}
\hline Style & Thickness $(\mathrm{cm})$ & Thickness (in.) \\
\hline Filter Point & 12.7 & 5 \\
& 20.3 & 8 \\
Uniform Section & 25.4 & 10 \\
& 7.6 & 3 \\
& 10.2 & 4 \\
Articulating Block & 15.2 & 6 \\
& 20.3 & 8 \\
& 10.2 & 4 \\
& 15.2 & 6 \\
\hline
\end{tabular}

Table 3-11: Typical Thicknesses of FFR

Notes:

1). The equations for anchor stability can be used two ways: to calculate the grid spacing (s) and the anchor depth (d) for a required mat weight $\mathrm{Wm}$ ', or to calculate the additional resisting force for given anchor spacing and depth.

2). This design comes from that proposed by Bowser-Morner Associates and Simons, Li, and Associates Inc. (Sprague, 1992).

3). It is assumed that the additional shear resistance Fp (i.e. acting along the slope) is added to the resisting shear stress $M$. This increases the factor of safety. 


\subsection{Concrete Blocks (Articulating Block Systems - ABS) - Description}

Concrete blocks interlock together in regular patterns to resist hydraulic forces. These systems are designed to have freedom of movement between individual units. Hence, such systems are usually referred to as articulating block systems (ABS). Concrete blocks often have about $15-35 \%$ open area by design. This area allows vegetation to be established. The vegetation conceals the revetment (improving aesthetics) and significantly increases hydraulic stability (up to $50 \%$ according to CIRCA 1987).

A major advantage of concrete blocks over riprap is in its ability to resist ice flow damage. For example, one 8-year study at Rock State Park in Illinois compared riprap to Tri-Lock by American Excelsior. After 8 years, the Tri-Lock section remained fully intact while most of the riprap had eroded (Cabalka and Lutyens, 1996). This same lock and key block system was used to control severe erosion along Spring Branch Creek in Harris County, Texas (Starrett, 1994). In this case, the area was used for recreation. Obviously, the vegetation-covered revetment offered a safer solution than large diameter jagged riprap.

Notice that ABS do not add structural strength to slopes and banks like lateral earth retaining walls. They only protect the geotextile and underlying soil from erosion. As the bank angle approaches the natural angle of repose for the saturated soil, it becomes unstable. Adding concrete blocks to a bank near the angle of repose increases the likelihood of a rotational failure (the blocks add a large component driving down the slope) (Fuller, 1992).

For simplicity, concrete blocks are divided up into two categories: cabled and non-cabled. Cabled blocks have pre-cast holes which are threaded with high strength polyester or steel cable. These cables turn the concrete blocks into articulating mats. The mats then are easily placed on prepared slopes. Another benefit of using cabled systems is that mats are easily placed under water. In addition, earth anchors installed along the top of the bank create "hanging" revetments. Such installations can maintain shear resistance even if a toe failure occurs. Non-cabled blocks rely only on the weight of the blocks. These blocks are hand placed on the channel bed. Although these units are cheaper than cabled units, the installation is very labor intensive. Consequently, non-cabled installation is not widely used anymore (Fuller, 1992). 


\subsubsection{Design of Concrete Block Systems}

The design of ABS systems focuses on the lift and drag forces producing overturning moments of a single block. Failure here is defined as the loss of intimate contact between a block (or group of blocks) and the subgrade which they protect (Clopper, 1988, 1990). It is assumed that the friction angle developed between the geotextile, blocks, and subgrade is sufficient to prevent a sliding failure. This leads to the concept of incipient overturning - overturning moments are equal to the resisting moments. In this analysis, the resistance added by the cables is neglected. In order for tension to develop in the cables, some finite rotation of the block must have occurred and by our definition, the system has already "failed" (i.e. overturning has begun) (Clopper, 1990). This focus on overturning of one unit lends itself to the previously detailed Simons and Senturk procedure.

The procedure requires knowledge of the moment arms for a given block. These distances are not intuitive which complicates the design procedure. Moreover, the procedure assumes a relationship between the lift and drag force (Simons assumes $F / F_{d}=2$ ). However, it is commonly used and the procedure is presented here.

Fuller (1992) points out that concrete block systems must be designed for both wave attack and high velocity flows. He presents the Pilarcyzk approach to designing against wave attack. As with FFR, the object is to make the blocks thick enough to resist wave erosion. These equations are based on wave height, bank slope, wave period, and block strength coefficient. Caution is needed when using this approach. This method does not account for the destructive force of oblique waves (e.g. those produced by a boat running parallel to shore) (Fuller, 1992).

\subsubsection{Design Equations for Concrete Block Design - Simons Approach (1977)}

(a). Factor of safety equation and required parameters

$$
\mathrm{SF}=\frac{\left(1_{2} / 1_{1}\right) \cos \theta}{\frac{\frac{M}{N}+\sin (\lambda+\beta)}{\frac{M}{N}+1} \eta \frac{1_{2}}{1_{1}}+\sin \theta \cos \beta}
$$


$\beta=\tan ^{-1}\left[\frac{\cos \lambda}{\left(\frac{\mathrm{M} / \mathrm{N}-1}{\eta} \frac{1_{1}}{l_{2}}\right) \sin \theta+\sin \lambda}\right]$

$\frac{\mathrm{M}}{\mathrm{N}}=\frac{1_{4}}{1_{3}} \frac{\mathrm{F}_{\mathrm{L}}}{\mathrm{F}_{\mathrm{D}}}$

$\eta=\frac{\tau_{0}}{\tau_{\mathrm{c}}}$

$\tau_{0}=\gamma \mathrm{d} S$

$\tau_{0} \quad=$ design shear stress

$\tau_{\mathrm{c}} \quad=$ critical shear stress

$\lambda=$ longitudinal bed slope angle

$\theta \quad=$ bank slope angle

$\beta, \eta=$ computation parameters

$\gamma \quad=$ specific weight of water

$\mathrm{d}=$ normal depth

$\mathrm{S} \quad=$ bed slope

$\mathrm{l}_{\mathrm{i}} \quad=$ moment arms $(\mathrm{i}=1,2,3,4)$

$F_{L}, F_{D}=$ lift and drag force

(b). Equations for designing against wave attack

$$
\begin{aligned}
& \frac{\mathrm{H}}{\mathrm{D} \rho_{\mathrm{m}}}=\psi \frac{\cos \theta}{\sqrt{\zeta}} \\
& \zeta=\frac{\tan \theta}{(\mathrm{H} / \lambda)^{0.5}}=1.25 \frac{\mathrm{T}}{\sqrt{\mathrm{H}}} \tan \theta
\end{aligned}
$$

$$
\begin{array}{ll}
\mathrm{H} & =\text { wave height } \\
\mathrm{T} & =\text { wave period } \\
\theta & =\text { bank angle } \\
\lambda & =\text { wavelength in deep water } \\
\psi & =\text { strength coefficient } \\
& =3 \text { to } 5 \\
\zeta & =\text { wave breaking parameter } \\
\rho_{\mathrm{m}} & =\text { density of concrete block } \\
\mathrm{D} & =\text { thickness of the concrete block }
\end{array}
$$


Notes:

1). Several manufacturers have their own method for designing against wave attack. Consult chosen manufacturer for variations from this procedure.

2). Although most ABS allow vegetation to grow between blocks, the added resistance provided by plant roots is not included. Extended periods of drought, floods, or environmental damage can weaken and/or destroy any vegetation in a short period of time. Hence, it is not conservative to include vegetation resistance in ABS designs.

3). Even though not reflected in the design procedure, site grading and compaction often determines the success or failure of an ABS project. Moreover, a geotextile filter must be placed underneath the ABS. The selected geotextile must be strong enough to survive installation and the design hydraulic forces. It also must retain the base soil and resist clogging. The FHWA design procedure for geotextiles is found in Appendix B. 


\subsubsection{Escarameia and May ABS Design Procedure (1995)}

Recently, another design approach has been suggested by Escarameia and May (1995). They modified their riprap design equation to account for concrete blocks. Recall that their design method is based on quantifying the level of turbulence in a channel. They found that the stability of ABS systems lies in the blocks weight per unit area. Their research also noted that threshold of movement of concrete blocks was difficult to quantify. Once one block failed, the remaining blocks failed rapidly.

These researchers give an equation for the thickness of the concrete block. Essentially, Escarameia and May reduce their riprap equation by a factor of 0.75 for flat beds and slopes less than 2.5H:1V. For 2:1 slopes, the reduction factor for $\mathrm{ABS}$ is 0.5 . The equations for this procedure are given below.

Equations for Escarameia and May ABS Design Procedure

(a). Thickness of Concrete Blocks

$$
\begin{aligned}
& D_{n}=0.75 C \frac{V_{b}^{2}}{2 g\left(G_{c}-1\right)} \\
& C=12.3 T_{i}-0.2 \\
& T_{i}=V_{m m} / V_{b} \\
& D_{n} \quad=\text { Thickness of concrete block } \\
& C \quad=\text { dimensionless turbulence coefficient } \\
& T_{i} \quad=\text { turbulence intensity at } 0.1 \text { yo } \\
& V_{b} \quad=\text { velocity at } 0.1 \text { yo } \\
& G_{c} \quad=\text { specific gravity of concrete } \\
& V_{m s} \quad=\text { root means square velocity fluctuation about the mean }
\end{aligned}
$$

Notes:

1). It is not clear in the paper exactly how to compute $V_{b}$. An estimate appears to be given by Rouse's formula for velocity against the stone:

$$
\mathrm{U}_{\mathrm{d}} / \mathrm{V}_{\mathrm{b}}=0.68 \log \left(\mathrm{y}_{0} / \mathrm{D}_{\mathrm{n}}\right)+0.71
$$

2). This method does not account for wave turbulence. Also, given the fact that once one block fails, the entire revetment fails rapidly, a large safety factor should be built into the design. However, no a safety factor is provided. 


\subsection{Summary of Hard Armor Design}

This chapter has presented numerous design methodologies for hard armor design. Four separate technologies are addressed: riprap, gabions, fabric formed revetments, and articulating blocks. Each hard armor alternative has several design methods associated with it.

For example, riprap alone has 10 accepted design procedures that vary from the simple (based on velocity) to the complex (analyzing overturning moments of each particle). It is difficult, if not impossible, to select an appropriate design procedure for riprap design without testing. Blodgett (1986) indeed provides subjective evaluation of 8 methods, but it is limited only to 26 locations. The merits of each design procedure could be quantified by examining successful and failed riprap sites around Indiana, quantifying the field $\mathrm{D}_{50}$, and calculating a $\mathrm{D}_{50}$ based on each of the 10 design procedures given in this section.

Following the descriptions and deficiencies of each riprap design method, several methods for calculating Manning's $n$ are provided. Often $\mathrm{D}_{50}$ is used to quantify channel roughness which in turn is used to calculate $D_{50}$. Hence sizing riprap is almost always an iterative procedure to equate the assumed and calculated $\mathrm{D}_{50}$.

The riprap section included a discussion of defining a class system for riprap. ILDOT provides gradations; however, it does not explain how to convert from $D_{50}$ to one of the seven gradations. HEC-11, Cal-B\&SP, and USCOE all provide gradation estimates from a calculated $\mathrm{D}_{50}$. Moreover, each gives several classes of riprap based on percent finer by weight. It seems that either the HEC-11 or the USCOE classification systems are acceptable (Cal-B\&SP is difficult to interpret). However, field testing would be necessary before adopting either of these classification schemes.

Gabion, fabric formed revetment, and concrete block designs are also reviewed. For each technology, the materials are described, design procedures and equations are given, and deficiencies are noted. There are noticeably fewer design procedures available in the literature for these technologies. This is mainly due to the relatively recent introduction of these materials. 


\subsection{Designing for Composite Channel Linings}

As noted in the first design section, shear stress is typically less on the side slopes than on the bottom of the channel. Consequently, the channel liner requirements may not be nearly as great. The side slope lining can have a lower permissible shear stress than that used in the middle of the channel. Figure 3-25 shows a schematic of a typical composite lining.

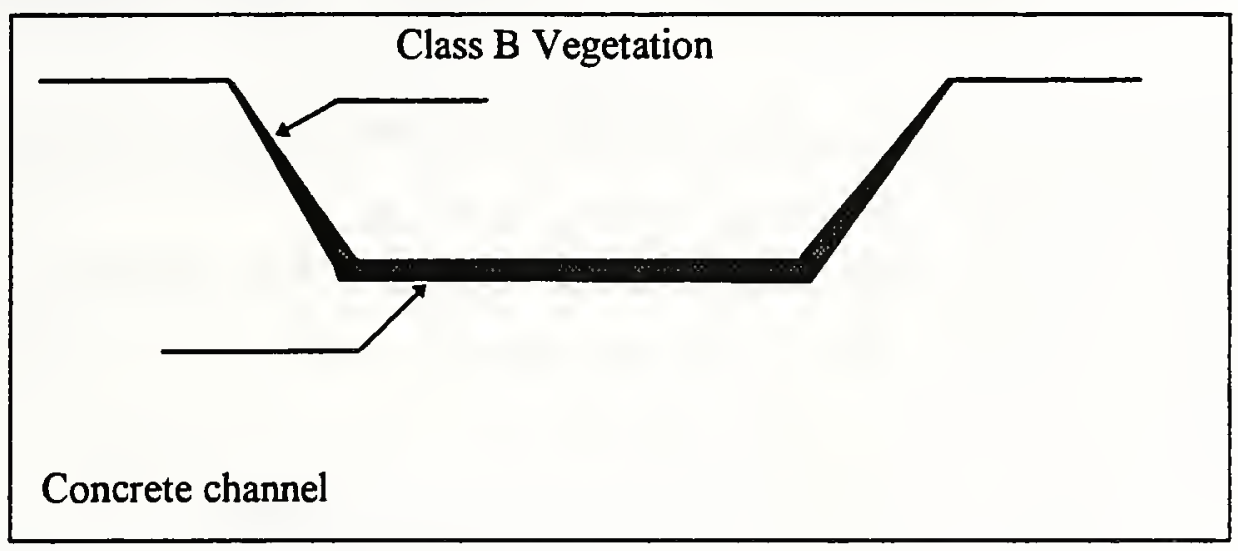

Figure 3-25: Composite Channel Lining

Beyond economics, low flows are another reason for selecting a composite lining. Often, sustained low flows kill the submerged vegetation and this decreases the erosion resistance of the channel lining. Large discharges then loosen the blanket and ultimately cause it to fail. A solution then is to use riprap or concrete in the center of the channel and reinforced vegetation on the side slopes (Chen and Cotton, 1988). Another reason for using a composite lining is for the case of side slopes with different $Z$ values ( $H: V$ ratios). Obviously, the shear requirements of a 2:1 slope are much greater than a 4:1 slope. This situation is shown in figure 3-26.

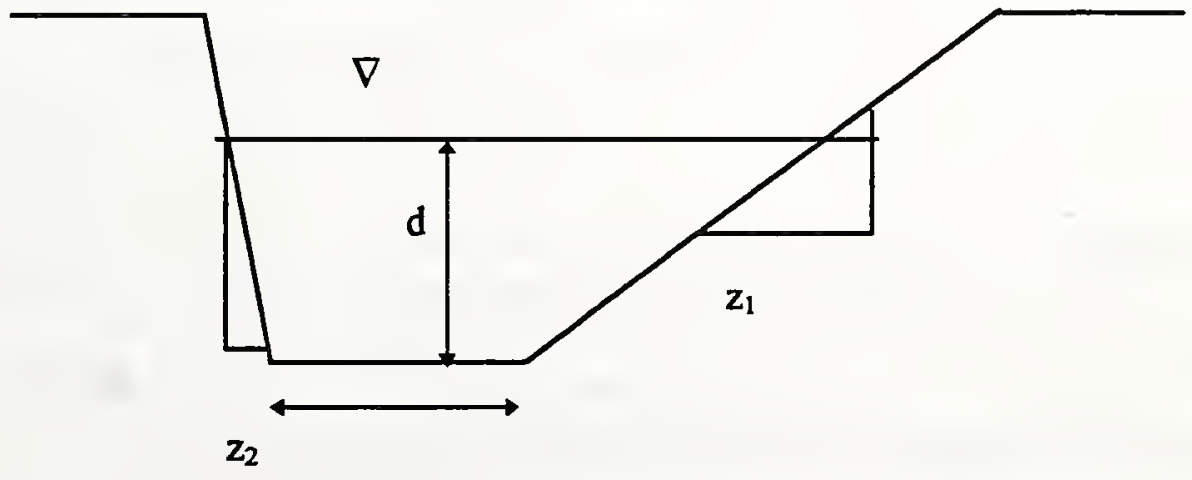

B

Figure 3-26: Composite lining for unequal side slope ratios $\left(Z_{1} \neq Z_{2}\right)$ 
There are a few important points that must be considered when using a composite lining. First, the bed lining (bottom lining) must extend a small distance up the slope - say, 6". Second, adjacent linings of different roughness induces erosion near the interface of the two materials. Erosion of the weaker lining then causes the entire system to fail. Channels with bare side slopes and a riprap bottom often have this problem. The solution uses a temporary lining (jute, straw, coconut) on the side slopes to provide erosion resistance until the vegetation is established.

\subsubsection{Composite Lining Design Procedure (Adapted from Chen and Cotton, 1988)}

1). Determine channel geometry, design discharge, and slope

2). Determine permissible shear stress, $\tau_{p}$, from table 3 or 4 .

3). Estimate flow depth, $d_{i}$.

4). Determine Manning's " $n$ " for each lining type.

5). Compute the composite Manning's " $n$ " from the following equation:

$$
n_{c}=\frac{\left(P_{1} n_{1}^{3 / 2}+P_{b} n_{b}^{3 / 2}+P_{r} n_{r}^{3 / 2}\right)^{2 / 3}}{P_{1}^{2 / 3}}
$$

$\mathrm{n}_{\mathrm{c}}, \mathrm{n}_{\mathrm{l}}$, = Manning's " $\mathrm{n}$ " of the composite, left side slope, right

$n_{r}, n_{b} \quad$ side slope, and bottom, respectively

$P_{1}, P_{r}=$ Wetted perimeter of left side slope, right side slope,

$P_{b}, P_{t} \quad$ bottom, and entire channel, respectively, in meters (feet)

6). Using $\mathrm{n}_{\mathrm{c}}$, compute the flow depth using Manning's equation for the appropriate channel shape (See appendix A for equations). Note that if the side slopes are unequal, the equations in appendix A do not apply. You need to use more general equations. For a trapezoidal channel with side slopes $Z_{1}$ and $Z_{2}$, base $B$, and depth $d$, we have:

$$
\begin{aligned}
& A=B d+\frac{1}{2} Z_{1} d^{2}+\frac{1}{2} Z_{2} d^{2} \\
& P=B+d \sqrt{Z_{1}{ }^{2}+1}+d \sqrt{Z_{2}{ }^{2}+1} \\
& R=A / P
\end{aligned}
$$

7). Compare the estimated flow depth, $d_{i}$, with the calculated flow depth, $d$. If the difference is greater than $|0.1 \mathrm{ft}|$, then repeat steps 3-6. 
8). Determine shear stress at maximum depth, $\tau_{\mathrm{d}}$, and shear stress on the side slopes, $\tau_{\mathrm{a}}$.

$$
\begin{aligned}
& \tau=\gamma_{w} D S \\
& \tau_{s}=K_{1} \tau_{d}
\end{aligned}
$$

where, $\mathrm{K}_{1} \quad$ = side slope shear coefficient from Chart 13

$\mathrm{D} \quad=$ calculated maximum depth

$\mathrm{S} \quad=$ slope of channel

$\gamma_{\mathrm{w}} \quad=$ unit weight of water $-9.807 \mathrm{kN} / \mathrm{m}^{3}\left(62.4 \mathrm{lb} / \mathrm{ft}^{2}\right)$

$\tau_{\mathrm{d}} \quad=$ maximum shear stress

$\tau_{\mathrm{s}} \quad=$ side slope shear stress

9). Compute factor of safety for each lining. Each must be greater than 1.2. If either lining fails, then select a new combination of linings and repeat steps 3-8.

$$
\begin{aligned}
& \mathrm{FS}_{\text {bottom }}=\frac{\tau_{p}}{\tau_{\mathrm{d}}} \\
& \mathrm{FS}_{\text {side }}=\frac{\tau_{\mathrm{p}}}{\tau_{\mathrm{s}}} \\
& \tau_{\mathrm{p}} \quad=\text { permissible shear stress from tables } 1 \text { or } 6
\end{aligned}
$$

10). Using the calculated flow depth, compute the velocity using modified Manning's equation for both the bottom and side slopes. Notice that the bend factor is included here as a reminder that channel bends must be considered if $R_{0} / B<10$. Refer to section 2 to for complete details on how to design for channel bends.

$$
\begin{aligned}
V_{\text {bottom }}= & \frac{K_{s}}{n_{c}} R^{1 / 6}\left(K_{b} \tau_{d}\right)^{1 / 2} \\
V_{s i d e}= & \frac{K_{s}}{n_{c}} R^{1 / 6}\left(K_{b} \tau_{s}\right)^{1 / 2} \\
n_{c} \quad= & \text { composite Manning's " } n \text { " computed from equation } 3.4 \\
K_{b} \quad= & \text { bend coefficient, if } R_{d} / B<10 \\
K_{s} \quad= & \text { conversion factor from shear stress to velocity } \\
& 0.189 \text { for English units } \\
& 0.0316 \text { for S.I. units }
\end{aligned}
$$


11). Compute factor of safety against velocity failure. Again, a minimum factor of safety is 1.2. If either lining fails to meet this criteria, then a new combination of linings must be selected. In this case, repeat steps 2-10.

$$
\begin{aligned}
& S F_{\text {bottom }}=\frac{V_{\text {allow }}}{V_{\text {bottom }}}>1.2 \\
& S F_{\text {side }}=\frac{V_{\text {allow }}}{V_{\text {side }}}>1.2 \\
& V_{\text {allow }}=\text { permissible velocity found in table } 6 \\
& V_{\text {bottom }}=\text { calculated velocity on the channel bottom } \\
& V_{\text {side }}=\text { calculated velocity on the side slopes }
\end{aligned}
$$




\section{4: Classification System for Erosion Control Products}

\subsection{Why is a classification system needed?}

As mentioned previously, there are a myriad of erosion control products on the market today. Some erosion control blankets are only meant to survive until the vegetation is fully established - say 6-10 months. Examples in this category are straw mats with and without a polypropylene netting, light excelsior blankets (under $0.5 \mathrm{lb} . / \mathrm{yd}^{2}$ ), hydromulches, jute meshes, polypropylene roving, and straw bales.

Other materials last several growing seasons before they ultimately biodegrade. Such blankets are useful in harsher environments - steep sideslope channels, high water velocities, and high shear stresses. Examples in this category include high grade excelsior blankets, straw - coconut coir mixtures, coconut coir, and UV-stabilized polypropylene roving. All of these products also biodegrade, albeit over 2-5 growing seasons depending upon the material, thickness of netting, and installation protocol. Even though the early stages of growth rely upon the blanket for strength, ultimate shear resistance is provided solely by the mature vegetation. In other words, the vegetation shear resistance should be used in long term design calculations rather than the shear resistance of the blanket. However, note that in the early stages of growth, the design is controlled by the shear resistance of the erosion control blanket (i.e. two sets of design calculations are required in this case; short and long term).

Still other erosion control materials are considered non-degradable. These materials are made of UV stabilized monofilaments of polypropylene or similar plastic. Some are low profile and placed on top of the seedbed (ECRMs - Erosion Control and Revegetation Mats); whereas, others are soil and seed filled (TRMs - Turf Reinforcing Mats). Both of these products are used in extremely harsh environments - high velocity or deep flows. ECRMs and TRMs are necessary for drainage channels in which vegetation alone cannot provide sufficient shear resistance against the design discharge. For a full description of each class of products, refer to the Literature Review section of this report.

It is apparent that each class of products has their own applications. Erosion control products are selected based upon the requirements of the site. For a channel with a design discharge of $16 \mathrm{ft}^{3} / \mathrm{s}$, base width of $4 \mathrm{ft}$, slope of $0.03 \mathrm{ft} / \mathrm{ft}$, and sideslope ratio of 3 , a wood 
excelsior would be an acceptable lining. However, if the base width is halved to $2 \mathrm{ft}$, an ECRM is required due to increased shear.

This example illustrates the fact that erosion control products are selected based upon their performance rather than traditional geosynthetic index tests - tensile strength, Mullen burst, percent elongation, and resiliency. This statement should not be misconstrued to imply that these tests are not important; rather, they may be useful for product classification purposes. However, industry representatives (from American Excelsior, Synthetic Industries, Nutec Supply, and the Erosion Control Technology Council - ECTC) interviewed in the course of this study strongly favor the selection of an erosion control blanket based on its shear resistance rather than index test data. These representatives support their position by pointing out that index test conditions are rarely, if ever, realized in the field. Moreover, there are no ASTM standards for testing erosion control materials. Currently, the ECTC is attempting to standardize index tests for erosion control materials, but to date, no resolutions have been released. Because of the industry's position, only 2 of the 25 companies contributing product information provided index test data for their products. Since the available data is so limited, no classifications in this report are based on index tests.

This doesn't imply that index tests are not used to classify products. Presently, the

\section{U.S. Department of Transportation (Federal Highway Administration) provides minimum} index test values for various classes of erosion control products $(\varangle 713.07,1992)$. The FHWA requires only the non-degradable materials (ECRM's and TRM's) to undergo thorough index testing. In addition, Ohio and Illinois Departments of Transportation also select erosion control materials based upon index tests.

Although this report recommends classifying products on a performance basis, it is worthwhile to summarize the specifications used in other states. These summaries become the basis for the proposed classification system. Twenty states were asked to provide their current specifications for erosion control products. Of the 11 responses, only 7 states provided specifications on erosion control materials (the remainder did not have current specifications). Also, one erosion control manufacturer (Synthetic Industries) provided a framework for a specification. The next several pages summarize each specification, including those obtained from the FHWA and Synthetic Industries. 


\subsection{Summary of Erosion Control Product Classification Systems}

\subsubsection{Virginia}

Type: Performance based (velocity) using an "approved list" format

(a). Products for ditch liners are broken into 2 categories - EC-2 \& EC-3

(b). EC-2 includes all degradable materials (jute mesh, straw, excelsior, coconut, or combinations).

Range of permissible velocity $\left(\mathrm{V}_{\mathrm{p}}\right): 2.5-4.0 \mathrm{ft} / \mathrm{s}$

Channels with $V_{p}<2.5 \mathrm{ft} / \mathrm{s}$ do not require an erosion control blanket

(c). EC-3 are the non-degradable ECRM's and TRM's which are sub-divided into two groups - A \& B

A: Specified in ditches with a 2-yr storm discharge velocity of 4.0-7.0 ft/s

B: Specified in ditches with a 2-yr storm discharge velocity of 7.0-10.0 $\mathrm{ft} / \mathrm{s}$

(d). New products are installed next to an "approved" material. The new material is monitored through several storm events to ensure that the installation does not fail and that vegetation grows. If it performs in an equal manner to the previously approved material, it is considered acceptable and added to the "Approved Products List" for that category.

\subsubsection{Ilinois}

Type: Index test based

(a). Excelsior Blankets - $80 \%$ of the fibers must be $150 \mathrm{~mm} \mathrm{(6")} \mathrm{or} \mathrm{longer,}$ cured to obtain barbed fibers. The blanket must be covered and entwined with a 90-day degradable netting having minimum opening of $16 \times 16 \mathrm{~mm}$ $(5 / 8$ " $\times 5 / 8$ "). The blanket must also resist a cigarette smolder test.

Minimum width $\quad 600 \mathrm{~mm}$

Minimum unit weight $0.5 \mathrm{~kg} / \mathrm{m}^{2}$

(24")

Minimum roll length $45 \mathrm{~m}$

(b). Knitted Straw Mat - weed free straw with a loose thickness of $13 \mathrm{~mm}$ $(1 / 2$ ") with the topside of the mat covered with a 90-day biodegradable plastic mesh of $10 \times 10 \mathrm{~mm}(3 / 8 \times 3 / 8$ ") square openings.

Minimum width $2 \mathrm{~m}$

Minimum unit weight $0.38 \mathrm{~kg} / \mathrm{m}^{2}$

$\left(0.70 \mathrm{lb} / \mathrm{yd}^{2}\right)$ 
(c). Fiber Mat - entangled nylon monofilaments, melt-bonded at their intersections, forming a stable mat (UV resistance)

Carbon black content

Filament diameter

Mass

Strength

Elongation

Resiliency
$0.5 \%$ by weight

$0.406 \mathrm{~mm}$

$0.41 \mathrm{~kg} / \mathrm{m}^{2}$

$1.4 \mathrm{~N} / \mathrm{mm}$

$0.8 \mathrm{~N} / \mathrm{mm}$

$50 \% \mathrm{~min}$.

$50 \% \mathrm{~min}$.

$80 \%$ after 3 cycles of $690 \mathrm{kPa}(100$ psi loading)

\title{
4.2.3 Ohio
}

Type: Performance (velocity) and Index based classification

(a). Straw blanket - $100 \%$ straw mat with topside covered with polypropylene degradable netting having an approximate $6 \times 6$ to $13 \times 13 \mathrm{~mm}(1 / 4 \times 1 / 4$ to $1 / 2 \times 1 / 2$ ") square openings

Minimum weight

$0.27 \mathrm{~kg} / \mathrm{m}^{2} \quad\left(0.5 \mathrm{lb} / \mathrm{yd}^{2}\right)$

(b). $70 \%$ straw, 30\% cocomut blanket - mat with topside degradable netting 16 x $16 \mathrm{~mm}(5 / 8 \times 5 / 8 ")$ square openings
Minimum weight
$0.27 \mathrm{~kg} / \mathrm{m}^{2}$
$\left(0.5 \mathrm{lb} / \mathrm{yd}^{2}\right)$

(c). ECRM - vinyl monofilaments bonded together to form a stable 3dimensional web. It must be permeable, resistant to chemical, environmental and UV degradation. Manufacture must also provide certified test data proving the material meets the following specifications:

Porosity

Flexural rigidity

Weight

Tensile Strength

Elongation

UV Resistance
$90 \%$

2000

$0.61 \mathrm{~kg} / \mathrm{m}^{2}$

$67 \mathrm{~N}$

$22 \mathrm{~N}$

$150 \% \mathrm{~min}$.

$100 \%$ min.

$95 \%$ $\left(18 \mathrm{lb} / \mathrm{yd}^{2}\right)$

(15 lbs)

( $5 \mathrm{lbs}$ )

$\begin{array}{ll}\text { (length) } & 150 \% \min . \\ \text { (width) } & 100 \% \mathrm{~min} .\end{array}$

(1)


(d). TRM - bulky structure of entangled nylon monofilaments having a minimum content of $0.5 \%$ carbon black.

Filament diameter

Unit Weight

Tensile Strength

(length)

(width)

Elongation

(length)

(width)

Resiliency

$$
\begin{array}{ll}
0.351 \mathrm{~mm} & (0.0138 ") \\
0.246 \mathrm{~kg} / \mathrm{m}^{2} & \left(0.454 \mathrm{lb} / \mathrm{yd}^{2}\right) \\
19.6 \mathrm{~N} / 25 \mathrm{~mm} & (4.48 \mathrm{lb} / \mathrm{in}) \\
9.8 \mathrm{~N} / 25 \mathrm{~mm} & (2.24 \mathrm{lb} / \mathrm{in}) \\
50 \% \mathrm{~min} . & \\
50 \% \mathrm{~min} . & \\
80 \% \mathrm{~min} .
\end{array}
$$

(e). Permissible velocity $1.22-1.52 \mathrm{~m} / \mathrm{s}(4-5 \mathrm{ft} / \mathrm{s})$ for degradable blankets For permissible velocity $1.52<\mathrm{V}_{\mathrm{p}}<3.05 \mathrm{~m} / \mathrm{s}\left(5<\mathrm{V}_{\mathrm{p}}<10 \mathrm{ft} / \mathrm{s}\right)$, use synthetic, non-degradable blanket (ECRM or TRM) (from $\S 839 \& 840$ ).

\subsubsection{Texas}

Type: Performance based using shear resistance, sediment loss, and minimum vegetation density

(a). A four class system that defines minimum performance standards for each class - E, F, G, H

\begin{tabular}{c|cccc}
\hline Type & $\begin{array}{c}\text { Shear Stress } \\
P a\left(l b / \mathrm{ft}^{2}\right)\end{array}$ & $\begin{array}{c}\text { Maximum } \\
\text { Sediment Loss } \\
\left(\mathrm{kg} / 10 \mathrm{~m}^{2}\right)\end{array}$ & $\begin{array}{c}\text { Minimum } \\
\text { Vegetation } \\
\text { Density }\end{array}$ \\
\hline $\mathbf{E}$ & $0-96$ & $(0-2)$ & 1.15 & $70 \%$ \\
$\mathbf{F}$ & $0-192(0-4)$ & 1.00 & $70 \%$ \\
$\mathbf{G}$ & $0-287(0-6)$ & 1.00 & $70 \%$ \\
$\mathbf{H}$ & $0-383(0-8)$ & 0.80 & $70 \%$ \\
\hline
\end{tabular}

(b). Manning's " $n$ " determined for all approved products by flume tests

(c). Contractors may use any of the products provided that the product is listed by brand name on the current "Approved Products List" for the Class and Type specified.

\subsubsection{Maryland}

Type: Performance based (velocity)

(a). Products classified into 2 categories - A \& B
A: $\quad \mathrm{V}_{\mathrm{p}}<1.52 \mathrm{~m} / \mathrm{s}$
$(<5 \mathrm{ft} / \mathrm{s})$
B: $\quad 1.52<\mathrm{V}_{\mathrm{p}}<2.44 \mathrm{~m} / \mathrm{s}$
$(5-8 \mathrm{ft} / \mathrm{s})$ 


\subsubsection{Connecticut}

Type: Performance based (shear strength)

(a). Products classified into 4 categories: E, F, G, H

\begin{tabular}{c|cc}
\hline Type & Shear Stress Range $-P a\left(b / f^{2}\right)$ \\
\hline E & $0-45$ & $(0-0.5)$ \\
F & $45-96$ & $(0.5-1.0)$ \\
G & $96-192$ & $(1.0-2.0)$ \\
H & $192+$ & $\left(2.0^{+}\right)$ \\
\hline
\end{tabular}

4.2.7 Synthetic Industries (Leading erosion control manufacturer)

Type: Performance based (velocity and shear strength)

(a). Products classified into 5 categories (C-1, C-2, C-3, C-4, C-5) that reflect the realistic performance limits for these materials

\begin{tabular}{|c|c|c|}
\hline Type & $\begin{array}{c}\text { Shear Resistance } \\
\mathrm{Pa}\left(\mathrm{lb} / \mathrm{ft}^{2}\right)\end{array}$ & $\begin{array}{c}\text { Permissible Velocity } \\
m / s \quad(f t / s)\end{array}$ \\
\hline C-1 & $<20 \quad(0.4)$ & $\begin{array}{ll}<0.5 & (1.6)\end{array}$ \\
\hline C-2 & $20-45(0.4-1.0)$ & $0.5-1.5(1.6-4.9)$ \\
\hline C-3 & $45-95(1.0-2.0)$ & $1.5-2.0(4.9-6.6)$ \\
\hline C-4 & $45-95(1.0-2.0)$ & $1.5-2.5(4.9-8.2)$ \\
\hline C-5 & $95-140(2.0-2.9)$ & $2.5-3.0(8.2-9.8)$ \\
\hline
\end{tabular}

4.2.8 FHWA - FP-92, 1992 \{Standard Specifications\}

Type: Index Based

(a). Synthetic Polypropylene Mesh
Minimum Weight
$0.76 \mathrm{~kg} / \mathrm{m}^{2}$
$\left(0.14 \mathrm{lb} / \mathrm{yd}^{2}\right)$
Tensile Strength
$3.3 \times 1.7 \mathrm{kN} / \mathrm{m}(225 \times 120 \mathrm{lb} / \mathrm{f})$
Elongation at break $32 \% \times 40 \%$
Mullen burst strength
$827 \mathrm{kPa}$
(120 psi)

(b). Erosion Control Mulch Blanket

Excelsior blanket

$80 \%$ of fiber 8 " or longer in length, top net of biodegradable plastic mesh
Dimensions
(Width)
$1.22 \mathrm{~m}$
(Length)
$55 \mathrm{~m}$
Weight
$0.42 \mathrm{~kg} / \mathrm{m}^{2}$
$(4 \mathrm{ft})$
$(180 \mathrm{ft})$
$\left(0.94 \mathrm{lb} / \mathrm{yd}^{2}\right)$ 
Straw blanket - $100 \%$ straw with medium to heavyweight square degradable netting
Weight
$0.22 \mathrm{~kg} / \mathrm{m}^{2}$
$\left(0.40 \mathrm{lb} / \mathrm{yd}^{2}\right)$

(c). Turf Reinforcing Mat

High strength, melt bonded polymer netting, monofilaments or fibers.

Tensile strength

Max. elongation

$1.4 \times 0.8 \mathrm{kN} / \mathrm{m}(94 \times 54 \mathrm{lb} / \mathrm{ft})$

Min. porosity

$75 \% \times 75 \%$

Resiliency

$90 \%$

UV Stability

$80 \%$

$80 \%$

(d). Synthetic Erosion Control and Revegetation Mat

Polyolefin monofilament fibers positioned between 2 biaxially orientated nets and mechanically bound by parallel stitching

Tensile strength

Max. elongation

$1.6 \times 0.53 \mathrm{kN} / \mathrm{m}(108 \times 36 \mathrm{lb} / \mathrm{ft})$

Min. porosity

$150 \% \times 100 \%$

Resiliency

$85 \%$

UV Stability

$80 \%$

$80 \%$

(e). Polypropylene Roving

Form a mat from continuous strands of fibrillated polypropylene yarn

Strands per rove

$20-28$

Fiber Diameter

360 denier

$\mathrm{m} / \mathrm{kg}(\mathrm{yd} / \mathrm{lb})$ of rove

$340-1050$

$(170-515)$ 


\subsection{Defining a Classification System for Erosion Control Products}

This report proposes to classify erosion control products by their performance rather than index test data. Limiting velocity and shear resistance for each product define its classification. Even though the industry is moving toward defining product strengths in terms of shear resistance, many manufactures do not yet provide this data. Flume tests are extremely expensive to perform properly. Hence, manufactures who have already performed velocity tests on their products are reluctant to spend additional money on shear resistance flume tests. More importantly, there are situations (already noted in the design methodology section of this paper) where the liner fails even though the shear resistance safety factor is greater than one (i.e. low depth, high velocity flow). In this case, failure is caused by the high velocity water eroding the soil below the blanket.

Because this synthesis is based on existing data only, the proposed classification relies on the classification schemes of other DOT's. Specifically, our classification system combines elements from Virginia, Texas, Connecticut, and Ohio as well as the Synthetic Industries model specification. Table 4-1 provides an overview of the proposed classification system.

\section{Proposed Classification System for Flexible Channel Liners}

\begin{tabular}{|c|c|c|}
\hline Classification & $\begin{array}{l}\text { Permissible Velocity } \\
\qquad \mathrm{m} / \mathrm{s}(\mathrm{ft} / \mathrm{s})\end{array}$ & $\begin{array}{l}\text { Permissible Shear } \\
\quad P a\left(l b / f t^{2}\right)\end{array}$ \\
\hline \multicolumn{3}{|c|}{$\begin{array}{c}\text { A (Degradable): Product degrade within } 2 \text { years (e.g. jute mesh, straw or coconut } \\
\text { blanket, excelsior, toving, straw bales, mulches.) }\end{array}$} \\
\hline A-1 & $0.0-1.2 \quad(0-4)$ & $0-45 \quad(0-1)$ \\
\hline A-2 & $1.2-2.1 \quad(4-7)$ & $45-96(1-2)$ \\
\hline \multicolumn{3}{|c|}{$\begin{aligned} \text { B (Non-degradable): } & \begin{array}{l}\text { Products stabilized with carbon black (e.g. nylon mesh, heat } \\
\text { bonded 3-D TRM, synthetic erosion control and revegetation mat) }\end{array}\end{aligned}$} \\
\hline B-1 & $1.2-2.1 \quad(4-7)$ & $45-96 \quad(1-2)$ \\
\hline B-2 & $2.1-3.0 \quad(7-10)$ & $96-240(2-5)$ \\
\hline
\end{tabular}

Table 4-1: Proposed classification system for erosion control products 
This classification system is entirely performance based. Indeed, the concept for this classification system is derived from other state DOT's specifications (refer back to the summaries of the DOT's specifications). By dividing the products into two general categories (A \& B), one can eliminate half of the products by answering the question, "Must the erosion control material last for the entire design life?" If the answer is "Yes," then the contractor is limited to category B. Further subdividing the categories by performance characteristics allows selection of cheaper products for less erosive situations.

Moreover, using both velocity and shear resistance limits falls in line with the proposed design methodology. Recall that the design methodology was based on computing both the shear and velocity induced during a given storm event. It follows then that the classification system should use both quantities. In the event that shear resistance and permissible velocity for a site fall under different classifications, one must choose the more resistant category (either A-2 or B-2).

Defining product classification by both velocity and shear resistance is beneficial. It encourages designers to calculate both shear strength and velocity (and their safety factors). It also allows more products to be classified (Recall that some manufactures only provide velocity or shear data alone). Unfortunately, herein lies a problem. What guarantee does the contractor have that a product classified using permissible velocity performs equally as well as one classified using shear resistance? We need some proof that the velocity range for a particular class provides the same strength as the shear range for that class. In other words, we need to determine if the two classifications are equivalent.

This requires finding a relationship between the velocity and shear resistance. Recall that the proposed design methodology uses a modified form of Manning's equation:

$$
\mathrm{V}_{\mathrm{p}}=\frac{0.189 \mathrm{R}^{1 / 6} \tau_{\mathrm{p}}{ }^{1 / 2}}{\mathrm{n}_{\mathrm{c}}}
$$

Using this equation and the ranges of shear strength provided in the proposed classification, one generates limiting velocities. The Velocity-Shear graph (figure 4.1) plots this equation for several values of $\mathbf{R}$ (hydraulic radius). Superimposed on the graph are shaded regions corresponding to the categories of the proposed classification system. Notice that the shaded regions by no means encompass all possible geometries. However, given the 

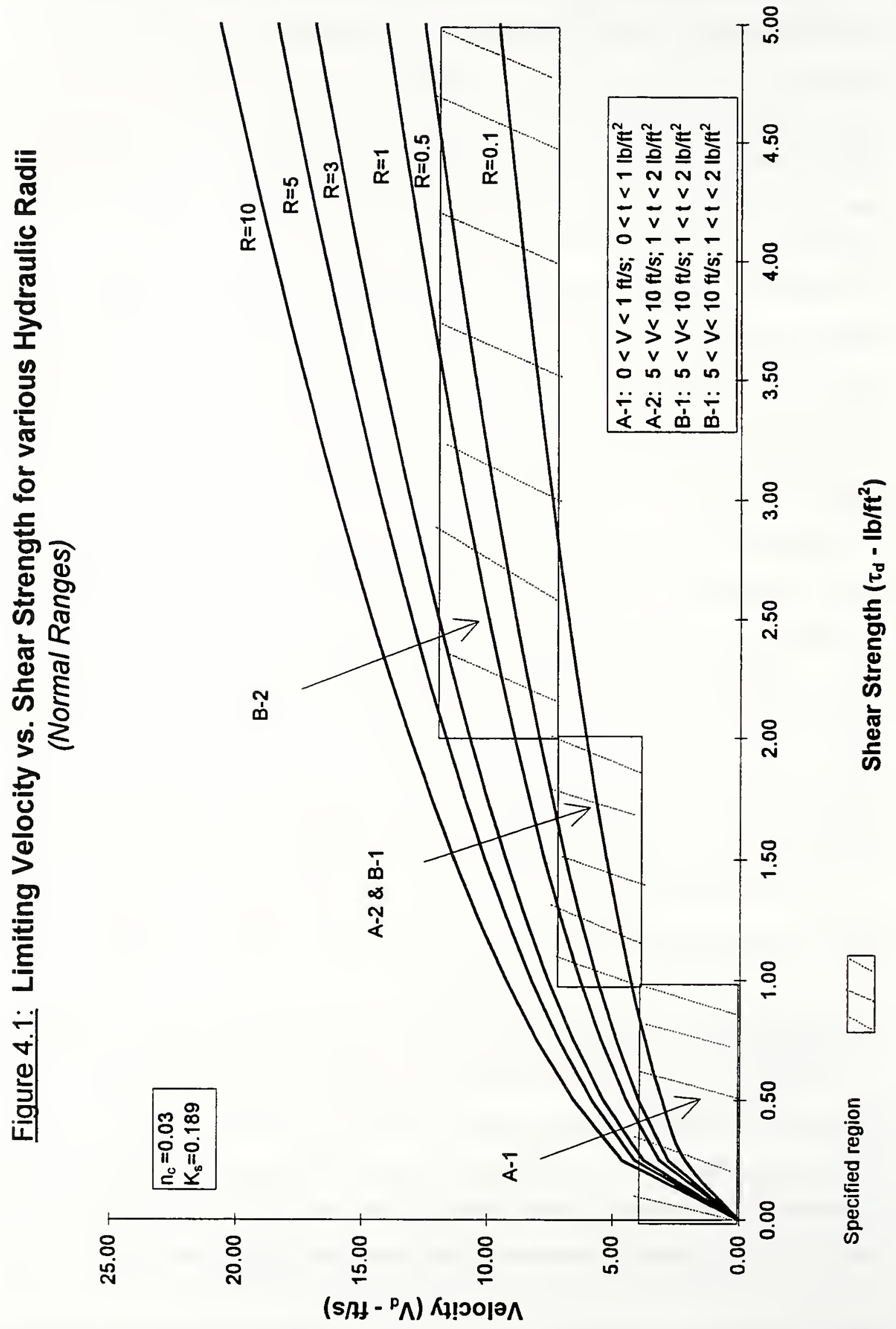
limitations of using a simple model, the proposed ranges of shear stress and velocity appear to be equivalent. If the classification system was grossly in error, most of the lines would not be included in any of the shaded regions.

In order to improve the classification system to include more area of the graph, it is necessary to change the ranges of either velocity or shear stress requirements. The suggested shear stress ranges are pretty much standard, but the velocity ranges are somewhat variable (see the previous specification summaries). As such, changes to the velocity ranges are made as shown in table 4-2.

\section{Classification System with Modified Velocity Ranges}

\begin{tabular}{|c|c|c|}
\hline Classification & $\begin{array}{l}\text { Permissible Velocity } \\
\mathrm{m} / \mathrm{s}(\mathrm{ft} / \mathrm{s})\end{array}$ & $\begin{array}{l}\text { Permissible Shear } \\
P a\left(l b / f t^{2}\right) \\
\end{array}$ \\
\hline \multicolumn{3}{|c|}{$\begin{array}{l}\text { A (Degradable): Product degrade within } 2 \text { years (e.g. jute mesh, straw or coconut: } \\
\text { blanket, excelsior, roving, straw bales, mulches.) }\end{array}$} \\
\hline A-1 & $0.0-1.5 \quad(0-5)$ & $0-45 \quad(0-1)$ \\
\hline A-2 & $1.5-3.0 \quad(5-10)$ & $45-96(1-2)$ \\
\hline \multicolumn{3}{|c|}{$\begin{array}{l}\text { B (Non-degradable): } \begin{array}{l}\text { Products stabilized with carbon black (e.g nylon mesh, heat } \\
\text { bonded 3-D TRM, synthetic erosion control and revegetation mat) }\end{array}\end{array}$} \\
\hline B-1 & $1.5-3.0 \quad(5-10)$ & $45-96(1-2)$ \\
\hline B-2 & $3.0-4.6(10-15)$ & $96-240(2-5)$ \\
\hline
\end{tabular}

\section{Table 4-2: Classification system with modified velocity ranges that better fit} Manning's equation

Figure 4-2 uses these new velocity ranges. Notice that these ranges encompass nearly all of the graph. From a theoretical standpoint then, these modified velocity ranges correspond better to the proposed shear strength ranges. That is, these alternative velocity ranges are more representative of the available strength.

The question then is which velocity range is more appropriate? Based on other DOT specifications, the first velocity range is more accepted even though it does not fit the theoretical data as well. More sophisticated shear stress - velocity models such as the Lane method (1953) which utilizes drag and lift coefficients, soil diameter, and density may provide a better correspondence between the theory and suggested shear / velocity ranges. One could also use a modified Shields diagram from Vanoni (1975) to obtain a similiar velocity-shear 

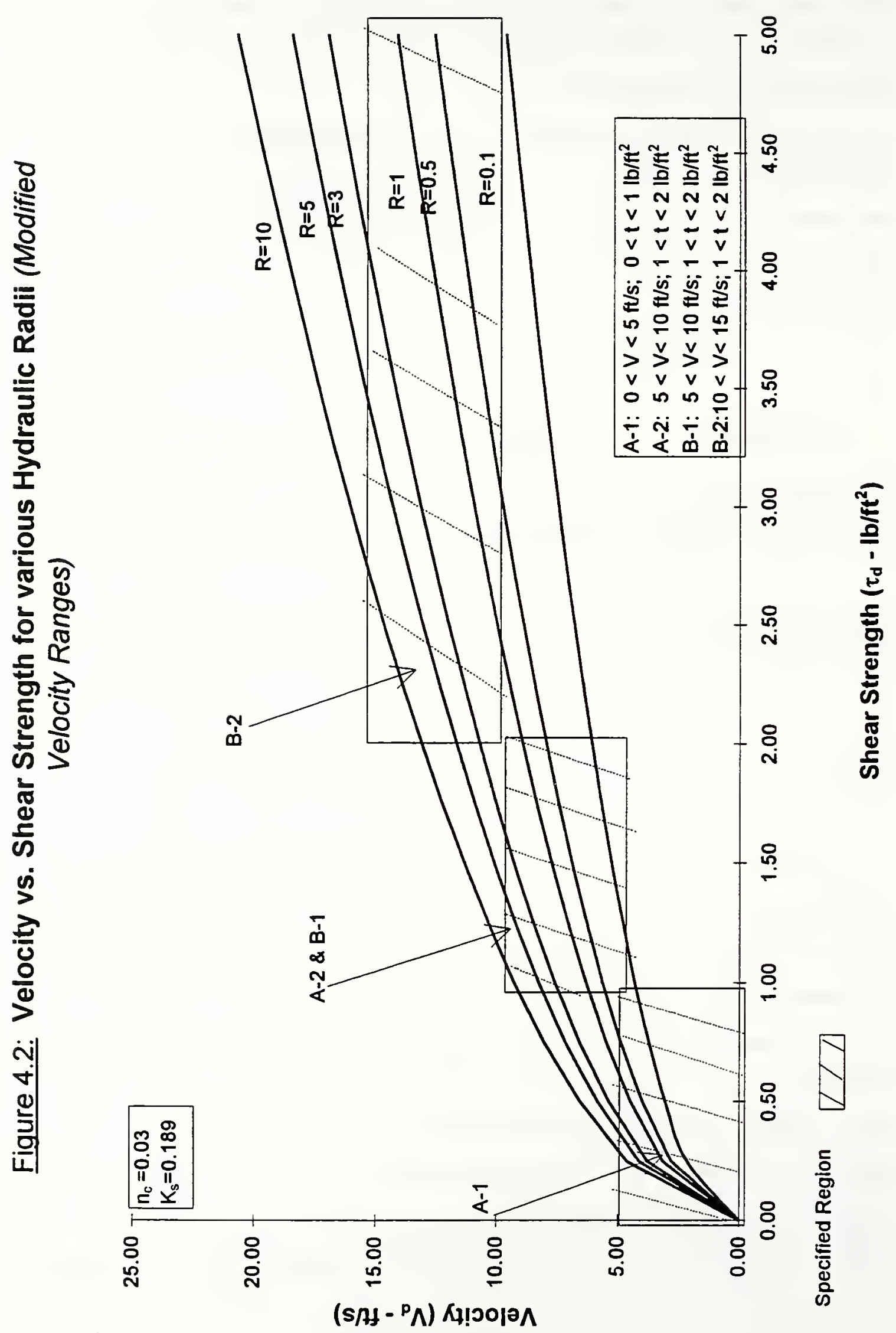
relationship (see figure 4-3). Unfortunately, the diagram is only useful for bare soil; further testing must be done to determine where erosion control materials lie on such a diagram. However, such testing and analysis is beyond the scope of this report. The point of this discussion is to at least loosely show that a theoretical basis exists for a combined shear velocity classification system.

The next question to ask is whether index tests have any place in the proposed specification. It was already mentioned that some of the available tests do not simulate field conditions closure. Recall that such tests (Mullen burst, tensile strength, and elongation, and resiliency) are derived from the textile (clothing) industry tests.

On the other hand, other tests and/or material parameters may be useful. Among them include UV stability, porosity or percent ground cover, thickness, unit weight, length, and width. Of these tests, UV stability is of utmost importance for ECRMs and TRMs. It may either be specified by percent carbon black or the percent strength remaining after the Xenon light test. Percent ground coverage would be useful for selecting a material of appropriate density. Unfortunately, there is currently no accepted method of determining a product's "ground cover factor" (note: light projection is used, but no ASTM standard exists). Index test are also useful in quantifying the survivability during installation. For a complete review of index tests and survivability criteria for geosynthetics, the interested reader should consult Koener's text, Designing with Geosynthetics (1994).

In terms of the products dimensions, no literature or research result is available that compares the merits of using longer, wider materials over shorter, thinner ones. However, several states including the FHWA do have minimum or approximate roll dimensions. If specified, the roll dimensions should only be approximate; products rarely fail because they are too short! The primary reason for specifying dimensions is to speed installation (no one wants installation encumbered by thin or short products). Using longer, wider products means fewer overlap areas or seams. 


\section{Modified Shields Diagram}

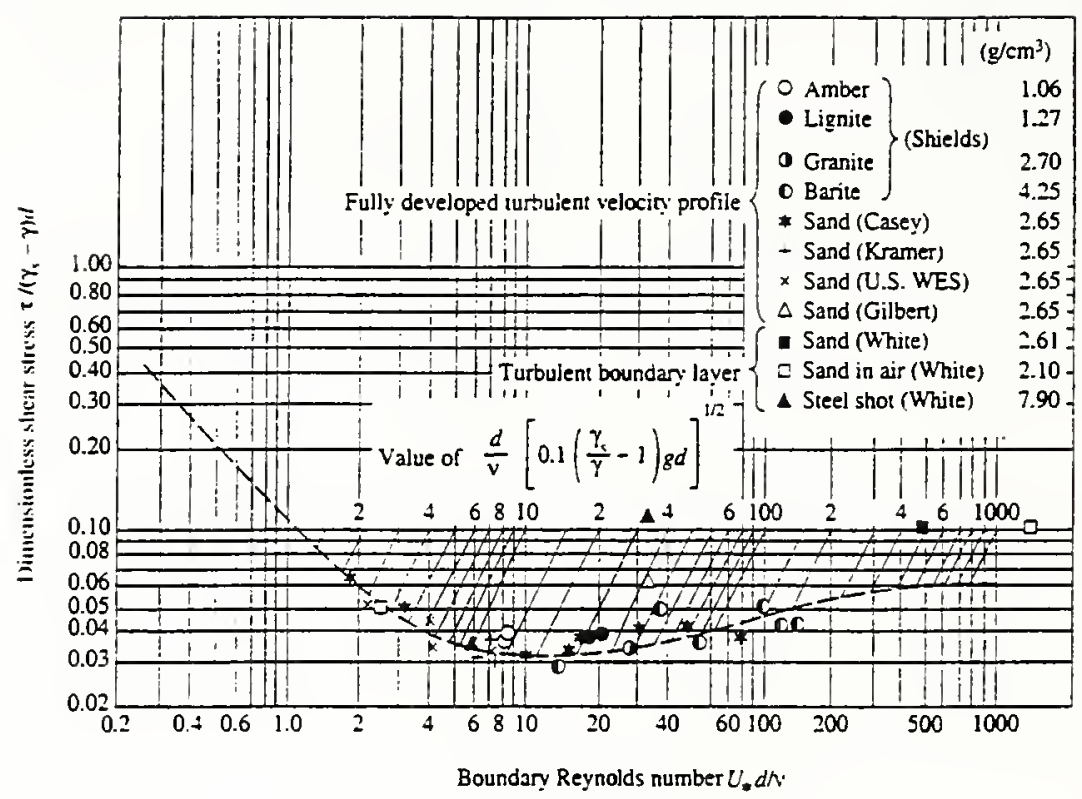

Figure 4-3: Shields diagram for incipient motion. Notice it includes the Vanoni modification. (Reprinted from Chih Ted Yang, 1996) 
In terms of index tests then, this report recommends the following:

$\checkmark \quad$ Approximate roll dimensions

$\checkmark \quad$ Short product descriptions (name, material, \& color)

$\curvearrowleft \quad$ Material parameters (mass per unit area, netting size, carbon black content)

On the other hand, the following index tests are not included in this specification

\& Mullen burst

$\approx$ Tensile Strength

\& Elongation

\& Resiliency

$£$ Ground Cover Factor

It is the opinion of the authors that these material properties are useful for classification and quantifying survivability. However, ultimate selection of an erosion control product still rests with its performance characteristics (i.e. shear and velocity resistance). The following pages outline the index tests relevant to each performance classification.

The information is compiled from HEC-15, 1988; Standard Specifications for Construction for Roads and Bridges on Federal Highway Projects, FP-92, 1992, FWHA; Synthetic Industries Proposed Index Based Specification, Nov. 1995; Illinois, Ohio, and Texas DOT's Construction Specification Guides, 1993,1994, \& 1995. 


\subsection{Index Properties for Classification A (A-1, A-2)}

\section{Jute Mesh}

Description: Uniform open weave, smolder resistant, fabricated from jute yarn that does not vary in thickness by more than $1 / 2$ its normal diameter.

Material Properties (Approximate):

$\begin{array}{lll}\text { Length } & 68.6 \mathrm{~m} & (225 \mathrm{ft}) \\ \text { Width } & 1.22 \mathrm{~m} & (4.0 \mathrm{ft}) \\ \text { Mass/Area: } & 0.59 \mathrm{~kg} / \mathrm{m}^{2} & \\ \text { UV Resistance: } & \text { N/A } & \\ \text { Color: } & \text { Brown } & \end{array}$

\section{Polypropylene Roving}

Description: Continuous fibers drawn from molten polypropylene that is ejected by compressed air; the mat of fibers are coated with a degradable, liquid asphalt. Neither the polypropylene nor the asphalt shall contain chemicals toxic to plant or animal life.

Material Properties:

Variable length, width, and thickness

Strands per rove: $\quad 20-30$

$\mathrm{m} / \mathrm{kg}(\mathrm{yd} / \mathrm{lb}$ ) of rove: $340-600$

$\mathrm{km} / \mathrm{kg}(\mathrm{yd} / \mathrm{lb})$ strand: $26.2-28.2$

Organic content : $\quad 1.0 \%$ (max.)

Mass/Area:

$0.19 \mathrm{~kg} / \mathrm{m}^{2}$

\section{Excelsior (Curled Wood) Mat}

Description: Machine produced excelsior wood mat of $80 \%, 6$ " or longer fiber. The top side should be covered with a biodegradable plastic mesh. The wood from which the excelsior is cut shall be properly cured to achieve adequately curled fibers

Material Properties (Approximate)

$\begin{array}{lll}\text { Length } & 45.7 \mathrm{~m} & (150 \mathrm{ft}) \\ \text { Width (min.) } & 0.91 \mathrm{~m} & (4.0 \mathrm{ft}) \\ \text { Mass/Area (min.) } & 0.51 \mathrm{~kg} / \mathrm{m}^{2} & \left(0.94 \mathrm{lb} / \mathrm{yd}^{2}\right) \\ \text { Netting size } & 16 \times 16 \text { to } & (5 / 8 \times 5 / 8 " \text { to } \\ & 50 \times 25 \mathrm{~mm} & 2 " \times 1 ")\end{array}$




\section{Index Properties for Classification A (Continued)}

\section{Straw Blanket}

Description: Machine produced 100\% agricultural straw mat that is sewn to a degradable polypropylene netting.

Dimensions (Approximate)

$\begin{array}{lll}\text { Length } & 45.7 \mathrm{~m} & (150 \mathrm{ft}) \\ \text { Width } & 1.22 \mathrm{~m} & (4.0 \mathrm{ft}) \\ \text { Thickness } & 13 \mathrm{~mm} & (0.5 \mathrm{inch}) \\ \text { Mass/Area } & 0.27 \mathrm{~kg} / \mathrm{m}^{2} & \left(0.5 \mathrm{lb} / \mathrm{yd}^{2}\right) \\ \text { Netting Weight } & 1.1 / 93 \mathrm{~kg} / \mathrm{m}^{2} & \left(2.5 \mathrm{lb} / 1000 \mathrm{ft}^{2}\right) \\ \text { Netting Size } & 10 \times 10 \mathrm{to} & (3 / 8 \times 3 / 8 " \text { to } \\ & 13 \times 13 \mathrm{~mm} & 1 / 2 \times 1 / 2 ")\end{array}$

\section{Combined Straw and Coconut Blanket}

Description: Blanket consists of $70 \%$ straw and $30 \%$ coconut coir with a top side degradable netting. The blanket shall be of consistent thickness with the straw and coconut fiber evenly distributed over the entire area of the mat. Both sides of the mat should be covered with a degradable netting which is sewn to the mat with degradable thread.

Material Properties:

$\begin{array}{lll}\text { Length } & 45.7 \mathrm{~m} & (150 \mathrm{ft}) \\ \text { Width } & 1.22 \mathrm{~m} & (4.0 \mathrm{ft}) \\ \text { Mass/Area } & 0.27 \mathrm{~kg} / \mathrm{m}^{2} & \left(0.5 \mathrm{lb} / \mathrm{yd}^{2}\right) \\ \text { Netting Size } & 6 \times 6 \mathrm{~mm} \text { to } & \left(1 / 4 \times 1 / 4^{\prime \prime} \text { to }\right. \\ & 16 \times 16 \mathrm{~mm} & 5 / 8 \times 5 / 8 ”)\end{array}$

\section{Coconut Coir Blanket}

Description: Blanket consists of $100 \%$ coconut fiber. The blanket shall be covered on the top and the bottom with a polypropylene netting. The netting shall be sewn together with polyester thread.

Material Properties:

$\begin{array}{lll}\text { Length } & 45.7 \mathrm{~m} & (150 \mathrm{ft}) \\ \text { Width } & 1.22 \mathrm{~m} & (4.0 \mathrm{ft}) \\ \text { Mass/Area } & 0.27 \mathrm{~kg} / \mathrm{m}^{2} & \left(0.5 \mathrm{lb} / \mathrm{yd}^{2}\right) \\ \text { Netting size (approx.) } & 16 \times 16 \mathrm{~mm} & (5 / 8 \times 5 / 8 ")\end{array}$




\subsection{Index Properties for Classification B: (B-1, B-2)}

\section{Turf Reinforcing Mat (TRM):}

Description: Synthetic mat consisting of 3-D structure of entangled nylon monofilaments, melt bonded, or mechanically bonded to form a dimensionally stable mat. Bonding methods include polymer wielding, thermal fusion, or the placement of fibers between 2 nets bound together by polyolefin thread. Must include minimum $0.5 \%$ carbon black by weight. Every component of the matrix shall be stabilized against UV degradation and inert to chemicals normally found in the environment.

Material Properties (Approximate)

Color:

Black

Thickness:

$15.2 \mathrm{~mm}$

(0.6 inch)

UV Resistance:

$80 \%$

Mass/Area:

$0.48 \mathrm{~kg} / \mathrm{m}^{2}$

Width:

$0.97 \mathrm{~m}$

Length:

$100 \mathrm{~m}$

\section{Synthetic Erosion Control Revegetation Mats (ECRM)}

Description: Dense web of green polyolefin fibers positioned between two biaxiallyorientated nets and mechanically bound by parallel stitching with polyolefin thread. Every component of the matrix shall be stabilized against UV degradation and inert to chemicals normally found in the environment.

Material Properties (Approximate)

Color:

Green

Width:

$0.97 \mathrm{~m}$

Length:

$100 \mathrm{~m}$

Thickness:

$6.35 \mathrm{~mm}$

Mass/Area

$0.54 \mathrm{~kg} / \mathrm{m}^{2}$

$(327 \mathrm{ft})$

UV Stability

$85 \%$

(0.25 inch)

$\left(1 \mathrm{lb} / \mathrm{yd}^{2}\right)$ 


\subsection{Summary of Erosion Control Product Classification}

This section outlined a proposed classification system for erosion control products. Input received from industry representatives guided us toward a performance based system. In mirroring other DOT's erosion control specifications, products are categorized according to their shear and velocity resistance characteristics. First, two general classifications are created degradable and non-degradable. Next, each of these general classifications is subdivided into two performance based categories. Each category has a suggested shear and velocity range. The table below reiterates the proposed classification system.

\begin{tabular}{|c|c|c|}
\hline Classification & $\begin{array}{c}\text { Permissible Velocity } \\
\mathrm{m} / \mathrm{s}(\mathrm{ft} / \mathrm{s})\end{array}$ & $\begin{array}{l}\text { Permissible Shear } \\
\mathrm{Pa}\left(\mathrm{lb} / \mathrm{ft}^{2}\right)\end{array}$ \\
\hline \multicolumn{3}{|c|}{$\begin{array}{l}\text { A (Degradable): Product degrade within } 2 \text { years (e.g. jute mesh, straw or coconut } \\
\text { blanket, excelsior, roving, straw bales, mulches..) }\end{array}$} \\
\hline A-1 & $0.0-1.2 \quad(0-4)$ & $0-45 \quad(0-1)$ \\
\hline A-2 & $1.2-2.1 \quad(4-7)$ & $45-96(1-2)$ \\
\hline \multicolumn{3}{|c|}{$\begin{array}{l}\text { B (Non-degradable): Products stabilized with carbon black (e g. nylon mesh, heat } \\
\text { bonded 3-D TRM, synthetic erosion control and revegetation mat) }\end{array}$} \\
\hline B-1 & $1.2-2.1$ & $45-96(1-2)$ \\
\hline B-2 & $2.1-3.0 \quad(7-10)$ & $96-240(2-5)$ \\
\hline
\end{tabular}

A theoretical basis for this combined shear and velocity classification is suggested. The proposed ranges are superimposed on a plot of limiting velocity versus shear strength. A modified form of Manning's equation provides a simple relationship between permissible velocity and permissible shear strength. Since the ranges cover most of the feasible region of the graph, we conclude that the ranges indeed have a theoretical basis.

Several states, including the FWHA, use index based systems to classify erosion control products. Unfortunately, rarely are the test conditions for these indices realized in the field (recall that these tests came out of the textile industry). Consequently, this report only recommends using the most basic material properties: descriptions, dimensions, color, unit weight, and UV stability (or carbon black content). These parameters may be considered "minimum performance standards." The first step in approving an erosion control material may be how well the product meets these index properties. 
The index values suggested in this report are only approximate since the products come in wide range of length, width, weight, etc. Furthermore, no literature was found that correlates index properties to field performance. Hence, there appears to be no one length, width, unit weight, elongation, or tensile strength that is most appropriate for any material. While these material properties are useful for initial product classification and survivability, their utility in final product selection is debatable. 


\section{5: Classifying New Products / Product Approval Methods}

\subsection{Introduction to product classification}

The erosion control industry is rapidly expanding. With each passing year, 20-30 new products are placed on the market. Some are upgrades of previous products, while others are new materials altogether. Verdyol's High Velocity Ero-Mat and BonTerra's CS-2 are examples of the former while Synthetic Industries' Pyramat and North American Green's C350 - 3 Phase are examples of the latter. Over the past 5 years, nearly 150-200 new erosion control products have appeared on the market. At the same time, some products have been upgraded or even dropped entirely from manufacturers lines.

Unfortunately, not all products are created equal. Some are degradable, while others are UV stabilized. The degradable products include jute, straw, roving, excelsior, hydromulch, netting, and even coconut fiber. Each manufacturer typically carries 2-5 products made of the same material. For example, Belton Industries carries 3 types of coconut coir blankets (Dekowe 400, 700, and 900). Similarly PPS Packaging Company supplies 3 excelsior blankets (X-Cel Regular, Superior, and Super Duty). Many more companies could be added to this list as well.

For instance, typical differences between the Dekowe products (as with other manufactures product lines) include netting size and/or weight, overall unit weight of the blanket, stitching differences, increased UV stability, rapid degradation (so called "environment friendly" products) and the addition of seed mixtures.

For non-degradable materials, there are even more choices. Differences here include stitching methods, unit weight, monofilament patterns, thickness, UV stability, porosity, tensile strength, texture, flexibility, and most importantly, shear resistance. In short, classifying erosion control products can rapidly become a Materials Departments worst nightmare.

This section presents two current DOT methods of classifying erosion control products - Texas and Virginia. Each of these states use a performance based classification system, similar to the one proposed for Indiana. As such, they provide a good basis for the suggested new product approval process for Indiana. Following this review, two methods for approving erosion control products are proposed. Method 1 is based on the Texas and Virginia approval procedures. Using the data collected from manufacturers' product documentation, a tentative 
"Approved Products List" is proposed. Method 2 uses a "guarantee specification" format. It is based on the recommendations of the Study Advisory Committee.

\subsection{Texas DOT New Erosion Control Product Evaluation Procedure}

Source: Northcutt, Paul, "Final Performance Analysis - 1995 Evaluation Cycle: Class 1 - Slope Protection, Class 2 - Flexible Channel Liners,” TxDOT / TTI Hydraulics and Erosion Control Laboratory, 1996.

Texas DOT uses an approved list format for erosion control products. Each product is installed in a channel at their facility and tested at various channel flows (shear stresses) after vegetation is established. Products are evaluated based on shear resistance, sediment loss, and vegetation density.

Texas DOT in conjunction with the Texas Transportation Institute - TTI (an affiliate of Texas A \& M) has the premiere erosion control testing facility in the country. The facility is located on a ridge above the Brazos River where it is exposed to harsh climatic conditions. The flexible liner testing area consists of 10 channels ( 6 with a $7 \%$ grade and 4 with a $3 \%$ grade). Each channel has a trapezoidal cross section, 1 foot bottom width, 1:1 channel sideslopes, a 3 feet depth, and a 85 feet length.

Participants in the approval program may elect to install the blankets themselves or commission TTI to do the work. In either case, the manufacturer may specify the shear stress range most appropriate for their product. Generally, the $3 \%$ channels are used to evaluate degradable products that withstand up to $96 \mathrm{~Pa}$ ( $2 \mathrm{psf}$ ); whereas, the $7 \%$ channels are used to evaluate products that withstand higher shear stresses.

All soil retention blankets are installed in strict accordance with the manufacturer's procedure. Each plot receives the same seed mixture and quantity of fertilizer. Products are installed in mid-March and testing is completed by the end of December. After determining Manning's " $n$ " in laboratory flume tests, plots are left to grow for 90 days. Before testing, vegetation density is established. Two short term tests (20 minutes each) are performed starting at $96 \mathrm{~Pa}$ (2 psf). Tests continue on a $48 \mathrm{~Pa}$ (1 psf) increment. Soil loss is monitored and compared to the standard at each increment. Products are approved for a given shear resistance as long as sediment loss and vegetation density are within established standards. Passing products are placed in the appropriate category $(\mathrm{E}, \mathrm{F}, \mathrm{G}, \mathrm{H})$ depending on the shear 
resistance (see previous section for shear ranges for each category). Currently, sediment loss is limited to $1.00 \mathrm{~kg} / \mathrm{m}^{2}$ while vegetation density must be at least $70 \%$.

One important restriction is that TTI does not test cellulose fiber mulch (i.e. hydromulch) using the above procedure. It is their opinion that the these materials cannot perform as well as a soil retention blanket. Plots are instead monitored solely for vegetation density. If the final density is greater than the minimum, it is placed on the approved list for slopes 3:1 and less (See table 5-1 for the current TXDOT approval list)

Approved Erosion Control Products for the Texas DOT - 1995 Evaluation Cycle

Type E. Shear Stress Range 0-96 Pa (0-2 psf)

Contech C-45

Enkamat 7020

Landlok ECRM 450

Miramat TM8

North American green C350 - 3 Phase

Pec-Mat

Tensar Erosion Mat TM3000

Webmat 280

Type F: Shear Stress Range 0-192 (0-4 psf)

Contech C-45

Landlok ECRM 450

Miramat TM8

North American green C350 - 3 Phase

Pec-Mat

Webmat 280

Tensar Erosion Mat TM3000

Type G: Shear Stress Range 0-287 Pa (0-6 psf)

Contech $\mathrm{C}-45$

Landlok ECRM 450

Webmat 280
North American green C350 - 3 Phase

Pec-Mat

Tensar Erosion Mat TM3000

Type G. Shear Stress Range 0-287 Pa (0-6 psf)

Contech C-45

Landlok ECRM 450
North American green C350 - 3 Phase

Tensar Erosion Mat TM3000

\section{Table 5-1: Texas DOT Approved Products List}




\subsection{Virginia DOT New Erosion Control Product Evaluation Procedure}

Because of the wide variety of synthetics used and strength specifications listed for each material, VDOT also uses an "Approved Products List." Similar to TxDOT, VDOT requires a successful field installation before placing a product on the approved list. After new products are submitted to VDOT for approval, they are installed on an active construction project adjacent to a product on the "Approved Products List." The new material is monitored through several storm events to ensure the installation does not fail. It is also monitored to ensure the vegetation is established and grows. If the product performs in an equal manner to the previously approved material, it is considered acceptable and added to the "Approved Products List." However, if the product tears, shears, or exhibits characteristics that inhibit the establishment of vegetation, it is rejected. Extremely dense mats that prevent vegetation from growing through them or materials that leach toxic chemicals are examples of these characteristics.

After approval, products are periodically inspected. If a product had a successful test but later fails (tear, washout, no vegetation growth), then the material is removed from the "Approved Products List." It is recognized that failure may not have been caused by poor materials. Rather, poor installation (improper check slots or staking patterns), underestimating the storm discharge, and bad seed mixtures are often the real reason the material failed. Consequently, the failure is documented and reviewed. Following this period, products may reapply to the "Approved List" if the failure was caused by these other factors.

Table 5-2 is the current VDOT "Approved List" for erosion control materials. There are two general categories - EC-2 (2.5-4.0 ft/s) and EC-3 (4-10 ft/s). 
VDOT “Approved Products List” for Erosion Control Materials

EC-2: Permissible Velocity 2.5-4.0 fi/s

\section{Curlex}

Dekowe 700, 900

Jute Mesh - Bemis Brothers Bag Co.

Jute Mesh - Belting Bagging Co.

Jute Mesh - JMD

Jute Mesh - Ludlow Manufacturing

Jute Mesh - B\&M Packaging Co.

North American Green S-75, SC-150

Soil Saver Heavy Jute Mesh
Anti-wash Geojute

X-Cel, X-Cel Superior, Permamat 100

Poplar Stitched Blanket - Winters Excelsior

Ridgegrow Excelsior ECB

Std \& High Velocity Excelsior

BioD-Mat 70, 90

BonTerra S-1, S-2, CS-2, C-2

North American Green C-125

Earthlock - ECS Products

EC-3 Type A: Permissible Velocity 4.0 - 7.0 ft/s

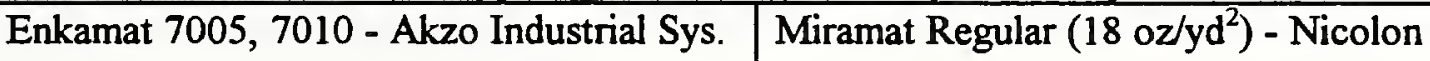

Landlok 1050 - Synthetic Industries

\section{EC-3 Type B: Permissible Velocity 7.0-10.0 ft/s}

Bon Terra America SFB

Tensar TB1000 \& TM3000

Landlok 435, 450, 460, \& 1060

PEC-MAT - Greenstreak
Enkamat 7012, 7020, 7210, \& 7220

Miramat Heavyweight - Nicolon

North American Green P-300, P300P

Table 5-2 Virginia DOT Approved Products List 


\subsection{Proposed Erosion Control Product Approval Procedure}

Based on the reviews of the Texas and Virginia erosion control approval procedures, it is apparent that a field test should be implemented. Method 1 then details a procedure (largely drawn from the Virginia DOT) that incorporates a season long field test. However, given the large number of products that are available today and the limited manpower of the INDOT new products committee, it has been suggested that a less rigorous approval procedure be investigated. Specifically, the SAC wanted to look at a "guarantee" approval process. This is detailed under Method 2.

\subsubsection{Method 1 - field test approval procedure}

Because the suggested design procedure and classification system is entirely performance based, it makes sense to include field testing in the approval process. The best case scenario indeed is to create a separate testing facility as in Texas. However, this is not economically feasible. On the other hand, Virginia's approval process may be more appropriate for Indiana. Classification followed by a short field monitoring program is all that is needed.

This report suggests a two-step approval process. The first step following the submittal of a new material is its classification. The manufacturer must provide complete product documentation, a 6 " square sample, and installation guidelines. Using this information, the erosion control material is classified (A-1, B-1, etc...). Notice that permissible shear and/or permissible velocity data must be included in the application packet. Without this information, the product could not be approved.

Also, the available index test data (dimensions, UV stability, unit weight, etc..) should be compared to the suggested index test parameters. If the product is degradable, one must determine its type (i.e. coconut, straw, excelsior, or a combination). If the product is nondegradable, one needs to determine whether the product is an ECRM or a TRM. Based on the performance and index data, the material is given a tentative classification.

After installation, the product is monitored for one growing season. Product performance is quantified in terms of appearance, vegetation density, sediment loss, and shear resistance. The following questions should be answered for each site. 
Appearance: Look at the vegetation. Is the growth thick, spotted, or non-existent? Is the blanket still intact or is washed out. Look especially along the centerline of the channel. Does the blanket have any tears? Is it pulled out from its anchor slots? Did the blanket completely fail (wash downstream). Is undermining a problem (water flowing beneath the blanket).

Vegetation Mark off five points at 20' intervals along the channel. Qualitatively Density: determine the vegetation density at each location for both the sideslopes and centerline. Average should be greater than $70 \%$.

Sediment Are there any noticeable rills, gullies, bare spots, or other damaged areas? Loss: Is soil able to move under the blanket? (i.e. poor blanket to ground contact caused by poor stapling). Has soil caked over the blanket any choked off all seedlings?

Shear Did the blanket withstand the design flow? If not, how intense was the Resistance: storm? Was it above the design rate? If there is water in the channel, record depth, speed, and flow rate. Look especially around staples and check slots for tears. (This is more important for the non-degradable TRMs and ECRMs).

These assessments would be made at least three times during the growing season, say at 2,6, and 12 weeks after installation. It is important to have one site visit soon after installation since the site is most vulnerable to erosion during this period. Extreme weather (thunderstorms or drought) often devastates a site during vegetative establishment. Such extenuating circumstances should be noted during a site visit. Table 5-3 summarizes method 1 . 
Method 1 - Erosion Control Material Approval Process

\begin{tabular}{|ll|}
\hline Step in Approval Process & Description of Steps \\
\hline Step 1: Application & $\begin{array}{l}\text { Submit application, } 6 \times 6 \text { " product sample and } \\
\text { product documentation to Materials Dept. }\end{array}$ \\
\hline Step 2: Classification & $\begin{array}{l}\text { Place product into tentative category based on } \\
\text { performance data (A-1, B-1, etc...) }\end{array}$ \\
\hline Step 3: Field Installation & Install product in place of "approved" product \\
\hline Step 4: Field Monitoring & $\begin{array}{l}\text { Monitor appearance, vegetation density, sediment } \\
\text { loss, and shear resistance for one growing season }\end{array}$ \\
\hline Step 5: Final Approval & $\begin{array}{l}\text { Product placed on list if field performance is } \\
\text { satisfactory }\end{array}$ \\
\hline
\end{tabular}

\section{Table 5-3: Approval Procedure for Erosion Control Products}

Remember, with an "Approved-List Format," INDOT must maintain the following:

1). an approved list of erosion control products (see section 5.5 for an example)

2). installation procedures for each class of erosion control products

3). regular inspections for all erosion control projects

4). large databases of product documentation (performance data, etc...)

\subsubsection{Proposed New Product Approval Process - Method 2}

While Method 1 is sound, it requires extensive work by the materials department. The previous list highlights a some of this work. Among the tasks required under Method 1 are organizing the application, finding test sites, supervising installation, and season-long monitoring. Moreover, once such an approval process is adopted, the New Products Committee would be flooded with hundreds of applications which further make the process less attractive. Hence, on the recommendation of the Study Advisory Committee (SAC) an alternative procedure is offered.

Method 2 is called "guarantee specifications." This procedure seeks to take the testing burden off of the new products committee and hold the contractor and/or supplier accountable 
for product performance. Under this procedure, the manufacturer or contractor "guarantees" the erosion control product will perform as expected for a finite period of time.

For example, say a channel has design velocity of $10 \mathrm{ft} / \mathrm{s}$ and the engineer opts for a TRM. The TRM that is selected must withstand the design flow predetermined period, say 5 years. That is, if the TRM fails (rips, slides, or completely washes away), the manufacturer or supplier must repair the channel at their own expense.

Thus, "guarantee specifications" eliminate the season long field test. Any product that meets the design criteria for a particular channel may be used, but the manufacturer or contractor must guarantee the product performs for a set period of time in lieu of a field testing. The specific steps for product approval under Method 2 are given in Table 5-4.

Under this method, several items in this report would not be used. For example, INDOT would no longer need chapter 6 - "Installation Procedures" because the installation burden falls completely to the General Contractor (GC). That is, the INDOT specification guide would not contain installation procedures for each class of erosion control products (as is the case under method 1). All INDOT would need to do is provide the General Contractor with the classification scheme and design procedures detailed in this report. It is left to the GC to design, select, install, and maintain the erosion control product for a fixed period of years. Table 5-5 lists probable warranty periods for each class of erosion control products. Note that these periods are only offered as suggestions and may be altered to suit the needs of the SAC and INDOT. 


\section{Method 2 - Erosion Control Material Approval Process}

Step in Approval Process

Step 1: Application

Step 2: Classification

Step 3: Yearly Inspections as per Contract

Step 4: Final Approval

\section{Description of Steps}

Submit application, $6 \times 6$ " product sample and product documentation to Materials Dept.

Place product into tentative category based on performance data (A-1, B-1, etc...)

Manufacturer / Contractor guarantees the selected product will perform for a set period of years

Project approved if field performance is satisfactory; Evaluation made at end of warranty period

Table 5-4: Steps in Method 2 - "guarantee specification"

\section{Probable Warranty Periods for Each Class of Erosion Control Products}

Classification

$$
\text { A-1 }
$$

A-2

B-1

B-2

C-1

C-2

C-3

C-4
Design Storm

5 year

5 year

10 year

10 year

25 year

25 year

25 year

25 year
Warranty Period

3-6 months

12-18 months

2 years

3 years

5 years

5 years

5 years

5 years
Applicable Products

Straw blankets, jute mesh

Excelsior, and Coconut blankets

ECRMs (e.g. P300, Landlok 450)

TRM (e.g. C350, Pryamat, TM8)

Riprap

Gabions

Fabric Formed Revetments

Concrete / Articulating Blocks

Table 5-5: Probable warranty periods for each erosion control product class 
It appears that method 2 solves the problems associated with the "approved list" method. INDOT is able to maintain high quality channels without performing extensive field studies. Unfortunately, there are two problems that arise under Method 2. First, there is essentially no information in the literature on guarantee specifications (in the field performance sense implied here). Other DOT's do use guarantee specifications. However, in every case, the manufacturer/ contractor must guarantee a product meets a certain "minimum average roll value" (MARVs). These specifications say nothing about guarantees for field performance. Secondly, manufacturers are strongly against the guarantee specifications (in the sense of Method 2).

As a sample of the industries stance on guarantee specifications, several position letters from erosion control manufacturers are referenced (one is included as an example - figure 5-1). These letters represent three of the industries largest manufacturers / suppliers (i.e. Synthetic Industries, American Excelsior, and Contech Construction Products). Note also that Don Lutyens and Deron Austin regularly write for GFR and Erosion Control, two main publication for the industry.

The position of these firms is quite clear; they have no qualms about "guarantees" for their products as manufactured. However, they unanimously agree that they cannot control the quality of the contractors installation. Who, then, should take responsibility for the proper selection, installation, and long-term performance of the erosion control product? Don Lutyens of American Excelsior provides the following answer:

"My recommendation is to have the General or Landscape Contractor (whoever is making the final product selection and purchases the product) guarantee the product performance and establishment of vegetation....They are the firm in turnkey control and will be involved in the fine grading of the earthwork, selection and installation of the erosion products, and broadcasting the grass seed.

The position then is clear; make the general or landscape contractors guarantee the selection, installation, and performance of the erosion control products. The advantages of this "approval" procedure are as follows: 
- This procedure effectively eliminates the need for extensive DOT field testing of erosion control products. Without any testing, an erosion control ditch lining specification can be implemented immediately.

- The contractor selects the product. They take the risk in selecting a cheaper product.

- The manufacturer / supplier is not liable for the installation procedures of the contractor.

- There is no approved list. Any available erosion control product can be used immediately. There is no season long wait for approval.

Obviously, there are numerous administrative aspects to this procedure. Guarantee contracts must be drawn up and kept on file for the duration of the project. Retainers and/or bonds may be required in this contract. The length of the contract also must be fixed (example warranty periods were given previously). Suggested warranty periods are given for each proposed classification (see table 5-5).

Also, the definition of failure must be set. The degree of damage that requires repair must be quantified. In general mild damage is acceptable (see the hard armor chapter for a more quantitative "damage" description). For example, a critical damage state for geosynthetic products might be $1 / 2$ " erosion of the subgrade (this criteria is often used in flume tests). Other "damage assessment" parameters might include vegetation density, shear resistance, and sedimentation. Texas DOT for example requires channels to have a minimum $70 \%$ vegetation density. Moreover, the next chapter on installation procedures may become more of a checklist than a specification. That is, any trench not meeting the requisite depth, or channel section lacking sufficient staples requires fixing. In addition, all slumping failures, pullouts, major tears, ruts, gullies, or general washouts must be repaired. Table 5-6 list potential criteria that quantify the damage to a channel. Obviously, a channel not meeting these requirements needs repair if it is still under warranty.

Still another problem with warranty contracts is that the DOT needs to decide when the warranty is applicable. Most channels are designed for a 10 year storm event. If a $50+$ year event occurs and washes out the channel, the GC is no longer liable. However, if the channel fails from a 5 year storm event, then the GC must make the appropriate repairs. Hence, the selection of a design storm for drainage channels is necessary. Suggested design storms for each class of erosion control products is given in table 5-5. 


\title{
American Excelsior Company
}

\author{
Earth Science Division
}

8256 B. Ziunsille Road

Indianapolis, ladiana $\$ 6268$

\section{Page 2 of 2 pages / Warnanty of Erosion Control Products}

Also. the different manufacturers or distributors cannot guarantec whel product will be sclected by the Landscape Contractor The contractor involved nay choose to purchase the cheapest procuct arailable and it may not be hydraulically suited for the particular application. In this casc. the earthwork esosion product. and potentially establishcd vegetauon wall be lost once the storm event excecds the limitarion of the installed produci and vegetation.

In a more rcalistuc sinuation I have seen gencric blankets intact without established vegetation Hell beyond the first 26 days of the stitical germination and vegctauon establishnent period If the blanket is installed and intact it is stull control water run off. It is probably not the blanket that is inhubiung the germination or vegetation growth. It is more likely to be a case of nuatehing the proper secd mix with the local soil conditions for optimum gerounation results

Therefore. ny recommendation is to liave the General or Landscape Contractor who is nuaking the final product decision and purchase of the product guarantec the proctuct performance and establishment of vegetation. The reason is they are the finu in turnkey control and will be involved in the fine grading of the earthwork, the selection and installation of the erosion producl, and broadcasting the grass sced resiluing in establishnent of vegetation. I have seen this guarantee work at other state DOT levels I belicve this recommendation is the most fair guarantee as it protects the DOT. Consultants, adjacent Project or Property Owners. Suppliers, General Contractors, and the Sub-Contractor. This elimunates a proctuct purchascd based on price ondy: without consideration for the application. If a firm does choose a product based purely on price, and it does not perform or the grass seid does not germinate. the specifiers do not loose. The lim making the choice to use an inferior product took the risk and they make the rcplacement good whether it be regrading the carthwork rcplaceinent of the exosion control matenal. or re-sezding. As the Sub-Contractor is the Landscape Contractor it gllows them to control and remain competitive in their bids br choosing a proctuct within a approved proctucts per the particular application of classificalion of A. B. or C.

Al proctucts submined to erosion product classifications should be supponed with the basic liydraulic data to suppor its claim to a product applicarion within a classification $A, B$, or $C$ Case histories, test plots. and casc histories are recommended to compliment the Hydraulic Submittals

In the case of proctucts already on the approved lists that may wished to be considered for. other applications whin the same or other classifiedtions. test plots with similar conditions may be the nost appropriacc method of cetermining the success of pending applicanons until the appropriatc Hydraulic Data can be generatcd.

Tony. I belicve this covers the issucs and recommendations discussed. If there are any additional questions please feel free to contact me at the above telcphone numbers.

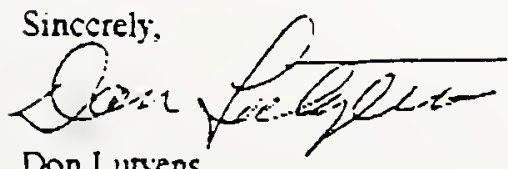

Don Luryens

Figure 5-1: Sample position letter on guarantee specifications

by Don Lutyens of American Excelsior 
To summarize, this section presents two ways in which erosion control products can be implemented. The first is a standard field testing regimen. It requires an application, preliminary classification, season long field test, periodic evaluations, and final approval. Because of concerns of being overwhelmed with applications, the New Products Committee would like to implement a guarantee specifications procedure. This method places the liability on the general contractor. Instead of an extensive testing protocol and maintaining an approved list, any product is acceptable as long as the channel performs satisfactorily. In the event that a channel shows severe erosion, the channel must be repaired while it is under the warranty period.

\section{List of Possible Damage Criteria for Drainage Channels}

\begin{tabular}{ll}
\hline Criteria & Damage Level \\
\hline Vegetation Density & Minimum $70 \%$ vegetative cover \\
Sedimentation & No more than 1" sedimentation \\
Erosion & No more than $1 / 2$ " erosion of channel grade \\
Appearance & No rills greater than 2" wide and 2" deep \\
& No ruts, dead spots greater than 2' diameter \\
Shear & No tears, washouts, bunching; \\
& No movement for permanent materials \\
& Minimal straining
\end{tabular}

Table 5-6: Damage Criteria for Drainage Channels 


\subsection{Current Product Classification}

Now that the classification system has been approved, all that remains is to categorize the existing products. In order to accomplish this task, a database of erosion control products was created. Information gathered from 25 companies (representing nearly 60 products) aided in setting up the database. The products listed in this section by no means include everything the industry has to offer. New products are constantly being introduced and it is difficult to keep track of every erosion control company. The list does however provide a representative cross section of currently available products.

The information was entered into Paradox v. 4.5 for Windows 3.11. As new products come available, the Materials Department can easily update the database. The database table includes many parameters (some of which are not applicable to all products). Some of the properties include shear resistance, permissible velocity, product dimensions, descriptions, recommended uses, color, and UV stability. Using the computerized database will save space and time to keep manufacturer documentation. A complete listing of the information is included in Appendix $\mathrm{E}$ of this report.

Table 5-7 is a tentative "approved list" solely based on the performance and index data provided by the erosion control manufacturers. It is again emphasized that this list is only tentative. The list is based only on existing literature, primarily manufacturer documentation. No experimental evidence was produced by the Investigators on this project. 


\section{Performance Based Approved List}

(Note: All performance values are adjusted by safety factor of 1.3 before classifying the erosion control product.)

\section{Classification}

Manufacturer

Product

A Degradable products. Includes jute mesh coconut, straw, combination, polypropylene roving, and wood excelsior blankets.

A-1: $0<\tau<1$ psf

American Excelsior Co.

Curlex

Belton Industries

Antiwash Geojute

BonTerra America

BonTersa CS2

BonTerra America

BonTerra S1

BonTerra America

BonTerra S2

Contech Const.

ERO-Mat

Contech Const.

Std. Excelsior

Greenfix America

CF072R

Greenfix America

CF072RR

Greenfix America

WS052

Greenfix America

WS072

North Amer. Green

S150

North Amer. Green

S75

North Amer. Green

SC150

PPS Packaging Co.

X-Cel Regular

PPS Packaging Co.

$\mathrm{X}$-Cel Superior

PPS Packaging Co.

$\mathrm{X}$-Cel Super Duty

Synthetic Industries

Polyjute

Synthetic Industries

Landstrand FRS

A-2: $1<\tau<2$ psf
Belton Industries

Belton Industries

Belton Industries

Belton Industries

BonTerra America

Contech Const.

Contech Const.

Contech Const.

Contech Const.

North Amer. Green
Dekowe 400 Cior

Dekowe 700 Cior

Dekowe 900 Cior

Geojute Plus

BonTerra C2

C-Jute

High Vel. ERO-Mat

Plus Excelsior

Super Excelsior

$\mathrm{C} 125$ 
B. Non-degradable products. Includes turf reinforcing mats (TRM's) and erosion control and revegetation mats (ECRM's)

\begin{tabular}{lll}
\hline B-1: $1<\tau<2$ psf & Akzo Industrial Systems Co. & Enkamat 7005, 7010 \\
North American Green & C350 \\
Nicolon Mirafi & Miramat Regular \\
& \\
Synthetic Industries & Landlok ECRM 1060 \\
Synthetic Industries & Landlok ECRM 1050
\end{tabular}

B-2: $2<\tau<5$ psf

Contech Const.

ECRM C-45

Contech Const.

ECRM C-50

Contech Const.

TENSAR TM-3000

Contech Const.

TRM C-60

Contech Const.

TRM C-61

Contech Const.

Tensar TB1000

Akzo Industrial Systems Co. Enkamat 7210, 7220

Akzo Industrial Systems Co.

Enkamat 7012,7020

Greenstreak

PEC-MAT

Nicolon Mirafi

Miramat Heavyweight

North American Green

C350

North American Green

P300, P300P

PPS Packaging Co.

Permamat 100

PPS Packaging Co.

Permamat 200F

Synthetic Industries

Landlok ECRM 435, 450, 460

Synthetic Industries

Pryamat

\section{Table 5-7: Classification of erosion control products}

Note: The above classification is based strictly upon mamufacturers data. No field monitoring has been done. Before adopting this "Approved List, "field testing is recommended for all products. Such testing is beyond the scope of this report. 


\section{6: Installation Procedures}

\subsection{Introduction}

Construction requirements depend on specific applications and site conditions. The following general construction considerations apply for most flexible erosion control mat systems. Special considerations related to specific site conditions need to be addressed by the Project Engineer.

These recommendations are derived from Standard Specifications for Road Construction in Illinois, Ohio, and Texas. In addition, the FHWA publication, "Construction Guidelines for Geosynthetics, 1995, provides insight into installing erosion control materials. Lastly, several manufactures installation procedures were consulted in compiling this section.

Some states do not list separate installation procedures for the various erosion control products (Texas). Most sources prefer to delineate procedures for several classes of erosion control products. This report also endorses listing unique procedures for the various classes of products.

A complete installation procedure is listed for a "fiber mat" (straw, coconut, straw/coconut combinations). Deviations from this basic procedure are noted for excelsior mats, polypropylene roving, TRMs, and ECRMs. Also, separate guidelines are provided for concrete blocks and fabric formed revetments. In Appendix F, several CAD drawings are included as a basis for construction documents. These drawings are modified from those provided in Synthetic Industries EC-Design Software manual.

\subsection{Installation Requirements for Soft Armor Materials}

\subsubsection{Fiber Mat}

All surfaces should be smoothed out to the lines, grades, and cross sections shown on the plans. Finished surfaces should not vary from the plans by more than $50 \mathrm{~mm}$ (2"). The area should be graded free of rocks, clods, and foreign material (sticks or garbage) $38 \mathrm{~mm}$ $\left(1.5^{\prime \prime}\right)$ in diameter or larger. Such material will prevent the close contact of the blanket with 
the seed bed. In addition, depressions or hole in the channel should be filled to avoid bridging and possible tearing when the erosion control mat is installed.

After the channel is graded, the area must be immediately seeded and fertilized. Prepare seedbed by loosening $50-75 \mathrm{~mm}$ of soil above final grade. Apply soil amendments (lime), fertilizer, and seed to scarified surface prior to installation of the erosion control material. A vegetative mulch may be placed over the area at approximately $0.12 \mathrm{~kg} / \mathrm{m}^{2}(25$ $\mathrm{lbs} / 1000 \mathrm{ft}^{2}$ ). If it rains and the prepared seed bed becomes crusted or eroded (visible ruts or depressions), the Contractor will be required to rework the soil until it is smooth. Once regraded, the soil must be reseeded and fertilized.

The blanket must be placed within 24 hours after seeding operations have finished. Care should be taken not to stretch the material. It should be laid loosely on the channel bed to ensure good blanket to ground contact. Installation and anchorage of the erosion control blanket must follow manufacturer recommendations and standard detail sheets.

For placement in ditches, the blanket shall be unrolled in the direction of flow. Excavate a $300 \mathrm{~mm}$ (12") deep by $150 \mathrm{~mm}$ (6") wide trench across the downstream end of the channel. This trench will inhibit undercutting by surface runoff. Place end in trench and secure with anchoring devices (staples, pins, or wood stakes) at $300 \mathrm{~mm}$ (12") intervals. After securing the mat in the trench, backfill the trench and compact. Roll mat across backfill and continue upstream.

The staples shall be made from No. 11 gauge or heavier coated black steel wire of sufficient thickness for soil penetration. They shall be of the " $T$ " or " $U$ " configuration with pointed ends, $25-50 \mathrm{~mm}$ wide (1-2") at the top with a minimum length of $150 \mathrm{~mm}$ (6") from top to bottom. Typical "staple densities" range from $1.2 / \mathrm{m}^{2}\left(1 / \mathrm{yd}^{2}\right)$ for low velocity channels to $3 / \mathrm{m}^{2}\left(2.5 / \mathrm{m}^{2}\right)$ for high velocity channels. Loose, rocky, or highly compacted soils may require longer and/or heavier gauge staples (or pins). An increase in staple density may also be needed. Any changes will be directed by the Engineer.

The staples shall be spaced in a diamond pattern with the longer dimension in the direction of flow and the shorter dimension across the channel. The longer dimension shall be

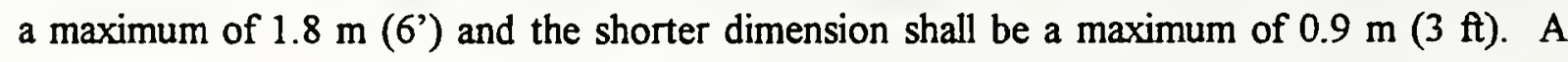
common row of staples on $1 \mathrm{ft}$ centers shall be used along seams of adjoining blankets. Care 
should be taken not to put irregular wrinkles in the erosion control material; significant erosion channels can form beneath the mat in these locations.

For channels that require multiple strips, the sides shall overlap at least $100 \mathrm{~mm}$ (4"). Junction slots are not required, but ends must overlap a minimum of $300 \mathrm{~mm}$ (12"). Ends must be anchored with two rows of staples $300 \mathrm{~mm}$ (12") apart on $300 \mathrm{~mm}$ (12") spacing. Note that the blanket shall be unrolled parallel to the direction of flow so that there are no seams within $600 \mathrm{~mm}$ (24") of the bottom centerline of the ditch.

Place check slots $200 \mathrm{~mm}$ (6") deep by $150 \mathrm{~mm}$ (6") wide across the channel at $10 \mathrm{~m}$ $(32.8 \mathrm{ft})$ intervals or less. These transverse slots are constructed by placing a tight fold at least $200 \mathrm{~mm}$ (8") vertically into the soil. Lay the material on the bottom of the slot and then fold back against itself. Staple the material at $300 \mathrm{~mm}$ (12") intervals.

Place edges of outside mats in previously excavated longitudinal slots $150 \mathrm{~mm}$ (6") wide by $150 \mathrm{~mm}$ (6") deep. These trenches should be $300-600 \mathrm{~mm}$ (12-24") inches above the crest of channel side slopes if possible. These trenches are used to bury the edges of the matting. Anchor at $300 \mathrm{~mm}$ (12") intervals, backfill, and compact the soil.

Upslope edges of the fiber mat must be anchored in a $300 \mathrm{~mm}$ (12") deep by $150 \mathrm{~mm}$ (6") wide trench. Roll the mat through the trench being sure to allow sufficient amount of mat to cover backfilled trench. After stapling the mat in the bottom of the trench, backfill and compact firmly. Roll remaining mat downstream across the trench and staple in place.

Once installation is complete, the area should be overseeded, fertilized, and irrigated to promote vigorous plant growth. Use only light weight equipment for channel work once the blanket is placed. No tracked or heavy vehicles should be used in any phase of the installation procedure. Table 6-1 summarizes these steps. 


\section{General Guidelines for Installing Erosion Control Materials}

\section{Installation Step: : $: 1.70$.}

1). Grade channel area

2). Seed channel bed

3). Excavate all trenches (Check slots, longitudinal, up \& downstream anchors)

4). Secure mat in downstream trench

5). Roll mat upstream

6). Staple all seams

7). Fold \& staple mat through all check slots

8). Staple, bury, \& compact longitudinal trench

9). Secure mat in upstream trench

10) Reseeding
Remove all foreign material $38 \mathrm{~mm}$ in diameter and larger

Fertilize and broadcast seed over scarified channel bed

Downstream - $300 \mathrm{~mm}$ deep by $150 \mathrm{~mm}$ wide trench Upstream $-150 \mathrm{~mm}$ deep by $150 \mathrm{~mm}$ wide trench Longitudinal $-150 \mathrm{~mm}$ deep by $150 \mathrm{~mm}$ wide trench Check Slots - 200 mm x 150 mm @ 10 m intervals

Anchor mat @300 mm intervals, bury \& compact soil Anchor mat in a regular pattern (approx. 1 staple intervals)

Overlap adjacent rolls $100 \mathrm{~mm} \&$ staple a common row on $300 \mathrm{~mm}$ centers along the seam;

Shingle-lap ends of roll \& staple 2 rows across blanket on $300 \mathrm{~mm}$ centers

Fold material into $200 \mathrm{~mm}$ deep slot and staple on $300 \mathrm{~mm}$ centers across the channel

Fold material into $150 \mathrm{~mm}$ deep trench, anchor at $300 \mathrm{~mm}$ intervals, bury the mat, and compact the soil Roll mat through trench. Staple on $300 \mathrm{~mm}$ centers across the channel. Bury and compact the soil. Roll remainder downstream and staple in place.

Reseed, fertilize, and irrigate the channel 


\section{Excelsior Mat}

Within 24 hours after the specific area has been seeded, excelsior matting shall be laid down, stapled, and overseeded as specified under the fiber mat procedure. The following changes are made to the above procedure.

1). Only overlap edge and ends $50 \mathrm{~mm}(2 ")$.

2). No check slots nor upslope trenches are required; adjacent blankets should be butted snugly and stapled in place. The upstream end shall be stapled in place using 6 staples across the roll and placing staples on $1.2 \mathrm{~m}\left(4^{\prime}\right)$ centers along each side. All seams shall over lap $50 \mathrm{~mm}$ (2"). Note: The Engineer may require burying the upslope end the mat under certain site conditions.

3). No vegetative mulching material should be used with excelsior matting.

\section{Polypropylene Roving}

Within 24 hours after seeding, the roving shall be applied over the channel to form a random mat of continuous fibers at a rate of $0.14 \mathrm{~kg} / \mathrm{m} 2$. Position $1-4$ spools on the dispenser unit. Tie fibers from each spool together and extend roving to air gun.

1). Construct 150 (6") $\mathrm{mm}$ by $150 \mathrm{~mm}\left(6^{\prime \prime}\right)$ check slot every $10 \mathrm{~m}(32.8 \mathrm{ft})$

2). Bury the upslope end in a $300 \mathrm{~mm}$ (12") deep by $150 \mathrm{~mm}$ (6") wide trench to prevent undermining.

3). Without delay, apply emulsified asphalt overspray at the specified rate, typically 0.28 to $0.40 \mathrm{~d} / \mathrm{m}^{2}$.

4). Do not apply roving in windy conditions or if significant rainfall is anticipated shortly after installation (asphalt emulsion must cure).

\section{ECRM}

Within 24 hours after seeding, the ECRM shall be installed in the channel. Follow all installation procedures specified under the Fiber Mat. The following changes and/or additions apply:

1). Do not apply mulch prior to placing mat.

2). Both upstream, downstream, and longitudinal anchor trenches are required as specified under the fiber mat. Also, check slots must be excavated every $10 \mathrm{~m}$ $(32.8 \mathrm{ft})$. 
3). Wire staples should be 8 gauge minimum; pins should be $4.8 \mathrm{~mm} \mathrm{(3/16")} \mathrm{in}$ diameter, (18") long, and include a 1" steel washer at the head of the pin.

4). Overlap adjacent rolls by $100 \mathrm{~mm}$ (4"); Staple according to manufacture guidelines.

5). Shingle-lap roll ends a minimum of $300 \mathrm{~mm}$ (12"). Anchor with 2 rows of staples (pins) at $300 \mathrm{~mm}(12 ")$ centers.

TRM

Within 24 hours of seeding the mat, install the TRM in the channel. The area shall be prepared as specified under Fiber Mat. That is, all transverse check slots, longitudinal, upstream, and downstream anchor trenches must be excavated. The following additions and/or changes to the procedure apply.

1). No mulch shall be applied prior to placement of the matting.

2). Triangular wooden stakes (approximately $300 \times 75 \times 25 \mathrm{~mm}$ or 12 " $\times 3$ " x 1") may be used in lieu of wire staples. Staples must be 8 gauge and 8-18" long (they must have sufficient ground penetration to resist pullout).

3). Overlap rolls a minimum of 4".

4). Shingle-lap roll ends a minimum of $300 \mathrm{~mm}$ (12"). Anchor with 2 rows of staples (pins) at $300 \mathrm{~mm}$ (12") centers.

5). For maximum turf reinforcement, place soil filling in TRM. After seeding, lightly rake $12-20 \mathrm{~mm}\left(1 / 2-3 / 4^{\prime \prime}\right)$ of fine topsoil into the mat apertures to completely fill mat thickness (the backside of a rake is often useful). If equipment is used, limit it to lightweight loaders and backhoes. Avoid sharp turns. Do not drive tracked or heavy equipment over the mat at any time.

6). Following installation (and soil filling), broadcast additional seed. Mulch is then applied above the filled mat as directed by the Engineer.

Note: Manufacturers installation procedures may differ slightly from the above (i.e. different overlap requirements, check slot intervals, anchor trench depths, staple patterns, etc...). It is hard to generalize installation guides for all available products.

In the event that manufacturers installation guideline differs from the above, follow the more stringent specification. Moreover, if unique site conditions exist (i.e. natural springs, poor/loose soil, harsh climate, etc..), consult both the Engineer and manufacturer's technical representative for assistance. 


\subsection{Installation Requirements for Hard Armor Materials}

\section{Fabric Formed Revetments (FFR)}

The fabric shall consists of a double layer, open-selvage material joined in a mat configuration. Each layer shall have a minimum grab tensile strength of $900 \mathrm{~N}$ (200 lbs) in accordance with ASTM D 4632. Hydrostatic uplift pressure relief shall be provided by installing $40 \mathrm{~mm}$ ( $1.5 \mathrm{inch}$ ) diameter filter points on approximately $200 \mathrm{~mm}$ (8 inch) centers for filter point style mats and $2.4 \mathrm{~m}(8 \mathrm{ft})$ centers for uniform section style mats.

Similar to the soft armor products, all slopes or channels to be protected shall be graded such that they are normally stable in the absence of erosive forces. For FFRs, the mat is placed over the graded area and filled with a pumpable sand/cement grout. Note that for fine grained soils, a 6 " sand blanket or suitable geotextile may be required to eliminate piping.

Excavation and preparation of anchor trenches, terminal anchor trenches, and toe trenches follow the method in the previous section. Prior to grout injection, the lower fabric is placed in the design location. Allowances should be made for contraction that occurs as a result of grouting. Any reinforcing cables should then be installed in the fabric (note: these are optional). Adjacent panels should be joined before injecting the concrete grout. The two bottom layers and the two top layers of fabric must be sewn or zippered together. All seams should be downward facing. Where it is impossible to sew or zipper the panels, they may be overlapped a minimum of $600 \mathrm{~mm}(2 \mathrm{ft})$ at the discretion of the engineer. No simple butt joints are allowed.

Small cuts are next made in the fabric to allow the grout to be injected. Injection pressure should not damaged the integrity of the fabric. Starting at the lowest point and working up the slope or upstream, the grout shall be injected to the recommended thickness. Also, the distance from the point of injection to the edge of the panel cannot be greater than $9 \mathrm{~m}(30 \mathrm{ft})$. Excessive grout that has inadvertently spilled on the mat surface mush be cleaned up. Do not use a water hose to remove this spilled aggregate from freshly placed mats. Once grouting is complete, all trenches should be backfilled.

Following grouting, the holes left by the removal of the injection pipe shall be closed by inserting a piece of burlap or similar material. Once the concrete is no longer fluid, the burlap is removed and the concrete smoothed by hand. Foot traffic on the FFR is restricted to an 
absolute minimum for one hour after pumping in order to reduce indentations. Also, all filter points shall be checked and cleaned after the mat has been pumped and the grout has been set.

To summarize, the steps for installing FFRs are:

1). Compact and grade soil to grade shown on the plans. Remove all foreign debris.

2). Install an appropriate geotextile filter

3). Excavate longitudinal, upstream, and downstream trenches.

4). Place the fabric over the design location, allowing for post-grout contraction

5). Insert reinforcing cables; zipper or sew all seams of adjacent panels. Overlap $600 \mathrm{~mm}(2 \mathrm{ft})$ if zippering or sewing is not practical.

6). Slit the fabric and insert grout hoses. Inject the grout until the FFR reaches maximum thickness.

7). Remove hoses; Place burlap (or similar material) in hose hole.

8). Remove spilled grout (do not hose it off); no walking on the fabric for at least one hour after grouting complete

\section{Mixing Grout:}

The grout shall consist of a mixture of Portland cement, fine aggregate, water, Pozzolan (up to $20 \%$ of the cement), and grout fluidizer. The range of quantities as delivered is given table $6-2$ below. The grout shall have an air content between $6 \%$ and $9 \%$. The mix shall obtain a strength of $17 \mathrm{MPa}(2500 \mathrm{psi})$ at 28 days. Mixing time must be greater than one minute. If agitated continuously, the grout may be held for a maximum of 2.5 hours in the mixer.

\section{Range of Quantities as Delivered}

\begin{tabular}{lcc}
\hline Material & $\mathrm{lb} / \mathrm{cy}$ & $\mathrm{kg} / \mathrm{m}^{3}$ \\
\hline Cement & $800-900$ & $470-530$ \\
Sand & $2030-2120$ & $1200-1250$ \\
Water & $540-550$ & $320-325$ \\
Air & As required & As required \\
\hline
\end{tabular}

Table 6-2: Mix proportions for FFR 


\section{Concrete Block Systems (CBS)}

Before laying concrete blocks, the site must be graded free of clogs, roots, rubbish, stones, or other foreign matter. Voids or soft areas should be filled and compacted to bring the surface to its final grade.

After grading, the geotextile filter is laid out. It cannot contain any rips, wrinkles, or punctures. The geotextile shall fit tightly against all abutting structures (culverts, piers, boulders). Adjacent sheets shall be overlapped a minimum of $30 \mathrm{~cm}(1 \mathrm{ft})$ and the initial and terminal ends must be secured in an anchor trench.

The blocks shall be cast solid; all aggregate must meet requirements for soundness, gradation, and other physical properties listed under the concrete aggregate section. The concrete shall have $24 \mathrm{MPa}(3500 \mathrm{psi})$ at 14 days. Tests will be performed on cores or the entire block itself depending on size and testing limitations. Blocks will have $4-7 \%$ entrained air and a maximum slump of $40 \mathrm{~mm}$ (1.5 inches). All blocks shall have uniform dimensions; minimum size is $200 \mathrm{~mm} \times 200 \mathrm{~mm}$ x $400 \mathrm{~mm}$ ( 8 " x 8" x 16").

Concrete blocks are laid with the joints perpendicular to the slope. Blocks of any row should be arranged to lock with the blocks of preceding and succeeding rows (i.e. blocks must be installed in straight lines). Around structures, concrete grout shall fill the entire depth in the void between blocks and structures. For non-interlocking blocks, each 10th row shall be embedded into the slope (long dimension perpendicular to the slope).

Once installation is complete, the blocks must be backfilled within 7 days to prevent UV degradation of the filter. Topsoil is used for blocks that will be seeded and vegetated; whereas, $1.25 \mathrm{~cm}$ nominal gravel is used for blocks left unvegetated. All debris, waste materials, excess materials, etc., must be removed from the site. 
The steps for installing CBS are as follows:

1). Grade the area according to project documents. Make sure area is free of debris and compacted to specifications.

2). Geotextile is laid out on the graded surface. It is entrenched as necessary. Minimum overlap of $30 \mathrm{~cm}(1 \mathrm{ft})$ for adjacent panels.

3). Lay concrete blocks perpendicular to the slope. This applies for singlely-placed blocks as well as machine placed articulating mats.

4). Grout areas full around structures where blocks cannot fit snugly

5). Backfill CBS within 7 days after installation. Use topsoil if CBS is to be vegetated or use crushed gravel if CBS is left unvegetated.

6). Remove all waste materials from the site 


\section{7: Proposed Draft Specification}

This section presents a tentatvie erosion material specification. The text's language is combined from several DOT's - Texas, Ohio, Illinois, Virginia, and Wisconsin. However, the details are all taken in part or whole from the proposed guidelines. It essentially summarizes the previous sections into the form of Indiana's Standard Specifications for Road and Bridge Construction.

\section{Section 001: Flexible Ditch Lining}

\subsection{1: General}

This work shall consist of furnishing and installing temporary as well as permanent flexible linings in roadside ditches. These materials include (but are not limited to) wood excelsior mats, straw or coconut fiber mats, paper mat, jute mesh, polypropylene roving, and synthetic mats. The geosynthetic erosion control material will be secured in newly constructed and rehabilitated stormwater channels intended to be seeded and vegetated. This includes all labor, tools, and materials necessary to install and secure the geosynthetic erosion control material on the prepared surface as shown on the Contract Drawings.

\subsection{2: Materials}

All erosion control materials shall meet the requirements of this section. They must be pre-qualified by the Director of the Materials Department prior to use. The flexible ditch lining shall be one (1) of the following classes and types as shown on the plans: 


\begin{tabular}{|c|c|c|}
\hline Classification & $\begin{array}{c}\text { Permissible Velocity } \\
\mathrm{m} / \mathrm{s}(\mathrm{ft} / \mathrm{s})\end{array}$ & $\begin{array}{c}\text { Permissible Shear } \\
P a\left(l b / f t^{2}\right)\end{array}$ \\
\hline \multicolumn{3}{|c|}{$\begin{array}{c}\text { A (Degradable): Product degrade within } 2 \text { years (e.g. jute mesh, straw or coconut } \\
\text { blanket, excelsior, roving, straw bales, mulches..) }\end{array}$} \\
\hline A-1 & $0.0-1.2 \quad(0-4)$ & $0-45 \quad(0-1)$ \\
\hline A-2 & $1.2-2.1 \quad(4-7)$ & $45-96(1-2)$ \\
\hline \multicolumn{3}{|c|}{$\begin{array}{l}\text { B (Non-degradable): Products stabilized with carbon black (e.g. nylon mesh, heat } \\
\text { bonded 3-D TRM, synthetic erosion control and revegetation mat) }\end{array}$} \\
\hline B-1 & $1.2-2.1 \quad(4-7)$ & $45-96 \quad(1-2)$ \\
\hline B-2 & $2.1-3.0 \quad(7-10)$ & $96-240(2-5)$ \\
\hline
\end{tabular}

\section{Properties of Erosion Control Materials}

Jute Mesh

Polypropylene Roving

Excelsior

Mat

Straw

Blanket

Straw / Coconut Blanket
Uniform open weave, smolder resistant, fabricated from jute yarn that does not vary in thickness by more than $1 / 2$ its normal diameter.

Continuous fibers drawn from molten polypropylene that is ejected by compressed air; the mat of fibers are coated with a degradable, liquid asphalt. Neither the polypropylene nor the asphalt shall contain chemicals toxic to plant or animal life.

Machine produced excelsior wood mat of $80 \%, 6$ " or longer fiber. The top side should be covered with a biodegradable plastic mesh. The wood from which the excelsior is cut shall be properly cured to adequately curl the fibers

Machine produced $100 \%$ agricultural straw mat that is sewn to a degradable polypropylene netting.

Blanket consists of $70 \%$ straw and $30 \%$ coconut coir with a top side degradable netting. The blanket shall be of consistent thickness with the straw and coconut fiber evenly distributed over the entire area of the mat. Both sides of the mat should be covered with a degradable netting which is sewn to the mat with degradable thread. 
Coconut Coir

Blanket

Turf Reinforcing Mat (TRM)
Blanket consists of $100 \%$ coconut fiber. The blanket shall be covered on the top and the bottom with a polypropylene netting. The netting shall be sewn together with polyester thread.

Synthetic mat consisting of 3-D structure of entangled nylon monofilaments, melt bonded, or mechanically bonded to form a dimensionally stable mat. Bonding methods include polymer wielding, thermal fusion, or the placement of fibers between 2 nets bound together by polyolefin thread. Must include minimum $0.5 \%$ carbon black by weight. Every component of the matrix shall be stabilized against UV degradation and inert to chemicals normally found in the environment.

Erosion Control

Revegetation Mats (ECRM)
Dense web of green polyolefin fibers positioned between two biaxially-orientated nets and mechanically bound by parallel stitching with polyolefin thread. Every component of the matrix shall be stabilized against UV degradation and inert to chemicals normally found in the environment.

\section{Properties of Erosion Control Materials}

\begin{tabular}{|c|c|c|c|c|c|c|}
\hline Material & $\begin{array}{l}\text { Width } \\
m(f t)\end{array}$ & $\begin{array}{l}\text { Length } \\
m(f t)\end{array}$ & $\begin{array}{c}\text { Unit Weight } \\
k g / m^{2}\left(l b / y d^{2}\right)\end{array}$ & $\begin{array}{c}U V \\
\text { Stability }\end{array}$ & $\begin{array}{l}\text { Netting Size } \\
\text { mm (inch) }\end{array}$ & Color \\
\hline Jute Mesh & $1.2(4.0)$ & $68.6(225)$ & $0.59(1.1)$ & $*$ & $*$ & $\begin{array}{l}\text { Brown/ } \\
\text { Beige }\end{array}$ \\
\hline${ }^{1}$ PP Roving & Varies & Varies & $0.19(0.35)$ & $0-80 \%$ & * & $\begin{array}{l}\text { white / } \\
\text { green }\end{array}$ \\
\hline $\begin{array}{l}\text { Excelsior } \\
\text { Mat }\end{array}$ & $1.2(4.0)$ & $45.7(150)$ & $0.51(0.94)$ & * & $\begin{array}{l}16 \times 16 \text { to } 50 \times 25 \\
(5 / 8 \times 5 / 8 \text { to } 2 \times 1)\end{array}$ & $\begin{array}{l}\text { Beige / } \\
\text { Tan }\end{array}$ \\
\hline Straw Mat & $1.2(4.0)$ & $45.7(150)$ & $0.27(0.50)$ & * & $\begin{array}{c}10 \times 10 \text { to } 13 \times 13 \\
(3 / 8 \times 3 / 8 \text { to } 1 / 2 \times 1 / 2)\end{array}$ & $\begin{array}{l}\text { Beige/ } \\
\text { Yellow }\end{array}$ \\
\hline $\begin{array}{l}\text { Coconut / } \\
\text { Straw Mat }\end{array}$ & $1.2(4.0)$ & $45.7(150)$ & $0.27(0.50)$ & * & $\begin{array}{c}6 \times 6 \text { to } 16 \times 16 \\
(1 / 4 \times 1 / 4 \text { to } 5 / 8 \times 5 / 8)\end{array}$ & $\begin{array}{l}\text { Brown } \\
\text { Yellow }\end{array}$ \\
\hline $\begin{array}{l}\text { Coconut } \\
\text { Mat }\end{array}$ & $1.2(4.0)$ & $45.7(150)$ & $0.27(0.50)$ & * & $\begin{array}{c}16 \times 16 \\
(5 / 8 \times 5 / 8)\end{array}$ & Brown \\
\hline TRM & $0.97(3.0)$ & $100(327)$ & $0.48(0.81)$ & $80 \%$ & $*$ & Black \\
\hline$\overline{\text { ECRM }}$ & $0.97(3.0)$ & $100(327)$ & $0.54(1.0)$ & $85 \%$ & * & Green \\
\hline
\end{tabular}

'Roving Material Properties:

Strands per rove: 


\section{Anchoring Devices}

The ground anchoring devices for the geosynthetic erosion control material shall consist of U-shaped wire staples, metal pins, or triangular wooden stakes. The temporary blanket staples shall be made from No. 11 gauge or heavier coated black steel wire of sufficient thickness for soil penetration (staples for permanent mats must be minimum 8 gauge). They shall be of the "T" or "U" configuration with pointed ends, 25-50 mm wide (1-2") at the top with a minimum length of $150 \mathrm{~mm}$ (6") from top to bottom.

Pins should be at least $5 \mathrm{~mm}$ diameter steel with a washer at the head of the pin. Triangular wooden stakes (approximately $300 \times 75 \times 25 \mathrm{~mm}$ or 12" x 3" x 1") may be used in lieu of wire staples for TRMs.

\subsection{3: Construction Requirements}

\section{General}

The geosynthetic erosion control blanket shall conform to the class and type shown on the plans. The Contractor has the option of selecting an approved erosion control mat conforming to the class and type shown on the plans and according to the current approved products list. The flexible channel liner shall be placed within 24 hours after seeding or mulching operations have been completed.

The mat shall be free of any treatment which might significantly alter its physical properties. During shipment and storage, the mat shall be wrapped in a heavy-duty protective covering to protect it from direct sunlight, dirt, dust, and other debris.

The manufacture shall submit certified test data to cover each shipment. Required data includes permissible shear or permissible velocity. In addition, relevant index properties (as specified in section 001.02) shall be included. Products will not be accepted without this data. 


\section{Preparation}

A. All surfaces to be protected shall be graded and compacted in accordance with the Contract Drawings or as directed by the Engineer.

B. The surface shall be cleared of large rocks, soil clods, vegetation, or other foreign material larger than $38 \mathrm{~mm}$ that may inhibit intimate the erosion control material's contact with the subgrade.

C. Prepare the seedbed by loosening 50 to $75 \mathrm{~mm}$ of soil above the final grade.

D. If directed, apply all soil amendments, fertilizer, and seed to the scarified surface prior to the installation of the geosynthetic erosion control material.

E. Construct $150 \times 300 \mathrm{~mm}(6 \times 12 ")$ anchor trench at the downstream end of the channel and a $150 \times 150 \mathrm{~mm}(6 \times 6 ")$ anchor trench at the upstream end of the channel. Excavate $150 \times 150 \mathrm{~mm}$ check slots at $10 \mathrm{~m}$ intervals along the length of the channel. Finally, cut longitudinal anchor slots $150 \times 150 \mathrm{~mm}$ along the edge of the mat installation. 
Steps for Installing Erosion Control Materials

\section{Installation Step Comments}

1). Grade channel area

2). Seed channel bed

3). Excavate all trenches (Check slots, longitudinal, up \& downstream anchors)

4). Secure mat - downstream trench

5). Roll mat upstream

6). Staple all seams

7). Fold \& staple mat through all check slots

8). Staple, bury, \& compact longitudinal trench

9). Secure mat in upstream trench

10) Reseeding
Remove all foreign material $38 \mathrm{~mm}$ in diameter and larger

Fertilize and broadcast seed over scarified channel bed

Downstream - $300 \mathrm{~mm}$ deep by $150 \mathrm{~mm}$ wide trench Upstream $\quad-150 \mathrm{~mm}$ deep by $150 \mathrm{~mm}$ wide trench Longitudinal $-150 \mathrm{~mm}$ deep by $150 \mathrm{~mm}$ wide trench Check Slots-200mm x 150 mm@10 m intervals

Anchor mat @300 mm intervals, bury \& compact soil

Anchor mat in a regular pattern (approx. 1 foot intervals in a diamond or square-shaped pattern)

Overlap adjacent rolls $100 \mathrm{~mm} \&$ staple a common row on $300 \mathrm{~mm}$ centers along the seam;

Shingle-lap ends of roll \& staple 2 rows across blanket on $300 \mathrm{~mm}$ centers

Fold material into $200 \mathrm{~mm}$ deep slot and staple on 300 $\mathrm{mm}$ centers across the channel

Fold material into $150 \mathrm{~mm}$ deep trench, anchor at $300 \mathrm{~mm}$ intervals, bury the mat, and compact the soil

Roll mat through trench. Staple on $300 \mathrm{~mm}$ centers across the channel. Bury and compact the soil. Roll remainder downstream and staple in place.

Reseed, fertilize, and irrigate the channel

If as a result of rain, the prepared bed becomes crusted or eroded or if any eroded placed ruts or depressions exist for any reason, the Contractor shall be required to reworked the soil until it is smooth and to reseed or refertilize the area at the Contractor's expense. 
Installation of all geosynthetic erosion control mats shall be in accordance with the Manufacturer recommendations and the Standard Detail Sheet, "Erosion Control Mat" (See Appendix F for drawings).

\subsection{4: Literature}

The Contractor shall submit one (1) full set of manufacturer's literature and manufacture's installation recommendations to the Engineer for the soil retention blanket selected in accordance with the approved products list.

\subsection{5: Maintenance}

The matting areas shall be maintained until all work on the contract has been completed and accepted. Maintenance shall consist of the repair of areas damaged by erosion, wind, fire, or other causes. The soil in such areas shall be restored to the condition and grade existing just prior to application of the matting. Restored or reclaimed areas shall be relimed, refertilized, and reseeded. Where necessary, the geosynthetic erosion control mat shall be completely replaced.

\subsection{6: Method of Measurement}

The area of seeding and erosion control mat shall be the number of square meters (square yards) of ground surface area placed in accordance with these specifications, completed and accepted.

\subsection{7: Basis of Payment}

Payment shall be full compensation for furnishing all materials, labor, tools, equipment, and incidentals necessary to complete the work. Anchors, check slots, terminal or junction slots, and wire staples, pins, or wood stakes will not be paid for directly, but will be considered subsidiary to this Item. Payment for accepted quantities placed will be made at contract prices for:

$\underline{\text { Item }}$

001 $\underline{\text { Unit }}$

$\mathrm{m}^{2}\left(\mathrm{yd}^{2}\right)$
Description

Seeding and erosion control matting 


\section{Section 002: Hard Armor Ditch Lining - FFR \& CBS only}

\subsection{1: General}

This work shall consist of furnishing and installing permanent hard armor channel linings. These materials include fabric formed revetments and concrete block systems. The hard armor erosion control material will be placed in newly constructed and rehabilitated stormwater channels. In the case of concrete block systems, the blocks must be backfilled and seeded to stimulated vegetation. This section includes all labor, tools, and materials necessary to install and secure the hard armor erosion control material on the prepared surface as shown on the Contract Drawings.

\subsection{2: Materials}

All erosion control materials shall meet the requirements of this section. They must be pre-qualified by the Director of the Materials Department prior to use. The hard armor shall be one of the following classes:

\begin{tabular}{|cc|c|}
\hline Class & Material & See Installation Section $\square$ \\
\hline C-1 & Fabric Formed Revetments & 002.03 \\
C-2 & Concrete Block Systems & 002.03 \\
C-3 & Gabions & INDOT Spec. Manual \\
C-4 & Riprap & INDOT Spec. Manual \\
\hline
\end{tabular}

\section{Properties of Hard Armor Materials}

Fabric Formed Revetments (FFR) filled

Concrete Block Systems (CBS)
Fabric formed revetments (FFR's) consist of two synthetic fabric plies linked to form a series of small cells. This "formwork" is with highly impermeable, high strength concrete. Some FFR's are further reinforced with cables to form articulating mats.

Concrete blocks interlock together in regular patterns to resist hydraulic forces. These systems are designed to have freedom of movement between individual units. Concrete blocks often have about $15-35 \%$ open area by design to allow for backfilling of topsoil or crushed stone. 
Gabions

Riprap placed in wire-enclosed baskets. These structures are more rigid than dumped riprap. Rather than individual particle displacement, gabions tend to deform as a unit.

Riprap

Typically angular, well graded stone with a that is quantified by a mean diameter and standard gradation. distribution curve.

\subsection{3: Construction Requirements}

\section{General}

The hard armor materials shall conform to the size, class, and/or type shown on the plans. The Contractor has the option of selecting an approved erosion control mat conforming to the class and type shown on the plans and according to the current approved products list. The hard armor channel liner shall be placed within 24 hours the geotextile has been installed. All materials shall be free of any treatment which might significantly alter its physical properties. During shipment and storage, FFRs and CBS shall be wrapped in a heavy-duty protective covering to protect it from direct sunlight, dirt, and other debris.

The manufacture shall submit certified test data to cover each shipment. Required data includes permissible shear or permissible velocity for FFR, weight of each block for CBS, median stone size and gradation for riprap and gabions. Products will not be accepted without this data.

\section{Preparation - All products}

A. All surfaces to be protected shall be graded and compacted in accordance with the Contract Drawings or as directed by the Engineer.

B. The surface shall be cleared of large rocks, soil clods, vegetation, or other foreign material larger than $38 \mathrm{~mm}$ that may inhibit intimate the erosion control material's contact with the subgrade.

C. Cut all longitudinal, terminal, and anchor trenches as required by the contract plans. 


\section{Installation}

The grout shall consist of a mixture of Portland cement, fine aggregate, water, Pozzolan (up to $20 \%$ of the cement), and grout fluidizer. The range of quantities as delivered is given in the table below. The grout shave have an air content between $6 \%$ and $9 \%$. The mix shall obtain a strength of $17 \mathrm{MPa}(2500 \mathrm{psi})$ at 28 days. Mixing time must be greater than one minute. The grout may be held for a maximum of 2.5 hours in the mixer.

\section{Range of Quantities as Delivered}

\begin{tabular}{lcc}
\hline Material & $l b / c y$ & $\mathrm{~kg} / \mathrm{m}^{3}$ \\
\hline Cement & $800-900$ & $470-530$ \\
Sand & $2030-2120$ & $1200-1250$ \\
Water & $540-550$ & $320-325$ \\
Air & As required & As required \\
\hline
\end{tabular}

\section{Steps for Installing FFRs}

\begin{tabular}{|c|c|}
\hline Step & Comments \\
\hline 1). Compact and grade soil & $\begin{array}{l}\text { Make grade as shown on plans; } \\
\text { Remove all foreign debris; }\end{array}$ \\
\hline 2). Install geotextile filter & Use 1995 FHWA design guidelines \\
\hline $\begin{array}{l}\text { 3). Excavate longitudinal, upstream, and } \\
\text { downstream trenches }\end{array}$ & These are required as per the plans \\
\hline 4). Lay fabric on geotextile & $\begin{array}{l}\text { Place the fabric over the design location, } \\
\text { allowing for post-grout contraction; } \\
\text { Insert reinforcing cable; }\end{array}$ \\
\hline 5). Zipper or sew all seams & $\begin{array}{l}\text { All seams must be facedown; } \\
\text { Overlap } 600 \mathrm{~mm}(2 \mathrm{ft}) \text { if zippering or } \\
\text { sewing is not practical }\end{array}$ \\
\hline 6). Inject the grout & $\begin{array}{l}\text { Slit the fabric and insert grout hoses; } \\
\text { Fill until FFR reaches maximum thickness }\end{array}$ \\
\hline 7). Place burlap in hose hole & $\begin{array}{l}\text { Remove burlap once grout no longer fluid } \\
\text { and smooth the surface; } \\
\text { Remove any spilled grout from the surface } \\
\text { Limit walking on fabric for at least } 1 \text { hour }\end{array}$ \\
\hline
\end{tabular}


Steps for Installing CBSs

\begin{tabular}{ll}
\hline Installation Step & Comments \\
\hline 1). Compact and grade soil & $\begin{array}{l}\text { Make grade as shown on plans; } \\
\text { Remove all foreign debris; }\end{array}$ \\
2). Install geotextile filter & Use 1995 FHWA design guidelines \\
3). Place concrete blocks & $\begin{array}{l}\text { Lay blocks perpendicular to the slope; } \\
\text { Blocks may be placed one at a time or in a } \\
\text { cabled mat configuration }\end{array}$ \\
& $\begin{array}{l}\text { Near culverts, piers, etc.., grout the space } \\
\text { between the blocks and the structure full }\end{array}$ \\
4). Grout areas around structures & $\begin{array}{l}\text { Use topsoil if CBS is to be vegetated; } \\
\text { Use gravel if CBS is to be left unvegetated; } \\
\text { CBS must be backfilled within } 7 \text { days after } \\
\text { installation }\end{array}$ \\
\hline
\end{tabular}

Installation procedures for rirpap and gabions is already found in the INDOT Construction specification guide. They will not be repeated here.

\subsection{4: Literature}

The Contractor shall submit one (1) full set of manufacturer's literature and manufacture's installation recommendations to the Engineer for the hard armor material selected in accordance with the approved products list.

\subsection{5: Maintenance}

The hard armor areas shall be maintained until all work on the contract has been completed and accepted. Maintenance shall consist of the repair of areas damaged by erosion, wind, fire, or other causes. The soil in such areas shall be restored to the condition and grade existing just prior to application of the matting. Restored or reclaimed areas shall be relimed, refertilized, and reseeded. Where necessary, the hard armor materials shall be completely replaced. 


\subsection{6: Method of Measurement}

Fabric formed mats will be measured in place and the area computed in square meters or square yards. The measurement area includes the exposed surface of the mat. The mat in the trenches shall be considered included in the cost of the mat and is not measured for payment. No allowance is made for overlaps. Concrete blocks and riprap will be measured for payment in place and the area computed in square meters or yards. Measurement area includes exposed surface plus the horizontal surface of the toe anchor.

\subsection{7: Basis of Payment}

Payment shall be full compensation for furnishing all materials, labor, tools, equipment, and incidentals necessary to complete the work. Anchors, check slots, terminal or junction slots, and wire staples, pins, or wood stakes will not be paid for directly, but will be considered subsidiary to this Item. Payment for accepted quantities placed will be made at contract prices for:

$\underline{\text { Item }}$

Unit

Description

002.1

$\mathrm{m}^{2}\left(\mathrm{yd}^{2}\right)$

Placing and filling FFR mats

002.2 $\mathrm{m}^{2}\left(\mathrm{yd}^{2}\right)$ Placing riprap and CBS 
Appendix A

Equations for Three Common Channel Geometries

Triangular

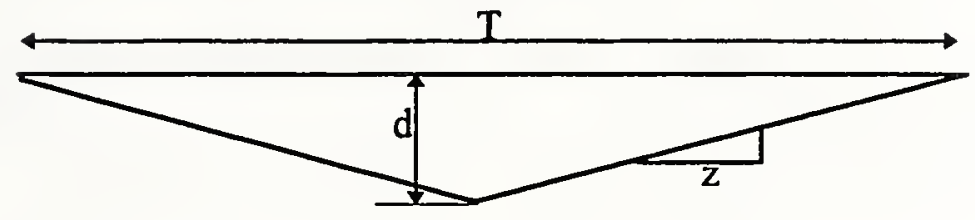

$$
\begin{aligned}
& A=Z d^{2} \\
& P=2 d \sqrt{Z^{2}+1} \\
& T=2 d Z
\end{aligned}
$$

To find d, iterate on: $\frac{Q n}{\varnothing S^{1 / 2}}=\frac{A^{5 / 3}}{P^{2 / 3}}=\frac{\left(Z d^{2}\right)^{5 / 3}}{\left(2 d \sqrt{Z^{2}+1}\right)^{2 / 3}}$

\section{Parabolic}

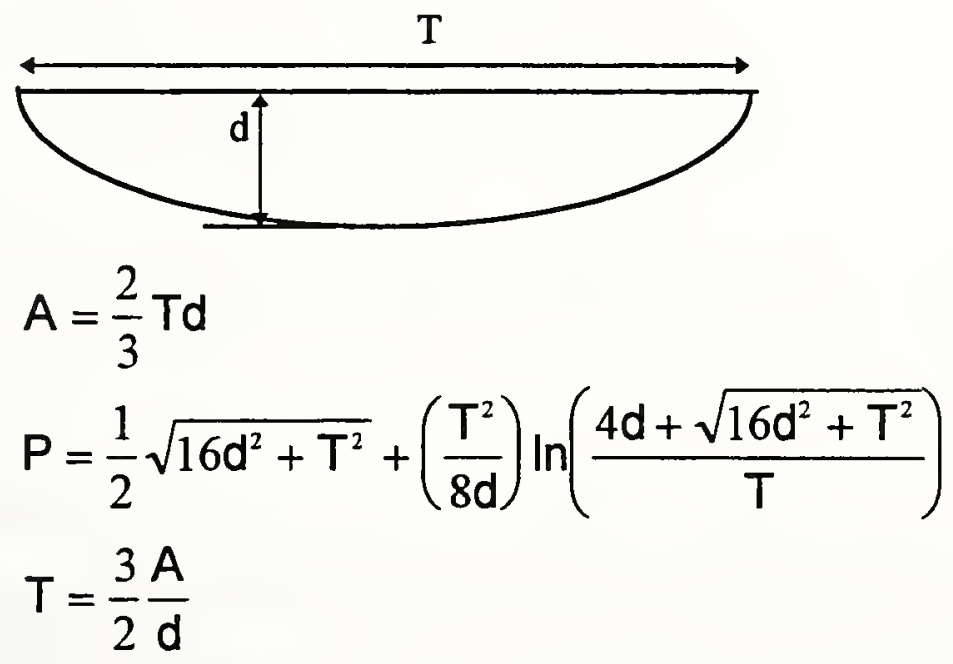

To find d, iterate on:

$$
\frac{Q n}{\varnothing S^{1 / 2}}=\frac{A^{5 / 3}}{P^{2 / 3}}=\frac{\left(\frac{2}{3} T d\right)^{5 / 3}}{\left(\frac{1}{2} \sqrt{16 d^{2}+T^{2}}+\left(\frac{T^{2}}{8 d}\right) \ln \left(\frac{4 d+\sqrt{16 d^{2}+T^{2}}}{T}\right)\right)^{2 / 3}}
$$




\section{Appendix A (continued)}

\section{Trapezoidal}

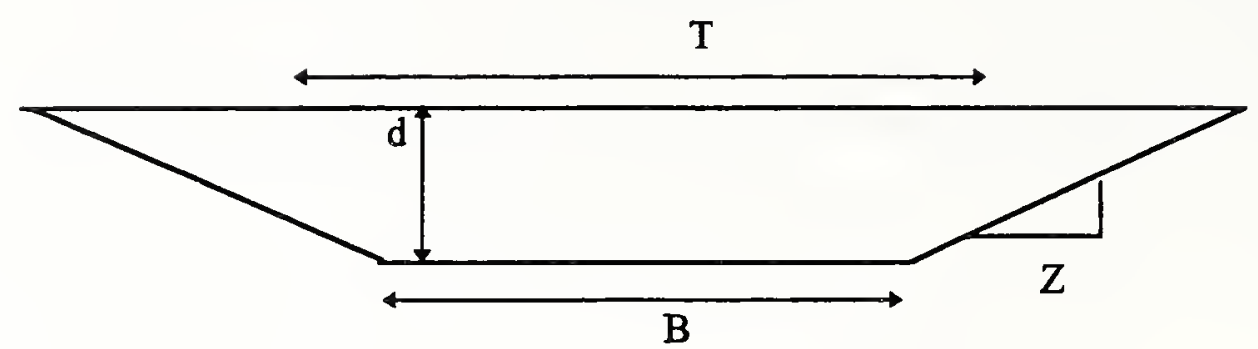

$$
\begin{aligned}
& A=B d+Z d^{2} \\
& P=B+2 d \sqrt{Z^{2}+1} \\
& T=B+2 d z
\end{aligned}
$$

To find d, iterate on: $\quad \frac{Q n}{\varnothing S^{1 / 2}}=\frac{A^{5 / 3}}{P^{2 / 3}}=\frac{\left(B d+Z d^{2}\right)^{5 / 3}}{\left(B+2 d \sqrt{Z^{2}+1}\right)^{2 / 3}}$ 


\section{Appendix B}

\section{Designing Geotextile Underlay for Riprap Channel Lining}

Reprinted from Geosynthetics Design and Construction Guidelines - FHWA-HI-95, 1995

Most riprap lined channels designed today include a geotextile underneath the stone layer. Such layers often replace graded granular filters. Geotextiles hold the soil in place. Special considerations are necessary for geotextiles beneath hard armor erosion control systems. They are briefly described below.

\section{Retention Criteria for Cyclic Flow}

During cyclic or dynamic flow, soil particles move behind the geotextile if it is not properly secured to the soil bed. Typically, the average opening size (AOS) of the geotextile is given as:

$$
O_{95 \text { (geotextile) }}=B D_{85 \text { (soil) }}
$$

where, $\mathrm{B}=$ dimensionless coefficient, function of the uniformity coefficient

$\mathrm{O}_{95} \quad=$ opening size in geotextile for which $95 \%$ are smaller

$\mathrm{D}_{85}=$ soil particle size for which $85 \%$ are smaller

Often it is assumed $B=1$. However, if uplift forces are possible, then the $B$ value should be reduced. Optimally, the largest opening in the geotextile is small enough to retain the smallest particles of soil.

\section{Permeability of Geosynthetic}

Since flow through the geosynthetic is restricted by the riprap, it is imperative that the available area carry the required flow. In equation form:

$$
\begin{aligned}
q_{\text {required }} \leq q_{\text {geolextile }} \frac{A_{g}}{A_{t}} \\
\text { where, } A_{g} \quad=\text { Reduced geotextile area available for flow } \\
A_{t} \quad=\text { Total geotextile area }
\end{aligned}
$$




\section{Clogging Resistance for Dynamic Flow}

Soil-Geotextile filtration tests should always be conducted. One would like the geotextile to allow water to pass and retains all but the finest particles. For sandy and silty soils $(k>10-5$ $\mathrm{cm} / \mathrm{s}$ ), the long term gradient ratio test is recommended (ASTM D 5101). For fine grained soils, the hydraulic conductivity ratio test should be performed (ASTM D 5567). Better results for this test are obtained if piezometers are included near the geotextile / soil interface.

\section{Survivability Criteria}

The geotextile must be able to withstand the weight and roughness of the riprap. Under high flows, riprap moves and abrades the geotextile. Consequently, the required property values are much higher than in other applications (see included design tables). These values are minimum survivability criteria. They were derived from successful application of geotextile underlays. Site specific and product specific tests are always encouraged.

The following pages present the FWHA design guidelines (1995) for geotextiles under hard armor. After the $D_{s 0}$ of the riprap is selected (based on one of the methods outlined in section 3.2) and normal depth of the channel is calculated, the geotextile underlay is designed using these procedures. They are included in this report for completeness. 
U.S. Department

Publication No. FHWA-HI-95-xox

of Transportation

Federal Highway

Administration

NHI Course No. 13213

\section{GEOSYNTHETIC DESIGN \& CONSTRUCTION GUIDELINES}

\section{PARTICIPANT NOTEBOOK}
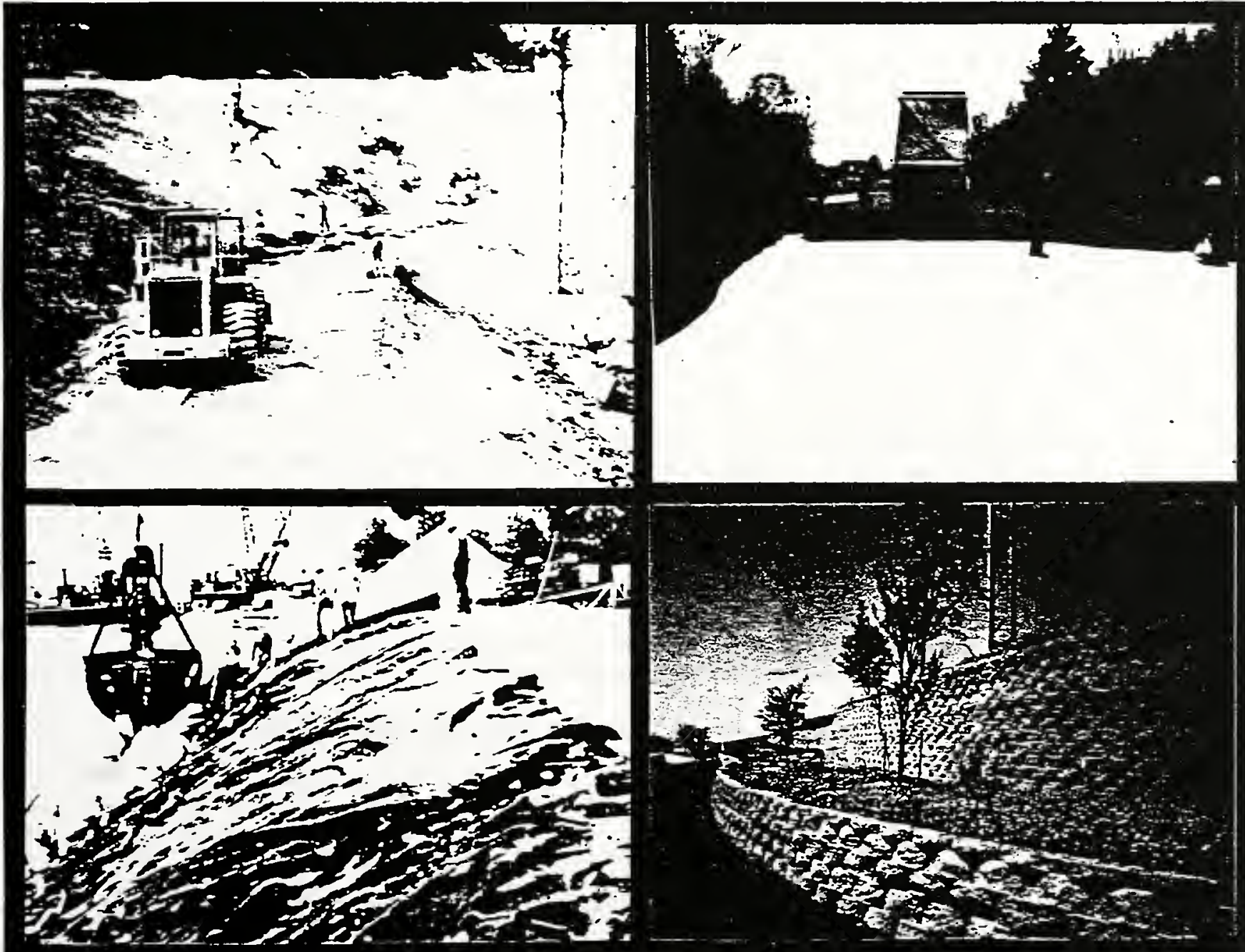
TABLE 3-1

SUMMARY OF GEOTEXTILE DESIGN AND SELECTION CRITERIA FOR HARD ARMOR EROSION CONTROL APPLICATIONS

I. SOII RETENTION (PIPING RESISTANCE CRITERIA)

Soils

Steady Stato Flow

$<50 \%$ Passing $0.075 \mathrm{~mm}$

$250 \%$ Passing 0.075 mm

For cobesive soils (PI > 7)
AOS or $0_{95} \leq B D_{s s}$

C. $\leq 2$ or $28: \quad B=1$

$2 \leq C_{a} \leq 4: \quad B=0.5 C_{a}$

4s $C_{8} \leq 8: \quad B=8 / C$.

Woven: $0_{95} \leq D_{v s}$

Nonwoven: $0_{\text {os }} \leq 1.8 \mathrm{D}_{2 s}$
Dyanmic, Pulsating and Cyclic Flow (if geotextile can move)

$O_{9 s}$ (geotextile) $\leq 0.3 \mathrm{~mm}$

II. PERMEABILITYTPERMITITVITY CRTIERIA ${ }^{3}$

A. Critical/Sovero Applications

$k_{\text {manis }}=10 \mathrm{k}$

B. Lea Critical/Laes Severe Applications (with Clean Medium to Coarse Sands and Gravels)

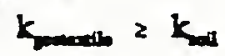

C. Pormitivity Requiroment

$$
\begin{array}{lll}
\psi=0.7 \sec ^{-1} & \text { for }<15 \% \text { passing } 0.075 \mathrm{~mm} \\
\psi=0.2 \sec ^{-1} & \text { for } 15 \text { to } 50 \% \text { passing } 0.075 \mathrm{~mm} \\
\psi=0.1 \sec ^{-1} & \text { for }>50 \% \text { passing } 0.075 \mathrm{~mm}
\end{array}
$$

III. CLOGGNG CRITERIA

A. Critical/Sovere Applications ${ }^{4}$

Solect geotextilo meeting I, II, IIIB, and perform soil/geotextile filtration tests before specification, prequalifying the geotextile, or after selection before bid closing. Alternative: use approved list specification for filtration applications. Suggested performance test method: Gradient Ratio, ASTM D 5101 for cobesionless soils or Hydraulic Contuctivity Ratio, ASTM D 5567 for cohesive soils.

B. Less Critical/Less Severo Applications

1. Perform soil-geotextile filtration tests.

2. Alternative: $O_{9 g}>3 D_{15}$ for $C_{a}>3$

3. For $C_{z} \leq 3$, specify geotextile with maximm opening size possible from retention criteria

4. Apparent Open Area Qualifiers

For soils with \% passing $0.075 \mathrm{~mm}$

Woven monofilament geotextiles: Percent Open Area : z

Nonwoven geokextiles: Porosity 2 
IV. SURVIVABILITY REQUIREMENTS

PHYSICAL REQUIREMENTS 6.7 .4

FOR EROSION CONTROL GEOTEXTILES

(after AASHTO-AGC-ARTBA Task Force 25)

\section{Broperty}

Grab Strength (N)

Elongation (\%) (min)

Seam Strength (N)"

Puncture Strength (N)

Burst Streagth (kPa)

Trapezoid Tear

Ultraviolet Degradation

at $500 \mathrm{br}^{13}$
High
Sucriyability. 14

890

15

800

356

2206

222

$70 \%$ strength retained for

all classes
Moderate

Survivability 10,14 Test Method

400

15

356

178

965

133
ASTM D 4632

ASTM D 4632

ASTM D 4632

ASTM D 4833

ASTM D 3787

ASTM D 4533

ASTM D 4355

\section{NOTES:}

1. When the protected soil contains particles passing the $0.075 \mathrm{~mm}$ sieve, use only the gradation of soil passing the $4.75 \mathrm{~mm}$ sieve in selecting the geotextile (i.e., scalp off the $+4.75 \mathrm{~mm}$ material.)

2. Solect gectextile on the besis of largest opening value required.

3. Permenbility should be besed on the actual geotextile open area available for flow. For example, if $50 \%$ of geotextilo area in to be covered by flat concreto blocks, the effective flow area is reduced by $50 \%$.

4. Filtration test aro performance tests and, as they depend on specific soil and design conditions, they cannot be performed by the manufucturer. Tests aro to be performed by specifying agency or their representative. It should also be recognized that experience is required to obtain reproducible results from performance tests.

5. Porosity requiremeots aro based on graded gramular filter porosity.

6. Acceptance of geotextiles should be based on ASTM D 4759.

7. Coneructing ageocy may require a letter from the supplier certifying that its geotextile meets specification requiremeats.

8. Minimum - use vahue in weaker principal direction. All numerical values represent minimum average roll values (i.e., teet results from any sampled roil in a lo shall meet or exceed the minimum values in the table). Stated values aro for leas criticalless severo conditions. Lot should be sampled according to ASTM D 4354.

9. High Survivability erosion control applications are used when geotextile installation stresses are more severe than Moderate Survivability (i.e., stode plecement beight should be less than $1 \mathrm{~m}$ and stone weights should not exceed $100 \mathrm{~kg}$ ).

10. Moderate Survivability erosion control applications are those in which geotextiles are used in structures or under corditions where the geotextile is protected by a sand cushion or by "zero drop beight" placement of stone.

11. Vahues apply to both field and mamufactured seams.

12. If the armor stone can move after installation (e.g., due to high wave action), then larger stone should be used or abrasion resistance requirements for the geotextile should be considered, using the results of ASTM D 4886.

13. 500 bours is the recommendation of the authors, Task Force 25 recommended 150 hours.

14. Numeric values are hard metric conversions of English units. 


\subsection{GEOTEXTILE DESIGN GUIDELINES}

STEP 1. Application evaluation.

\section{A. Critical/less critical}

1. If the erosion control system fails, will there be a risk of loss of life?

2. Does the erosion control system protect a significant structure,. and will failure lead to significant structural damage?

3. If the geotextile clogs, will failure occur with no warning? Will failure be catastrophic?

4. If the erosion control system fails, will the repair costs greatly exceed installation costs?

B. Severe/less severe

1. Are soils to be protected gap-graded, pipable, or dispersive?

2. Are soils present which consist primarily of silts and uniform sands with $85 \%$ passing the $0.15 \mathrm{~mm}$ sieve?

3. Will the erosion control system be subjected to reversing or cyclic flow conditions such as wave action or tidal variations?

4. Will high hydraulic gradients exist in the soils to be protected? Will rapid drawdown conditions or seps or weeps in the soil exist? Will blockage of seeps and weeps produce high hydraulic pressures?

5. Will high-velocity conditions exist, such as in stream channels?

NOTE: If the answer is yes to any of the above questions, the design sbould proceed under the critical/severe requirements; othorwiso use tho less crivicalless severe design approach.

STEP 2. Obtain soil samples from the site.

\section{A. Perform grain size analyses}

1. Determine percent passing the $0.075 \mathrm{~mm}$ sieve.

2. Determine the plastic index (PI).

3. Calculate $C_{0}=D_{60} / D_{10}$.

NOTE: When the protected soil contains particles passing the 0.075 mm sieve, use only the gradation of soil passing the $4.75 \mathrm{~mm}$ siove in selecting the geotextile (i.e., scalp off the $+4.75 \mathrm{~mm}$ materia).

4. Obtain $D_{8 s}$ for each soil and select the worst case soil (i.e., soil with smallest $B x$ $\left.D_{8 s}\right)$ for retention. 
B. Perform field or laboratory permeability tests

1. Select worse case soil (i.e., soil with highest coefficient of permeability k).

NOTE: The permeability of clean sends ( $<5 \%$ passing $0.075 \mathrm{~mm}$ sieve) with $0.1 \mathrm{~mm} \mathrm{D}_{10}<3 \mathrm{~mm}$ and $C_{a}$ $<5 \mathrm{~cm}$ be extimated by Hazea's formula, $k=\left(D_{10}\right)^{2}\left(k\right.$ in $\mathrm{cm} / \mathrm{s} ; D_{10}$ in mm). This formula should not be used for finor-grained soils.

STEP 3. Evaluate armor material and placement.

Design reference: FHWA Hydraulic Engineering Circular No. 15 (FHWA, 1988).

A. Size armor stone or riprap

Where minimum size of stone exceeds $100 \mathrm{~mm}$, or greater than a $100 \mathrm{~mm}$ gap exists between blocks, an intermediate gravel layer $150 \mathrm{~mm}$ thick should be used between the armor stone and geotextile. Gravel should be sized such that it will not wash through the armor stone (i.e., $D_{8 s}$ gravel $2 D_{15}$ riprap/5).

B. Determine armor stone placement technique (i.e., maximum height of drop).

STEP 4. Calculate anticipated reverse flow through erosion control system.

Here we need to estimate the maximum flow from seeps and weeps, maximum flow from wave runout, or maximum flow from rapid drawdown.

A. General case - use Darcy's law

$$
q=k i A
$$

where:

$\mathrm{q}=$ outflow rate $\left(L^{3} / T\right)$

$\mathbf{k}=$ effective permeability of soil (from Step $2 B$ above) $(L / T)$

$\mathrm{i}=$ average hydraulic gradient in soil (e.g., tangent of slope angle for wave runoff)(dimensionless)

$A=$ area of soil and drain material normal to the direction of flow $\left(L^{2}\right)$. Can be evaluated using a unit area.

Use a conventional flow net analysis (Cedergren, 1977) for seepage through dikes and dams or from a rapid drawdown analysis.

B. Specific erosion control systems - Hydraulic characteristics depend on expected precipitation, runoff volumes and flow rates, stream flow volumes and water level fluctuations, normal and maximum wave heights anticipated, direction of waves and tidal variations. Detailed information on determination of these parameters is available in the FHWA (1989) Hydraulic Engineering Circular No. 11. 
STEP 5. Determine geotextile requirements.

\section{A. Retention Criteria}

From Step $2 A$, obtain $D_{s 5}$ and $C_{u}$; then determine largest pore size allowed.

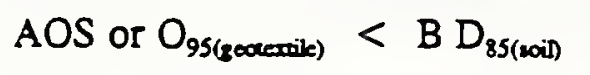

where: $\mathrm{B}=1$ for a conservative design.

For a less-conservative design and for $s 50 \%$ passing $0.075 \mathrm{~mm}$ sieve:

$$
\begin{array}{lll}
B=1 & \text { for } C_{u} \leq 2 \text { or } 28 & \text { (Eq. 2 - 2a) } \\
B=0.5 C_{u} & \text { for } 2 \leq C_{u} \leq 4 & \text { (Eq. 2 - 2b) } \\
B=8 / C_{u} & \text { for } 4<C_{u}<8 & \text { (Eq. 2 - 2c) }
\end{array}
$$

For $250 \%$ passing $0.075 \mathrm{~mm}$ sieve:

$$
\begin{array}{ll}
B=1 & \text { for wovens } \\
B=1.8 & \text { for nonwovens } \\
\text { and AOS or } O_{95} \text { (geotextile) } s 0.3 \mathrm{~mm} & \text { (Eq. 2 - 5) }
\end{array}
$$

For nondispersive cohesive soils (PI $>7$ ) use:

$$
\text { AOS or } \mathrm{O}_{95} \leq 0.3 \mathrm{~mm}
$$

If geotextile and soil retained by it can move:

$$
\mathrm{B}=0.5
$$

B. Permeability/Permittivity Criteria

1. Less Critical/Less Severe

$k_{\text {zoderexite }} 2 k_{\text {sail }}$

2. Critical/Severe

$\mathrm{k}_{\text {rosective }} \geq 10 \mathrm{k}_{\text {sal }}$

3. Permittivity $\Psi$ Requirement

$\psi>0.7 \mathrm{sec}^{-1} \quad$ for $<15 \%$ passing $0.075 \mathrm{~mm}$

$\psi>0.2 \mathrm{sec}^{-1}$ for 15 to $50 \%$ passing $0.075 \mathrm{~mm}$

$\psi=0.1 \mathrm{sec}^{-1}$ for $>50 \%$ passing $0.075 \mathrm{~mm}$

4. Flow Capacity Requirement
$q_{\text {secocrite }} 2\left(A_{1} / A_{2}\right) q_{\text {required }}$
(from Eq. 2 - 9)
or

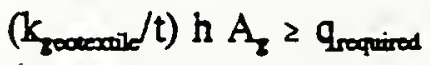


where:

$q_{\text {required }}$ is obtained from Step 4 (Eq. 15) above.

$\mathrm{k}_{\text {concrive }} / \mathrm{t}=\psi=$ permittivity

$\mathrm{h}=$ average head in field

$A_{g}=$ area of fabric available for flow (e.g., if $50 \%$ of geotextile covered by flat rocks or riprap, $A_{z}=0.5$ total area)

$A_{1}=$ total area of geotextile

C. Clogging Criteria

1. Less critical/less severe

a. Pefform soil-geotextile filtration tests.

b. Alternative: From Step $2 A$ obtain $D_{15}$; then determine minimum pore size requirement, for soils with $C_{u}>3$, from

$\mathrm{O}_{95} \geq 3 \mathrm{D}_{15}$

(Eq. 2 - 10)

c. Other qualifiers

For soils with \% passing $0.075 \mathrm{~mm}$

$\geq 5 \%$

$\leq 5 \%$

Woven monofilament geotextiles: Percent Open Area 2

Nonwoven geotextiles: Porosity 2

$4 \%$

$10 \%$

$50 \%$

$70 \%$

\section{Critical/severe}

Select geotextiles that meet retention, permeability, and survivability criteria; as well as the criteria in Step 5C.1 above; perform a filtration test.

Suggested filtration test for sandy and silty soils (i.e., $\mathrm{k}>10^{-7} \mathrm{~m} / \mathrm{s}$ ) is the gradient ratio test as described in Chapter 1. The hydraulic conductivity ratio test (see Chapter 1 ) is recommended for fine-grained soils (i.e., $\mathrm{k}<10^{-7} \mathrm{~m} / \mathrm{s}$ ), if appropriately modified.

D. Survivability

Select geotextile properties required for survivability from Table 3-1. Add durability requirements if applicable. Don't forget to check for abrasion and check drop height. Evaluate worst case scenario for drop height.

STEP 6. Estimate costs.

Calculate the volume of armor stone, the volume of aggregate and the area of the geotextile. Apply appropriate unit cost values. 


\section{Appendix C}

\section{List of References}

Agnew, William, (1991), "Erosion Control Products Selection", Geotechnical Fabrics Report, Vol. 9, No. 3, April 1991 pp. 24-27.

Ahmed, A., F. (1989), "Model Study of Side Slope Riprap", Proceedings of the International Symposium on Sediment Transport Modeling, New Orleans, LA, 1989, pp. 233-241.

Allen, S. R. (1996), "Evaluation and Standardization of Rolled Erosion Control Products", Geotextiles and Geomembranes, Vol. 14, pp. 207-221.

Anonymous, (1988), “Geomatrix Aids Soil Erosion Problem”, Better Roads, Vol. 58, No. 3 , pp. 38.

Anonymous, (1990), "Fabric Controls Roadside Erosion”, Better Roads, Vol. 58, No. 11, Nov. 1990 , pp. 28-29.

Austin, Deron, and Carroll, R. G., (1993), "History Investigation of the Role of Geosynthetics in Interrill Soil Erosion and Sediment Control", Geotechnical Fabrics Report, Vol. 11., No. 3, April 1993, pp. 16-33.

Austin, Deron, and Theisen, Marc S., (1994) "BMW Extends Vegetation Performance Limits”, Geotechnical Fabrics Report, April/May 1994, pp. 8-16.

Austin, Deron N., and Ward, Lynn E., (1996), "ECTC Provides Guidelines for Rolled Erosion Control Products”, Geotechnical Fabrics Report, Jan/Feb. 1996, pp. 18-21.

Barrett, James, "How to Control Roadside Erosion”, Better Roads, Feb. 1990, Vol. 60, No. 2, pp. 24-25.

Bathurst, James, \& Li, Ruh-Ming, \& Simons, Daryl, B., "Resistance Equation for LargeScale Roughness", Journal of the Hydraulics Division, Vol. 107, No. HY12, Dec. 1981, pp. 1593-1613.

Blodgett, J.C. (1986), "Rock Riprap Design for Protection of Stream Channels Near Highway Structures - Volume 1, Hydraulics of Open Channels", USGS Water Resources Investigations Report 86-4127, 65 pages.

Blodgett, J.C. (1986), "Rock Riprap Design for Protection of Stream Channels Near Highway Structures - Volume 2, Evaluation of Riprap Design Procedures", USGS Water Resources Investigations Report 86-4128, 95 pages. 
Brown, Scott, \& Clyde, Eric (1989), "Design of Riprap Revetment (Revised HEC-11)", FHWA Report No. FHWA-IP-89-016, 169 pages.

Cabalka, Dwight, \& Lutyens, Don (1996), "Revetment Quenches Erosion at Starved Rock State Park" Geotechnical Fabrics Report, Vol. 14, No. 5, June/July 1996, pp. 32-35.

Carroll, R.G. Jr., and Theisen, Marc S, (1990), "Turf Reinforcement for Soft Armor Erosion Protection", Proceedings of the IV International Conference on Geotextiles, Geomembranes and Related Products, June 1990, The Hague, Netherlands.

Carroll, R.G. Jr., Rodencal, Jeff, and Theisen, Marc S., (1991), "Evaluation of Turf Reinforcement Mats and Erosion Control and Revegation Mats Under High Velocity Flows", Proceedings of the XXII Annual Conference of the International Erosion Control Association, Orlando, Florida, USA.

Carroll, R. G., Rodencal, J., and Collin, J, (1992), “Geosynthetics in Erosion Control The Principles", Geotextiles and Geomembranes, Vol. 11, pp. 523-534.

Chen, Y. H., and Cotton, G. K., (1988), "Design of Roadside Channels with Flexible Linings", Federal Highway Administration, Report HEC 15 / FHWA-IP-87-7, McLean, VA, USA, 1988.

Chih, Ted Yang, (1996), Sediment Transport: Theory and Practice, McGraw Hill Co. Inc., New York, chapter 1-3.

Chow, Ven Te, (1964), Handbook of Applied Hydrology, McGraw Hill Book Co., New York.

Clopper, Paul, E (1990), "Minimizing Erosion damage to Embankments, Spillways, and Channels with Articulated Concrete Block Revetment Systems", Proceedings of the 1990 Conference on Hydraulic Engineering, San Diego, CA, Vol. 2, pp. 1141-1145.

Cotton, G. K., (1993), "Flow Resistance Properties of Flexible Linings", Proceedings National conference on Hydraulic Engineering, Part 2, 1993, Published by ASCE, NY, NY, pp. 1344-1349.

Diyaljes, Vishnu, and Stoeck, James, (1990), "Highway Erosion Remediation Measures", Proceedings: International Symposium on Sediment Transportation Modeling, Published by ASCE, NY, NY, pp. 154-159.

Dodson, G. I., (1989), "Vegetated Waterway Linings Reinforced with Geomatrix Matting - Design Methodology and Performance", Canadian Land Reclamation Association, American Society for Surface Mining and Reclamation, Calgary, Canada, and Proceedings of the XXI Annual Conference of the International Erosion Control Association, Washington D.C., Feb. 1990, pp. 249-255. 
"Erosion Control Product Data", Geotechnical fabrics Report - 1996 Specifiers Guide, Vol. 13, No. 9, Dec. 1995, pp. 163-179.

Escarameia, Eng., M., \& May, R. W. (1995), "Stability of Riprap and Concrete Blocks in Highly Turbulent Flows", Proceedings of the Institute of Civil Engineering Water, Maritime, and Energy, Vol. 112, No. 3, Sept. 1995, pp. 227-237.

Froehlich, David, C., \& Benson, Craig, A. (1996), "Sizing Dumped Rock Riprap", Journal of Hydraulic engineering, Vol. 122, No. 7, July 1996, pp. 389-395.

Fuller, Chip (1992), "Concrete Blocks Gain Acceptance as Erosion Control Systems", Geotechnical Fabrics Report, April 1992, pp. 24-34.

Godfrey, Sally, and Tatge, Joan, (1995), "Erosion Control Materials Tested at Texas Field Facility", TR News, Nov/Dec 1995, pp. 11-13, 35.

Hall, J. M., \& Moe, J. A, \& Legarra, J. A. (1970), "Bank and Shore Protection in California Highway Practice, State of California Business and Transportation Agency, Department of Public Works, Division of highways, 1970, pp. 101-110.

Hamm, John L, and Busche, Nancy, (1993), "Erosion Control: A Statewide Study - New Product Evaluation Final Report", Wisconsin Department of Transportation, Division of Highways, Research Report Number: WI-03-93. 15 pages.

Hewlett, H.W.M., Boorman, L.G., and Brambley, M.E., (1987), "Design of Reinforced Grass Waterways", Construction Industry Research and Information Report 116, London, England.

"High Velocity Shear Testing of Landlok ECRM 450, Landlok TRM 1060, Polyjute, and Pryamat Erosion Control Materials - A Laboratory Study", Synthetic Industries, Chattanooga, TN, 1995.

Holtz, Robert D, Christopher, Barry, and Berg, Ryan, (1995), Geosynthetic Design and Construction Guidelines - Participant Notebook, Federal Highway Administration, Report No. FHWA-HI-95-xxx, May 1995, chapter 2-3, pp. 27-105.

Illinois Department of Transportation, Standard Specifications for Road and Bridge Construction, 1994, SS 251, 283, 783.

Lamberton, Bruce, A. (1989), "Fabric Forms for Concrete", Concrete International: Design \& Construction, Vol. 11, No. 12, Dec. 1989, pp. 58-67. 
Lancaster, Tim, and Austin, Deron, (1994), "Classifying Rolled Erosion Control Products: A Current Perspective", Geotechnical Fabrics Report, Vol. 12, No. 8, Oct/Nov 1994, pp. $16-22$.

Maynord, Stephen, T (1991), "Flow Resistance of Riprap", Journal of Hydraulic Engineering, Vol. 117, No. 6, June 1991, pp. 687-695.

Maynord, Stephen, T (1992), "U.S. Army Corps of Engineers Riprap Design for Flood Channels", Transportation Research Record \# 1420, pp 14-22.

Maynord, Stephen, T (1995), "Gabion-Mattress Channel Protection Design", Journal of Hydraulic Engineering, Vol. 121, No. 7, July 1995, pp. 519-522.

Missouri Highway and Transportation Department, (1983), "Investigation of Erosion Control Materials for Ditches in Highway Corridors in Missouri", Published by Division of Materials and Research, Report No. 81-3.

Monnet, Walter (1990), "Concrete Mats in Hydraulic Engineering and Experience", Geotextiles, Geomembranes, and Related Products, 1990 Rotterdam.

Northcutt, Paul, (1993), "Field Performance Testing of Roll Type Erosion Control Blankets Through the Erosion Control Field Laboratory, Proceedings of the XXIV Annual Conference of the International Erosion Control Association, Indianapolis, IN, Feb. 1993, pp. 187-192.

Northcutt, Greg, (1995), "Geosynthetics Add Another Dimension to Erosion Control”, Erosion Control, Journal of the IECA, May/June 1995, pp. 34-41.

Ohio Department of Transportation, Construction and Materials Specifications, 1995, SS 666-673, 839-840.

Ohio Department of Transportation, Location and Design Manual, 1992, pp. 11-2 - 11-5.

Simons, Daryl, B., \& Senturk, Fuat (1977) Sediment Transport Technology, Water Resources Publications, Fort Collins, CO, 1977, Ch. 7, pp. 418-457.

Starrett, Ken (1994), “Concrete Revetment System Controls Severe Erosion”, Public Works, Vol. 125, No. 13, pp. 46-47.

Software Manual: "EC-Design - Erosion Control Design Package", Synthetic Industries, Chattanooga, TN, 1995.

Software Manual: "Erosion Control Materials Design Software”, North American Green, Evansville, IN, 1995. 
Sprague, C., J., \& Koutsourais, M., M. (1992), "Fabric Formed Concrete Revetment Systems", Geotextiles and Geomebranes, Vol. 11, pp. 587-609.

Texas Department of Transportation, "Final Performance Analysis through the 1995 Test Cycle - Class II, Channel Protection, Performance Testing of Selected Erosion Control Products at the Texas Department of Transportation / Texas Transportation Institute Hydraulics and Erosion Control Laboratory, prepared by Paul Northcutt, March 1996.

Theisen, Marc S, (1988), "Cost Effective Technique for Successful Erosion Control", Proceedings from the High Altitude Revegetation Workshop, No 8, Fort Collins, CO, USA, 1988.

Theisen, Marc S, and Carroll, R.G. Jr., (1990), "Turf Reinforcement - the 'Soft Armor' Alternative", Proceedings of the XXI Annual Conference of the International Erosion Control Association, Washington D.C., USA.

Theisen, Marc S, (1991), "The Role of Geosynthethics on Erosion and Sediment Control: An Overview", Proceedings of the 5th GRI Seminar, Geosynthetics in Filtration, Drainage, and Erosion Control, Philadelphia, PA, USA.

Theisen, Marc S, (1992), "Evaluation of Biotechnical Composites Under High Velocity and Shear Conditions", Conference Proceedings: International Erosion Control Association, 1992, pp. 285-301.

Theisen, Marc S, (1992), "The Expanding Role of Geosynthetics in Erosion and Sediment Control", Informational Paper published by Synthetic Industries, Chattanooga, TN, 20 pages.

Theisen, Marc S, (1992), "The Role of Geosynthetics in Erosion and Sediment Control: An Overview", Geotextiles and Geomembranes, Vol. 11, pp. 535-550.

Theisen, Marc S, (1992), "Geosynthetics in Erosion and Sediment Control", Geotechnical Fabrics Report, Vol. 10, No. 4, May/June 1992, pp. 26-35.

Theisen, Marc S, Hageman, M. and Austin, Deron, (1995), "Geosynthetic Erosion Mats for the Horse Ranch - A Case History," Geosynthetics, Vol. 1, 1995, pp. 405-418, and Proceedings of the XXVI Annual Conference of the International Erosion Control Association, 1995.

Thibodeaux, Kirk, (1985), "Performance of Flexible Ditch Linings", Federal Highway Administration, Report Number: FWHA/RD/86/114, September 1985, 91 pages.

U.S. Department of Transportation, Standard Specifications for Construction of Roads and Bridges on Federal Highway Projects, FP-92, 1992, Federal Highway Administration, SS 713, pp. 618-629. 
Urroz, Gilberto, (1995), "High Velocity Shear Testing of Mriamat TM8 Erosion Control Blanket", Report from Utah Water Research Lab, Utah State University, Logan, UT, 10 pages.

Virginia Department of Transportation, "Approved Erosion Control Products List", $\underline{\text { Road }}$ and Bridge Construction Specifications, 1996.

Wall, G.J., (1991), "The Effectiveness of Surficial Erosion Control Products, Ontario Ministry of Transportation, Research and Development Branch, Ontario, Canada, 23 pages.

Wang, Sayny-yi, \& Shen, Hsieh, Wen (1985), "Incipient Sediment Motion and Riprap Design", Journal of Hydraulic Engineering, Vol. 111, No. 3, March 1985, pp. 520-536.

Wu, K., J., \& Austin, D., N. (1992), “Three-Dimensional Polyethylene Geocells for Erosion Control and Channel Linings", Geotextiles and Geomembranes, Vol. 11, 1992, pp. 611-620.

\section{Contributing Companies}

Akzo Nobel Geosynthetics

Construction Techniques

Erosion Control Systems

North American Green

Synthetic Industries

Greenfix America

Aqua Shed Manufacturing Corp.

American Excelsior Company

Contech Construction Products

Hydrotex Synthetics

Tenax Corporation

Verdyol Alabama

Nutec Supply
BonTerra

Drainage Products

Nicolon Mirafi Group

PPS Packaging Company

Belton Industries

Webtec, Inc.

Amoco Fabrics and Fibers

Siltco Industries

Midwest Construction Products

Presto Products Company

EFS, Inc.

Eljen Corporation

Environmental Protection Products 


\section{Appendix D - FWHA 1995 Flexible}

Lining Design Prodedure

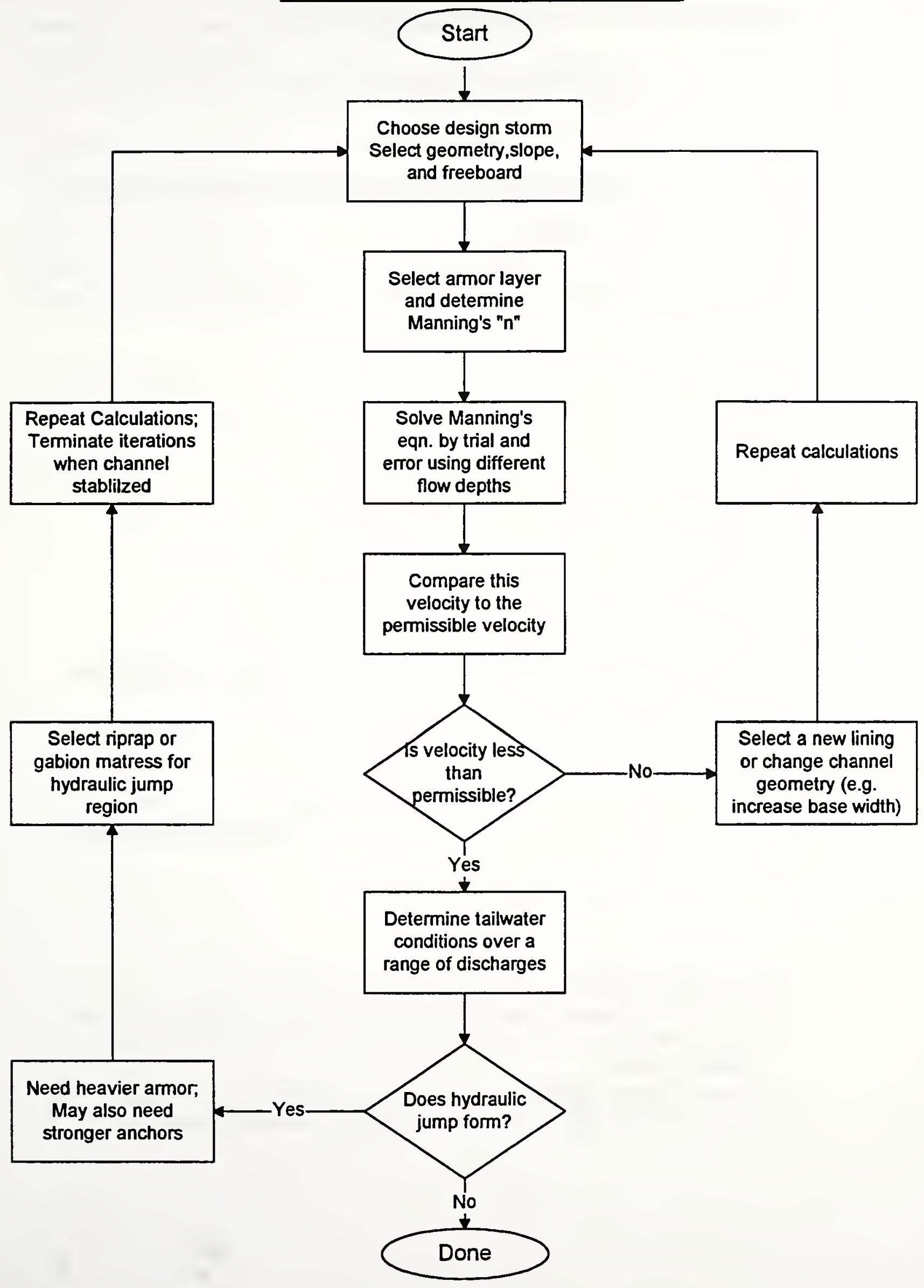




\section{Appendix D - FHWA 1995 Flexible Lining Design Procedure - Continued}

In addition to the design methodology outlined on the previous flow chart, there are several other design considerations:

1). If a reservoir is included in the channel flow path, you need to carry out a flood routing calculation for each option.

2). If a spillway or weir is involved, make sure that the freeboard is adequate. Include allowances for floods, waves, and freeze / thaw cycles.

3). General planning: Need to consider the following:

(a). acceptability of failure

(b). dry usage (risk of vandalism)

(c). maintenance ability of owner

(d). inspection strategy

4). Geotechnical considerations

(a). nature of subsoil

(b). existing and extreme water table levels

(c). investigate dry and wet slope stability; this requires strength and consolidation parameters

(d). consider if localized drainage needed beneath the waterway to relieve pore pressures

(e). consider settlement of subsoil; settlement must be small enough (or the liner must be flexible enough) so a failure doesn't occur.

5). Botanical considerations

(a). Obtain samples of soil and carry out physical and chemical tests to determine its suitability

(b). Select a grass mixture

(c). Decide on method of planting / spreading seed

6). Detailing and Specification

(a). Anchorage: plans should show anchorage at edges of all liners

(b). Pins, stakes, staples - shape, thickness, and location throughout the blanket

(c). Cross section must show freeboard, and any transition region between different slopes

(d). Joints, overlaps, check dams, temporary restraints must all be detailed

(e). Crest details: Upstream end must be designed to prevent erosion 


\section{Appendix E}

\section{Typical Channel Drawings}

The following pages provide typical engineering drawings for geosynthetic-protected drainage channels. Note that these drawings are modified from those found in the Synthetic Industries software package EC-Design ${ }^{\mathrm{TM}}$. They are by no means complete for construction purposes. Rather, these drawings are included as an example of how the designed channel should look. Those interested in complete drawings should consult one of the firms listed in Appendix C.

Note the following:

- Details of both the channel and slope situations are given.

- Detail 1-B includes a French drain to accommodate continuous flows (i.e. these drains handle perched water tables).

- The dimensions of the anchor trenches will vary according to manufacturer. Chapter 6 of this report provides some information about selecting an appropriate depth and width anchor trench or check slot.

- No staple patterns are included. These patterns are product specific and generalizations are difficult to make. Consult the product's manufacturer for staple pattern details. 

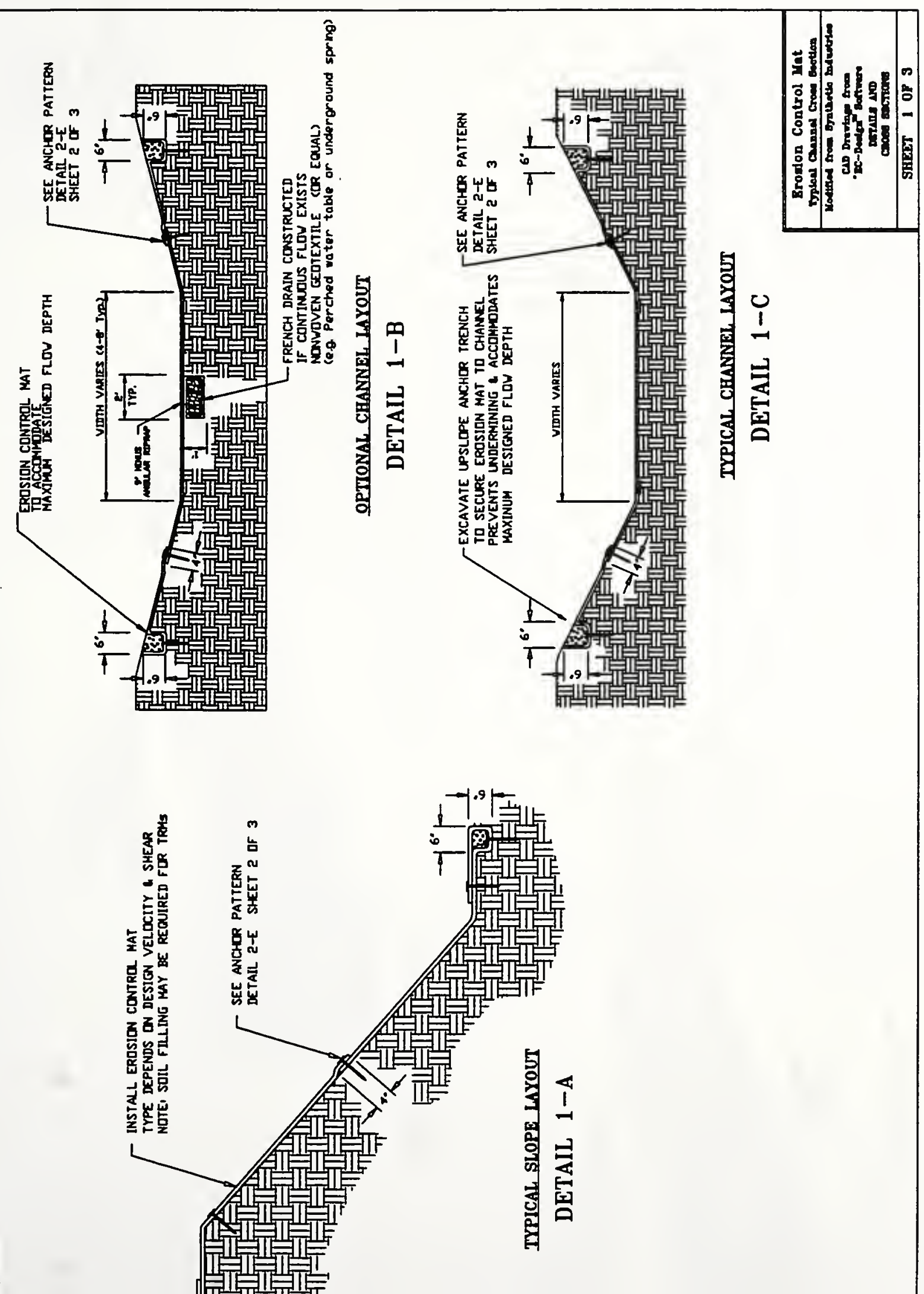

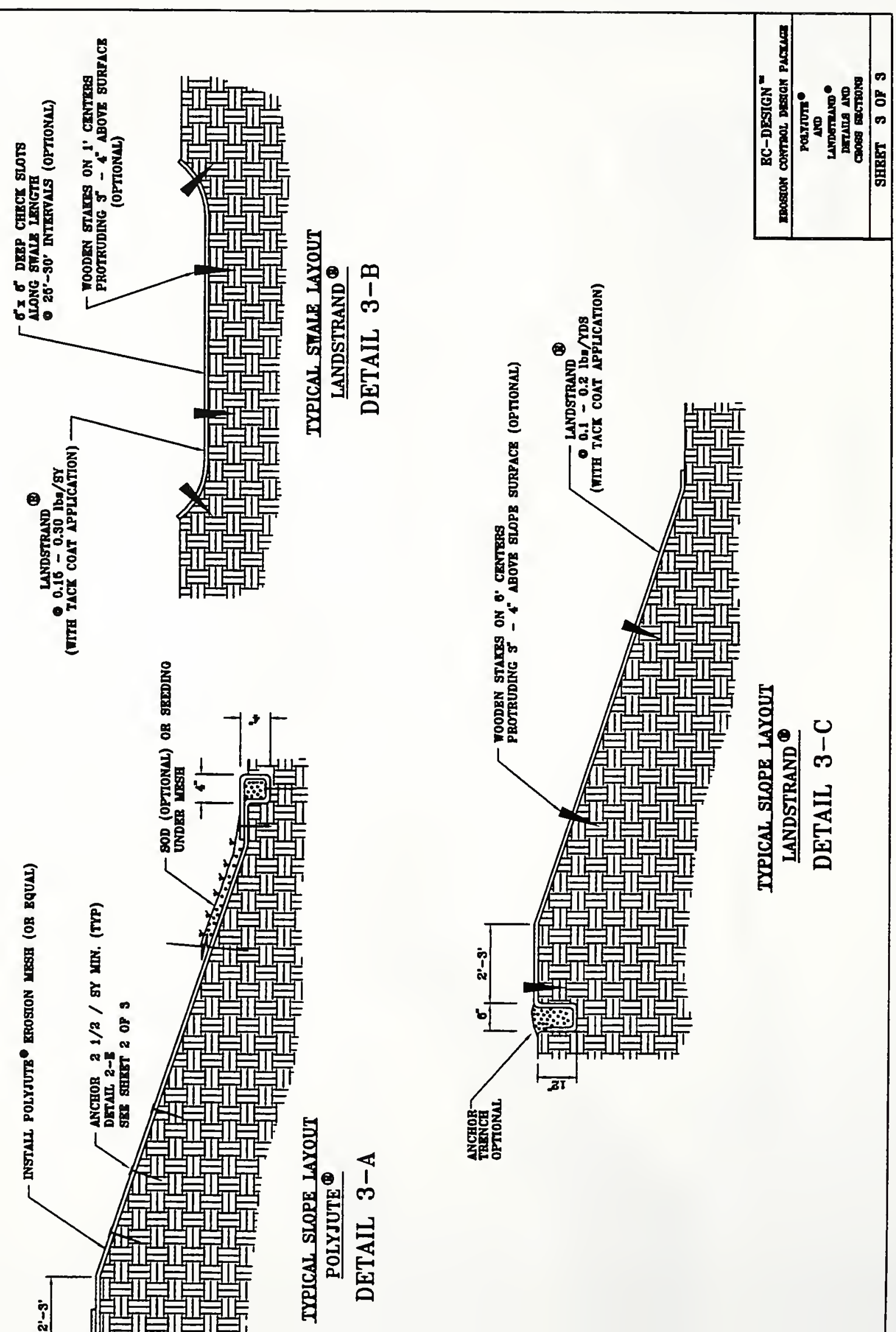


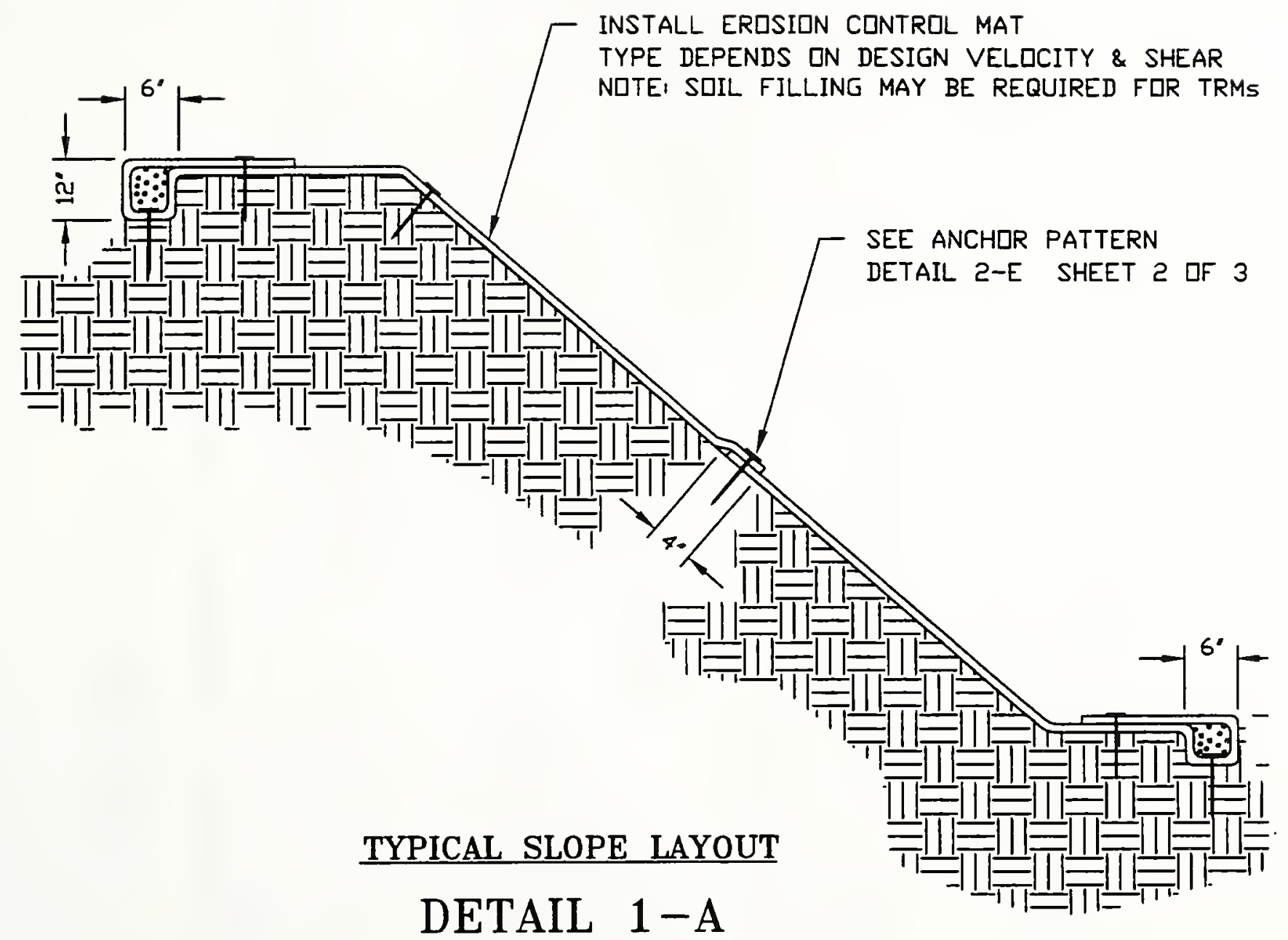




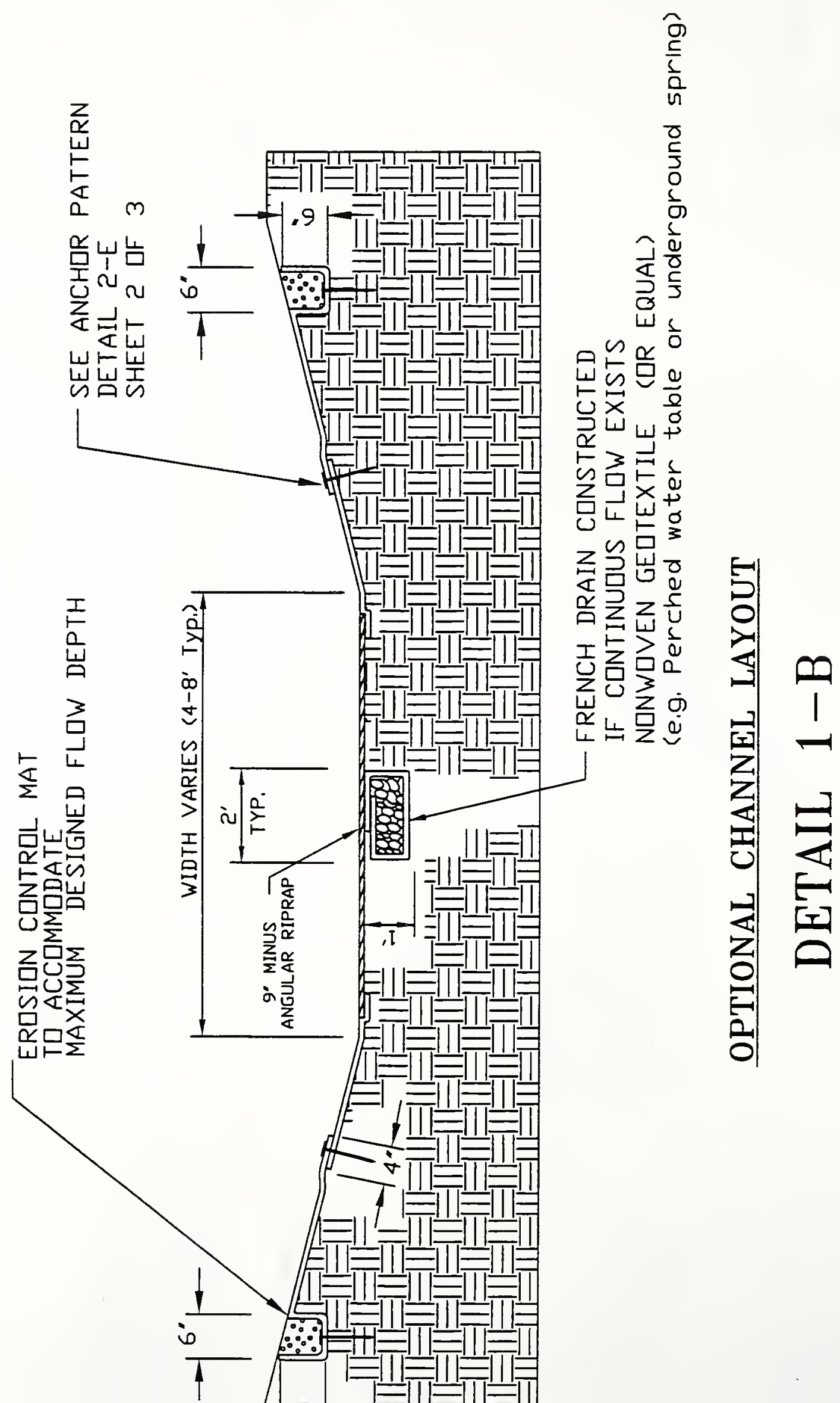




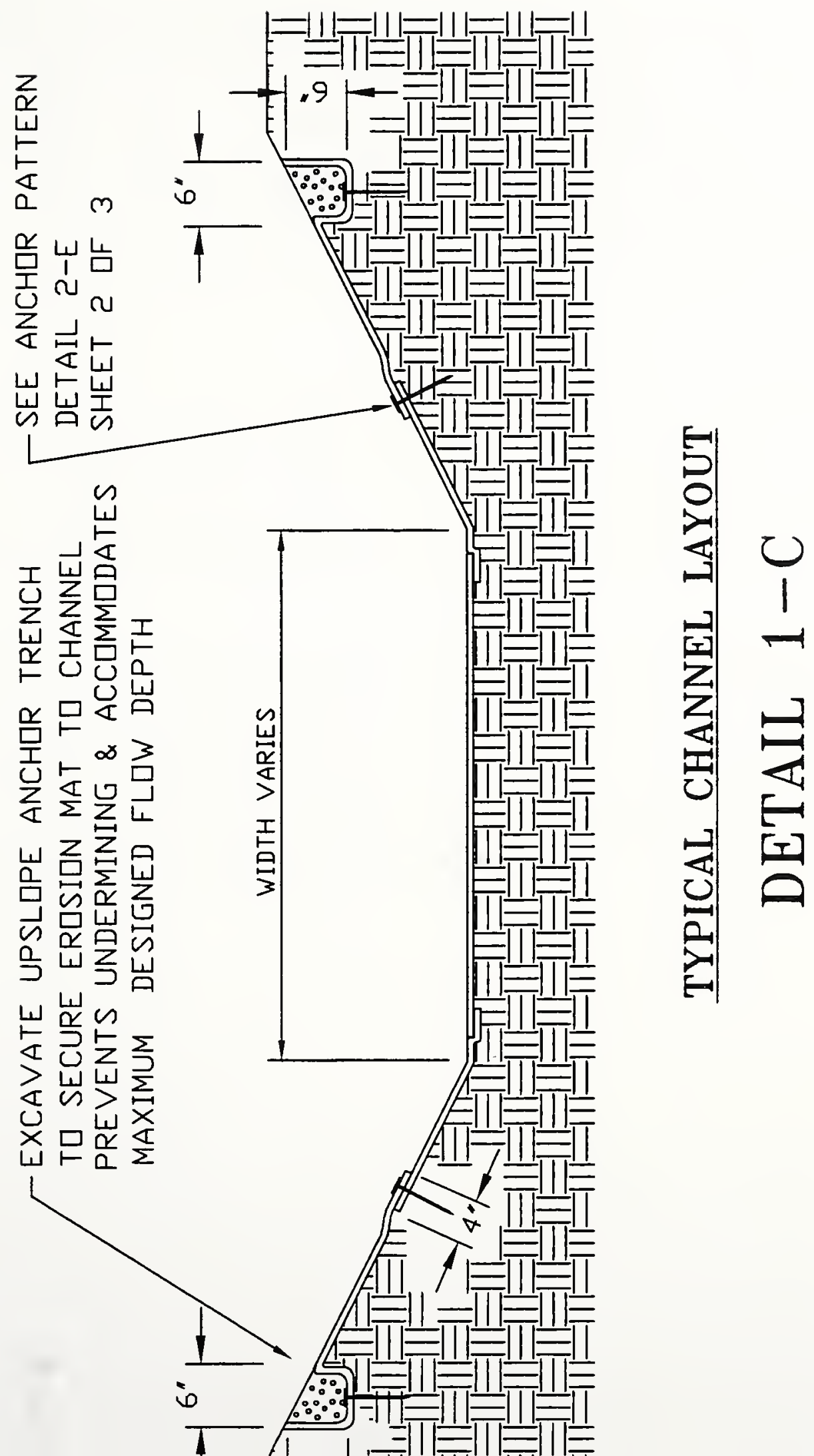




\section{Appendix F \\ Erosion Control Product Database}

One of the primary sources of information for this research was the erosion control manufacturers. Letters were sent out to 31 erosion control manufacturers and suppliers throughout the United States. Twenty-eight companies responded with product documentation, samples, company design software, drawings, specifications, performance data, and index test parameters. Documentation included the entire range of erosion control products - temporary blankets, permanent ECRMs and TRMs, and hard armor fabric formed revetments and concrete blocks.

In order to organize the information, the 62 products were entered into a computerized database (Paradox 4.0 for Windows). Product descriptions, recommended uses, performance properties (permissible shear and velocity data), index properties (tensile strength, UV stability, etc..), and physical properties (thickness, color) are included in the database.

Note that manufacturers typically do not provide data for all categories in the database. Hence, there are many blanks in the database. Moreover, the database is not an exhaustive collection of all products on the market today; rather it is a representative cross section of the erosion control market. It is merely a tool that demonstrates the range of product types, strengths, and uses of the erosion control products available today. 

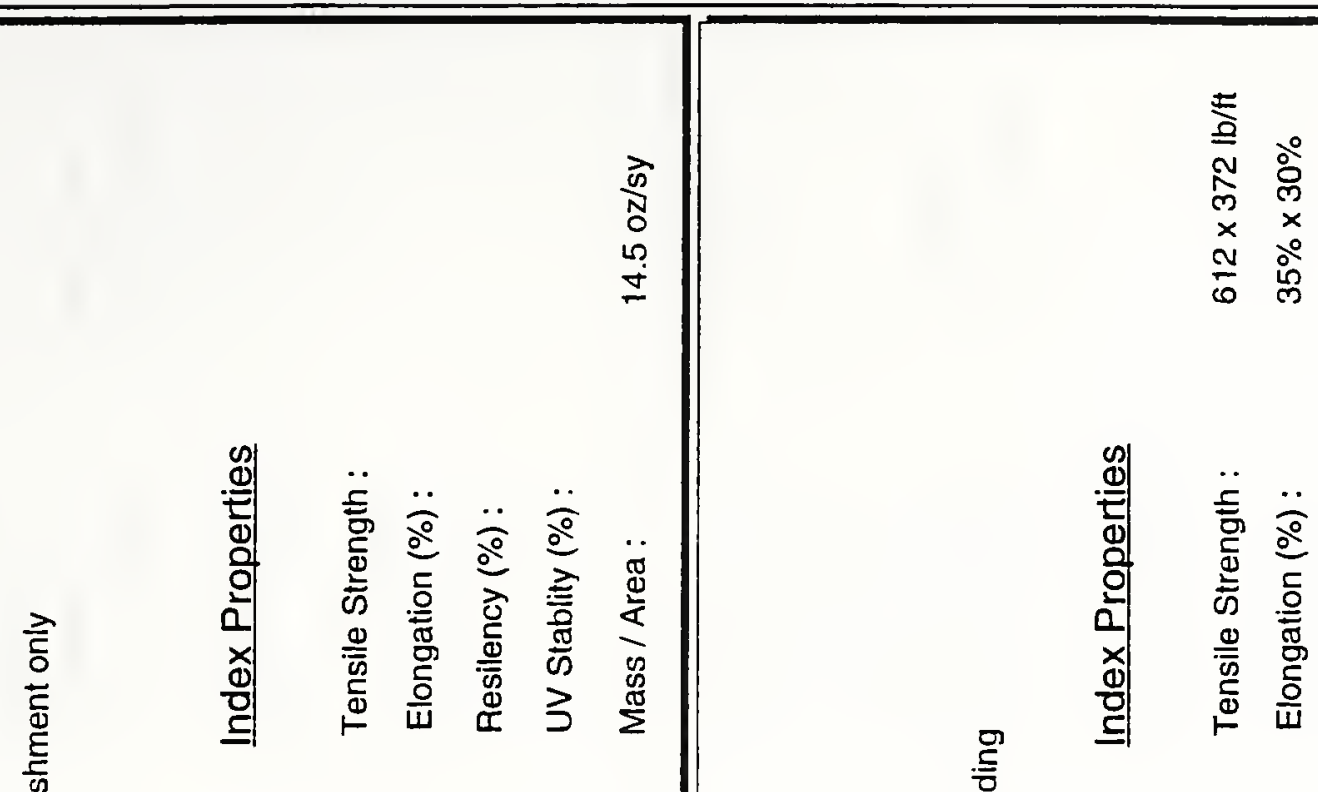

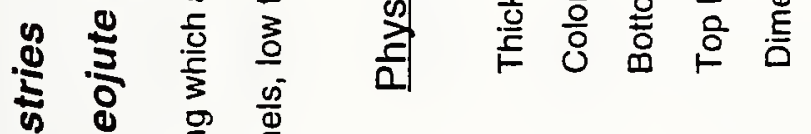

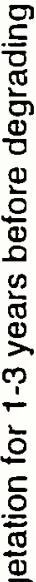

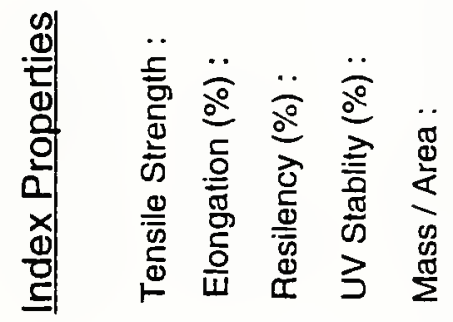

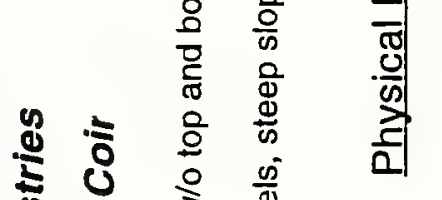
돔 


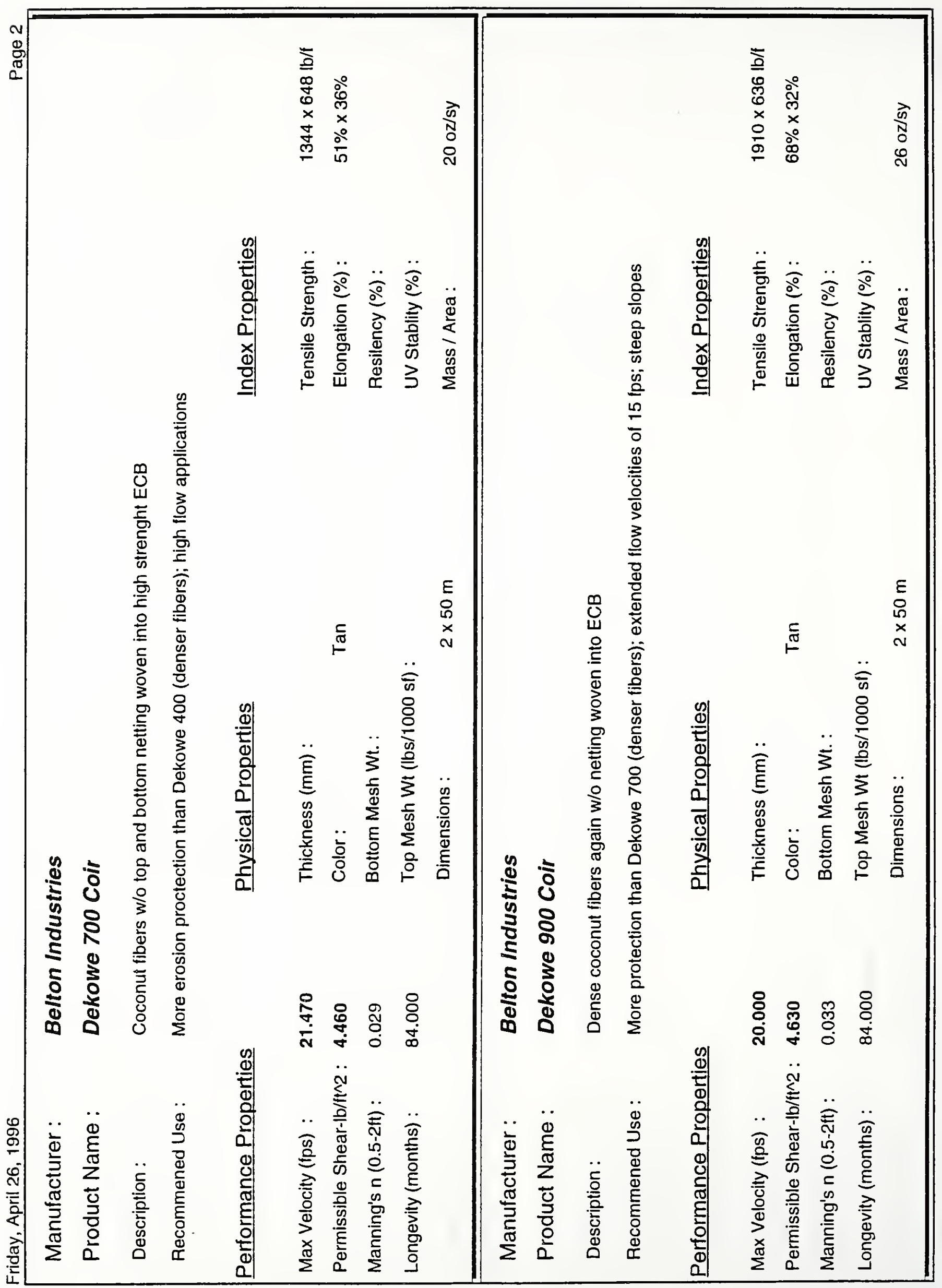



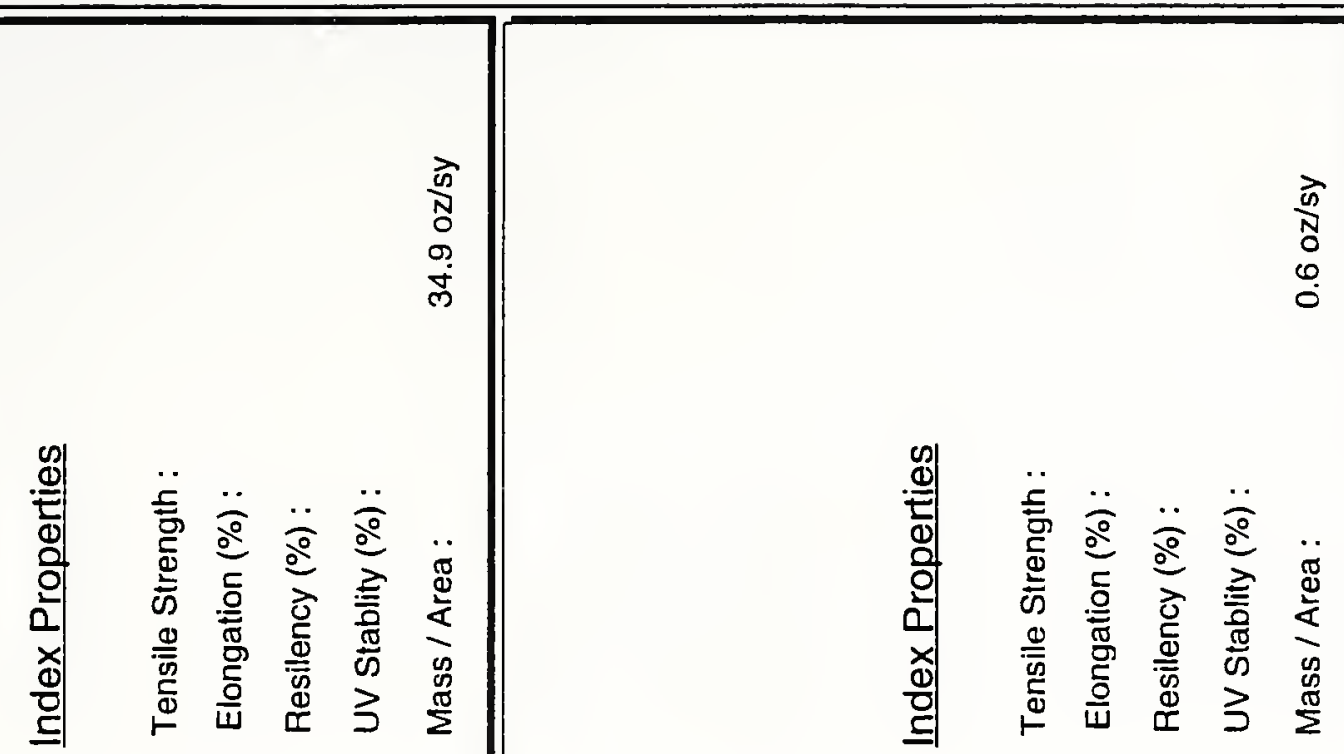

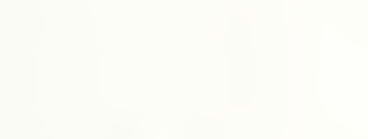

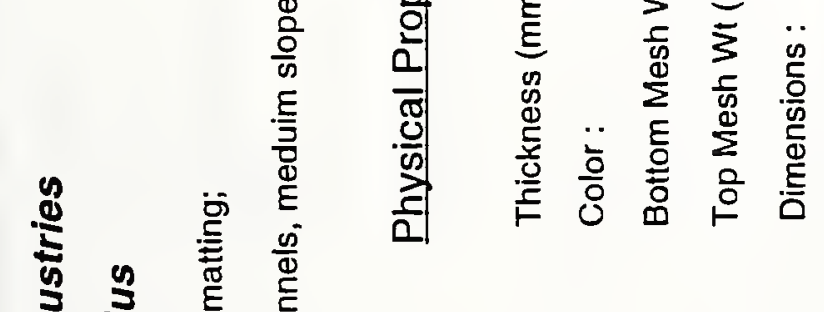

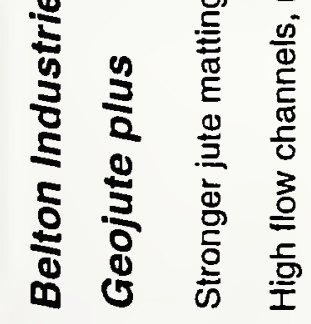

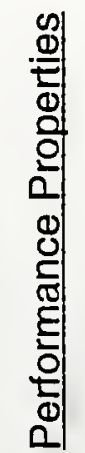

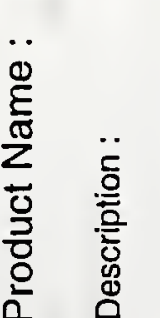

总
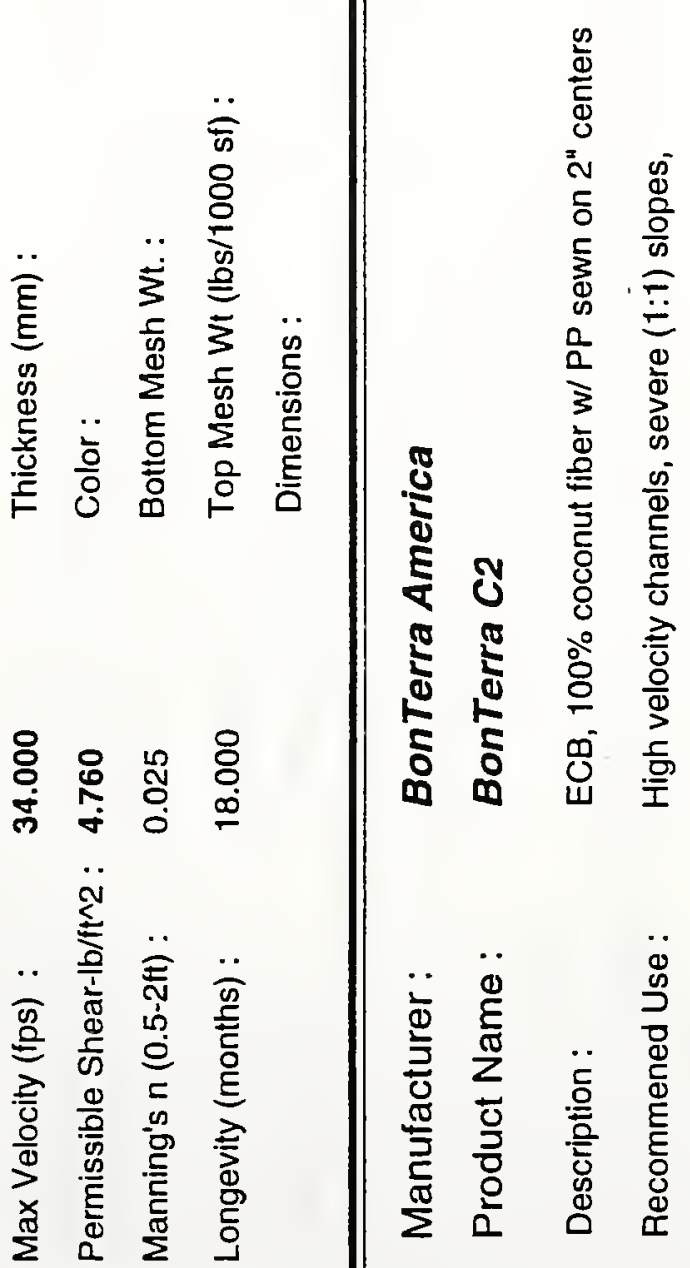

\begin{tabular}{llll}
8 & 0 \\
\hline & 0 & 0 & 8 \\
\hline & 0 & 0 \\
\hline & 0 & 0
\end{tabular}

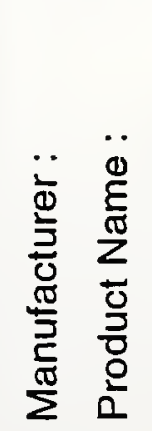

$\frac{\bar{\pi}}{\frac{\pi}{3}}$

임일

我

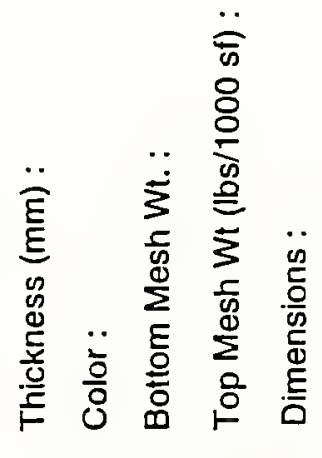

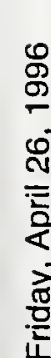

:
용

ஜ 

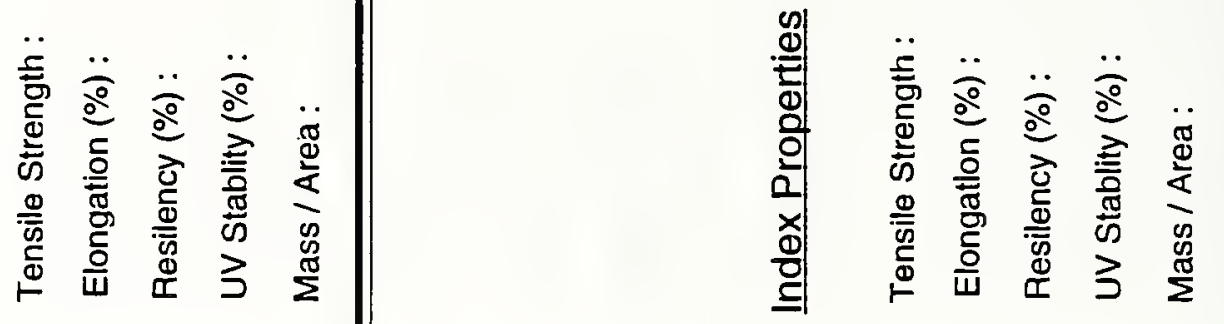

$\frac{\infty}{0}$
$\stackrel{0}{0}$
0
$\vdots$
$\frac{0}{0}$
$\frac{0}{0}$

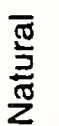

\%

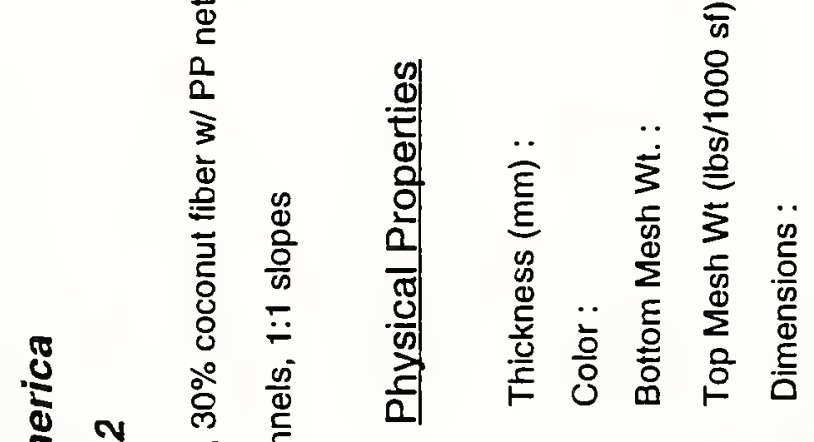
گु

๘

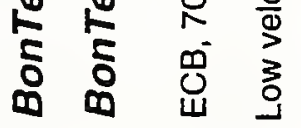

告|

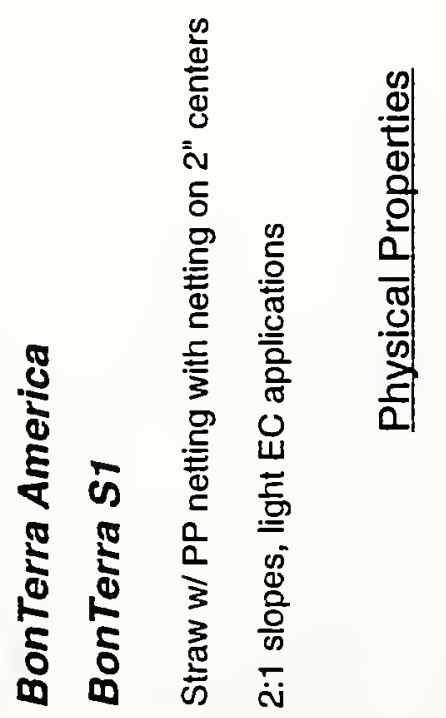

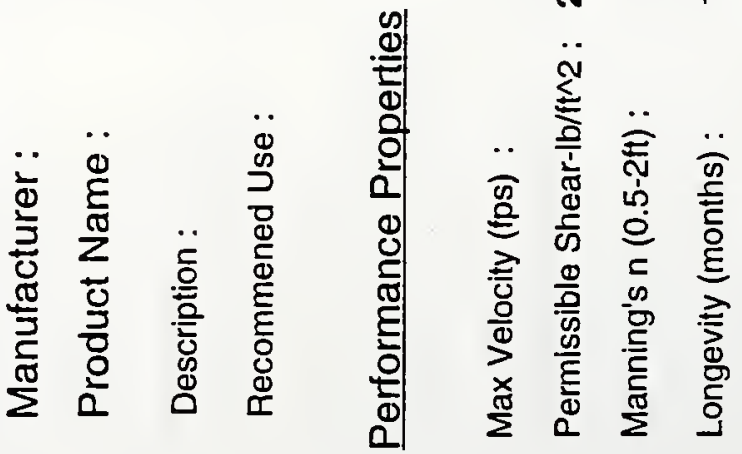

$\frac{\pi}{2}$

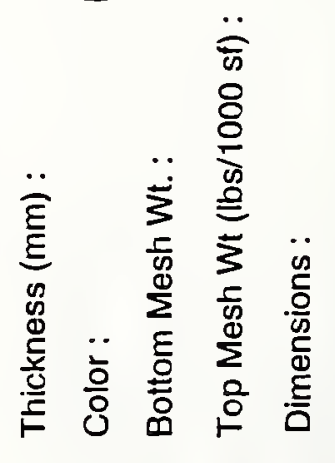

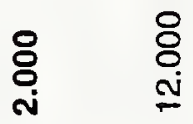



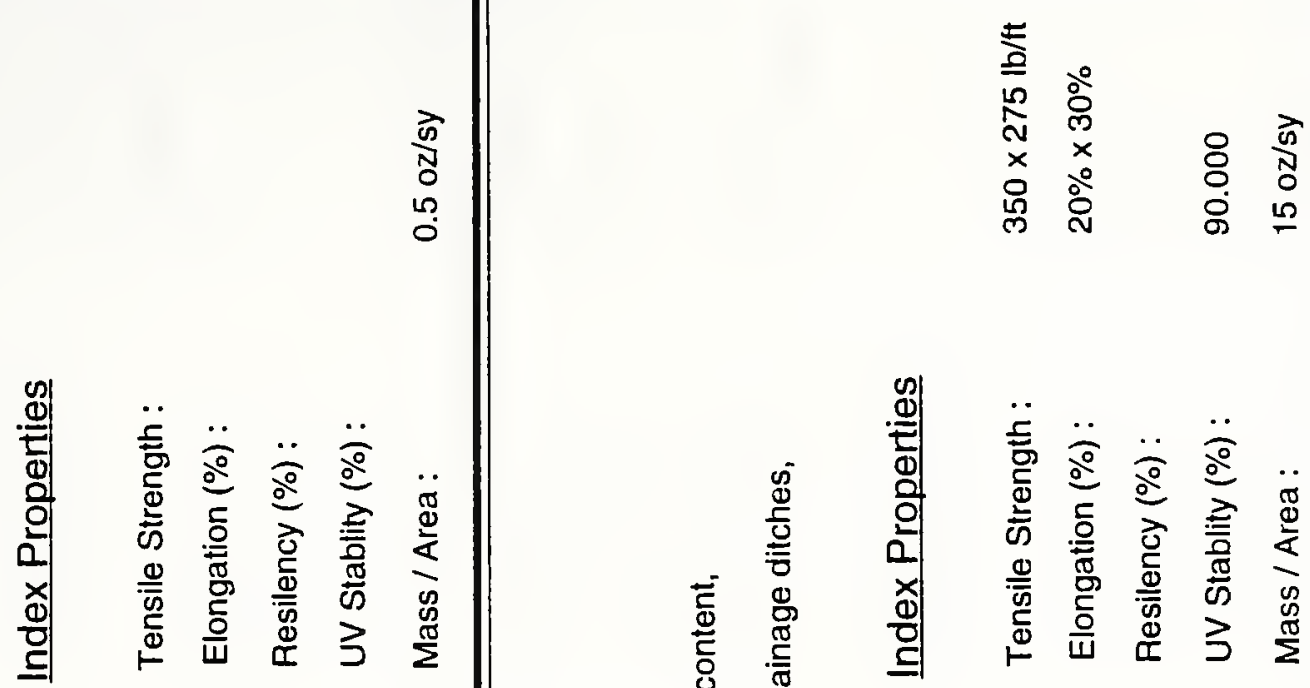

$\frac{0}{\frac{0}{0}}$

$$
\text { 离 }
$$

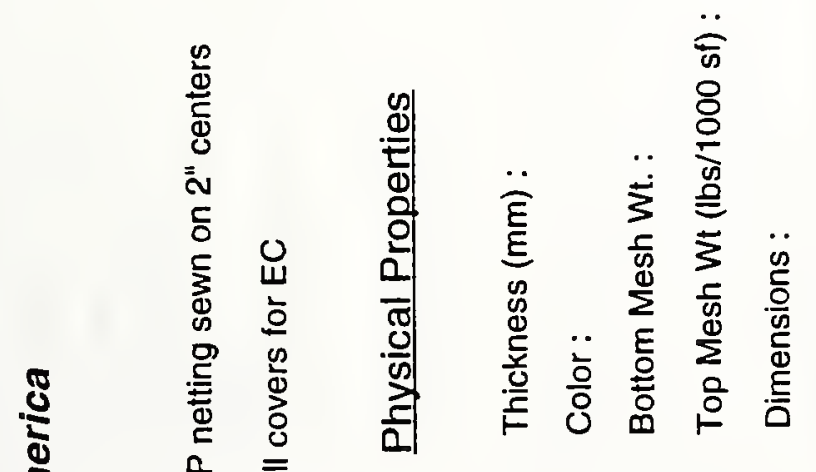

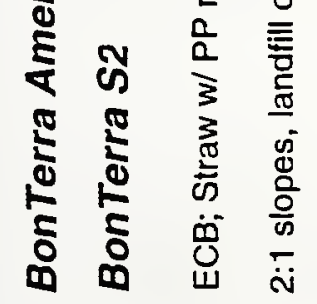

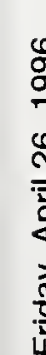

ฐั ฮั

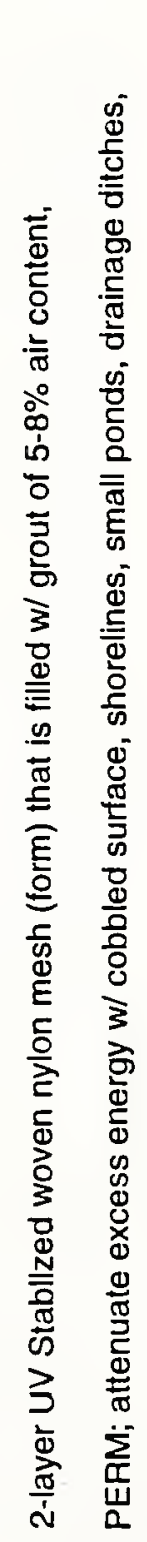

웧

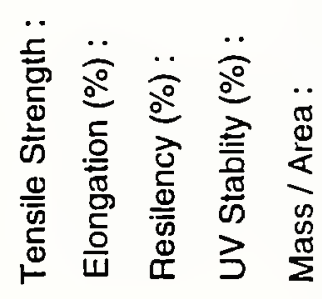

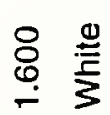

0
$\stackrel{+}{\alpha}$
$x$
0

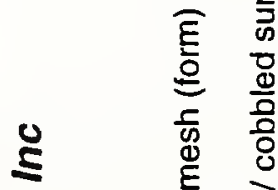

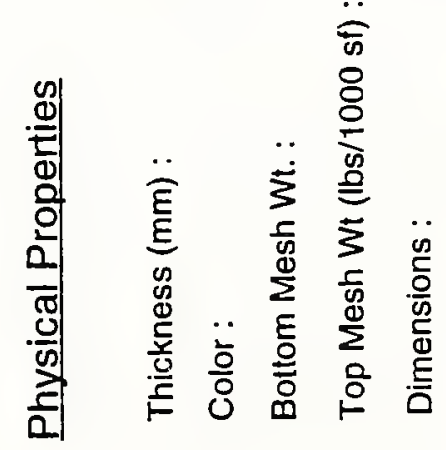

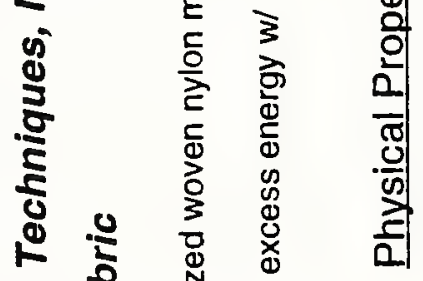

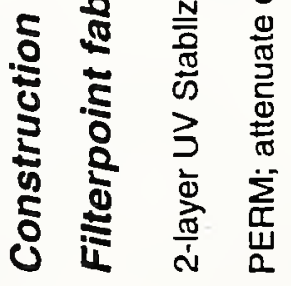

की

$\ddot{i}$

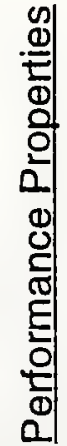

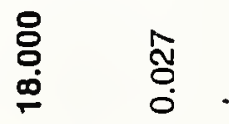

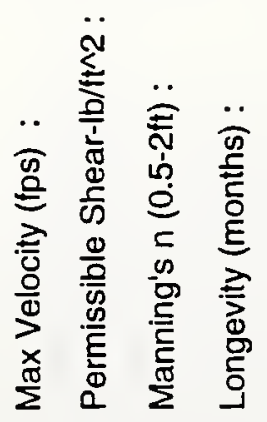


品

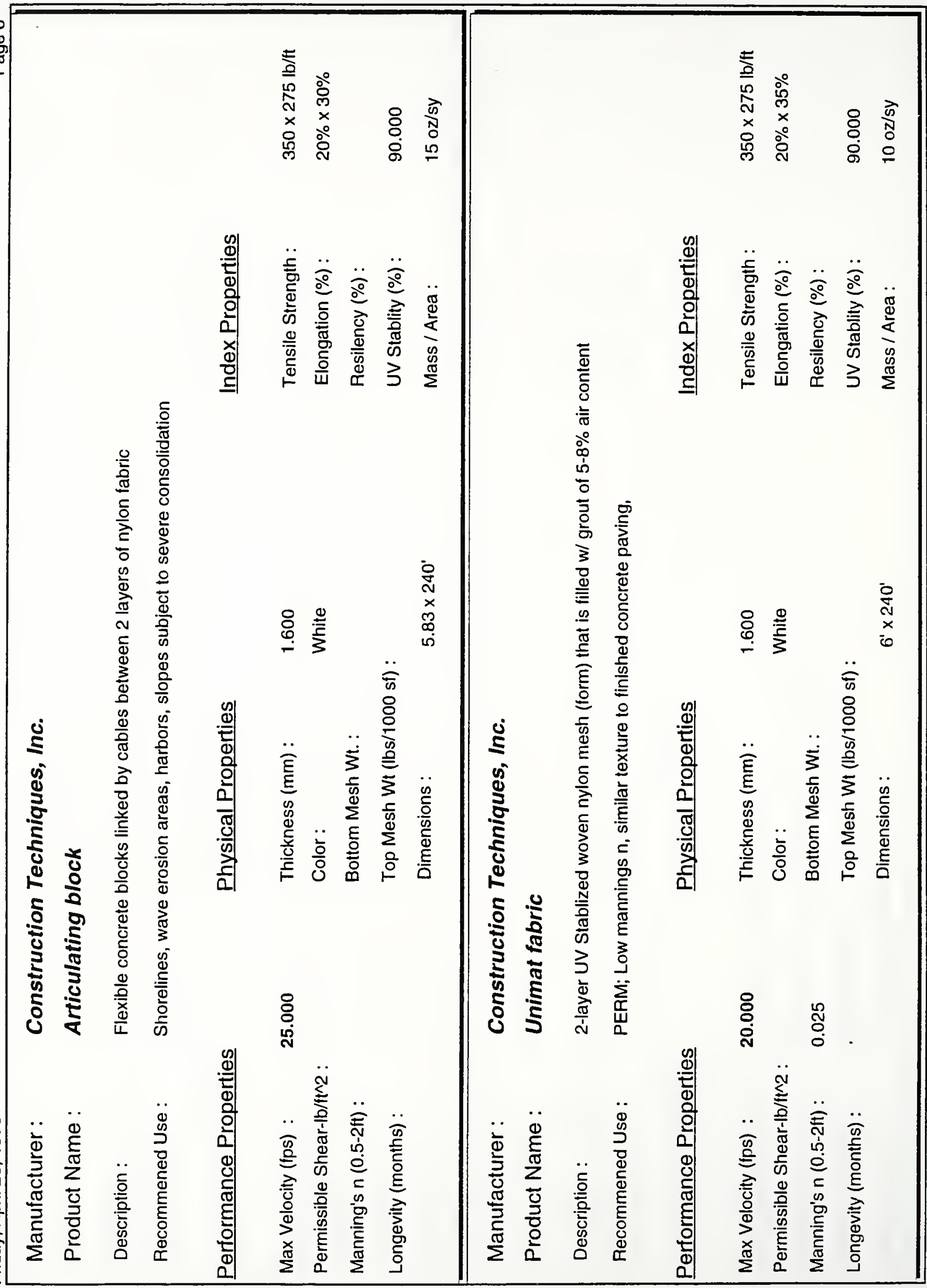




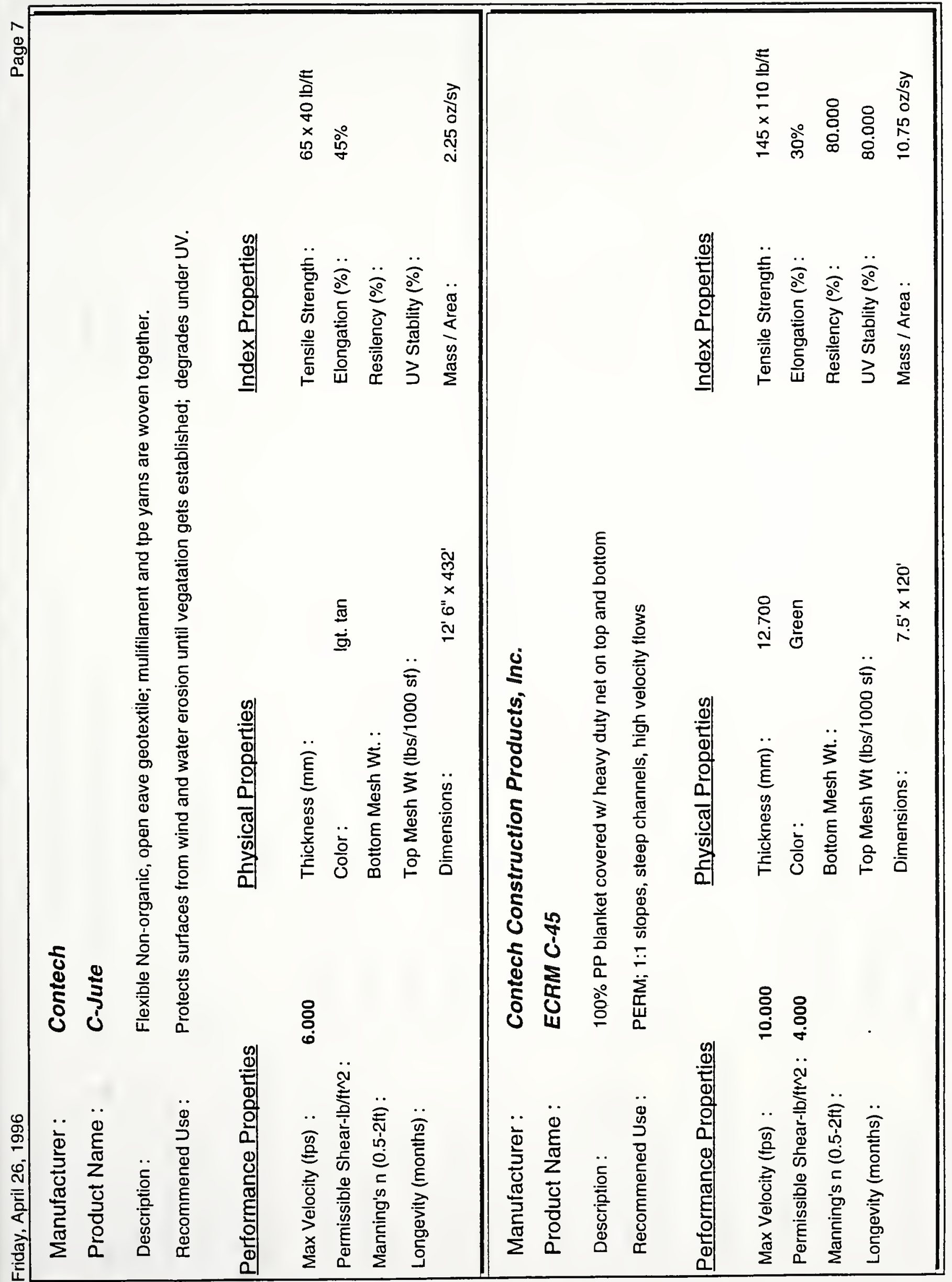




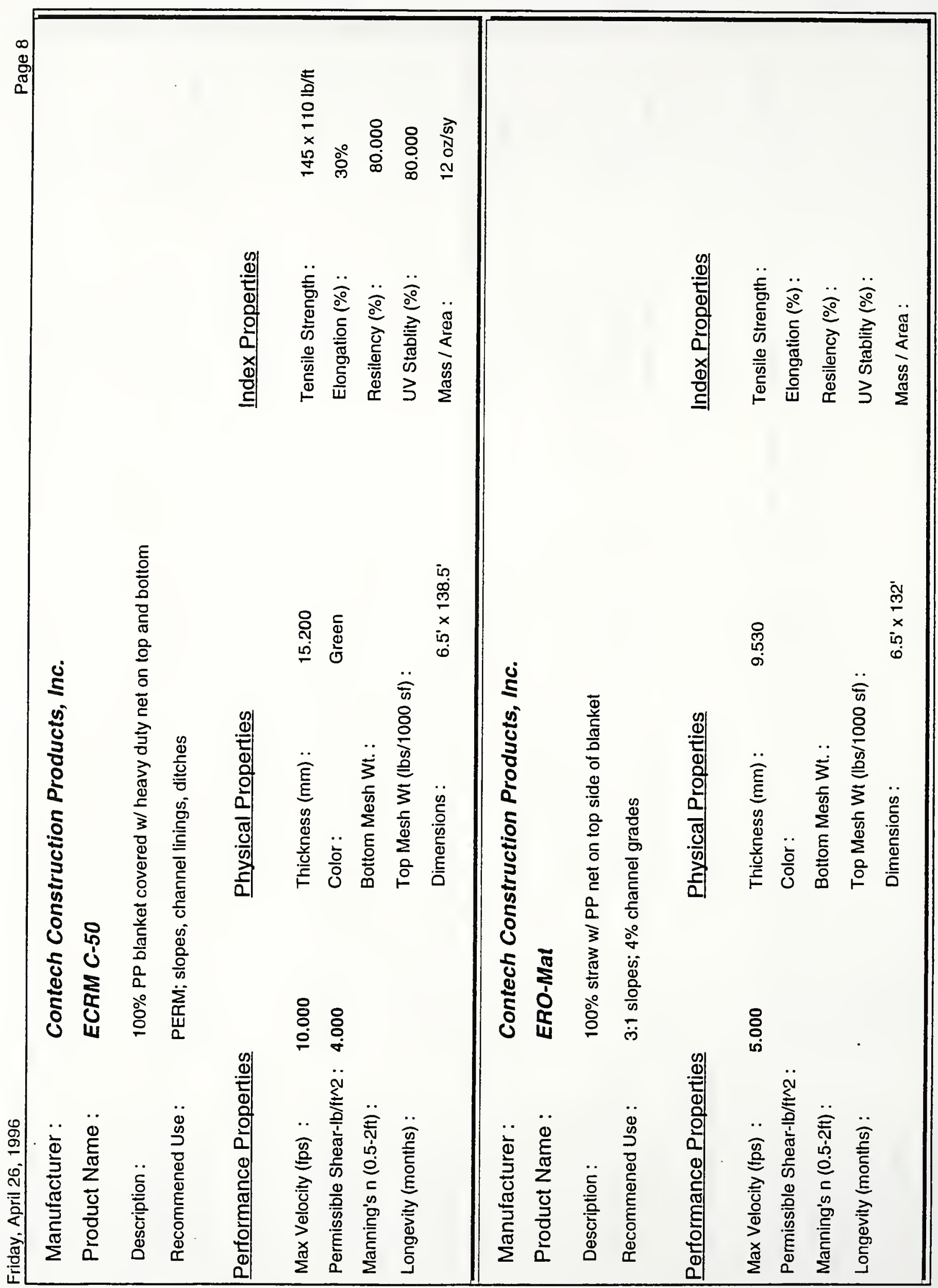




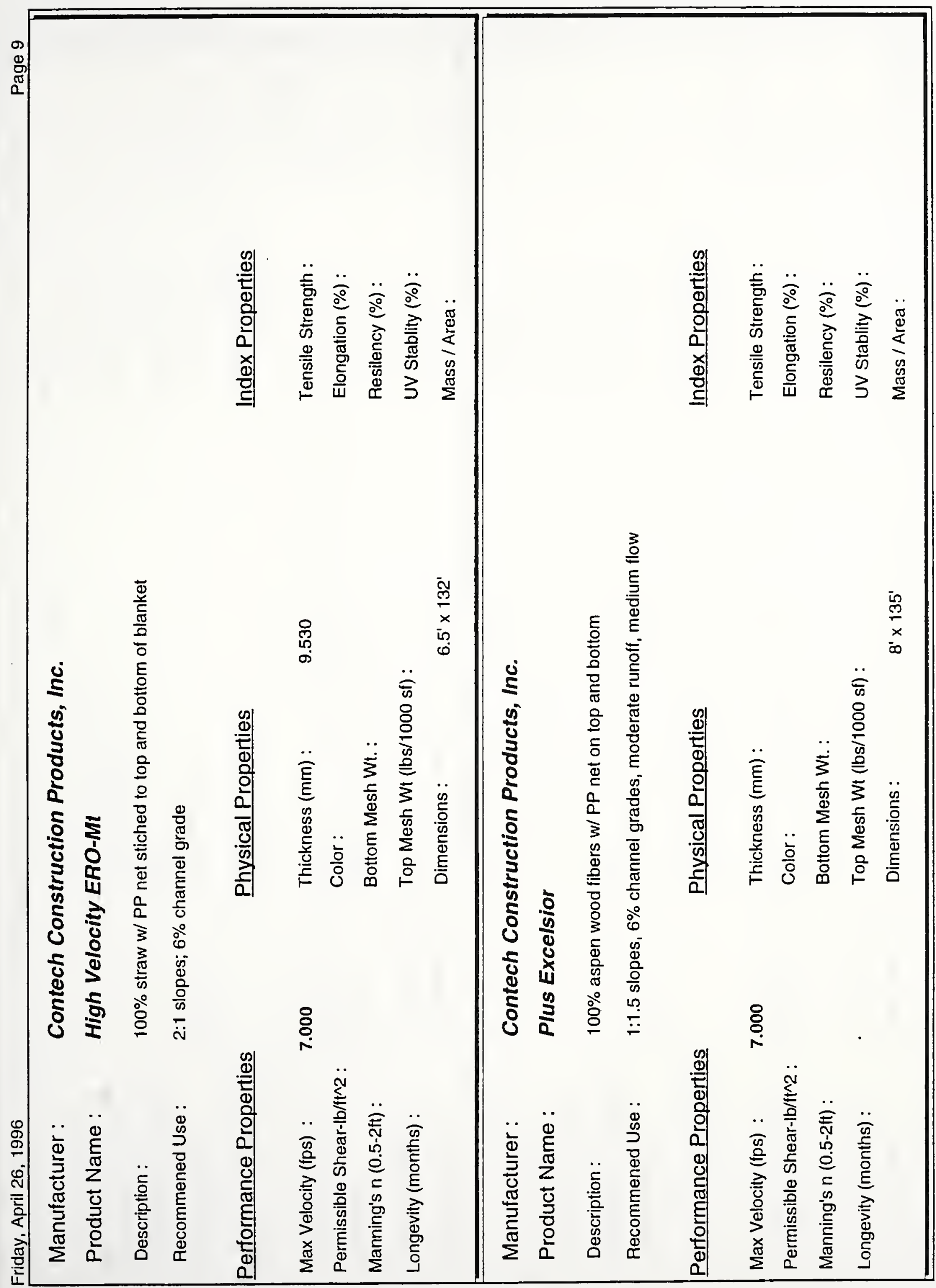




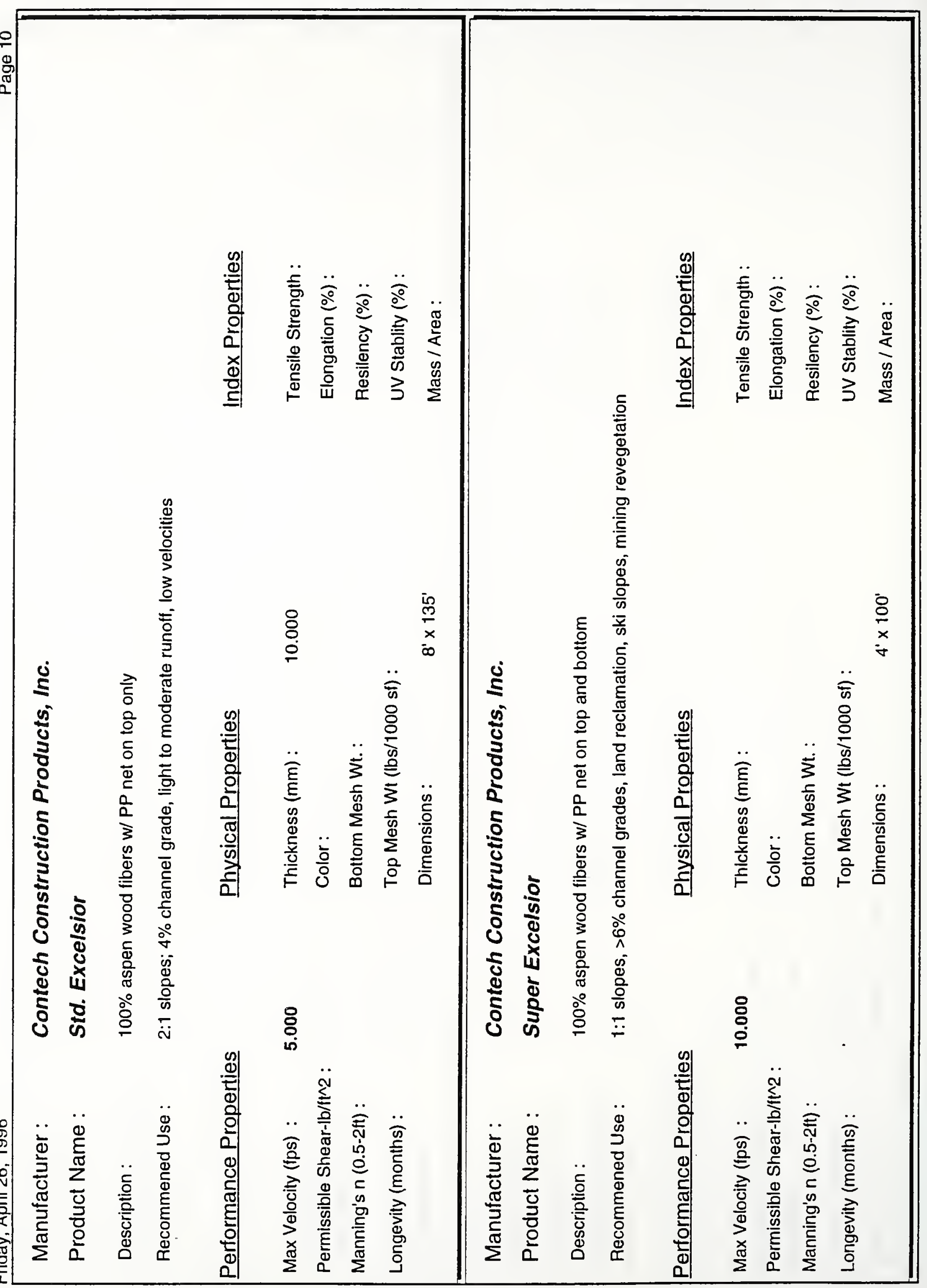




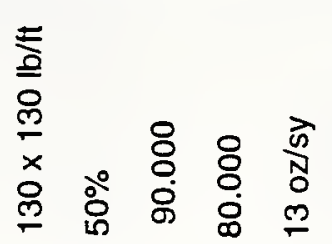

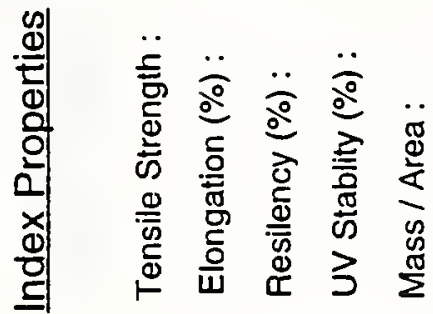

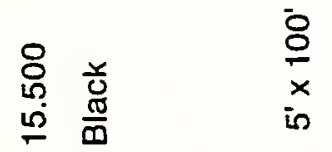

E

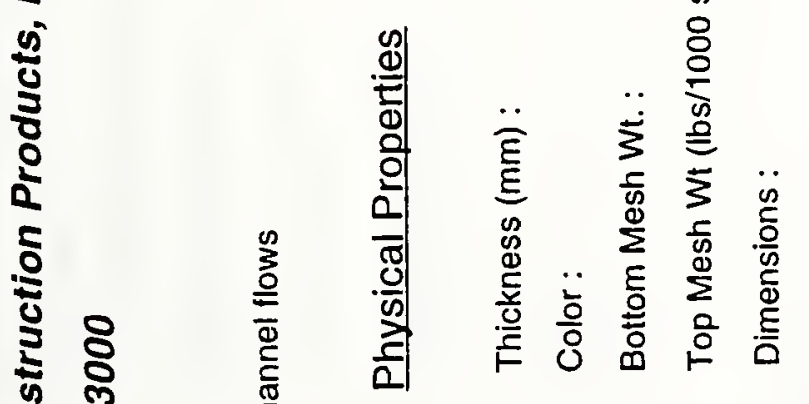

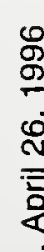

裹高

일. $\frac{\dot{s}}{\frac{5}{0}}$
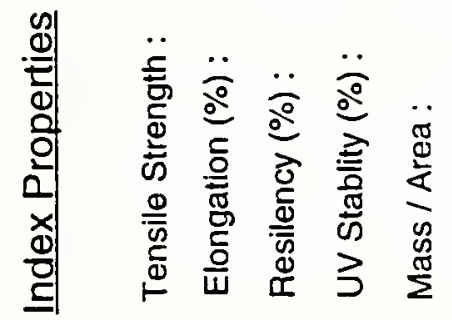
in

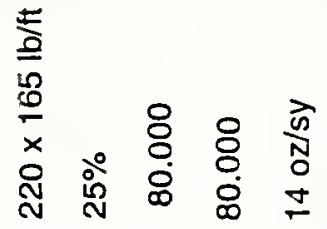

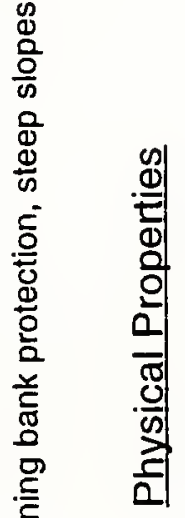

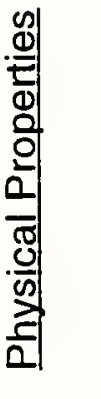

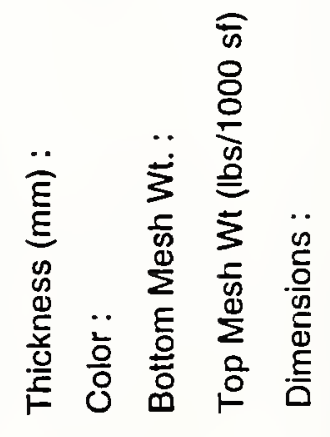

.

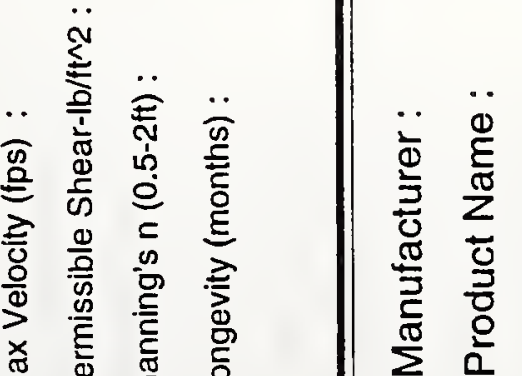

की $\stackrel{8}{\circ}$
$\stackrel{8}{\circ}$

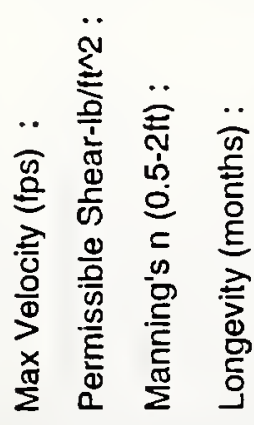




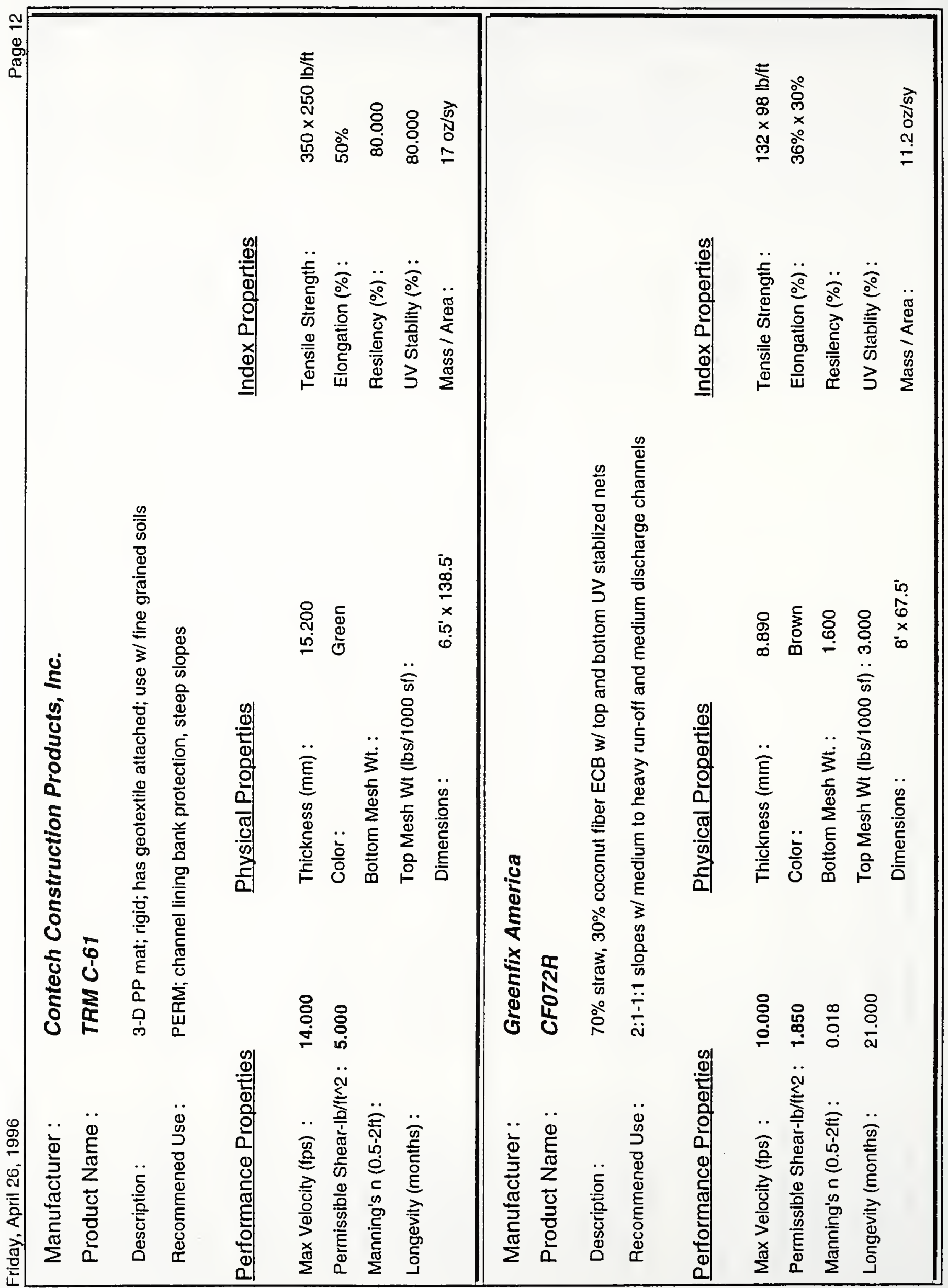




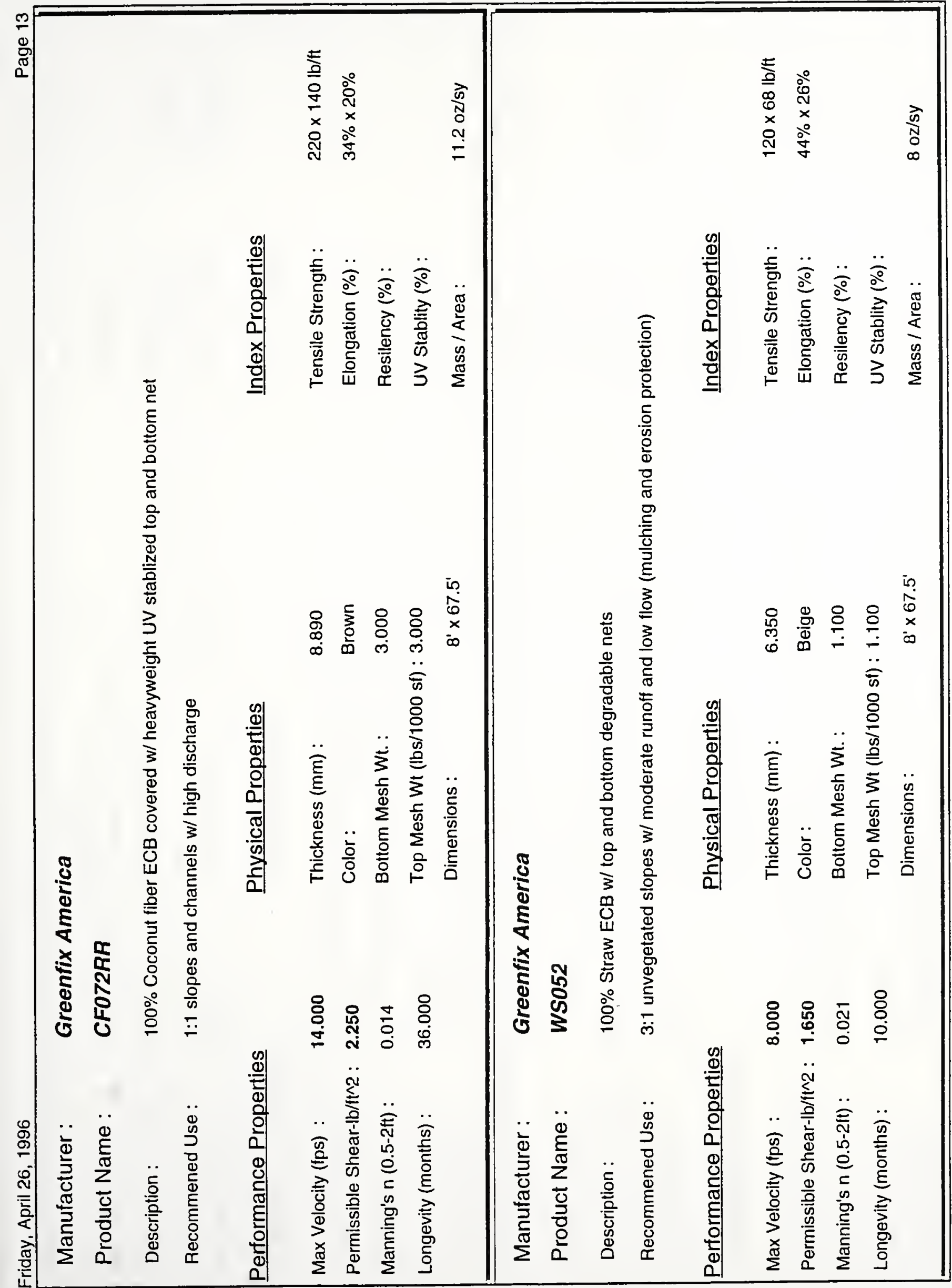



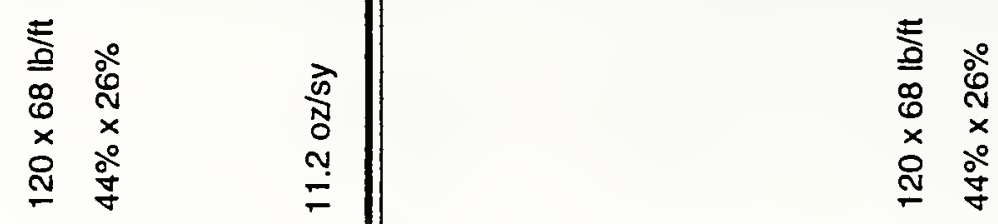

के
Nิ
พ̣
$=$

ơ

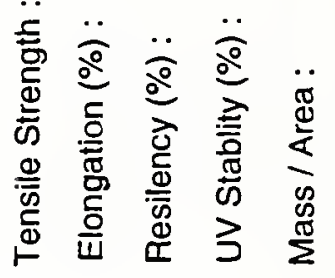

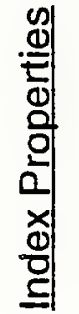
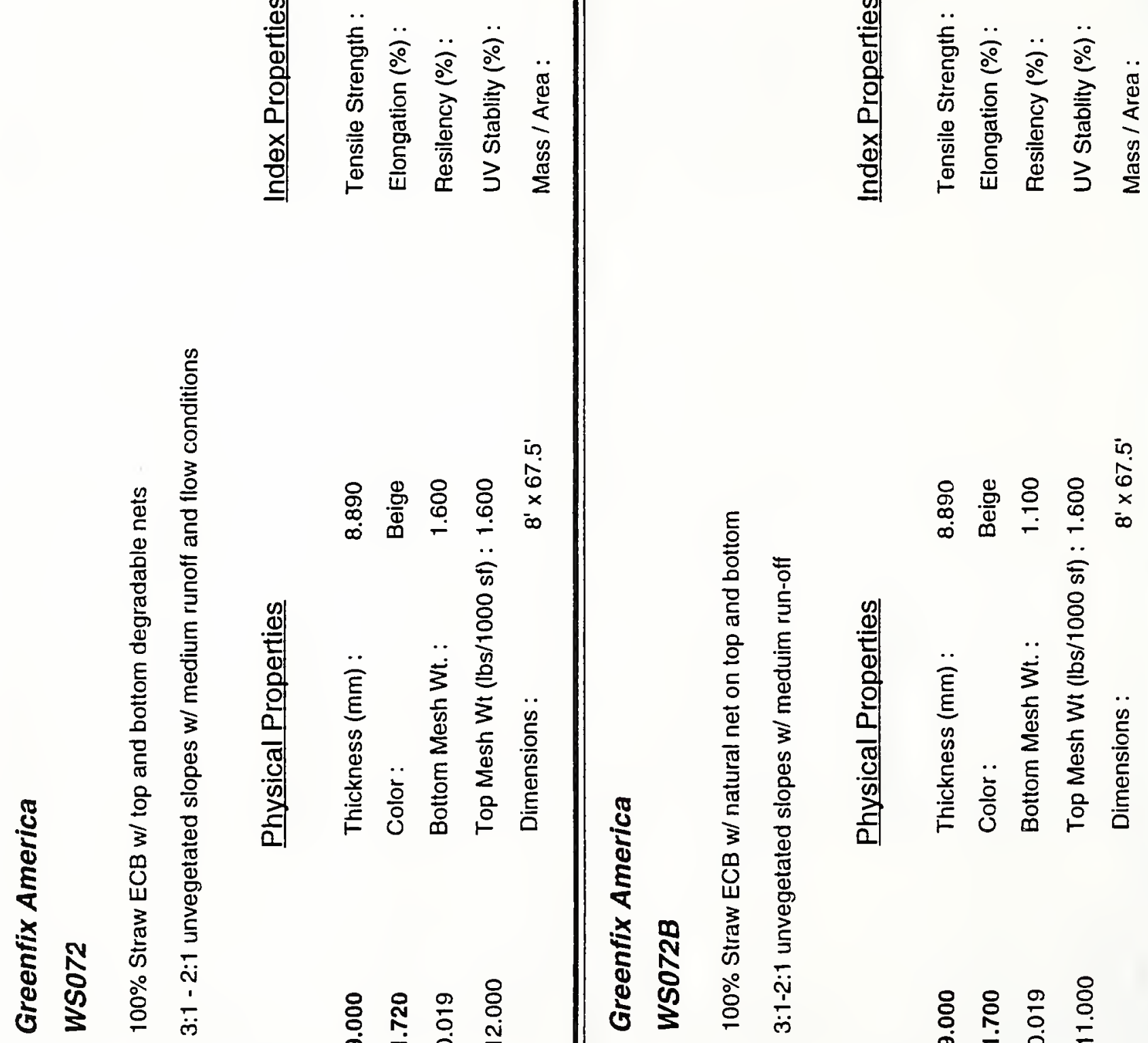

की

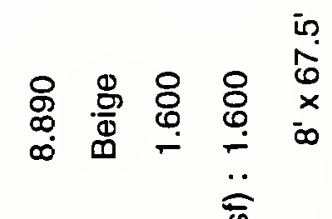

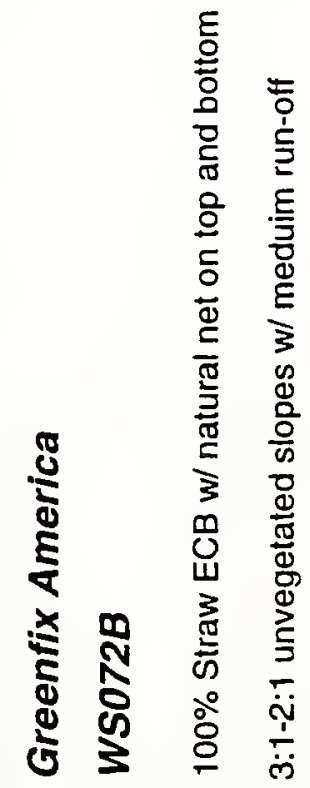

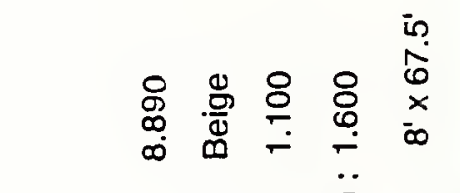

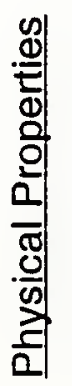

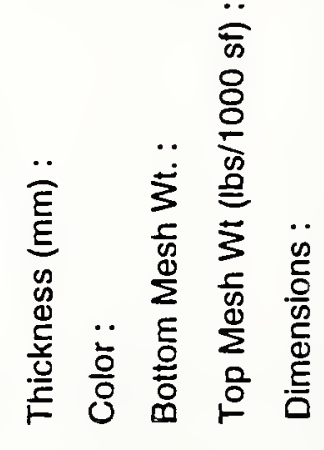

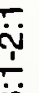

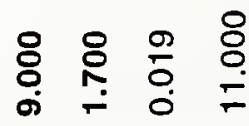
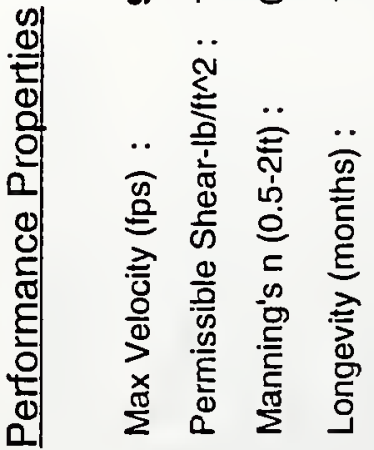
$\stackrel{\circ}{\infty}$

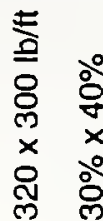

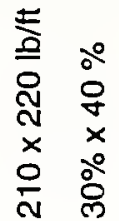

के
0
0

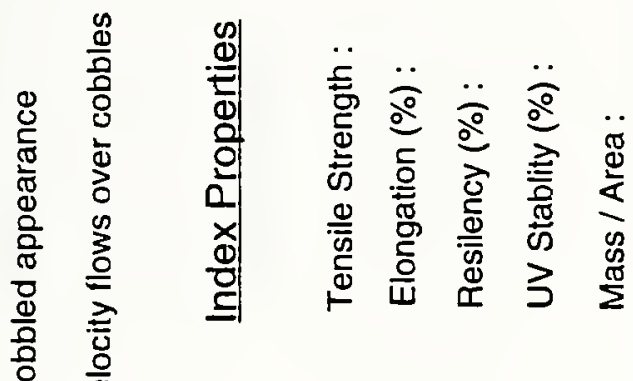

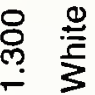

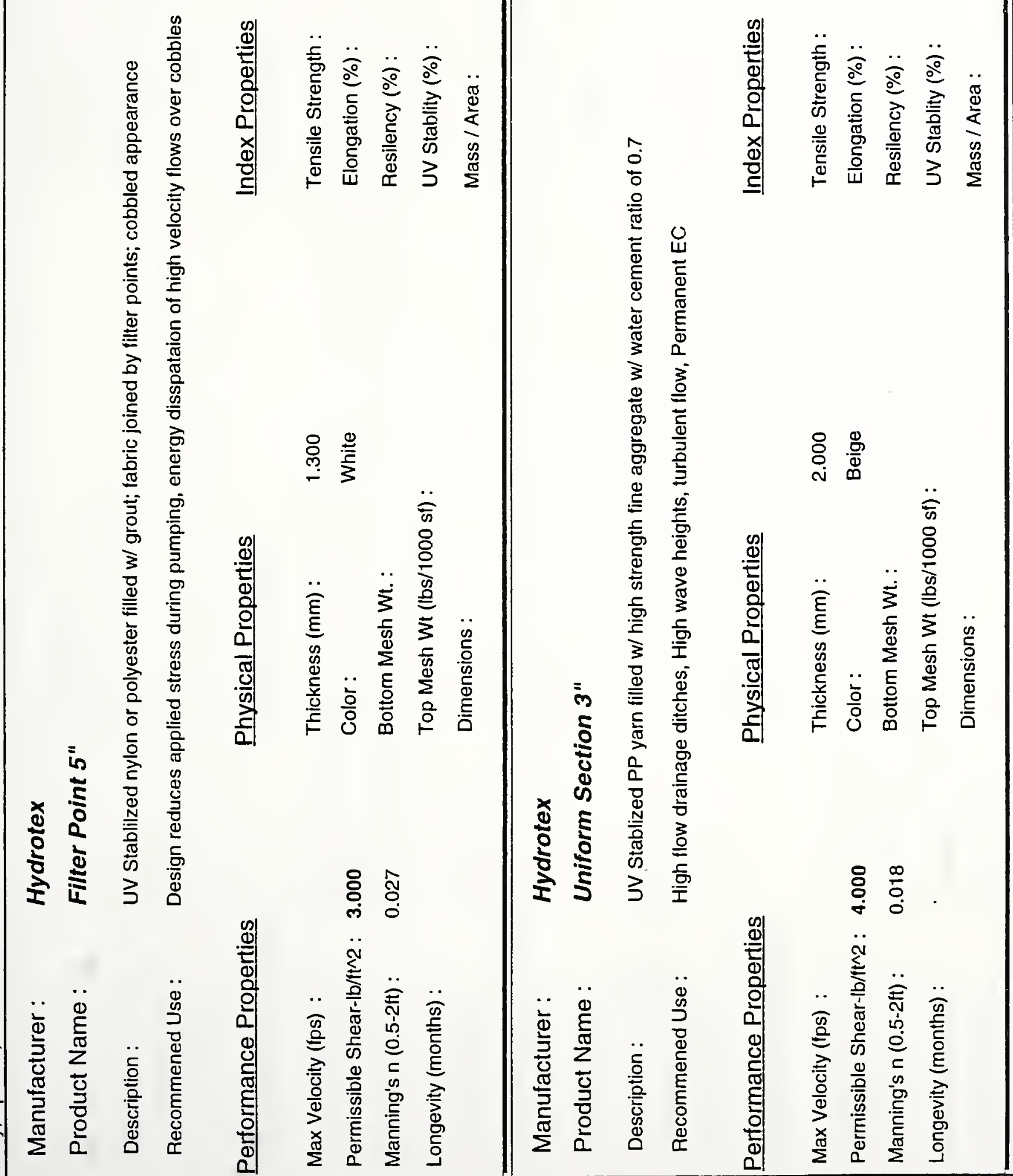




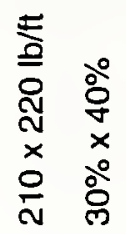

ลิ
0
0

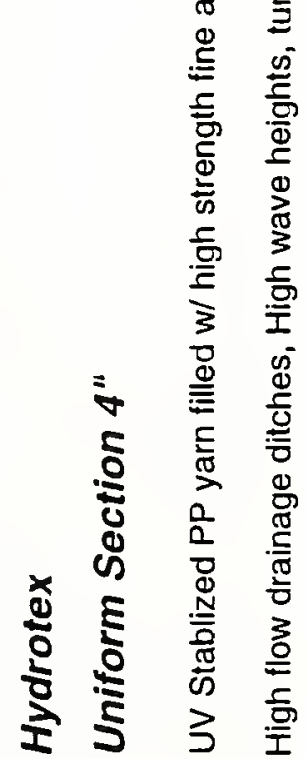

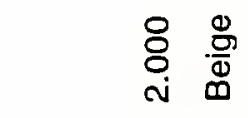

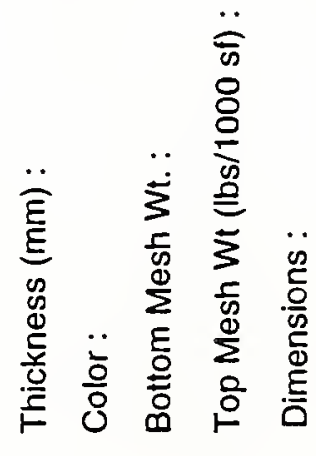
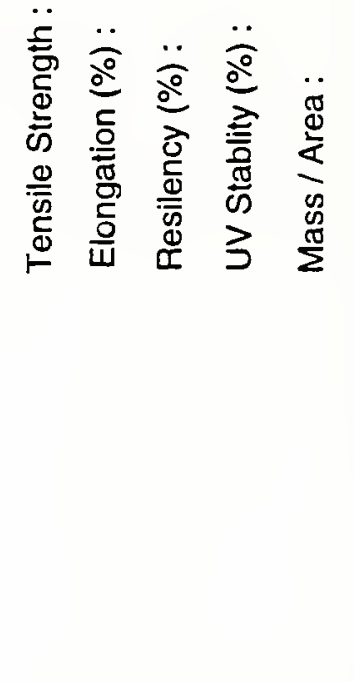

की

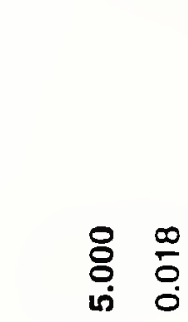

임

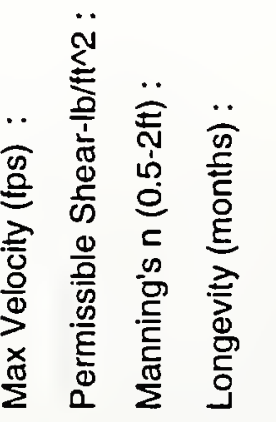

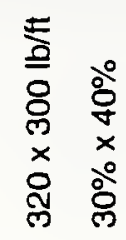

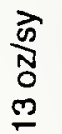

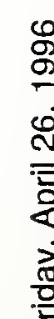

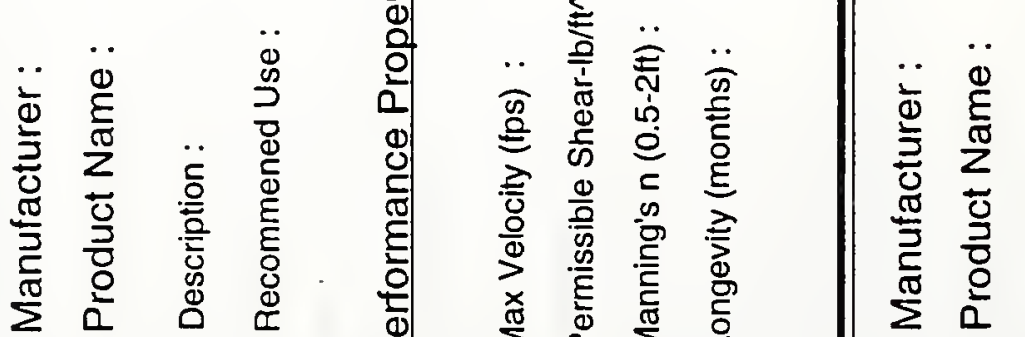

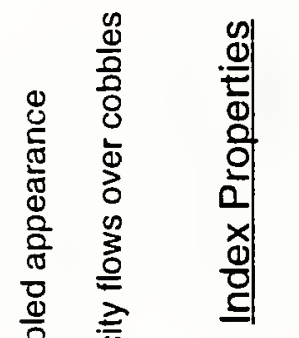

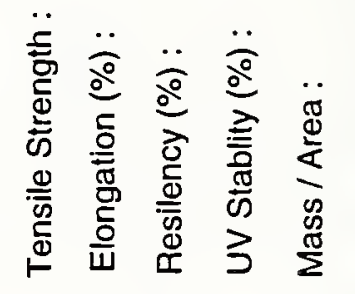

융 응

产 喜

흠

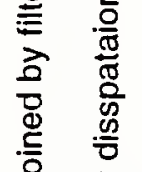

은 종

ஓ्ల

苛 它

इ है

क्वे

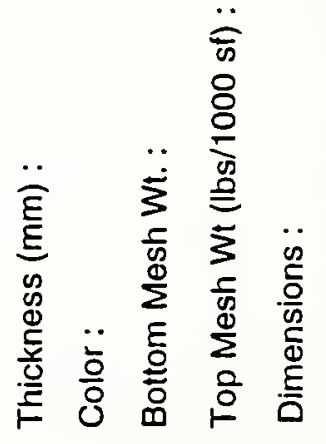

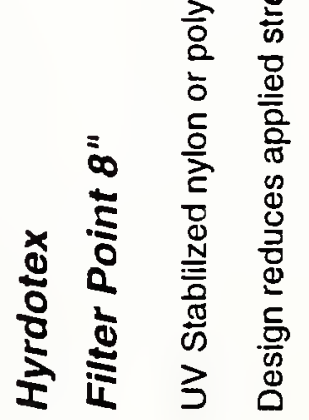

옹 仓ิ

임.

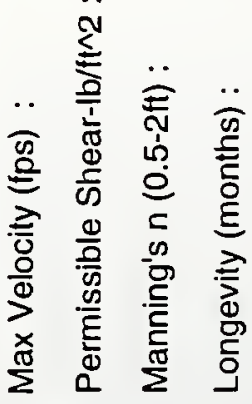




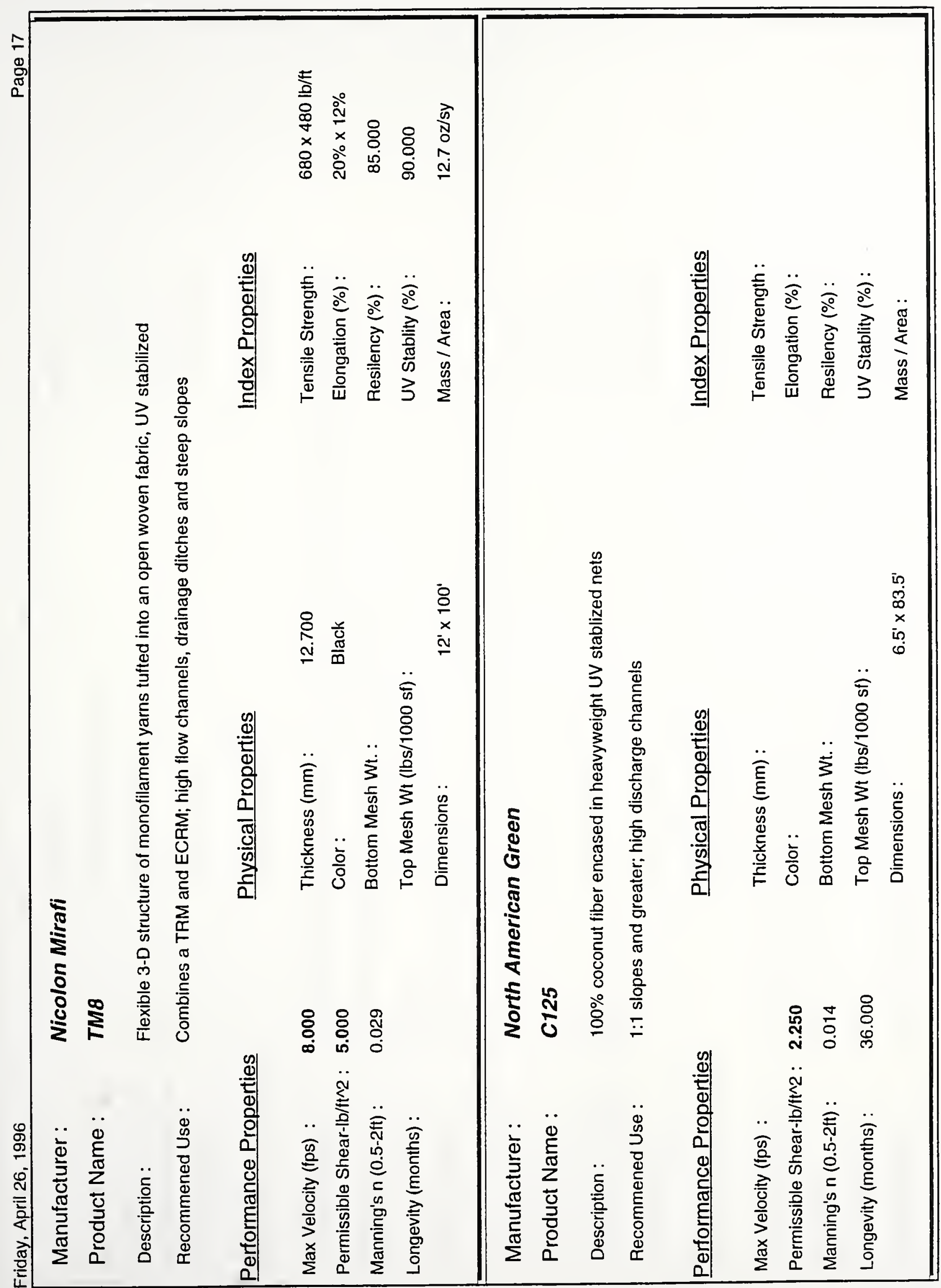




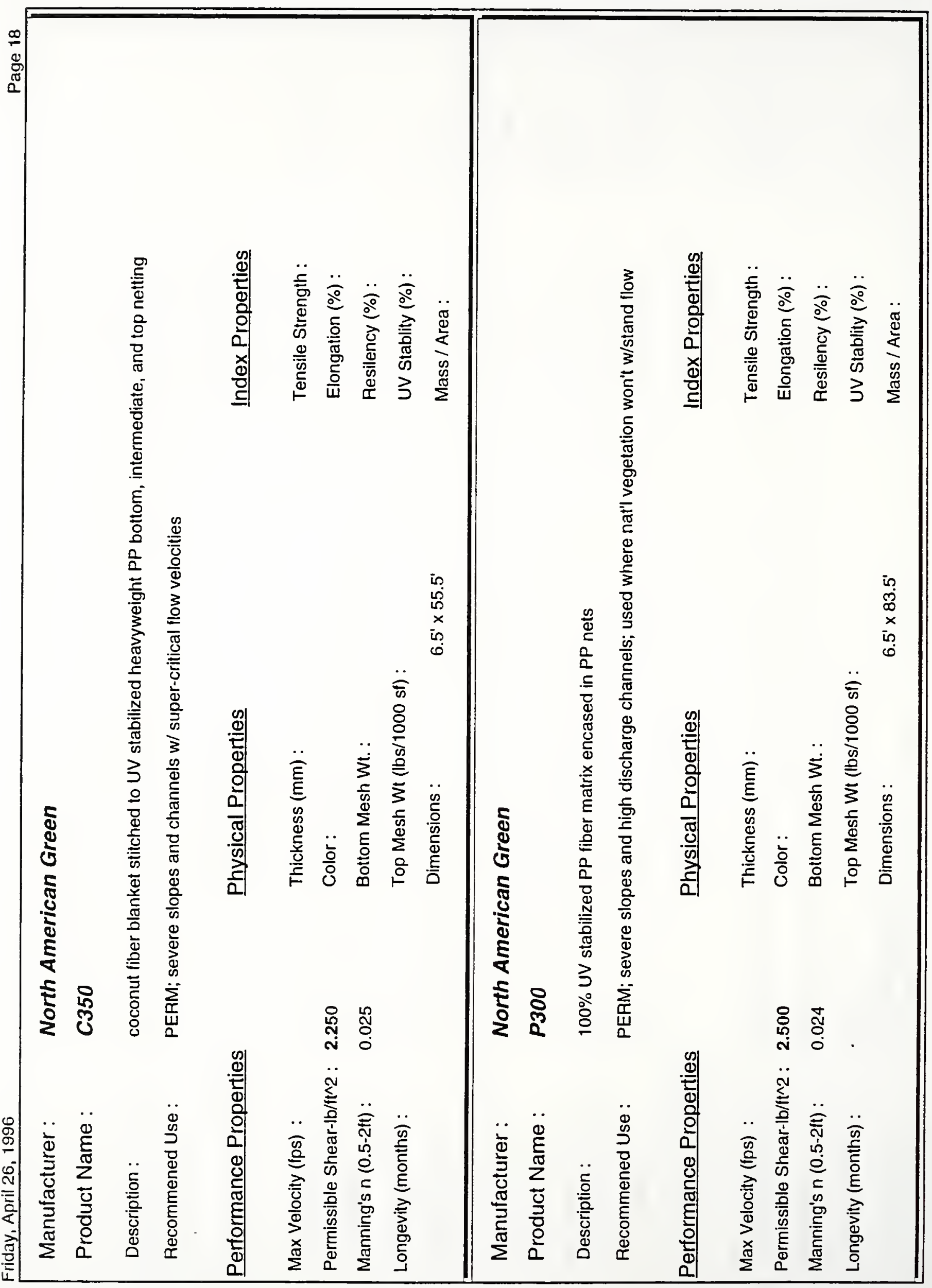



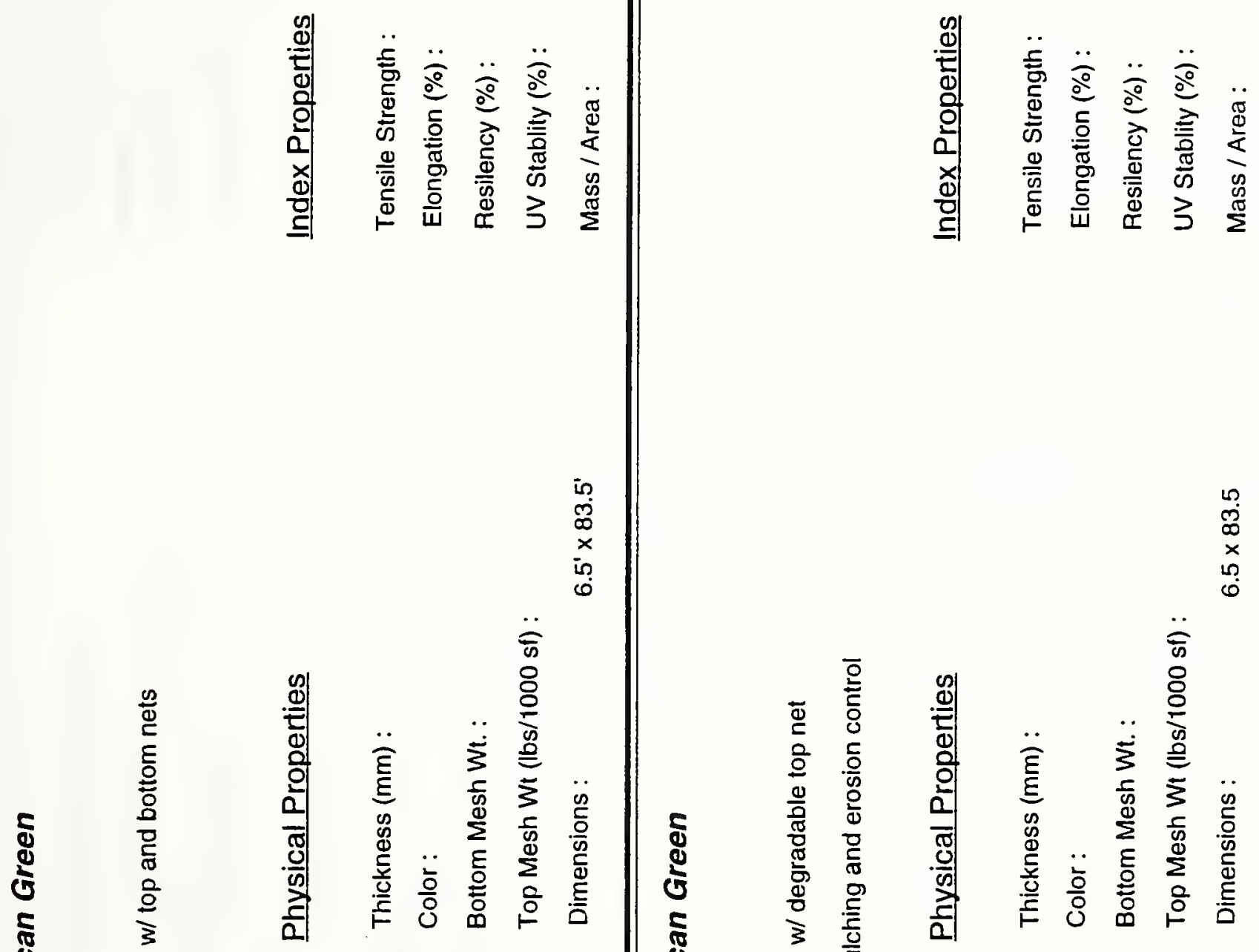

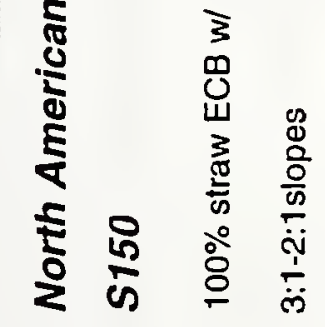

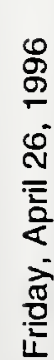




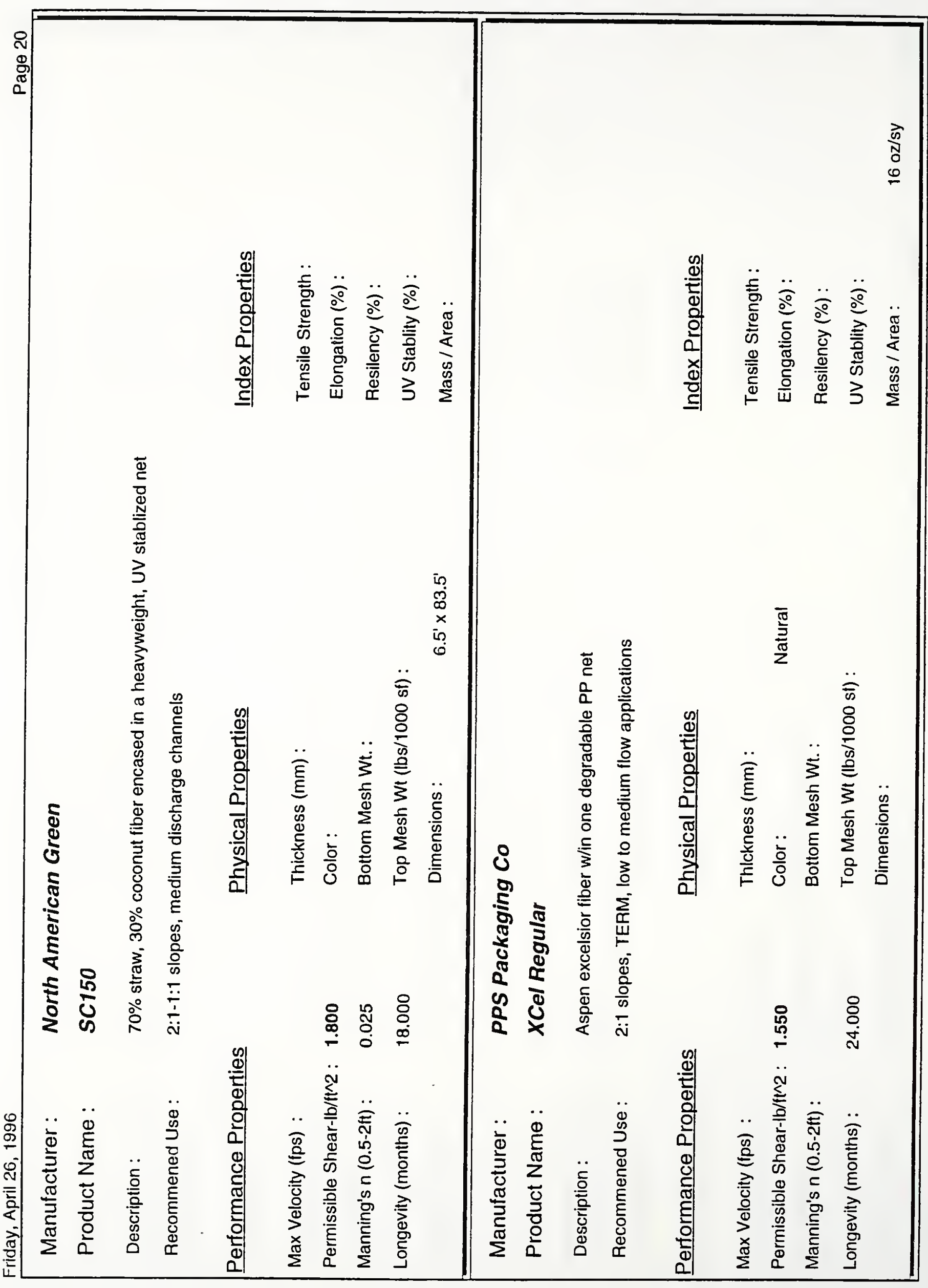




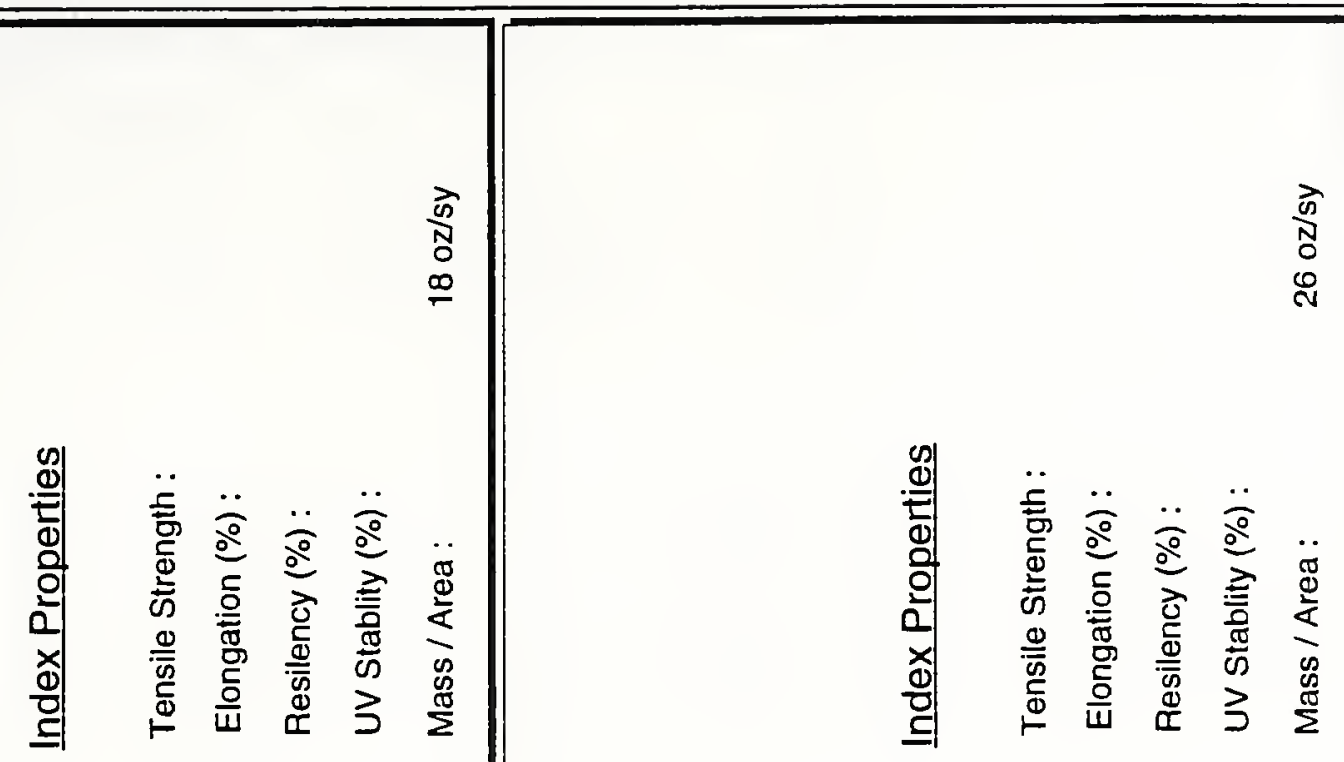

a

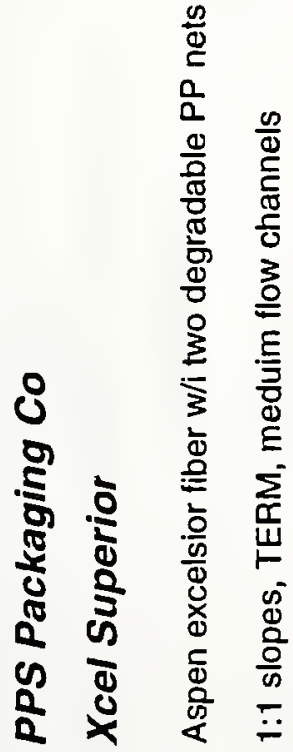

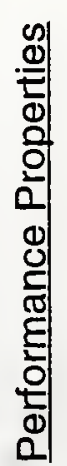

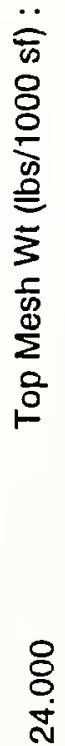

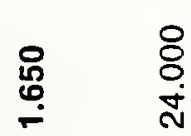

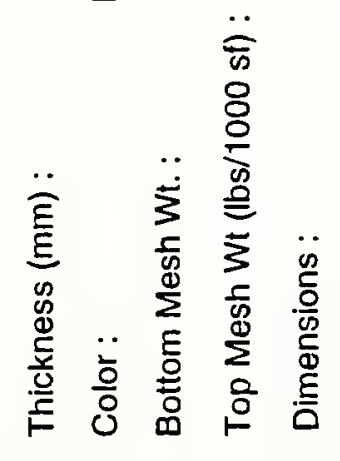

\% 


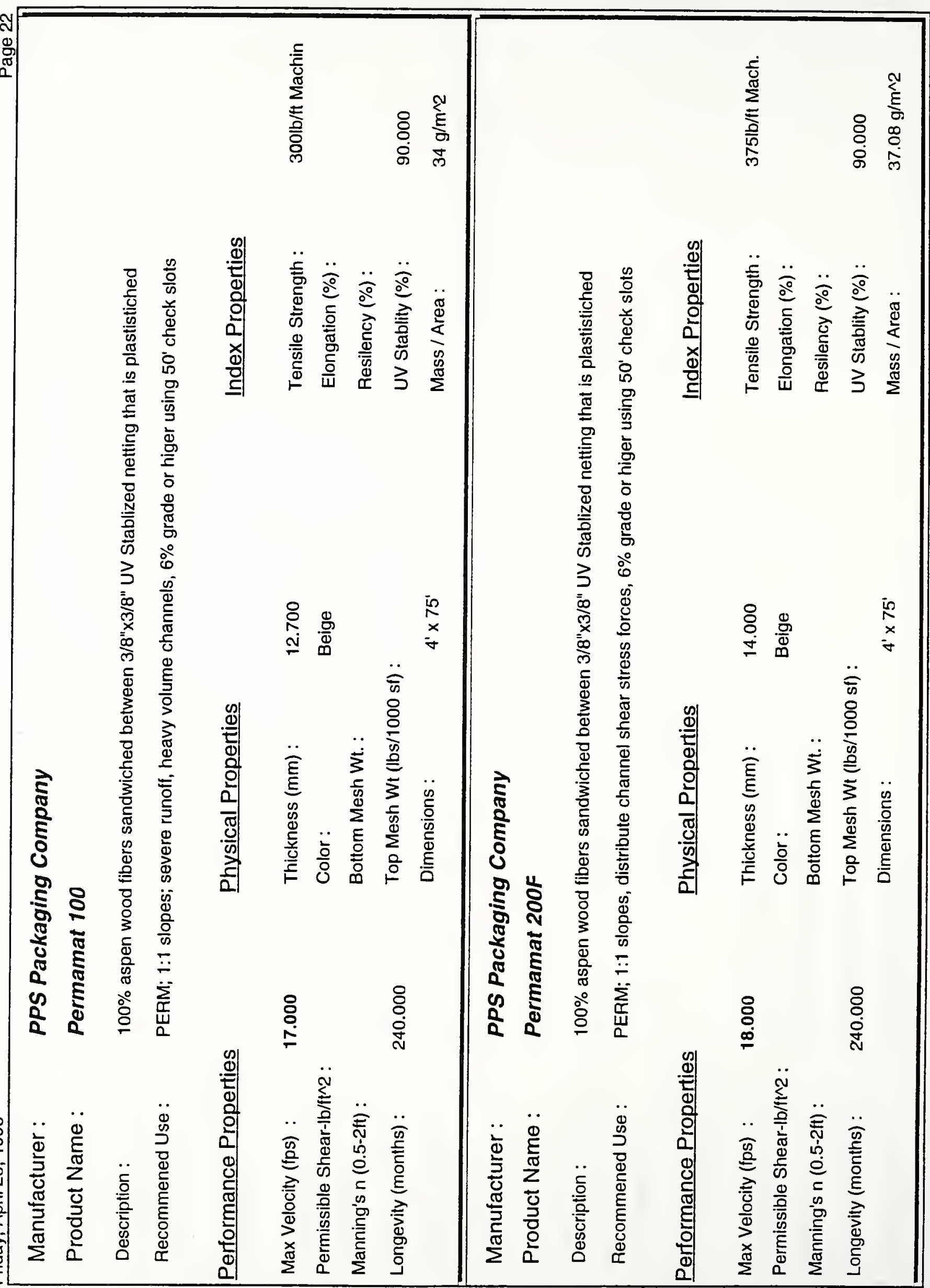




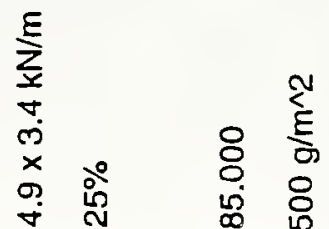

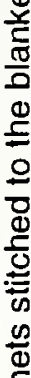

음

t

$\stackrel{0}{\stackrel{0}{0}}$

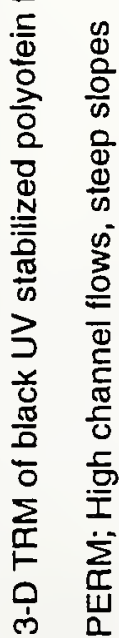

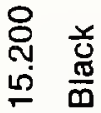

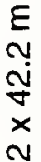

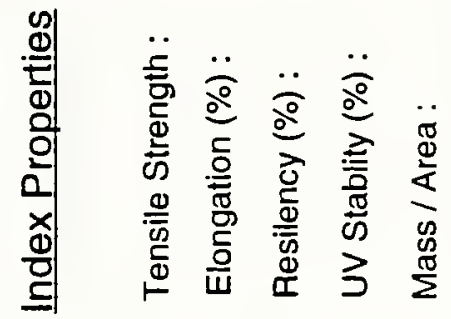

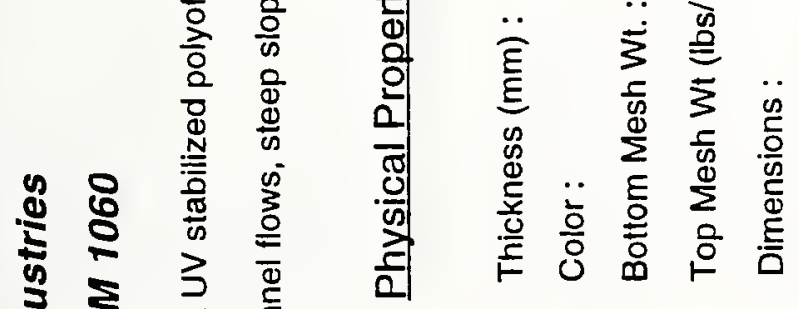

을

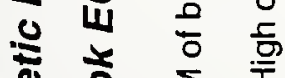

ڤ

?
की

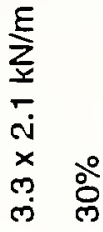

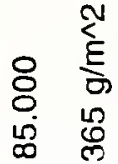

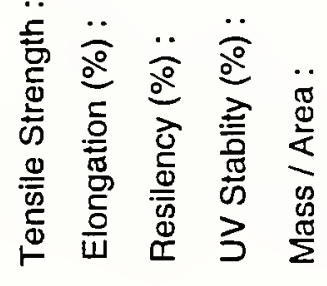

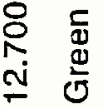

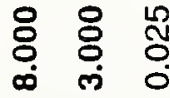

웜

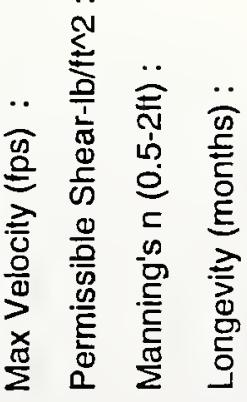




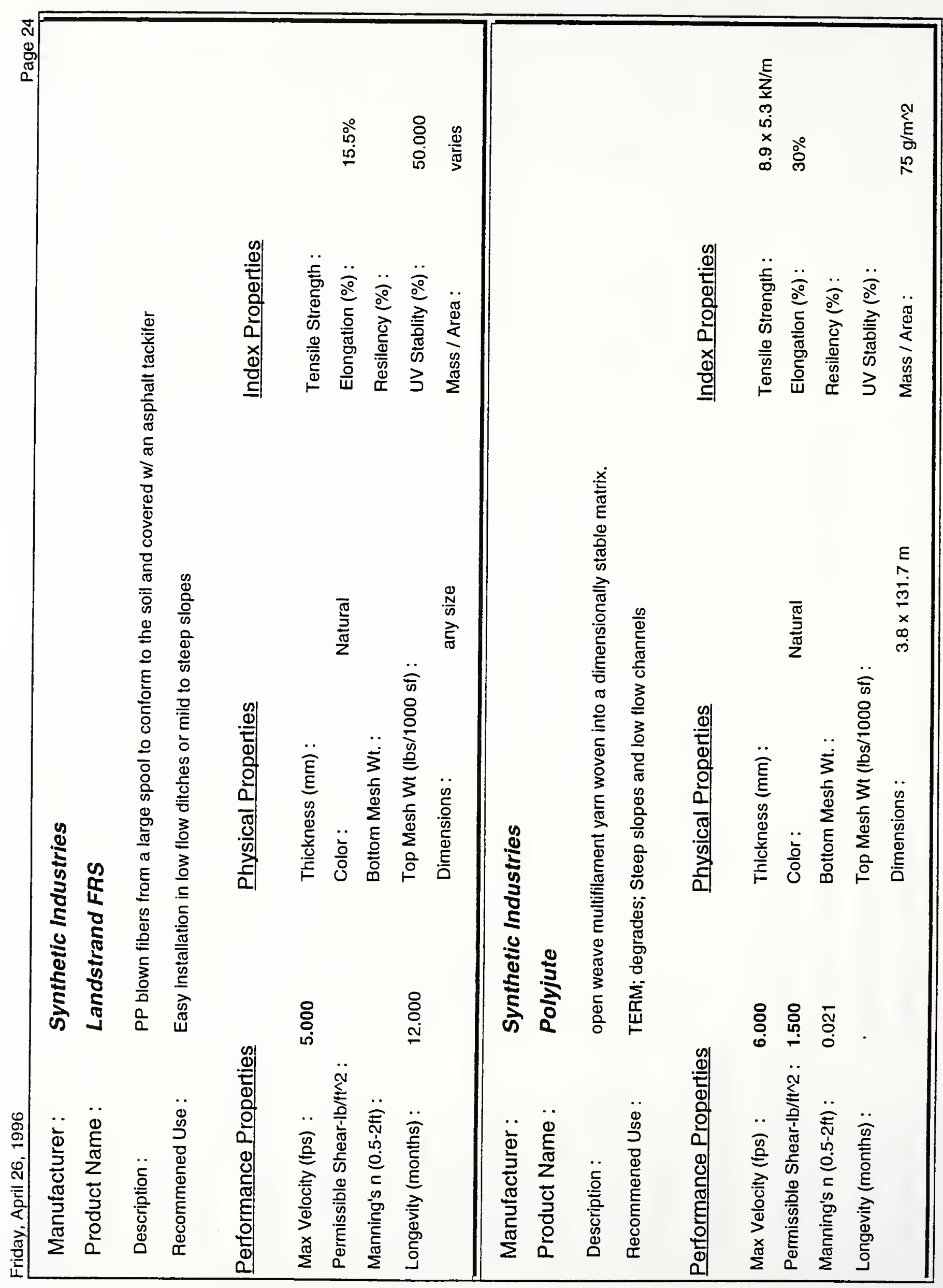




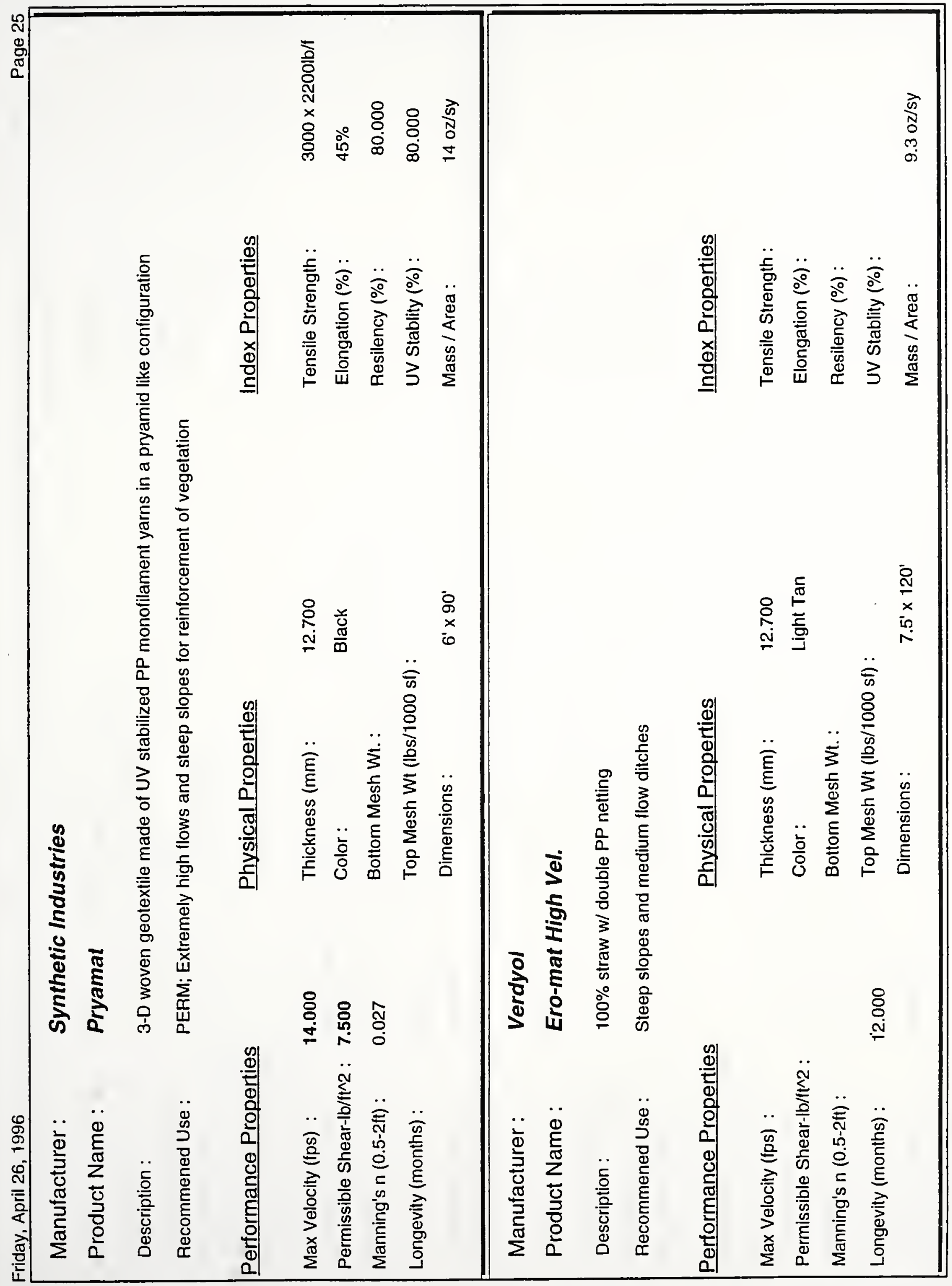




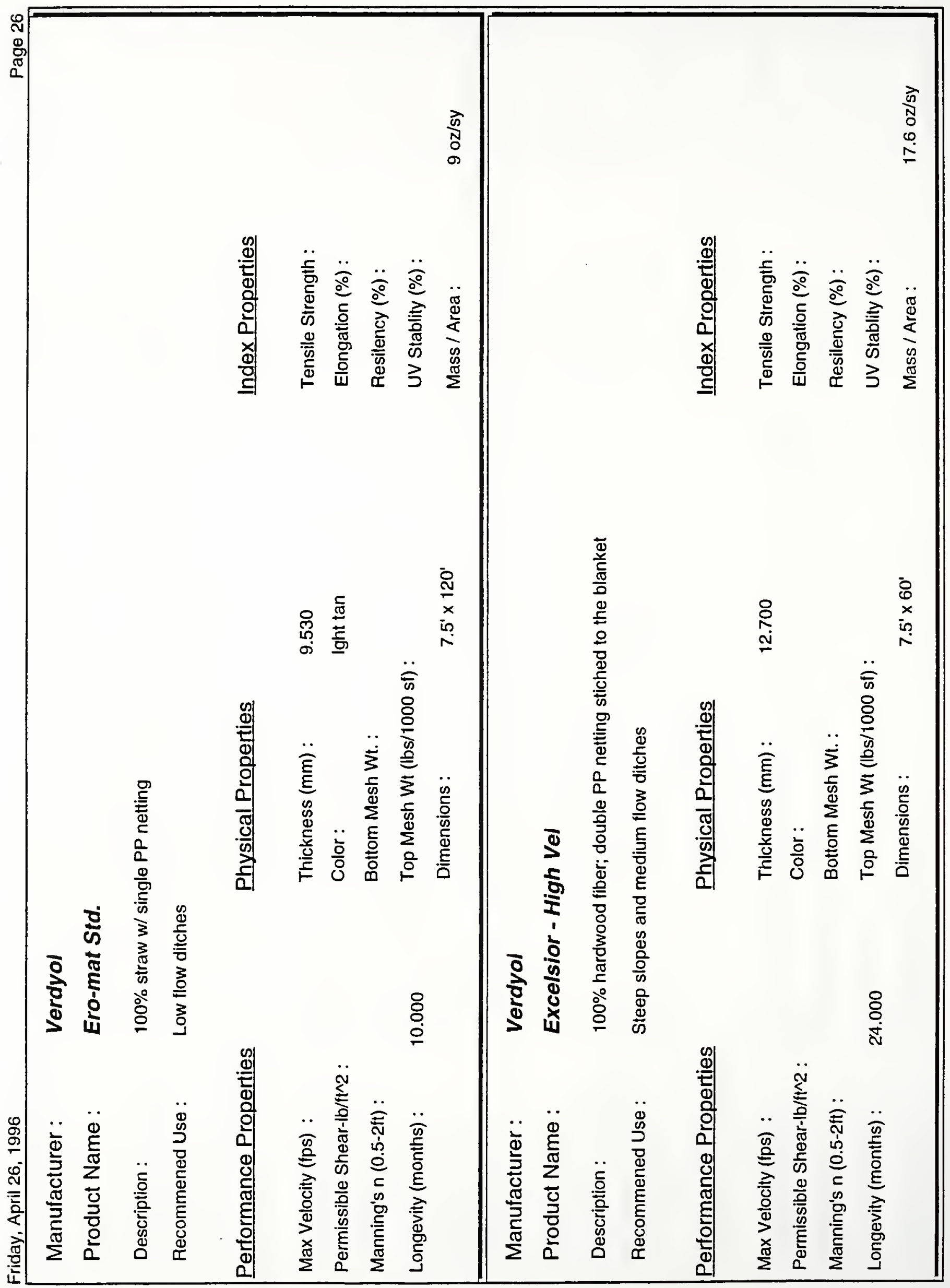




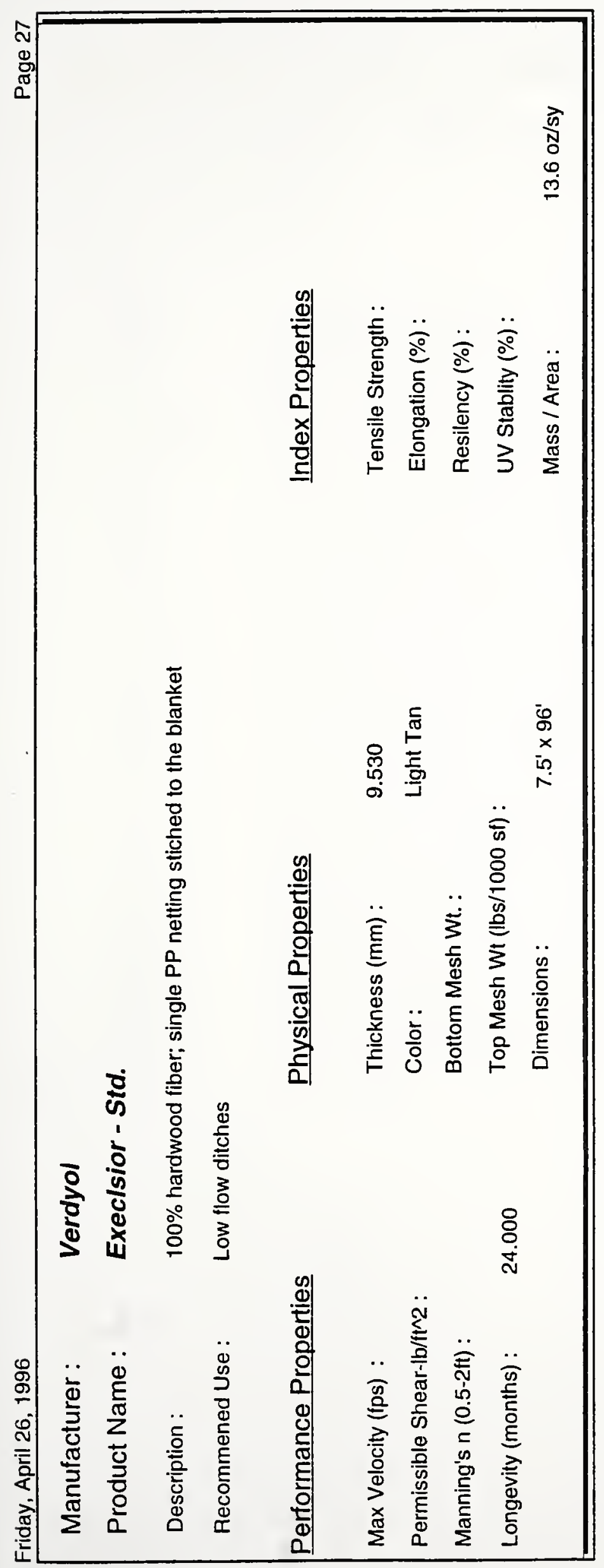




\section{Appendix G}

\section{Summary of Acronyms}

$\begin{array}{ll}\text { ABS } & \text { Articulated Block System } \\ \text { AOS } & \text { Average Opening Size } \\ \text { ASCE } & \text { American Society of Civil Engineers } \\ \text { BOP } & \text { Biaxially Orientated Process net } \\ \text { Cal-B\&SP } & \text { California DOT Bank and Shore Protection manual } \\ \text { CBS } & \text { Concrete Block system } \\ \text { CIRCA } & \text { Construction Industry Research and Information Association } \\ \text { E\&M } & \text { Escarameia and May procedure } \\ \text { ECB } & \text { Erosion Control Blanket } \\ \text { ECM } & \text { Erosion Control Material } \\ \text { ECN } & \text { Erosion Control Netting } \\ \text { ECRM } & \text { ErosionControl and Revegetation Mat } \\ \text { ECTC } & \text { Erosion Control Technology Council } \\ \text { EPA } & \text { environmental Protection Agency } \\ \text { FFR } & \text { Fabric Formed Revetment } \\ \text { FRS } & \text { Fiber Roving System } \\ \text { GCS } & \text { Geocellular Containment System } \\ \text { IFAI } & \text { Industrial Fabric Association International } \\ \text { PERM } & \text { Permanent erosion Control Materials } \\ \text { PVC } & \text { Poly-Vinyl Chloride } \\ \text { TERM } & \text { Temporary Erosion Control Materials } \\ \text { TRM } & \text { Turf Reinforcing Mat } \\ \text { USBR } & \text { United States Bureau of Reclamation } \\ \text { USCOE } & \text { United States Army Cor of engineers } \\ \text { USGS } & \text { United States Geological Survey } \\ \text { UV } & \text { Ultra Violet }\end{array}$




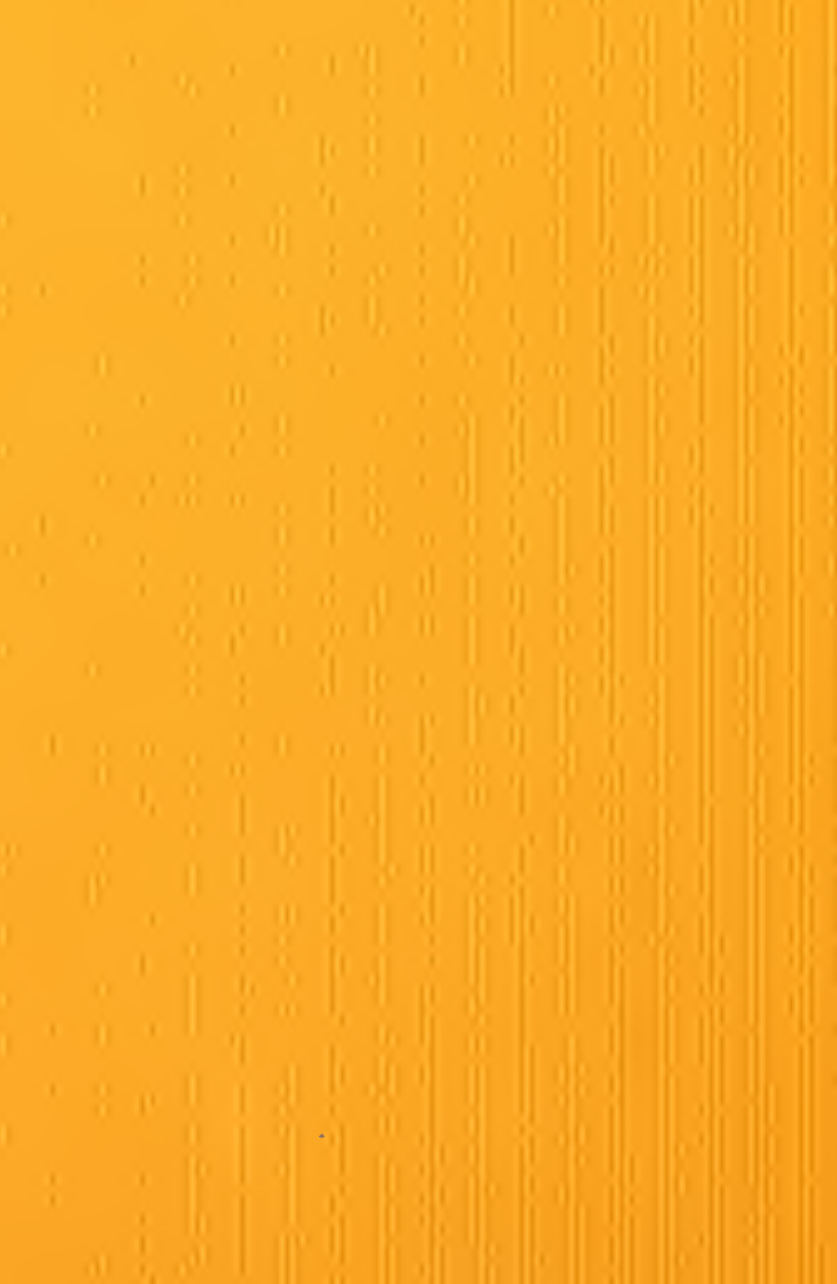

